\title{
INFLUENCE OF MELTWATER ON \\ GREENLAND ICE SHEET DYNAMICS
}

by

\author{
Laura A. Stevens \\ B.A., Wellesley College (2011)
}

Submitted in partial fulfillment of the requirements for the degree of

\begin{abstract}
Doctor of Philosophy
at the

MASSACHUSETTS INSTITUTE OF TECHNOLOGY

and the

WOODS HOLE OCEANOGRAPHIC INSTITUTION
\end{abstract}

September 2017

(C)2017 Laura A. Stevens. All rights reserved.

The author hereby grants to MIT and WHOI permission to reproduce and to distribute publicly paper and electronic copies of this thesis document in whole or in part in any medium now known or hereafter created.

Author

Joint Program in Oceanography/Applied Ocean Science \& Engineering Massachusetts Institute of Technology \& Woods Hole Oceanographic Institution

August 15, 2017

Certified by.

Dr. Sarah B. Das

Associate Scientist with Tenure in Geology \& Geophysics

Woods Hole Oceanographic Institution

Thesis Supervisor

Accepted by

Dr. Mark D. Behn

Senior Scientist in Geology \& Geophysics

Woods Hole Oceanographic Institution

Chair, Joint Committee for Marine Geology \& Geophysics 


\title{
INFLUENCE OF MELTWATER ON GREENLAND ICE SHEET DYNAMICS
}

by

\author{
Laura A. Stevens \\ Submitted to the MIT-WHOI Joint Program in Oceanography and Applied Ocean Science and \\ Engineering in Partial Fulfilment of the Requirements for the Degree of \\ Doctor of Philosophy in Geology and Geophysics.
}

\begin{abstract}
Seasonal fluxes of meltwater control ice-flow processes across the Greenland Ice Sheet ablation zone and subglacial discharge at marine-terminating outlet glaciers. With the increase in annual ice sheet meltwater production observed over recent decades and predicted into future decades, understanding mechanisms driving the hourly to decadal impact of meltwater on ice flow is critical for predicting Greenland Ice Sheet dynamic mass loss. This thesis investigates a wide range of meltwater-driven processes using empirical and theoretical methods for a region of the western margin of the Greenland Ice Sheet. I begin with an examination of the seasonal and annual ice flow record for the region using in situ observations of ice flow from a network of Global Positioning System (GPS) stations. Annual velocities decrease over the seven-year time-series at a rate consistent with the negative trend in annual velocities observed in neighboring regions. Using observations from the same GPS network, I next determine the trigger mechanism for rapid drainage of a supraglacial lake. In three consecutive years, I find precursory basal slip and uplift in the lake basin generates tensile stresses that promote hydrofracture beneath the lake. As these precursors are likely associated with the introduction of meltwater to the bed through neighboring moulin systems, our results imply that lakes may be less able to drain in the less crevassed, interior regions of the ice sheet. Expanding spatial scales to the full ablation zone, I then use a numerical model of subglacial hydrology to test whether model-derived effective pressures exhibit the theorized inverse relationship with melt-season ice sheet surface velocities. Finally, I pair near-ice fjord hydrographic observations with modeled and observed subglacial discharge for the Saqqardliup sermia-Sarqardleq Fjord system. I find evidence of two types of glacially modified waters whose distinct properties and locations in the fjord align with subglacial discharge from two prominent subcatchments beneath Saqqardliup sermia. Continued observational and theoretical work reaching across discipline boundaries is required to further narrow our gap in understanding the forcing mechanisms and magnitude of Greenland Ice Sheet dynamic mass loss.
\end{abstract}

Thesis Supervisor: Dr. Sarah B. Das

Title: Associate Scientist with Tenure in Geology \& Geophysics

Woods Hole Oceanographic Institution 


\section{Dedication}

This thesis is dedicated to my grandmother, Sarah "Sally" Ann Symon Stevens, who showed me how plants, and people, bend towards light.

$1930-2014$ 


\section{Acknowledgements}

Though my name sits alone on the title page, this thesis holds over a decade of work by many hands.

First and foremost, I thank my advisor, Sarah Das, without whom this thesis would not be possible. Sarah gave me the reigns to an incredible data set on day one, and advised me from a perfect distance. I hope I take away an ounce of her ability to communicate the right questions and arguments in words. I admire her for many reasons, least of which being her marathon PR and most of which being her unapologetic approach to to being a woman in science.

Second, I thank Mark Behn, without whom the computational and statistical aspects of this thesis would have progressed much slower. Mark brought enumerable clever ideas to our research meetings and always amazed me with his detailed critiques of my writing that arrived painfully back in my inbox within a few hours.

Third, I thank Fiamma Straneo, who brought me into the goings on of her lively research program and life. Thank you for modeling the importance of doing useful work with good people, sharing your wonderful family with me, and for selling me Giamma for an affordable $\$ 1.00$.

I am grateful to my committee members Tom Herring and Ian Hewitt, and my thesis defense chair, Jeff McGuire, for their open doors (email inboxes) and critical feedback throughout this thesis. Specifically, I would like to thank Ian for hosting my stay at the Mathematical Institute in Oxford, and for inviting me into the world of numerical modeling. I thank Jeff for providing the seismology toolset and approach that greatly enriched the third chapter of this thesis.

I have had the privilege of getting to know many sharp, dedicated, and creative minds during my tenure in the Das, Behn, and Straneo Labs. I thank my glaciology labmates Alison Criscitiello, Matthew Osman, and Luke Trussel for critiquing my dynamics talks and sharing their expertise on ice cores and climate models. I thank my geodynamics labmates Jean-Arthur Olive, Dorsey Wanless, Hannah Mark, and William Shinevar for knowing many command line shortcuts and never charging me for lab espresso. I thank my physical oceanographer labmates Rebecca Jackson, Nat Wilson, Joleen Heldrich, Marilena Oltmanns, Clark Richards, Roberta Sciascia, Nick Beaird, Mattias Cape, Donald Slater, Anna Fitz Maurice, Ken Mankoff, and Ben Hudson for teaching me everything I know about fjords as well as sharing the more philosophical arguments behind their research and responsibilities as ocean scientists. I am a better glaciologist for it, and hope to continue working with you all to narrow our knowledge gap at the ice-ocean interface.

Multiple field campaigns during and before my time as a Joint Program student obtained the data explored in second, third, and fourth chapters of this thesis. I am grateful to Sarah, Mark, and Ian Joughin for the many field campaigns and hardware and software updates required to keep the North Lake GPS array upright and logging for nearly a decade. Effectively my sixth committee member, Ian Joughin was deeply involved with the second and third chapters of this thesis as well as all field campaigns to the supraglacial lakes I joined. I thank him for graciously sharing data, imagery, and ideas on ice-flow in the North Lake region. Through Ian I had the opportunity to work in Greenland alongside David Shean and Laura Kehrl, two superb University of Washington graduate students. I thank former Joint Program graduate student Maya Bhatia and former University of Washington graduate students Josh Carmichael, Twila Moon, and Kristin Poinar for their assistance in maintaining 
the GPS array before my time on the project. I thank Kathy Young of CH2MHILL Polar Field Services for always being a great help in Greenland.

I am grateful to Sarah and Fiamma for bringing me along to Sarqardleq Fjord and giving me the opportunity to dive into fjord hydrography for the fifth chapter of this thesis. The physical oceanography skillset I gained from working on this project widened my understanding of the ice sheet and is increasingly useful for expanding the breadth of my research questions and collaborations. I thank Amy Kukulya for collecting a remarkable REMUS dataset and allowing me to have a go at explaining it. I thank Al Plueddemann and Claudia Cenedese for their guidance in working with REMUS data and plume models, respectively, during the writing of the fifth chapter of this thesis. I thank Rebecca Jackson for obtaining fjord bathymetry data before my time on the project. I thank Hanu Singh for introducing me to the joy and heartbreak of working with remote vehicles.

I am grateful for the opportunities I had to assist on field campaigns outside of my dissertation work. Each expedition greatly contributed to my understanding of the logistics required to do the science, with the added bonus exploring remote places with collaborators on no-fly days. Matthew Evans, Matthew Bingham, Ben Smith, Ashley York, and Sarah introduced me to shallow ice cores, snow pits, and radar surveys atop the coastal ice caps of Disko Island and the Nuussuaq Peninsula. Pablo Canales, Dan Lizarralde, Rob Evans, Roger Buck, Hannah Mark, Dorsey Wanless, Jimmy Elsenbeck, Greg Horning, Mark, and the rest of the SEIORZ Team introduced me to active seismic work among elephants in the Okavango Rift Zone. Ralph Stephen graciously gave me the opportunity to assist on an Antarctic field campaign across the Ross Ice Shelf, and provided incredibly detailed information on the trip pre-deployment. I am thankful to have dug many big holes on the I-348 project with Momme Hell, Alan Seltzer, and Melissa Carter of Scripps Institution of Oceanography. I thank Patrick Shore, Robin Carroccia, Peter Biskind, and Kyler Hale for their seamless execution in running Yesterday Camp and getting us out of the fog.

I greatly appreciated the support from WHOI scientists involved in the Joint Program through their teaching and advising. In particular, I would like to thank Dan Lizarralde, Delia Oppo, Adam Soule, Ralph Stephen, Ted Maksym, and Jack Whitehead for their participation in the Joint Program and my thesis. I thank my small and somewhat scattered Geology \& Geophysics cohort comprised of Christopher Kinsley, Niya Grozeva, Jaap Nienhuis, and Thomas DeCarlo for being superb office-, class-, and shipmates.

I am thankful to the WHOI Media Relations Office, who helped me communicate my research on a large stage.@WHOI Twitter avatar notwithstanding, I thank Lonny Lippsett, Ken Kostel, Jayne Doucette and Jack Cook for helping me craft and communicate my story.

I consider myself incredibly lucky to have completed my dissertation within the field of glaciology, an international community full of kind and collaborative scientists. In particular, I thank Gordon Hamilton for advising me on my first research proposal before I entered graduate school. I thank Gwen Flowers, Ellyn Enderlin, Leigh Stearns, Helene Seroussi, and Twila Moon for illuminating conversations and being excellent role models. I thank fellow graduate students Laura Levy, Laura Kehrl, Donald Slater, Kristin Schild, Laurence Dyke, Winnie Chu, Alexandra Messerli, Brooke Medley, Kristin Poinar, Martin Wearing, Alexander Robel, Mari Jensen, Kristin Lindbäck, Grant MacDonald, Bradley Markel, and David Shean for sharing your research, friendship, and opinions at conferences, workshops, and short courses over the years. 
I thank my Wellesley College advisors Brittina Argow, Dan Brabander, and David Hawkins for showing me how to see the world as an earth scientist and launching me on this path. My life is better for it.

I have enjoyed the comradery of many during my years in Woods Hole. To Isarbela, for getting lost in the woods. To Julie, for sharing encyclopedic emoji knowledge. To Becca, for evading the jim-jams, $\mathrm{R} / V$ Poopsie, and shower stall etiquette. To Arthur, for our deeply shared experiences commiserated over espresso or a Tavern beer. To Sarah, there can only be one Queen. To Sophie, there can only be One Dance. To \#w1lson, for taking The Gals into your home whenever needed. To Ellie, for rousing conversation. To CoffeeO, for never kicking me out after hours. To Ali, for extending a hand back to pull me across all the barriers you shattered. To Ben, for the whiskey I didn't buy. To Mari Ruti, for the wine I didn't buy. To Helen, for hoop breaks. To Nick, for a balsa wood airplane. To Mattias, for rescuing a rogue Giammai. To MegJ, for filling our office with dogs. To Hannah, for that ice sheet cake. To Sarah, for Somerset Creamery. To Lydia, for tales of the open sea. To my dearest Skoops, Toaster, Tink, Lizz, Bruce, Noodle, Tree, Chris, Jelly, Katie, Puppy, Nell, Jersey, Jess Kwan, Panda, Ding, Pippi, Pin, Junior, Hemo, and Marshall, for everything and anything over the years, not to mention frisbee games. To Julia, Jayne, Sheri, and Meghan for drinks, goats, and support. To Aleja, Alexis, Emily, Harriet, and Michaela, for when in need of a Wellesley word.

I thank my big family for their endless support and enthusiasm for my education and research. Especially, my mom and dad for providing countless opportunities for me to explore throughout my childhood. And to my sisters, Carolyn and Sarah, and my brother, David, and our dogs, Jake I and Jake II, for their humor, love of travel, and understanding.

To Katie, for the haircuts. To Devon, my paella man. To Adriane, for a good reunion.

To $R / V$ Poopsie, for endearing me to the residents of Eel Pond.

To Giammai, for keeping me on my toes.

To Woods Hole, for swift passage and safe harbor.

And finally, Reader, I hope you find this interesting.

Funding for this thesis was provided by the National Science Foundation Graduate Research Fellowship Program; the National Science Foundation's Office of Polar Programs through ARC0520077, ARC-1023364, PLR-1418256, and PLR-1023364; the National Aeronautics and Space Administration's Cryospheric Science Program through NNX10AI30G; the Woods Hole Oceanographic Institution Ocean and Climate Change Institute Arctic Research Initiative; and the American Geophysical Union Horton Research Grant. 


\section{Contents}

$\begin{array}{ll}\text { Abstract } & 3\end{array}$

$\begin{array}{ll}\text { Dedication } & 5\end{array}$

$\begin{array}{ll}\text { Acknowledgements } & 7\end{array}$

$\begin{array}{ll}\text { List of Figures } & 15\end{array}$

$\begin{array}{ll}\text { List of Tables } & 17\end{array}$

$\begin{array}{ll}\text { 1. Greenland Ice Sheet dynamics } & 19\end{array}$

1.1 Greenland Ice Sheet dynamics 19

1.2 Observations of meltwater-driven ice flow 23

1.3 Rapid supraglacial lake drainages $\quad 28$

1.4 Modeling the Greenland Ice Sheet subglacial drainage system 31

1.5 Ice-Ocean interactions at marine-terminating outlet glaciers 33

2. Greenland Ice Sheet flow response to runoff variability 39

$\begin{array}{ll}2.1 \text { Abstract } & 39\end{array}$

2.2 Introduction $\quad 40$

2.3 Methods 44

2.4 Results and discussion $\quad 47$

2.4.1 Interannual trends and variability in velocity and runoff $\quad 47$

2.4.2 Influence of past runoff magnitude on seasonal and annual ice flow 48

2.4.3 Variability in late summer slowdown 49

2.4.4 Mechanisms for a decadal or multiyear dependence of ice flow on runoff 50

2.5 Implications for future predictions of ice flow 53

$\begin{array}{ll}\text { Appendices } & 54\end{array}$

2.A List of symbols

2.B Local meltwater runoff

2.C Past mean runoff magnitude $\quad 55$

2.D Seasonal and annual ice-flow $\quad 56$

2.E Time series statistics 60

2.F Comparison to K-transect and Western Margin 61 


\section{Greenland supraglacial lake drainages triggered by hydrologically induced}

basal slip

3.1 Abstract

3.2 Main text

\section{Appendices}

3.A GPS Data

3.B Lake volume

3.C Network Inversion Filter

3.D Basal moment calculations

3.E Critical volume for driving water-filled hydro-fracture to bed 93

3.F North Lake basin stresses

3.G Precursors observed in previous studies

3.H Implications for inland expansion of seasonal acceleration 94

3.I 2012 North Lake drainage

95

3.J 2013 North Lake drainage

\section{Varying relationships between Greenland Ice Sheet melt season surface speeds and modeled effective pressures}

$\begin{array}{ll}4.1 \text { Abstract } & 109\end{array}$

4.2 Introduction 110

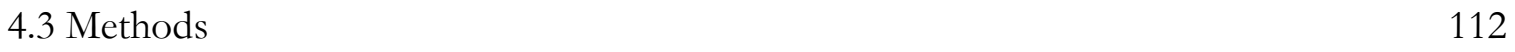

4.3.1 Study region $\quad 112$

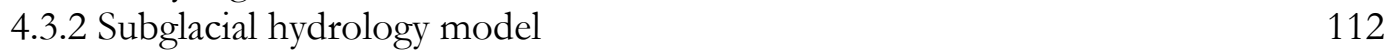

4.3.2.1 Governing equations $\quad 112$

4.3.2.2 Numerical procedure $\quad 116$

4.3.2.3 Model geometry and boundary conditions 116

4.3.2.4 Surface runoff forcing 118

$\begin{array}{ll}\text { 4.3.3 Coherence and spectral estimation } & 119\end{array}$

4.4 Results

4.4.2 Distribute versus discrete surface runoff input 124

4.4.3 Controls on 2009 melt-season surface speed and speedup compared to winter

4.4.4 Controls on 2010 melt-season surface speed and speedup compared to winter

4.4.5 Model Curiosities 1: Oscillatory behavior at high englacial void fraction $\quad 130$

4.4.6 Model Curiosities 2: Effects of a pressure dependent melting point $\quad 130$

4.5 Discussion

4.5.1 Controls on ice sheet margin surface speed dynamics 131

$\begin{array}{ll}\text { 4.5.2 Robust subglacial flow pathways } & 134\end{array}$

4.5.3 Model limitations and future directions 135

4.6 Conclusions 


\section{Linking glacially modified waters to catchment-scale subglacial discharge using autonomous underwater vehicle observations}

5.1 Abstract 164

5.2 Introduction $\quad 165$

$\begin{array}{ll}5.3 \text { Field campaign } & 167\end{array}$

$\begin{array}{ll}\text { 5.3.1 REMUS-100 AUV } & 167\end{array}$

5.3.2 Hydrographic and turbidity data 168

$\begin{array}{ll}\text { 5.3.3 Bathymetric data } & 169\end{array}$

5.4 Physical setting: The Sarqardleq Fjord-Saqqardliup sermia outlet glacier system $\quad 170$

5.4.1 Fjord bathymetry, subglacial topography, and historical terminus positions 170

$\begin{array}{ll}\text { 5.4.2 Subglacial catchment and runoff } & 171\end{array}$

5.5. Results 173

5.5.1 Glacially modified water (GMW) temperature, salinity, and turbidity properties in Sarqardleq Fjord 173

5.5.2 Saqqardliup sermia catchment and subglacial discharge across Saqqardliup sermia terminus 174

5.5.3 Buoyant plume model for the Sarqardleq Fjord-Saqqardliup sermia system 175

5.6 Discussion

5.6.1 Subglacial catchments, discharge, and GMW observations 177

5.6.2 Observing the heterogeneous near-ice environment 179

5.6.3 Observational constraints for modeling the heterogeneous near-ice environment 181

$\begin{array}{ll}5.7 \text { Conclusions } & 182\end{array}$

$\begin{array}{lr}\text { 6. Conclusions } & 196\end{array}$

6.1 Thesis summary 196

6.2 Future directions towards synthesis $\quad 200$

6.3 An appreciation for complexity 203

$\begin{array}{ll}\text { References } & 206\end{array}$ 


\section{List of Figures}

Figure 1-1. Ice sheet flow on a flat bed. 21

Figure 1-2. Greenland Ice Sheet hydrologic system.

Figure 1-3. Subglacial drainage system elements. 25

Figure 1-4: Annual velocity curve conceptually explained by evolving efficiency of subglacial

drainage system. 26

Figure 1-5. Subglacial topography beneath Sarqardliup sermia and the North Lake GPS array. 30

Figure 1-6. Subglacial channel and cavity physics. 33

Figure 1-7. Greenland tidewater glacier system. 34

Figure 2-1: Greenland Ice Sheet marginal velocity campaigns. 43

Figure 2-2: Seasonal ice velocity and runoff time series. 46

Figure 2-3: Annual ice velocity and past mean runoff magnitude relationships at North Lake,

K-transect, and the Western Margin.

Figure 2-4: Daily ice velocity and runoff time series.

Figure 2-5. Seasonal ice velocity and runoff time series.

Figure 2-6. Variation in displacement across the 16 GPS stations in 2011.

Figure 2-7. Runoff magnitude and variability at North Lake. 65

Figure 2-8. Seasonal and annual velocities at North Lake. 66

$\begin{array}{ll}\text { Figure 2-9. Summer velocity versus single and multiyear runoff. } & 67\end{array}$

Figure 2-10. Winter velocity versus single and multiyear runoff. 68

Figure 2-11. Annual velocity versus single and multiyear runoff.

Figure 2-12. Trough amplitude, $\left|V_{\min }\right|$, versus single and multiyear runoff. 70

Figure 2-13. Annual velocities versus $\bar{R}_{m a g}^{[-4,-1]}$ for North Lake and the K-transect. 71

Figure 2-14. Monte Carlo simulations for synthetic $R_{\text {mag }}$ and $V_{A}$ values. $\quad 72$

Figure 3-1. June 17, 2011 Synthetic Aperture Radar image showing the extent of North Lake
and surrounding lakes one day before the 2011 rapid North Lake drainage.

Figure 3-2. 2011, 2012, and 2013 North Lake Drainages. 85

Figure 3-3. 2011 Basal slip and cavity opening at hydro-fracture initiation and maximum
hydro-fracture opening.

Figure 3-4. Change in Crack-normal Stress during the Precursor. 87

Figure 3-5. July 21, 2011 WorldView image of an empty North Lake basin after the 2011 rapid
drainage event.

Figure 3-6. Images and Digital Elevation Model of 2011 and 2013 North Lake basin. 100

Figure 3-7. 2011 and 2013 North Lake Depths. 101

Figure 3-8. 2012 Basal slip and cavity opening at hydro-fracture initiation and maximum

hydro-fracture opening. $\quad 102$

Figure 3-9. 2013 Basal slip and cavity opening at hydro-fracture initiation and maximum

$\begin{array}{ll}\text { hydro-fracture opening. } & 103\end{array}$

Figure 3-10. 2011 Station Timeseries. 104

Figure 3-11. 2011 NL08 and NL04 Station flowline, crack-normal, and uplift displacements
computed from NIF displacement sources.

Figure 3-12. Maximum Likelihood Estimation of NIF hyperparameters. 106

Figure 3-13. Stress changes across North Lake basin. 107

Figure 4-1. Model domain and ice sheet velocities. 138

Figure 4-2. Cross-section schematic of subglacial hydrology model with distributed surface input. 139

Figure 4-3. Averages of surface melt forcing, subglacial water discharge, and effective pressure over the 2009 melt season for a distributed surface input scenario. 
Figure 4-4. Averages of surface melt forcing, subglacial water discharge, and effective pressure over the 2009 melt season for a discrete surface input scenario.

Figure 4-5. Moulin density and discrete surface runoff catchment delineation.

Figure 4-6. Coherence-square estimation of synthetic data.

Figure 4-7: Surface ice displacement during the rapid drainage of North Lake on 2009 DOY 168.

Figure 4-8. Region of efficient drainage area increases at different rates across parameter space.

Figure 4-9. Region of efficient drainage area for 2009 distributed surface runoff input at $\sigma=0.01$ and $\sigma=0.0001$.

Figure 4-10. Region of efficient drainage area for 2009 discrete surface runoff input at $\sigma=0.01$ and $\sigma=0.0001$.

Figure 4-11. Region of efficient drainage area for 2010 distributed surface runoff input.

Figure 4-12. Region of efficient drainage area for 2010 discrete surface runoff input.

Figure 4-13. Differences in area-integrated model variables between the 2009 distributed and discrete surface runoff input scenarios.

Figure 4-14. Averages of surface melt forcing, subglacial water discharge, and effective pressure over the 2010 melt season for a distributed surface input scenario.

Figure 4-15. Averages of surface melt forcing, subglacial water discharge, and effective pressure over the 2010 melt season for a discrete surface input scenario.

Figure 4-16. Differences in area-integrated model variables between the 2010 distributed and discrete surface runoff input scenarios.

Figure 4-17. Correlations with surface speeds evolve through the 2009 melt season.

Figure 4-18. Correlations with ice sheet thickness, surface slope, and surface speeds through the 2009 melt season.

Figure 4-19. Correlations with surface speeds evolve through the 2010 melt season.

Figure 4-20. Correlations with ice sheet thickness, surface slope, and surface speeds through the 2010 melt season.

Figure 4-21. Coherence between Speed and Effective Pressure on DOY 196 of 2009.

Figure 4-22. Linear and spectral relationships between $\tau_{d}$, bed elevation, effective pressure, and surface speed evolve over the 2009 winter and melt season.

Figure 4-23. Linear and spectral relationships between $\tau_{d}$, bed elevation, effective pressure, and surface speed evolve over the 2010 winter and melt season.

Figure 4-24. Averages of surface melt forcing, subglacial water discharge, and effective pressure over the 2010 melt season for a distributed surface input scenario with high englacial void fraction.

Figure 4-25. Averages of surface melt forcing, subglacial water discharge, and effective pressure over the 2009 melt season for a distributed surface input scenario with a pressuredependent melting point.

Figure 5-1. The Sarqardleq Fjord/Saqqarliup sermia outlet glacier system in West Greenland. 


\section{List of Tables}

Table 2-1. R $\mathrm{R}^{2}$ (5-95\% confidence intervals) and $p$-values for linear trends between velocities and runoff season characteristics.

Table 2-2. Runoff season and lake drainage timing characteristics.

Table 2-3. Summer, winter, and annual displacements for the $\boldsymbol{t}_{\boldsymbol{R} \mathbf{1}}$ to $\boldsymbol{t}_{\boldsymbol{V} \boldsymbol{m i n}}$ seasonal delineation method and the fixed calendar date seasonal delineation method.

Table 2-4. Trends in the seasonal and annual velocities from 2007-2013.

Table 2-5. $\mathrm{R}^{2}$ (5-95\% confidence intervals) and $p$-values for linear trends between velocities and future mean runoff magnitude.

Table 3-1. 2011, 2012, and 2013 North Lake Drainage Environmental, GPS, and Network Inversion Filter observations.

Table 4-1: Values and ranges used for model parameters.

Table 5-1: REMUS Missions in Sarqardleq Fjord

Table 5-2: Water mass properties in Sarqardleq Fjord

Table 5-3: Saqqarliup sermia subcatchments and runoff estimates

Table 5-4. Buoyant plume model simulations for D1 and D2 scenarios at MBM2014 subglacial discharge values. 


\section{Chapter 1}

\section{Greenland Ice Sheet dynamics}

\subsection{Greenland Ice Sheet Dynamics}

The two continental ice sheets on Earth at present are located in the polar regions of Greenland and Antarctica, where perennial ice has persisted for millions of years [Zachos et al., 2008; Alley et al., 2010]. Perennial ice results from positive mass balance between snow fall and snow melt over many years, which leads to an accumulation of snow that eventually reaches a depth (50-80 m) where the bottom layers of snow densify into ice under the weight of the layers above [Cuffey and Patterson, 2010]. As the ice body grows through continued positive mass balance and densification, ice begins to flow down surface or bed slope under its own weight through viscous deformation and basal sliding. An ice body where the direction of flow is dictated by the landscape (e.g. down a mountainside) is commonly referred to as a glacier. An ice sheet is an ice body so massive that its thickness blankets the topography underneath. Ice sheets on Earth are a few kilometers thick and up to hundreds of kilometers wide. The ability of ice sheets to record past changes in Earth's climate; change size and impact global sea level over centennial- to millennial-timescales; and sculpt landforms are a few reasons for the study of flowing ice.

This thesis focuses on the Greenland Ice Sheet, which originated approximately 3.2 million years ago as small ice caps on the mountainous regions of the island coalesced and eventually covered the majority of Greenland with ice [Alley et al., 2010]. The ice sheet volume and spatial extent has waxed and waned over the colder glacial and warmer interglacial periods of the Pleistocene (2.60.0117 million years ago), cataloging the ice sheet's susceptibility to changes in Earth's obliquity and atmospheric temperature [Alley et al., 2005, 2010; Dutton, 2015]. At present the ice sheet is 2.9 million $\mathrm{km}^{3}$ in volume, is over $3 \mathrm{~km}$ deep at its thickest point, and covers $80 \%$ of the island of Greenland [Bamber et al., 2013]. Though there are significant regions of the ice-sheet bed where elevations are below sea level, a complete melting of the ice sheet is estimated to result in over 7 meters of globallyaveraged sea level rise [Alley et al., 2005; Lemke et al., 2007; Bamber et al., 2013]. 
The mass balance of the Greenland Ice Sheet has become increasingly negative over recent decades, with the ice sheet losing mass at a rate of $-263 \pm 30$ gigatons per year from 2007-2011 [Shepherd et al., 2012]. As 360 gigatons of ice loss to the oceans is equivalent to $1 \mathrm{~mm}$ of global sea level rise [Lemke et al., 2007], mass loss from the Greenland Ice Sheet added $0.73 \pm 0.08 \mathrm{~mm}$ per year to global sea levels from 2007-2011 [Shepherd et al., 2012]. The increasing rate of mass loss from the ice sheet in recent decades is due to increases in surface melt [Hanna et al., 2013; van den Broeke et al., 2016] and changes in ice sheet dynamics [Pritchard et al., 2009]. The dynamical component of mass loss includes iceberg calving at outlet glacier termini [Moon et al., 2008; Nick et al., 2013; Enderlin et al., 2014] and acceleration of the ice sheet interior due to changes in basal sliding [Rignot and Kanagaratnam, 2006; Joughin et al., 2008]. From 2005-2012, ice sheet dynamics were responsible for 32-58\% of this mass loss, with fluctuations in the contributions of dynamic mass loss stemming from changes in ice discharge from marine-terminating outlet glaciers [Enderlin et al., 2014]. While progress has been made on calculating the annual volume of surface melt entering the ocean [van den Broeke et al., 2009, 2016; Shepherd et al., 2012; Enderlin et al., 2014], further work is needed to improve our understanding of the the physical processes relating meltwater abundance and timing to ice flow in the ablation zone [Zwally et al., 2002; Schoof, 2010; Hewitt, 2013; Andrews et al., 2014]. Understanding how meltwater-driven processes affect ice flow is crucial for determining the dynamic response of the ice sheet to increased meltwater forcing. These processes are unique to the Greenland Ice Sheet and mountain glaciers. With the exception of a few Antarctic ice shelves with melt ponds, these meltwater-driven processes do not have highly translatable analogs in the substantially lower meltwater forcing regime of the Antarctic Ice Sheet.

Ice flow velocity $\vec{u}=[u, v, w]$ at a location is driven by ice sheet stresses, ice sheet geometry, ice creep properties, and ice sheet bed properties over a wide area [Cuffey and Patterson, 2010]. The flow at some depth within the ice sheet $\vec{u}(z)$ is the summation of slip along the ice sheet bed and internal deformation of the ice sheet according to

$$
\vec{u}(z)=\vec{u}_{b}+\int_{B}^{z} \frac{\partial \vec{u}}{\partial z} d z
$$


where $\vec{u}_{b}$ is the basal sliding velocity, $z$ is the height within the ice sheet, and $B$ is the bed elevation (Figure 1-1) [Cuffey and Patterson, 2010]. Ice flow in the center of the ice sheet where the ice is frozen to the bed is primarily due to internal deformation. Basal sliding becomes an important contributor to ice flow in regions along the margin where the bed is thawed and in regions of high geothermal heat flux [Alley et al., 2010]. Observations of seasonal ice flow speedup in regions where meltwater reaches the bed [Zwally et al., 2002; Joughin et al., 2008] support the hypothesis that thawing a formerly frozen area of the bed induces faster flow in these regions because of changes in lubrication of the ice sheet bed [Parizek and Alley, 2004; Price et al., 2008]. The regions of the ice sheet that experience seasonal speed-up is projected to expand in a warming climate [Parizek and Alley, 2004; Leeson et al., 2015; Poinar et al., 2015]. The loss of ice shelves or the retreat of outlet glaciers causes a perturbation to the terminus force balance that can also lead to acceleration and thinning of inland ice [Nick et al., 2009], though the up-glacier extent of thinning can be limited in regions of confining bed topography [Nye, 1960; Felikson et al., 2017].

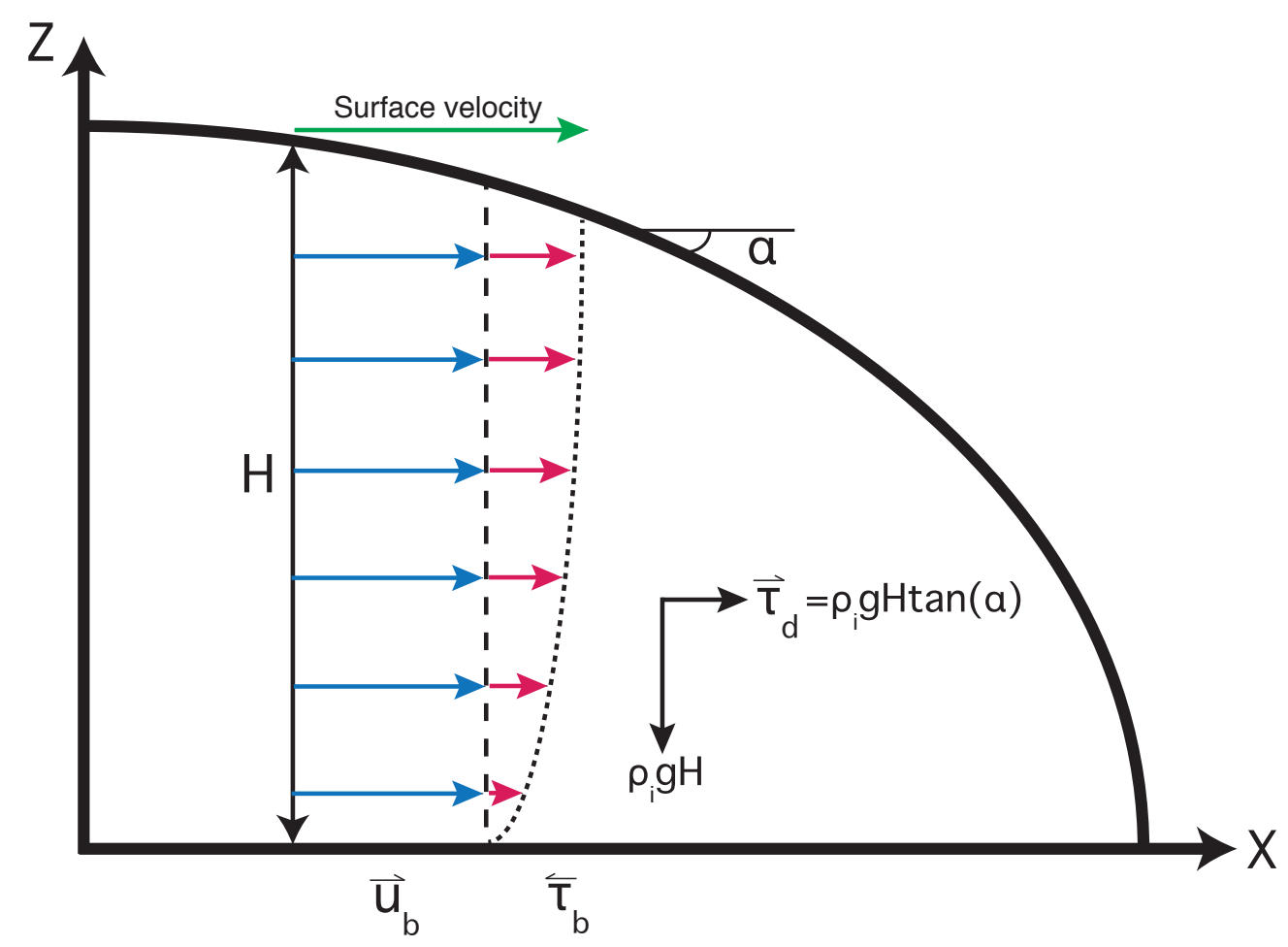

Figure 1-1. Ice sheet flow on a flat bed. Flow at a height within the ice sheet is the sum of basal slip (blue) and internal deformation (red). Surface velocity observations (green) measure an unknown proportion of basal slip and internal deformation. 
In the parts of the ice sheet where the bed is thawed, surface velocities are estimated to be dominated by basal sliding ( $90 \%)$ in the melt season and a balance between basal sliding and internal ice deformation in the winter [Ryser et al., 2014]. Basal sliding models for ice sheets were originally developed from studies of the hydromechanics of temperate alpine glaciers [Iken, 1981; Iken and Bindschadler, 1986; Iken and Truffer, 1997; Fountain and Walder, 1998; Flowers, 2011], and depend on stresses driving ice flow and pressure conditions at the ice bed interface. Models of basal sliding for glacial ice take the general form:

$$
\tau_{b}=u_{b}^{p} N^{q}, \quad p, q>0
$$

where $\tau_{b}$ is basal shear stress, $N$ is effective pressure (ice overburden pressure minus the water pressure), and $p$ and $q$ are positive constants [Iken and Bindschadler, 1986; Fowler, 1987; Cuffey and Patterson, 2010; Schoof, 2010]. In interior regions of the ice sheet, basal drag $\tau_{b}$ offsets almost all of the driving stress $\tau_{d}$, as longitudinal and wall stresses provide little resistance to flow in these regions [Cuffey and Patterson, 2010]. The driving stress, $\tau_{d}$, is given by

$$
\tau_{d}=\rho_{i} g H \tan (\alpha)
$$

where $\rho_{i}$ is the ice density $\left(917 \mathrm{~kg} \mathrm{~m}^{-3}\right), g$ is the gravitational acceleration $\left(9.8 \mathrm{~m} \mathrm{~s}^{-2}\right), H$ is the ice thickness $(\sim 1000-3000 \mathrm{~m})$, and $\alpha$ is the ice sheet surface slope $\left(\sim 1^{\circ}\right)$ (Figure 1-1). The ice thickness and ice sheet surface slope are constant on annual timescales.

The other main component of basal sliding models is effective pressure $N$ at the ice sheet bed given by

$$
N=p_{i}-p_{w}
$$

where $p_{i}$ is the ice-overburden pressure $\left(p_{i}=\rho_{i} g H\right)$ and $p_{w}$ is the basal water pressure. As components of the driving stress do not change significantly on sub-seasonal timescales, effective pressures are thought to control ice flow on hourly to seasonal timescales. Fluctuating basal water 
pressures sourced from evolving subglacial drainage systems fed by surface meltwater inputs can affect sliding velocity through the dependence of effective pressure on $p_{w}$.

This thesis focuses on meltwater as a driver of Greenland Ice Sheet and fjord dynamics. Observations from a mixed marine- and land-terminating region of the west Greenland Ice Sheet are analyzed to investigate various meltwater-driven processes from hourly to $\sim$ decadal timescales. I investigate a wide range of exciting meltwater-driven processes with both empirical and theoretical methods including trends in annual ice flow (Chapter 2), rapid supraglacial lake drainages (Chapter 3), the evolution of annual subglacial drainage systems (Chapter 4), and subglacial discharge at marineterminating outlet glaciers (Chapter 5). In order to contextualize each chapter within the broader system-based framework of meltwater-driven Greenland Ice Sheet dynamics, I next review requisite background information in Sections 1.2-1.5.

\subsection{Observations of meltwater-driven ice flow}

Meltwater-driven processes across the ablation zone of the Greenland Ice Sheet are controlled by seasonal fluxes in surface melt [Zwally et al., 2002; Joughin et al., 2008, 2013; Sundal et al., 2011; Hewitt, 2013]. At the ice sheet surface, meltwater runoff is routed via supraglacial streams and rivers that terminate in crevasse fields and moulins (vertical conduits kept open by a constant cascade of meltwater), supraglacial lakes, or proglacial streams off the ice sheet margin (Figure 1-2) [Chu, 2013; Poinar et al., 2015; Smith et al., 2015]. Within the ice sheet, moulins and hydro-fractures (water-driven fractures) transport meltwater from the surface to base of the ice sheet [Catania et al., 2008; Das et al., 2008]. As informed by earlier studies of mountain glacier hydrology [Fountain and Walder, 1998], at the bed of the ice sheet, subglacial channels and distributed hydrologic networks route meltwater over undulating topography towards land and marine termini, where meltwater enters proglacial streams and lakes or fjords, respectively [Hoffman et al., 2011; Chandler et al., 2013; Andrews et al., 2014]. In contrast to the slow-flowing interior of the ice sheet where meltwater at the bed is limited and the ice sheet is presumed to be frozen to the bed [Alley et al., 2010], the ice sheet margins exhibit seasonally enhanced ice flow where surface meltwater reaches the bed [Zwally et al., 2002; Joughin et al., 2008, 2013]. 


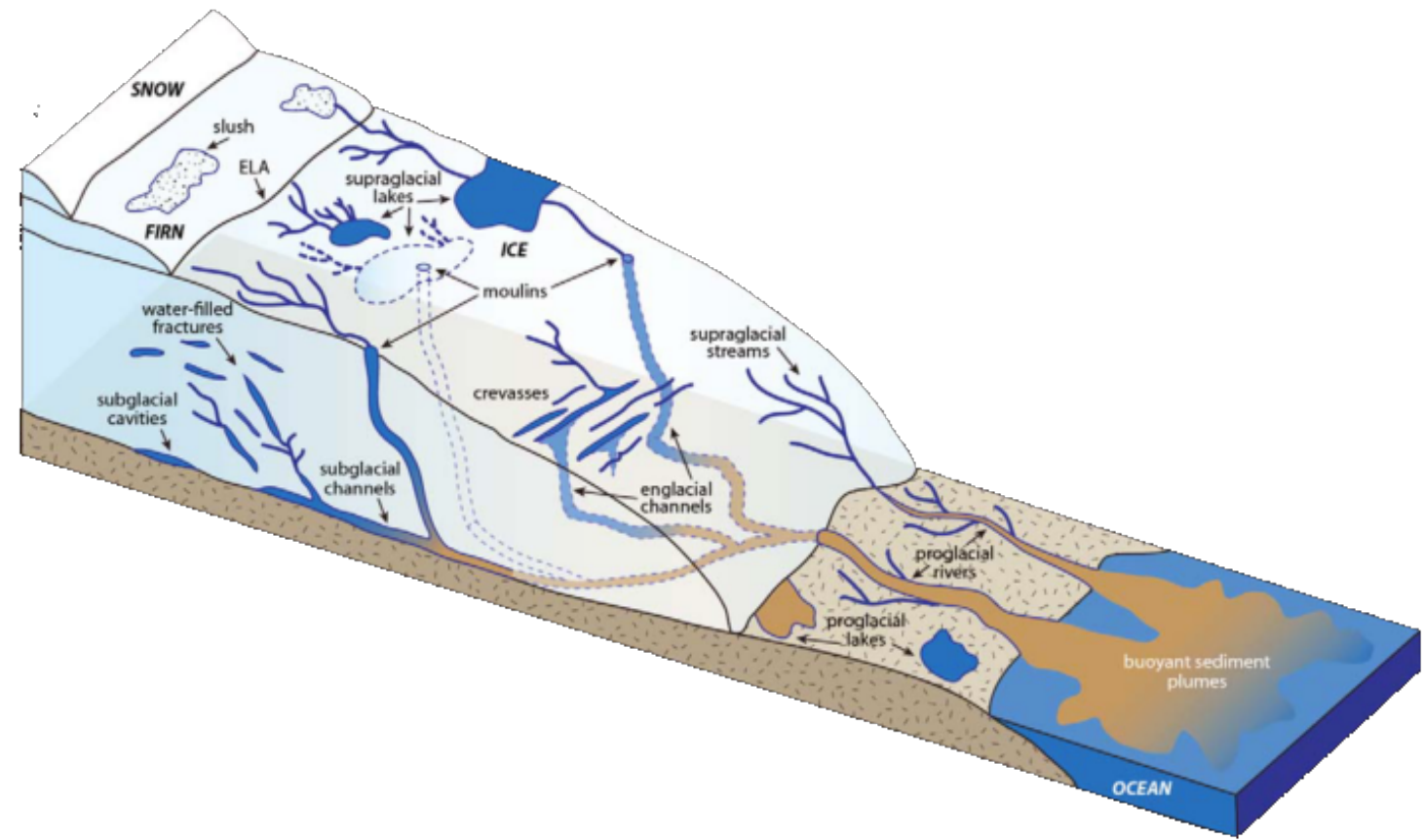

Figure 1-2. Greenland Ice Sheet hydrologic system. Elements of the supraglacial, englacial, and subglacial hydrologic system at a land-terminating margin of the Greenland Ice Sheet from Chu [2013].

Prior to continuous GPS observations of ice flow, Greenland Ice Sheet outlet glacier surface velocities were measured at annual timescale resolution with radar interferometry measurements calibrated to the locations of stakes drilled into the ice sheet surface [Joughin et al., 1996; Mohr et al., 1998]. The first in situ observations of continuous ablation zone velocity measured ice-flow acceleration during summer months, when runoff sourced from surface melt can access and lubricate the ice-bed interface and promote basal sliding [Zwally et al., 2002]. Posing the observed coupling between surface melt and ice-sheet flow as a mechanism for widespread dynamic response of the ice sheet to increased temperature forcing, the Zwally et al. [2002] findings sparked a suite of Global Positioning System (GPS) measurements of ice-flow to test this proposed hypothesis along the western margin, and reduce uncertainties on the present and future dynamical component of Greenland Ice Sheet mass loss [Solomon, 2007; Stocker, 2014].

With the addition of multiple datasets, a better picture of seasonal to inter-annual ice-flow variability emerged, which qualifies the mechanism proposed by Zwally et al. [2002]. Observations of ice-flow and surface mass-balance along the 143-km Kangerlussuaq transect (K-transect) in the ablation zone from 1990-2012 show that while velocities do spike in tandem with increases in surface 
melt on daily timescales, annual velocities are insensitive to annual surface melt forcing, suggesting ice-flow on decadal timescales may remain more or less constant [van de Wal et al. 2008; 2009; 2012]. Further exploration of the K-transect GPS observations has detailed the elevation-dependent annual velocity curve structure (Figure 1-4 a) [Bartholomew et al., 2010; 2011; van de Wal et al., 2015], characterized by slow flow through the spring; a sharp spike in velocities following surface melt onset; sustained fast flow during the first half of the summer with high daily- to multi-day velocity variations; overall decreasing but still variable velocities over the second half of the melt season; an annual minimum velocity following melt cessation; and a steady increase in velocities from the annual minimum over the fall and winter. This characteristic annual velocity curve is supported by observations in the Swiss Camp [Zwally et al., 2002; Colgan et al., 2011; Hoffman et al., 2011] and North Lake [Joughin et al., 2008] regions of the Greenland Ice Sheet, leading to further investigations on the relationship between the evolution of subglacial drainage system components (Figure 1-3) and basal sliding that could be producing this annual velocity curve.

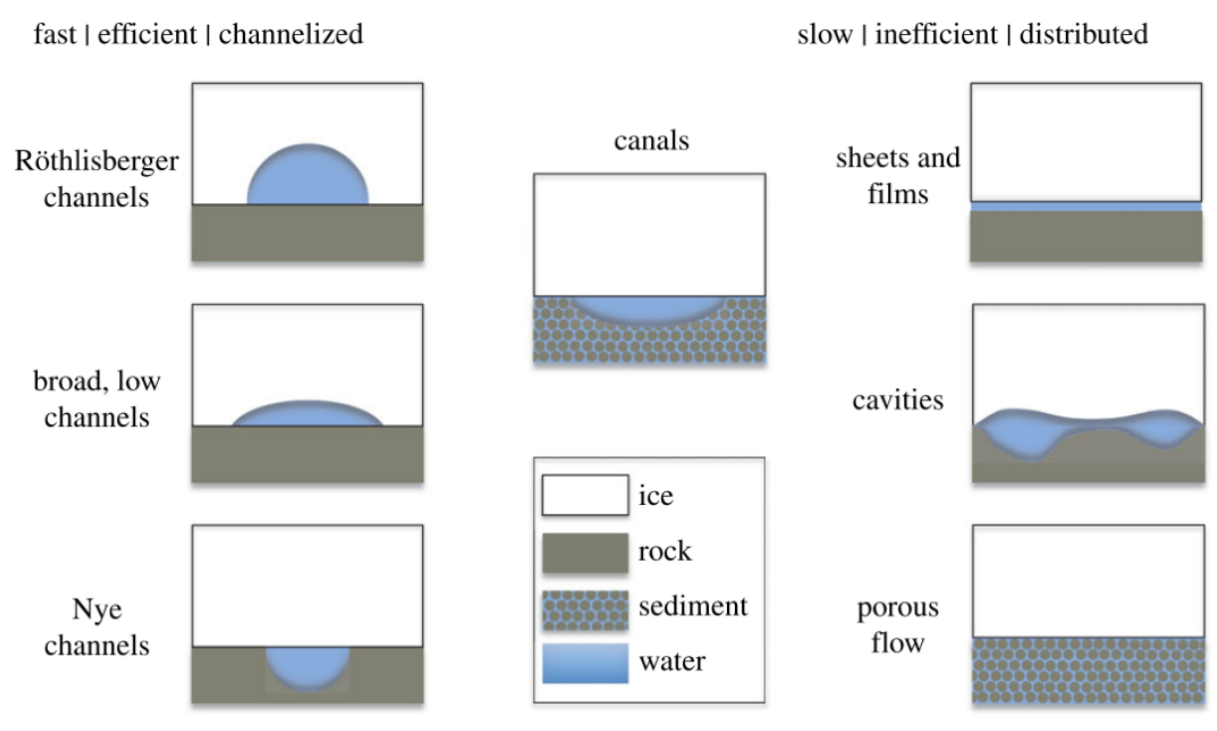

Figure 1-3. Subglacial drainage system elements. Idealized subglacial drainage system elements grouped by "fast" or "slow" drainage from Flowers [2015] Figure 1-2. 


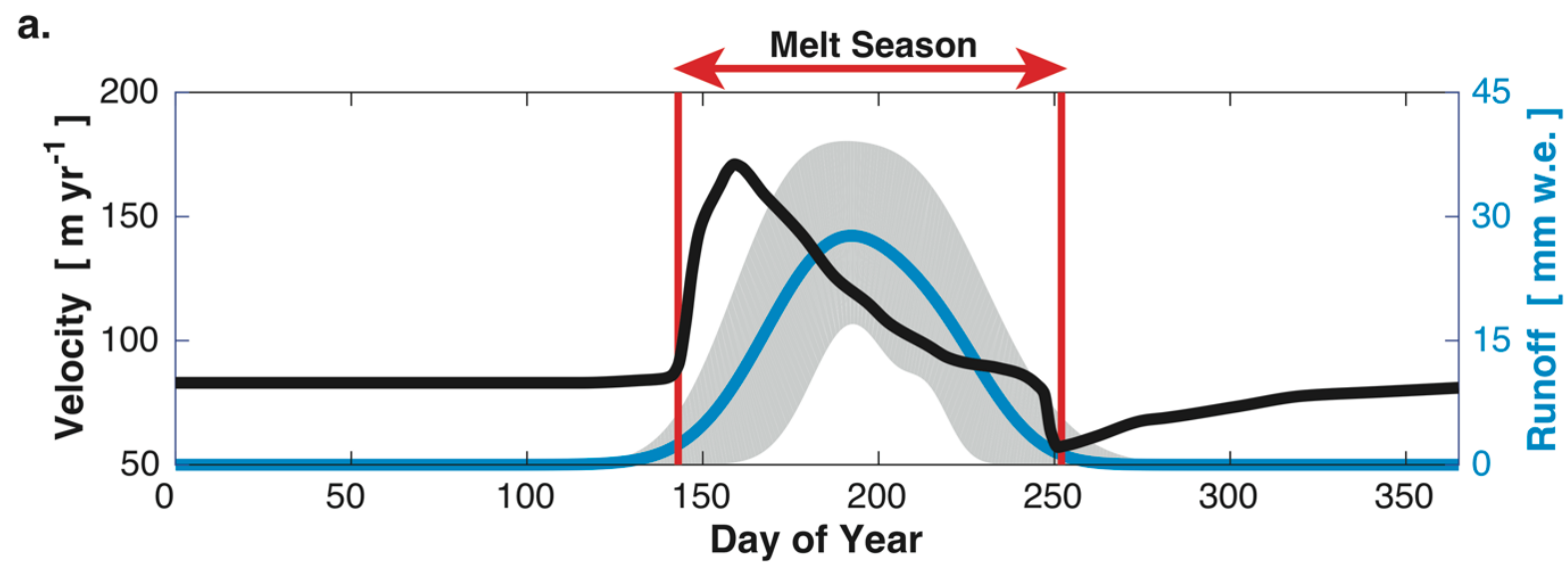

b.

Spring distributed system (DOY 350-145)

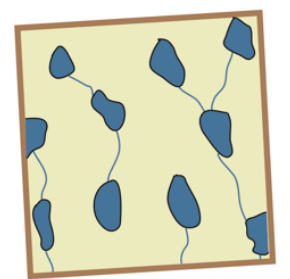

c.

Meltwater onset at bed (DOY 145-165)

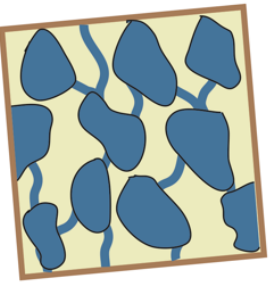

d.

Initial channel growth (DOY 165-190)

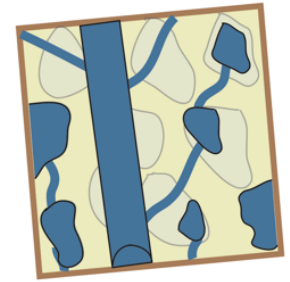

e.

Channelized system (DOY 190-250)

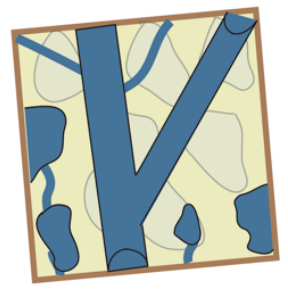

f.

Meltwater supply ends at bed (DOY 250-350)

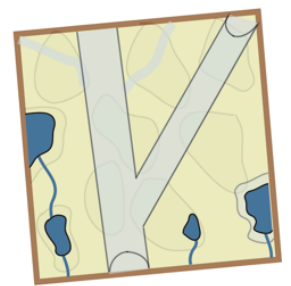

Drainage: slow, inefficient, distributed.

Drainage: fast, efficient, channelized.

Figure 1-4: Annual velocity curve conceptually explained by evolving efficiency of subglacial drainage system. a) Conceptual ablation zone velocity curve (black) and daily runoff $\pm 1 \sigma$ in $\mathrm{mm}$ water equivalent (w.e.) for the North Lake region from 1958 to 2014 (blue) from Stevens et al. [2016b]. b) Inefficient drainage system in spring moves water through linked cavities and/or porous flow. c) The onset of runoff at the surface and the opening of surface-to-bed pathways delivers meltwater to the bed, where it overwhelms the inefficient system resulting in cavity growth, peak basal water pressures, and peak basal sliding. d) Continued meltwater supply provides enough water to initiate channel growth into the basal ice. The drainage system efficiency increases, subglacial water pressures subside slightly, and basal sliding decreases. e) Continued meltwater supply initiates additional channels which may form an arborescent network. The drainage system is at maximum efficiency for the year, subglacial water pressures continue to subside, and basal sliding continues to decreases. f) The end of runoff at the surface terminates the majority of meltwater supply to the bed, resulting in the lowest basal water pressures and surface velocities of the year. Relict channels creep closed. Water supplied from basal melt or stored englacial or basal water returns the system to the linked cavities of b over the winter and spring. 
A conceptual model for a subglacial drainage system that becomes more efficient over the runoff season has been invoked to explain the various components of the characteristic annual velocity curve (Figure 1-4) [Flowers, 2015]. When the ice-bed interface is supplied with sufficient discharge, a slow, inefficient system of thin sheets, cavities, or porous flow through sediments evolves into a fast, efficient system of arborescent channels (Figures 1-3 \& 1-4) [Flowers, 2015]. For both an inefficient cavity system and efficient channelized system, the amount and variability of water input to the system can promote ice acceleration due to the coupling of basal sliding to effective pressures within the subglacial drainage system [Schoof, 2010]. The ability of the subglacial drainage system to evolve to accommodate changing magnitudes of runoff inputs explains why a daily melt forcing in the early summer often produces a greater velocity response than a similar magnitude melt forcing in the late summer. The transition to a channelized subglacial drainage system is also supported by tracer studies that show subglacial water velocities increasing from $\sim 0.3 \mathrm{~m} \mathrm{~s}^{-1}$ in the early melt season to over $1.0 \mathrm{~m}$ $\mathrm{s}^{-1}$ in the late melt season as the efficient channelized system is established [Chandler et al., 2013; Cowton et al., 2013]. The observed insensitivity of annual ice velocities to surface melt forcing has been proposed to be a result of seasonal compensation of ice velocities between the summer season speedup and winter season slow-down that follows, resulting in self-regulated annual velocities independent of melt forcing [Sole et al., 2013]. Through this work, we have gained a greater understanding of the key physics controlling the coupling between ice acceleration and surface melt forcing on daily to seasonal timescales. However, mechanisms invoked to explain the seasonal velocity structure characteristics may not translate to inter-annual timescales.

While the annual velocity curve has been suggested to be largely robust of changes in annual melt forcing [Sole et al., 2013; Tedstone et al., 2013; van de W al et al., 2008; 2015], regional velocities across the Greenland Ice Sheet western margin ablation zone derived from Landsat imagery feature tracking show declining ice velocities with increasing melt over the period from 1985-2014 [Tedstone et al., 2015], suggesting there is some longer time-scale control of melt magnitude on ice-flow. The multiyear control of melt magnitude on ice-flow is hypothesized to be a result of cumulative reduction of stored water in the unchannelized component of the subglacial hydrologic system that would reduce basal lubrication and regional ice velocities [Tedstone et al. 2015]. The Tedstone et al. [2015] hypothesis may hold for the region of the ice-sheet bed that experiences consistent and extensive channelization every year, though observations of its interior extent range from $<10 \mathrm{~km}$ [Meierbachtol et al., 2013] to as far as $41 \mathrm{~km}$ [Chandler et al., 2013] in from the ice margin, leaving broad regions of the ablation zone where 
effects of a non-channelized drainage system drive ice-flow [Andrews et al., 2015]. While the Tedstone et al. [2015] hypothesis has emerged to attempt to explain regional slowdown, the influence of past melt magnitude on ice-flow has not been investigated for a time series of GPS observations of ice velocity. As such, identifying the first-order control on inter-annual variability in ice-flow remains elusive.

In Chapter 2, we investigate a seven-year record of ice-flow collected by an array of GPS stations located at $1000 \mathrm{~m}$ a.s.l. in central west Greenland, $~ 50-\mathrm{km}$ south of the Jakobshavn-Isbræ catchment (Figure 1-5). Alongside the K-transect observations, this ice-flow record represents only the second available GPS record for Greenland greater than 5 years in length and of sufficient temporal detail to investigate both the seasonal and inter-annual relationships between ice-flow and melt forcing.

The questions driving Chapter 2 are:

1. How does seasonal and inter-annual ice flow respond to runoff variability?

2. What processes are driving the coherent slowdown across the western Greenland margin?

\subsection{Rapid supraglacial lake drainages}

In the melt season, thousands of supraglacial lakes form across the ablation zone of the Greenland Ice Sheet as meltwater routed by supraglacial streams accumulates in topographic depressions [Das et al., 2008; Sundal et al., 2009; Yang et al., 2015]. The position of lakes from year to year is fixed by the bedrock topography [Box and Ski, 2007; Fitapatrick et al., 2014], with the majority of supraglacial lakes forming in the middle to upper ablation zone in regions of lower surface slope with few surface-tobed meltwater pathways [Lampkin and VanderBerg, 2011; Sergienko, 2013]. Regions of high surface slopes and crevasses in the lower ablation zone prevent supraglacial lake formation, as meltwater can drain to the bed or off of the ice sheet without ponding [Sneed and Hamilton, 2007]. The number and extent of supraglacial lakes have increased across the ice sheet over the last few decades [Howat et al., 2013], and lakes are projected to continue to form at higher elevations in a warming climate [Parizek and Alley, 2004; Leeson et al., 2015]. 
Rapid supraglacial lake drainages provide an incredible natural experiment that enables us to probe the upper limits of meltwater's influence on ice flow acceleration. Roughly 13\% of lakes on the Greenland Ice Sheet drain rapidly [Selmes et al., 2011], and multiple supraglacial lakes have been observed in situ to drain rapidly via hydro-fracture within a few hours [Das et al., 2008; Doyle et al., 2013; Tedesco et al., 2013]. Rapid drainage event cause short-lived local ice flow acceleration and uplift [Das et al., 2008; Joughin et al., 2008; Doyle et al., 2013; Tedesco et al., 2013b]. While hydro-fracture processes through glacial ice are well known [Weertman, 1973; Van Der Veen, 2007; Krawcsynski et al., 2009], the trigger mechanism for initiating a hydro-fracture in an otherwise compressive supraglacial lake basin is unknown. Supraglacial lakes have been observed to drain in clusters [Joughin et al., 2013; Fitspatrick et al., 2014], though whether this phenomena is due to lake drainages dynamically triggering the drainage of neighboring lakes or merely an artifact of elevation-dependent melt and supraglacial lake formation is untested with in situ GPS observations of clustered drainage or a theoretical model. With poor understanding of a lake drainage triggering mechanism, little can be said about the timing of supraglacial lake drainages across a region [Banwell et al., 2012; Clason et al., 2012], or the future drainage patterns of supraglacial lakes forming in inland areas in a warming climate [Leeson et al., 2015].

In Chapter 3, we investigate three rapid drainages of North Lake $\left(68.72^{\circ} \mathrm{N}, 49.50^{\circ} \mathrm{W}\right)$, a $\sim 2.5-$ $\mathrm{km}$ diameter supraglacial lake located at $1000 \mathrm{~m}$ a.s.l. in central west Greenland, $\sim 50-\mathrm{km}$ south of the Jakobshavn-Isbræ catchment (Figure 1-5). We observe ice sheet surface motion before, during, and after the lake drainages using a dense GPS array that allows us to determine the distribution of meltwater at the ice-sheet bed. By identifying the trigger mechanism for rapid drainage of North Lake, we make a prediction for the drainage patterns of lakes forming at higher elevations.

The questions driving Chapter 3 are:

1. What mechanism triggers rapid supraglacial lake drainages?

2. Will supraglacial lakes forming at higher elevations drain rapidly via bydrofracture? 


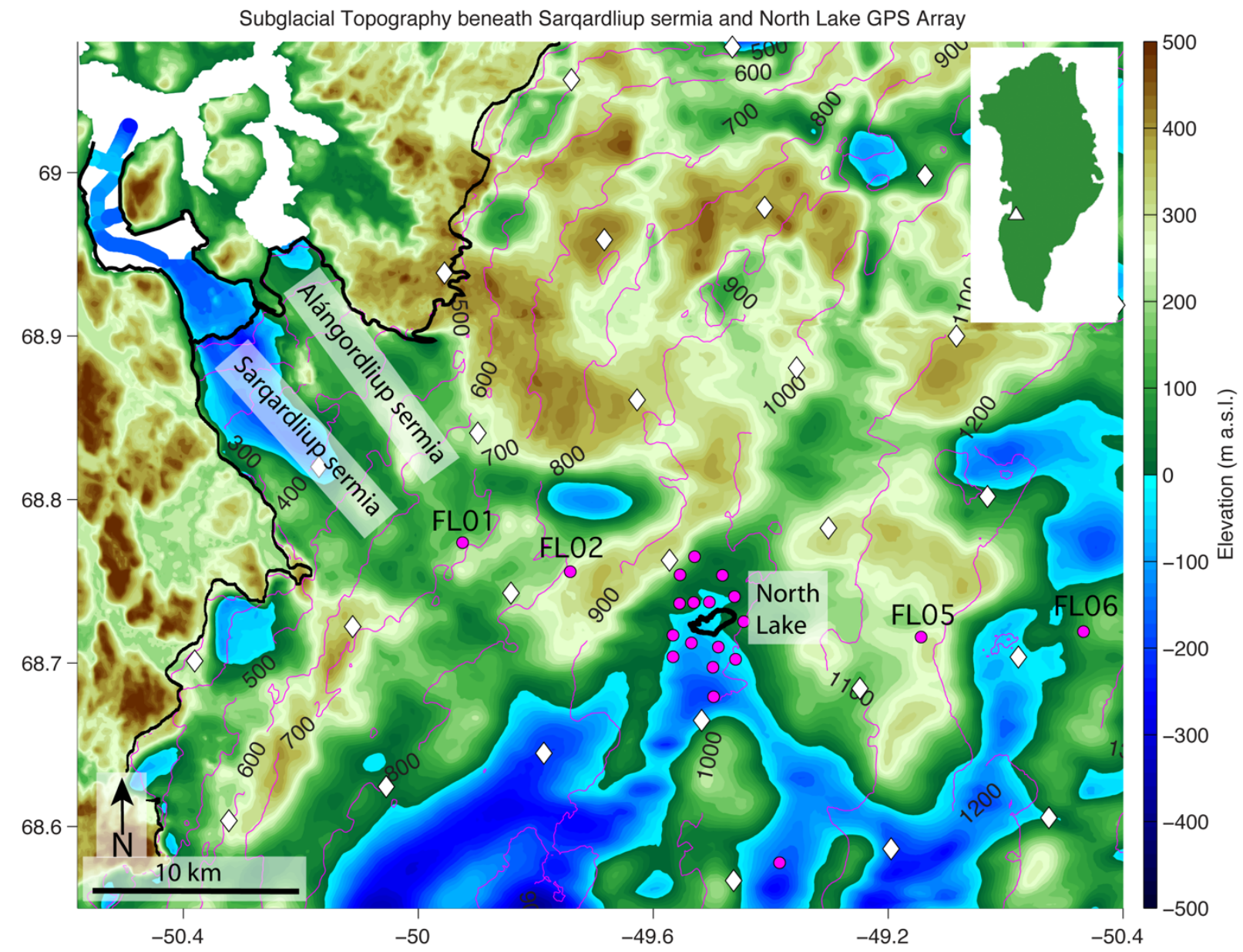

Figure 1-5. Subglacial topography beneath Sarqardliup sermia and the North Lake GPS array. Morlighem et al. [2014] bedmap (filled contours) and ice sheet surface elevations (magenta contours) plotted for the Sarqardliup sermia outlet glacier and North Lake supraglacial lake region. GPS stations (magenta circles) are positioned up- and down-flowline of North Lake (2011 lake margin plotted in black outline). RACMOGR-2.3 11-km resolution grid points shown with white diamonds. Ice sheet margin including the terminus positions for Sarqardliup sermia and Alángordliup sermia shown in black line. Sarqardleq fjord bathymetry map and outer fjord depth measurements plotted in filled contours within the fjord coastline. 


\subsection{Modeling the Greenland Ice Sheet subglacial drainage system}

As described in Section 1.2, meltwater is presumed to travel along the ice-bed interface through a subglacial drainage system that evolves in response to meltwater supply magnitude and variability [Flowers, 2015; Schoof, 2010] although direct observations are limited. Water flows in the direction of the downslope hydraulic potential gradient, which is dominantly a function of the ice sheet surface slope with minor contributions from the bed slope [Shreve, 1972]. Water flows through multiple proposed drainage system elements of different hydraulic efficiencies (Figure 1-3), with differences in form due to bed type, ice sheet thickness, and meltwater supply magnitude and variability [Flowers, 2015]. Conceptual models for subglacial drainage systems propose that the drainage system becomes more efficient over the runoff season [Flowers, 2015]. When the ice-bed interface is supplied with sufficient discharge, a slow, inefficient system of thin sheets, cavities, or porous flow through sediments evolves into a fast, efficient system of arborescent channels (Figure 1-4) [Fountain and Walder, 1998; Flowers, 2015].

Numerical models of ice sheet subglacial drainage systems enable the testing of theories relating subglacial water routing to ice flow (e.g., Equation 1.2) and the estimation of the impact of future warming scenarios on ice flow [Flowers, 2015]. Numerical models of water flow under glaciers and ice caps were first developed in the 1960s, and focused on quantifying the timing and volume of runoff [Fountain and Tangborn, 1985], and the control of subglacial hydrology on glacier dynamics [Iken and Bindschadler, 1986]. In the late 2000s, the first numerical models of water flow under the Greenland Ice Sheet were developed based on observations and numerical models of mountain glaciers [Fountain and Walder, 1998]. The most recent generation of glacier and ice sheet models captures the conceptual model of drainage system evolution over a melt season by routing flow through both fast and slow drainage elements in a two-dimensional framework [Schoof, 2010; Hewitt et al., 2012; Schoof et al., 2012; Hewitt, 2013; Werder et al., 2013]. These multi-element models pertain to ice sheet and glaciers that flow over a "hard bed" that is impermeable and rigid [Flowers, 2015]. Additionally, the two-dimensional nature of these models permits relatively easy coupling with two-dimensional ice flow models [Flowers, 2015].

This generation of two-dimensional, multi-element subglacial drainage system models has facilitated in the production of artificial drainage networks with the most realistic morphology to date 
[Flowers, 2015]. In the Schoof [2010] formulation, individual elements located along a two-dimensional numerical mesh dynamically switch between being a cavity (slow flow) or Röthlisberger channel (fast flow) depending on the effective pressure (Figure 1-6). Further development by Hewitt [2011] invokes a continuum description of the distributed system, which treats cavities as a continuous sheet where water flow is dictated by the effective hydraulic transmisivity and the hydraulic potential. This continuum description effectively treats the distributed system as turbulent flow through a porous medium, where the sheet can also open through basal sliding [Hewitt, 2011]. This generation of models has produced realistic drainage system behaviors for idealized [Schoof, 2010; Hewitt, 2013], alpine glacier [Werder et al., 2013] and Greenland Ice Sheet margin [Banwell et al., 2016] geometries.

Numerical model development has moved faster than observations for model calibration, resulting in increasingly detailed numerical models that lack realistic ice bed elevations and regional measurements of surface velocities for adequate calibration [Flowers, 2015]. Numerical models paired with surface observations provides one way to test theories relating subglacial water routing to ice flow; however, regional observations needed for model calibration are limited in Greenland with just three observations of the spatiotemporal evolution of ice flow through the melt season to date [Palmer et al., 2011; Joughin et al., 2013; Bougamont et al., 2014]. Continued data calibration is needed to adequately validate these models and test theoretical models of basal sliding.

In Chapter 4, we investigate annual subglacial drainage system morphology of a mixed marineand land-terminating sector of the west Greenland Ice Sheet with a numerical subglacial hydrology model. The model incorporates both distributed and channelized flow, and we have adapted it to include realistic ice sheet geometry and surface runoff input. We run the model across two years where regional observations of complex spatiotemporal pattern of melt-season ice surface speed are available for model calibration. We investigate whether model-derived effective pressures exhibit the theorized inverse relationship with melt-season surface speed (Equation 1.2) to test if effective pressure is the dominant control on surface speeds.

The questions driving Chapter 4 are:

1. Is subglacial drainage system morphology robust across years and for different surface runoff input types?

2. What is the relationship between model-derived effective pressures and surface speed across the melt season? 
a.

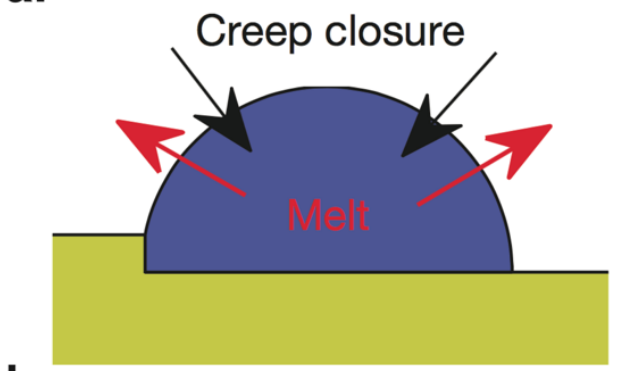

b.

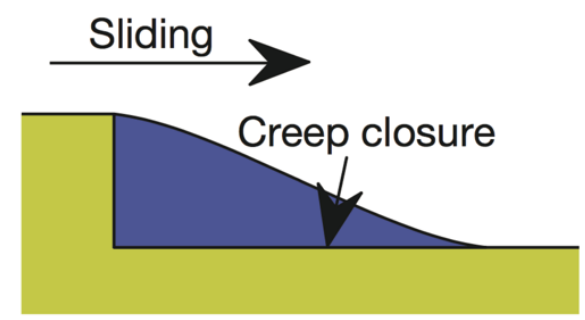

c.

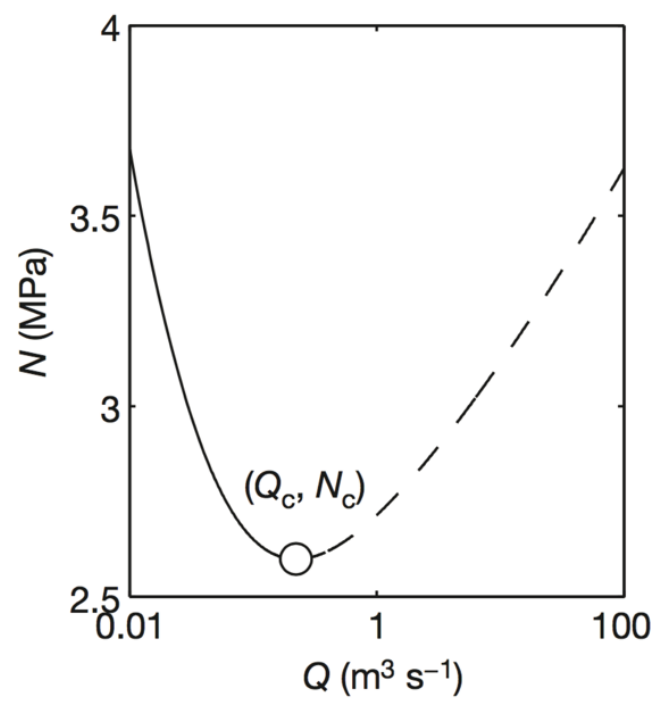

Figure 1-6. Subglacial channel and cavity physics. a) Channel area grows by melting of channel walls. Channel area decreases by creep closure. b) Cavity area grows by basal sliding. Cavity area decreases by creep closure. c) Effective pressure $N$ as a function of discharge $\mathcal{Q}$ for a cavity (solid line) or channel (dashed line) under steady-state conditions. Above a critical discharge, $Q_{C}$ a cavity becomes a channel. Effective pressure increases with increased discharge for a cavity; effective pressure decreases with increasing discharge for a channel. All panels from Schoof [2010] Figure 1.

\subsection{Ice-Ocean interactions at marine-terminating outlet glaciers}

Nearly all meltwater runoff created at the surface of the ice sheet eventually makes its way to the ice sheet terminus [Smith et al., 2015], contributing freshwater to the North Atlantic via subglacial channels exiting into proglacial streams and lakes along land-terminating margins (Figure 1-2) and as freshwater discharge at depth in fjords abutting marine-terminating outlet glaciers (Figure 1-7) [Bamber et al., 2012]. The synchronous retreat and speedup of marine-terminating glaciers in southeast Greenland in the early 2000s was likely initiated by a dynamic change at marine termini [Howat et al., 2007; Nick et al., 2009; Vieli and Nick, 2011; Moon et al., 2012], and points towards common external forcings from the warming atmosphere [Box et al., 2009] and/or ocean around Greenland [Holland et al., 2008; Straneo and Heimbach, 2013], though the exact forcing mechanisms and relative magnitudes remain unclear (Figure 1-7) [Joughin et al., 2012a; Straneo et al., 2013]. The gap in current understanding stems from the lack of studies bridging glaciologic and oceanographic disciplines and datasets, and the inherent difficulty 
in obtaining measurements in ice mélange near actively-calving glaciers [Joughin et al., 2012; Straneo et al., 2013].

Increased submarine melt rates at outlet glacier marine termini may be a leading cause of Greenland Ice Sheet outlet glacier speed up and retreat (Figure 1-7) [Holland et al., 2008; Post et al., 2011; Joughin et al., 2012b; Motyka et al., 2013]. The heat to drive submarine melting is supplied by waters from the subpolar North Atlantic and Arctic seas, whose circulation inside the fjords is a result of processes across a range of spatiotemporal scales [Straneo et al., 2010; Jackson et al., 2014; Jackson and Straneo, 2016]. Melt rates are affected by ocean temperature, stratification, and circulation in near-ice waters ( $<200 \mathrm{~m}$ from the terminus) [Jenkins et al., 2010]. Submarine melting is thought to be enhanced in summer as a result of meltwater runoff along the ice sheet bed entering the fjord across the grounding line as subglacial discharge, which provides an additional source of buoyancy alongside submarine melt for initiating buoyant plumes along the terminus face [Jenkins, 1999, 2011; Sciascia et al., 2013; Xu et al., 2013]. Relatively fresh waters rising in the core of these plumes become denser as they entrain salty ambient fjord waters, and this plume-driven entrainment serves as a mechanism for transporting ambient fjord waters to the glacier face [Jenkins, 1999, 2011; Sciascia et al., 2013; Xu et al., 2013].

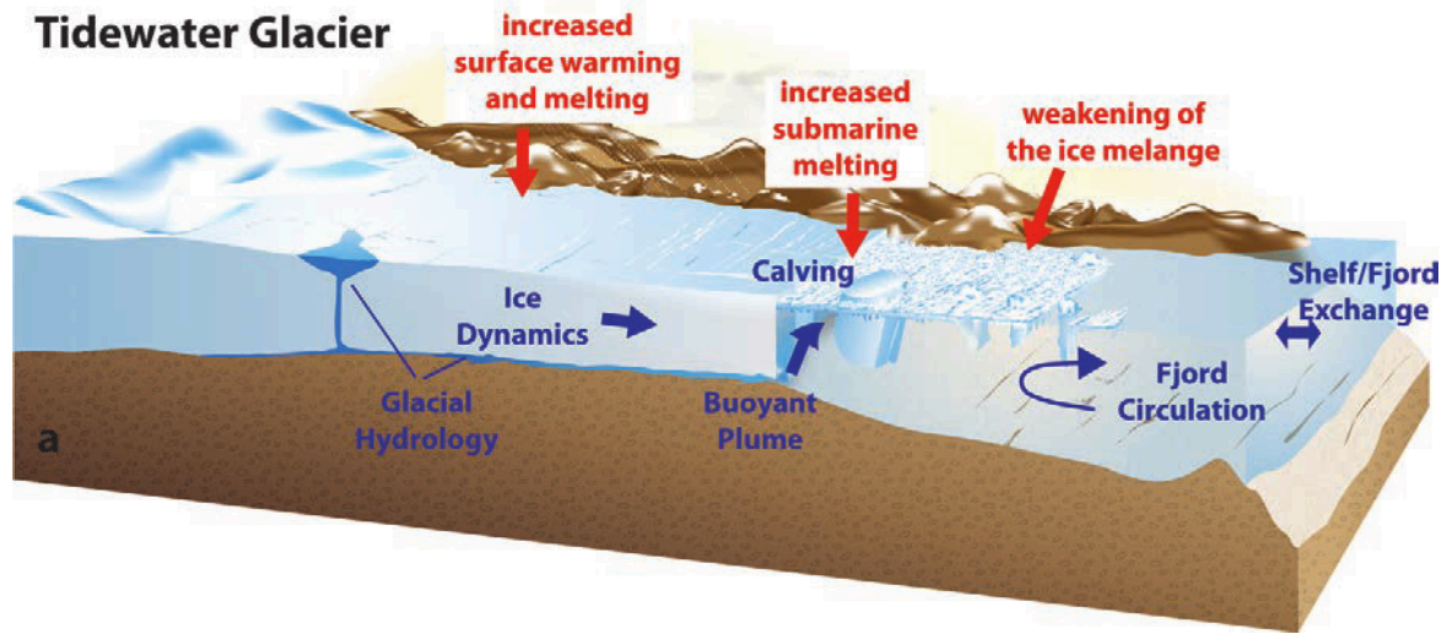

Figure 1-7. Greenland tidewater glacier system. Possible mechanisms for glacier and ice sheet retreat in red; key processes that may drive tidewater glacier retreat in blue. From Straneo et al. [2013] Figure 4. 
Plume theory and models suggest that higher subglacial discharge rates lead to higher submarine melt rates [Jenkins, 1999, 2011; Sciascia et al., 2013; Xu et al., 2013; Carroll et al., 2015]. However, ocean property and plume measurements needed to inform and validate model simulations are lacking [Straneo and Cenedese, 2015]. The current model-based estimates of submarine melt rates at tidewater glaciers and their sensitivity to external forcings of the near-ice environment are highly uncertain. The uncertainty in these estimates is due to plume models using ice/ocean boundary parameterizations forced by far field $(>1 \mathrm{~km})$ ocean property measurements and largely unknown subglacial discharge magnitude and distribution [Jenkins, 2011; Xu et al., 2012, 2013; Sciascia et al., 2013; Kimura et al., 2014; Slater et al., 2015]).

With a lack of observations of both the near-ice environment and subglacial discharge configurations, defining likely subglacial discharge scenarios and their associated influence on ice/ocean interactions has remained a distinct challenge, resulting in an inadequate understanding of how tidewater glaciers respond to oceanic forcing now and in the future [Straneo and Cenedese, 2015]. Specifically, ocean measurements collected at distances $>1 \mathrm{~km}$ from the glacier terminus have provided limited information on the near-ice processes because signals of glacial modification are largely smeared by lateral mixing processes over that distance. While far-field measurements suggest a horizontally invariant overturning cell(s) at this $>1 \mathrm{~km}$ distance [Johnson et al., 2011; Mortensen et al., 2011; Straneo et al., 2011; Chauché et al., 2014; Inall et al., 2014; Sutherland et al., 2014], there is likely much greater variability in glacially modified waters in the near-ice zone.

In Chapter 5, we present fjord hydrography and bathymetry measurements from the near-ice zone of Sarqardliup sermia tidewater glacier in west Greenland (Figure 1-5). This novel, high-risk field campaign was successful in obtaining multiple vertical sections of fjord water properties as close as $150 \mathrm{~m}$ from the terminus as well as detailed bathymetry of the previously unmapped fjord. We reconstruct the distribution of subglacial discharge along the grounded terminus through the delineation of subglacial catchments. The paired glaciologic and oceanographic datasets allow us to match the distribution of subglacial discharge with the glacially modified waters observed in the fjord. 
The questions driving Chapter 5 are:

1. What is the near-glacier expression of glacially modified water?

2. Do the locations and characteristics of glacially modified waters sourced from turbulent plumes align with subglacial discharge locations and magnitudes along the terminus? 


\section{Chapter 2}

\section{Greenland Ice Sheet flow response to runoff variability}

This chapter was originally published as: Stevens, L. A., M. D. Behn, S. B. Das, I. Joughin, B. P. Y. Noël, M. R. van den Broeke, and T. Herring (2016), Greenland Ice Sheet flow response to runoff variability, Geophysical Research Letters, 43, 1-9. Used with permission as granted in the original copyright agreement.

\subsection{Abstract}

We use observations of ice-sheet surface motion from a Global Positioning System (GPS) network operating from 2006-2014 around North Lake in west Greenland to investigate the dynamical response of the Greenland Ice Sheet's ablation area to inter-annual variability in surface melting. We find no statistically significant relationship between runoff season characteristics and ice flow velocities within a given year or season. Over the seven-year time series, annual velocities at North Lake decrease at an average rate of $-0.9 \pm 1.1 \mathrm{~m} \mathrm{yr}^{-2}$, consistent with the negative trend in annual velocities observed in neighboring regions over recent decades. We find that net runoff integrated over several preceding years has a negative correlation with annual velocities, similar to findings from the two other available decadal records of ice velocity in western Greenland. However, we argue that this correlation is not necessarily evidence for a direct hydrologic mechanism acting on the timescale of multiple years, but could be a statistical construct. Finally, we stress that neither the decadal slowdown trend, nor the negative correlation between velocity and integrated runoff, are predicted by current ice sheet models, underscoring that these models do not yet capture all the relevant feedbacks between runoff and ice dynamics needed to predict long term trends in ice sheet flow. 


\subsection{Introduction}

The rate of mass loss from the Greenland Ice Sheet is accelerating [Shepherd et al., 2012; Enderlin et al., 2014] due to increases in surface melt [van den Broeke et al., 2009; Hanna et al., 2013] and changes in ice sheet dynamics [Pritchard et al., 2009]. Zwally et al. [2002] presented the first in situ observations of summer ice-flow acceleration in Greenland's ablation zone, and proposed that during summer months surface meltwater accesses and lubricates the ice-bed interface promoting enhanced basal sliding. This observed coupling between surface melt and ice-sheet velocities suggests a potential mechanism for a widespread dynamic response of the ice sheet to increased temperature forcing. These findings sparked a series of Global Positioning System (GPS) measurements of ice-flow to test this hypothesis

(Figure 2-1 a) and to provide better constraints on the present and future dynamical component of ice-sheet mass loss [Solomon, 2007; Stocker, 2014]. With the addition of new datasets, a more detailed picture of seasonal to inter-annual ice-flow variability has emerged. However, contrasting ice-flow response to melt over different timescales continues to present a challenge to the interpretation of the physical processes underlying this variability.

Similar to the results of Zwally et al. [2002], observations of ice-flow and surface mass-balance in a land-terminating region of western Greenland show that velocities increase in tandem with surface melt on daily-to-weekly timescales [van de W al et al., 2008, 2015]. Multiple observations from regions of slow-moving $\left(<\sim 100 \mathrm{~m} \mathrm{yr}^{-1}\right)$ ice-sheet flow support the depiction of a characteristic annual velocity curve (Figure 2-1 b) with: (1) slow velocities through the winter and spring, (2) a sharp increase in velocities at the onset of surface melt, (3) fast and variable velocities during summer months, and (4) a velocity minimum near the end of the melt season [Zwally et al., 2002; Bartholomew et al., 2010; Hoffman et al., 2011].

Velocity and hydrological observations first made on temperate alpine glaciers (reviewed by Fountain and $W$ alder [1998]) led to the development of a conceptual model for subglacial drainage system evolution that can explain the seasonally-varying components of the characteristic annual velocity curve for temperate alpine glaciers and the Greenland Ice Sheet [Chandler et al., 2013; Cowton et al., 2013]. This model suggests that when meltwater input is low, the ice-bed interface is characterized by a slow, inefficient "distributed" subglacial hydrologic system of thin sheets, cavities, and/or porous flow through sediments. As meltwater input increases, the drainage system evolves 
towards a more efficient, "channelized" network of dendritic channels that draws water out of the distributed system. As the subglacial system channelizes over the melt season, this more efficient drainage system operates at lower water pressure. With this water-pressure drop, a greater region of the ice sheet is in contact with the bed, leading to greater frictional coupling and reduced velocities in the second half of the melt season [Schoof, 2010; Hoffman et al., 2011]. In this model, seasonal surface melt modulates the annual velocity curve by changing basal drag; however, numerous observations show that velocity averaged over the entire year is largely insensitive to the magnitude of annual melt [van de Wal et al., 2008, 2015; Sole et al., 2013; Tedstone et al., 2013]. This insensitivity to melt forcing has been proposed to result from seasonal compensation between summer speed-up and subsequent winter slow-down, resulting in a self-regulated system [Sole et al., 2013].

Yet, while the shape of the annual velocity curve (Figure 2-1 b) appears to be robust, questions remain regarding how time-averaged ice-sheet velocities respond now and in the future to long-term variability and/or trends in melt input. Specifically, a multi-decadal decline in velocity has been observed in concert with increasing melt across predominantly land-terminating regions of the western Greenland ice sheet (notably the K-transect [van de Wal et al., 2008; 2015] and the ablation zone south of Jakobshavn-Isbræ [Tedstone et al., 2015]) (Figures 2-1 a, 2-3 g,h). Furthermore, Tedstone et al. [2015] found an improved correlation when comparing 3-4 years of average past runoff with ice speed. Based on this relationship they proposed that ice-flow may respond to integrated past runoff over a multi-year time-scale through a cumulative reduction of stored water in the unchannelized portions of the subglacial hydrologic system reducing basal lubrication and slowing ice velocities. The observed regional slow-down, however, is spatially variable and most pronounced near the margin below 900 $\mathrm{m}$ above sea level (a.s.l.). This poses the question as to how representative this effect is, and whether differences in the subglacial drainage system, and therefore the dynamic ice response to increasing melt input, may vary as a function of ice thickness and/or the distribution of meltwater input to the bed.

Clearly, more and longer multi-year to decadal observations are needed to investigate relationships between meltwater runoff and ice velocity on seasonal to decadal timescales and to test the various hypotheses put forward thus far. Here we analyze a seven-year record (2007-2014) of iceflow collected using an array of GPS stations $\sim 50-\mathrm{km}$ south of the Jakobshavn-Isbræ catchment (Figure 2-1 a). The array was situated around North Lake $\left(68.72^{\circ} \mathrm{N}, 49.50^{\circ} \mathrm{W}\right.$ ), a supraglacial lake 
located at an elevation of $\sim 1000 \mathrm{~m}$ a.s.l. Based on the GPS data, we calculate seasonal and annual velocities alongside meltseason runoff characteristics (e.g., magnitude, variability). With the K-transect and Swiss Camp observations, our data represent the third 5+ year GPS record for Greenland. In contrast to the longer-term Landsat dataset along the western margin [Tedstone et al., 2015], our continuous GPS record provides seasonal resolution, allowing investigations of inter-annual flow variability at critical periods of the year, potentially providing more insight into the dynamics of the hydrological processes underlying the ice-flow variability. We examine our findings alongside the two other available decadal records to evaluate ice-flow variability on multi-year to decadal timescales and improve our understanding of the factors driving variability in annual ice velocity in the ablation region. 


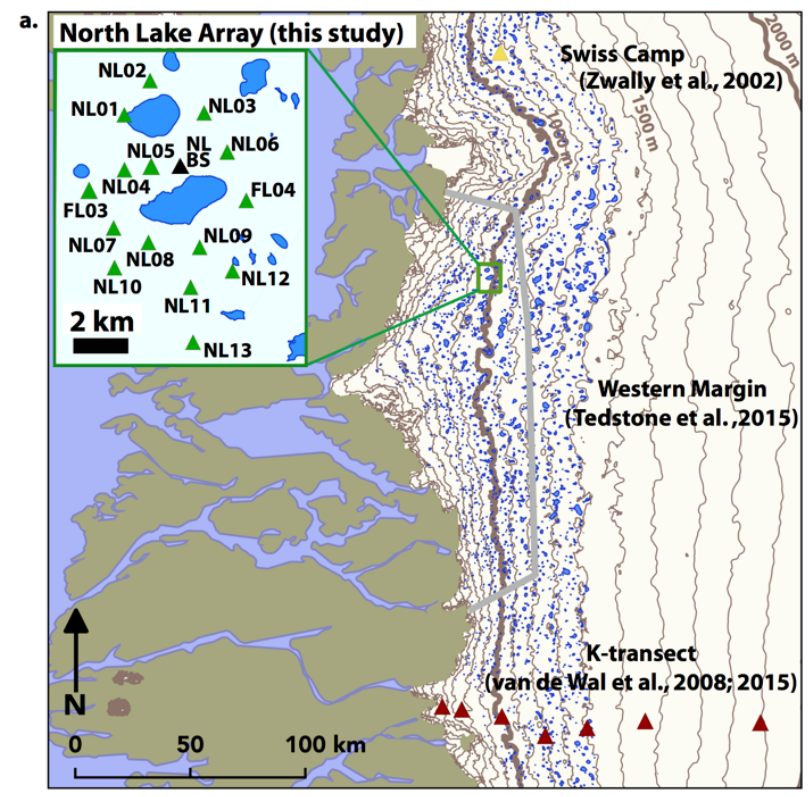

Figure 1: Greenland Ice Sheet marginal velocity campaigns.

(a) Swiss Camp (yellow), North Lake (green and inset), and K-transect (red) GPS campaigns. Blue circles show maximum extent of supraglacial lakes up to $1400 \mathrm{~m}$ a.s.l. from 2000-2010 from Yang et al. [2015] . Brown contours show ice sheet surface elevation 100-m contours derived from Howat et al. [2014]. Western Margin region of Tedstone et al. [2015] study in grey. (b) Conceptual ablation zone velocity curve (blue) and daily runoff $\pm 1 \sigma$ for the North Lake region from 1958-2014 (black). (c) Weekly-resolution and (d-e) 24-hr-resolution ice velocities from the North Lake GPS array (blue) plotted with daily runoff estimates (grey bars) for the North Lake region for a representative multi-year period 2009-2011. The dates of the start and end of the runoff season used to calculate seasonal velocities are shown with red bars. North Lake drainages are shown with green bars. Velocity records for all years (2006-2014) are shown in Figure S1.
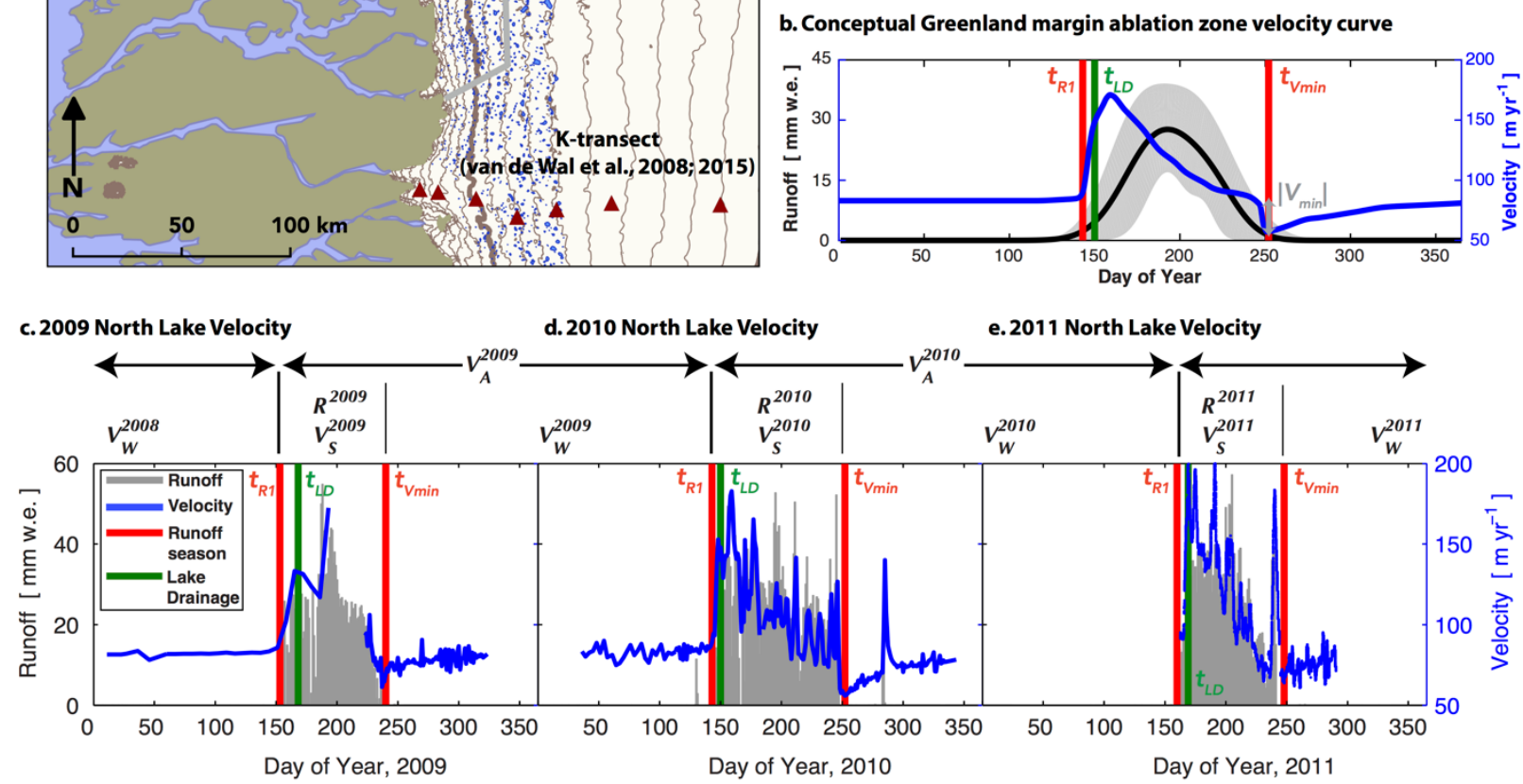

Figure 2-1: Greenland Ice Sheet marginal velocity campaigns. (a) Swiss Camp (yellow), North Lake (green and inset), and K-transect (red) GPS campaigns. Blue circles show maximum extent of supraglacial lakes up to $1400 \mathrm{~m}$ a.s.l. from 2000-2010 from Yang et al. [2015]. Brown contours show ice sheet surface elevation 100-m contours from Howat et al. [2014]. Western Margin region of Tedstone et al. [2015] study in grey. (b) Conceptual ablation zone velocity curve (blue) and daily runoff $\pm 1 \sigma$ for the North Lake region from 1958-2014 (black). (c) Weekly-resolution and (d-e) 24-hr-resolution ice velocities from the North Lake GPS array (blue) plotted with daily runoff estimates (grey bars) for the North Lake region for a representative multi-year period 2009-2011. The dates of the start and end of the runoff season used to calculate seasonal velocities are shown with red bars. North Lake drainages are shown with green bars. Velocity records for all years (2006-2014) are shown in Figure $2-4$. 


\subsection{Methods}

A GPS array consisting of 1-16 receivers was deployed at North Lake from July 2006 through July 2014 (Figure 1a) [Das et al., 2008; Joughin et al., 2008; Stevens et al., 2015]. The station data were processed individually with Track software [Chen, 1998] as kinematic sites relative to the 30-s resolution Greenland GPS Network KAGA base station on bedrock $\sim 55 \mathrm{~km}$ away [Bevis et al., 2012; Stevens et al., 2015]. Continuous (Figures 2-1 c-e; 2-4) and seasonal ice surface velocities (Figure 2-2 a) are calculated from the horizontal GPS position estimates. For years 2011-2014 where multiple GPS stations are available, the velocity of all online stations are averaged at 30-s intervals to produce a composite, continuous velocity across the array (Appendix 2.D; Figure 2-1 e, 2-4 f-i). The time periods over which annual and seasonal displacements (Figure 2-2 c) and velocities (Figures 2-2 b,d) were calculated are based on runoff estimates from the 11-km resolution Regional Atmospheric Climate Model (RACMO) v. 2.3 [Noël et al., 2015]. These runoff estimates are statistically downscaled using elevation dependence to 1-km resolution [Noël et al., 2016] based on a down-sampled version of the GIMP DEM [Howat et al., 2014] (Figure 2-1 c-e). The start of each year is defined as the date of the $1^{\text {st }}$ percentile of each year's cumulative runoff curve, $\boldsymbol{t}_{\boldsymbol{R} \mathbf{1}}$ (Figure 2-1 b-e). Annual velocities $\left(\boldsymbol{V}_{\boldsymbol{A}}\right)$ are split into summer velocities $\left(\boldsymbol{V}_{\boldsymbol{S}}\right)$ and winter velocities $\left(\boldsymbol{V}_{\boldsymbol{W}}\right)$. Summer velocities are calculated from $\boldsymbol{t}_{\boldsymbol{R} \mathbf{1}}$ to $\boldsymbol{t}_{\boldsymbol{V} \text { min }}$, the latter of which represents the midpoint within the characteristic velocity minimum at the end of the melt season (Figures 2-1 b-e). Winter velocities are calculated from $\boldsymbol{t}_{\boldsymbol{V} \text { min }}$ to $\boldsymbol{t}_{\boldsymbol{R} \mathbf{1}}$ of the following year. Because each year in the time series has different runoff characteristics, the start and end of the runoff season do not fall on consistent calendar dates (Figures 2-1 c-e, 2-2a, 2-4; Table 21). Using this method we calculate annual and seasonal velocities for melt seasons 2007-2013. In order to improve comparisons of our results to the prior studies of Sole et al. [2013] and van de Wal et al. [2015], we also calculate seasonal and annual velocities using their fixed calendar dates method. The resulting North Lake inter-annual trends are nearly identical regardless of the method used to delineate seasons (Appendix 2.D, Figure 2-5, Table 2-3).

We use the RACMO output to calculate total runoff magnitude $\left(\boldsymbol{R}_{\boldsymbol{m a g}}\right)$, seasonal variability in runoff $\left(\boldsymbol{R}_{\boldsymbol{v a r}}\right)$, and season length $\left(\boldsymbol{R}_{\text {length }}\right)$ for each year. We estimate the timing of North Lake drainage $\left(\boldsymbol{t}_{\boldsymbol{L} \boldsymbol{D}}\right)$ from satellite data and field observations (Figures 2-3b, 2-7). To investigate drivers of seasonal and annual ice-flow we assess the covariance between seasonal and annual velocities and runoff parameters by evaluating the coefficient of determination $\left(\mathrm{R}^{2}\right)$ and $p$-value of linear trends between all 
variables (Table 2-1; Figures 2-8-2-12). To illustrate the limitations of our small sample size, we calculated 5-95\% confidence interval bounds for all $\mathrm{R}^{2}$ values. We note that our results represent a measurement of local ice-flow within a region of the ice-sheet that exhibits substantial spatial variability in summer [Joughin et al., 2013] and inter-annual velocities [Tedstone et al., 2015]. 

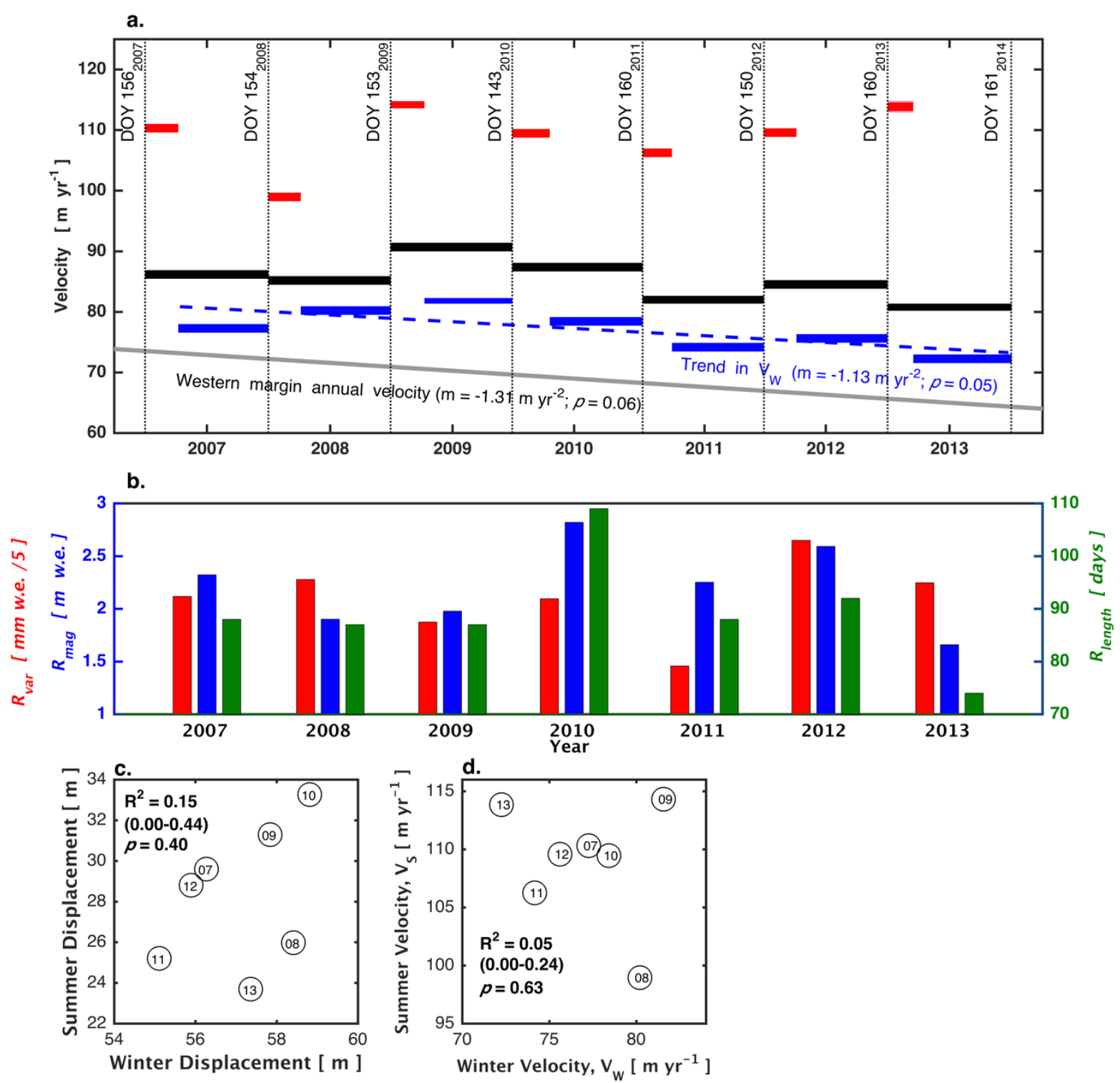

Figure 2-2: Seasonal ice velocity and runoff time series. (a) $\boldsymbol{V}_{\boldsymbol{S}}$ (red), $\boldsymbol{V}_{\boldsymbol{W}}$ (blue), and $\boldsymbol{V}_{\boldsymbol{A}}$ (black) \pm uncertainty (error bars smaller than bar width) across the North Lake array from 2007-2013. Time along the x-axis is plotted in days, with vertical dashed lines marking the start of summer $\left(\boldsymbol{t}_{\boldsymbol{R} \mathbf{1}}\right)$ in each year (subscript). The bar width in $\mathrm{x}$ - represents the length of time over which velocities were calculated. Trend in North Lake $\boldsymbol{V}_{\boldsymbol{W}}$ from $2007-2013$ is shown in dashed blue line (no significant trends were found for $\boldsymbol{V}_{\boldsymbol{S}}$ or $\boldsymbol{V}_{\boldsymbol{A}}$ ). Grey line shows annual velocity trend from 2007-2013 of the western margin [Tedstone et al., 2015]. (b) $\boldsymbol{R}_{\boldsymbol{m a g}}$ (blue), $\boldsymbol{R}_{\text {var }}$ (red), and $\boldsymbol{R}_{\text {length }}$ (green) at North Lake from 20072013. (c) Summer versus winter displacements and (d) $\boldsymbol{V}_{\boldsymbol{S}}$ versus $\boldsymbol{V}_{\boldsymbol{W}}$ (error bars smaller than circle diameter) for 2007-2013. 


\subsection{Results and Discussion}

We find a characteristic annual velocity curve consistent with results from previous studies (Figure 2$1 \mathrm{c}-\mathrm{e})$. The onset of runoff is associated with an abrupt increase in velocity, followed by multi-day velocity variations that are correlated with spikes in runoff and/or North Lake drainage events (Figures 2-1 c-e, 2-4). At the end of the runoff season, velocities reach their annual minimum (Figures 2-1 c-e, 2-4). This annual velocity structure-and in particular the velocity minimum following melt cessation — suggests that the subglacial drainage system becomes more efficient and channelized over the runoff season, consistent with hydrological observations from other regions in Greenland [Chandler et al., 2013; Cowton et al., 2013].

Due to variability in the relative length of summer versus winter (see Supporting Information), seasonal and annual velocities are a function of both displacement (Figure 2-2 c) and season length (Figure 2-2 b). For example, the highest summer displacement in our record occurred in 2010 (Figure 2-2 c), but due to that year's extremely long summer melt season (Figure 2-2 b), the 2010 summer velocity is comparable to other years (Figure 2-2 a,d). We note that by dividing each year into seasons based on runoff, the time interval over which $\boldsymbol{V}_{\boldsymbol{A}}$ is calculated varies on a year-to-year basis (i.e., a year does not always equal 365 days). We find $\boldsymbol{V}_{\boldsymbol{W}}$ in the North Lake region is largely independent of $\boldsymbol{V}_{\boldsymbol{S}}$ within the same year for both the $\boldsymbol{t}_{\boldsymbol{R} \mathbf{1}}$ to $\boldsymbol{t}_{\boldsymbol{V} \boldsymbol{m i n}}$ seasonal delineation method and the fixed calendar date method (Figures 2-2 d, 2-5 d). This result contrasts GPS observations of seasonal velocities from Sole et al. [2013], which were the basis of their hypothesis that annual velocities were self-regulated through a strong inverse relationship between winter and summer velocities.

\subsubsection{Inter-annual trends and variability in velocity and runoff}

The mean annual velocity, $\overline{\boldsymbol{V}}_{\boldsymbol{A}}$, for the North Lake region is $85.2 \pm 3.3 \mathrm{~m} \mathrm{yr}^{-1}$ over the observation period, $\sim 15 \mathrm{~m} \mathrm{yr}^{-1}$ greater than the mean annual velocity for the Western Margin found by Tedstone et al. [2015] over the same time period (Figure 2-2 a). This difference is likely due to the inclusion of the lower velocity ice margin in the larger Tedstone et al. [2015] region, as well as the spatial variability in velocities observed across the region more broadly [Joughin et al., 2013]. The North Lake annual velocity is intermediate between the mean summer velocity $\left(\overline{\boldsymbol{V}}_{\boldsymbol{S}}=109.0 \pm 5.2 \mathrm{~m} \mathrm{yr}^{-1}\right)$ and the mean winter velocity $\left(\overline{\boldsymbol{V}}_{\boldsymbol{W}}=77.1 \pm 3.3 \mathrm{~m} \mathrm{yr}^{-1}\right)$ (Figure 2-2 a), with the summer velocities displaying greater variability. We find that neither $\boldsymbol{V}_{\boldsymbol{A}}$ nor $\boldsymbol{V}_{\boldsymbol{S}}$ exhibit a statistically significant trend over the observation 
period (Figure 2-2 a). Nonetheless, the computed trend for $\boldsymbol{V}_{\boldsymbol{A}}$ of $-0.92 \mathrm{~m} \mathrm{yr}^{-2}(p=0.15)$ (Figure 2-3 g) and the statistically significant trend in $\boldsymbol{V}_{\boldsymbol{W}}$ of $-1.13 \mathrm{~m} \mathrm{yr}^{-2}\left(\mathrm{R}^{2}=0.54, p=0.05\right)$ are similar to trends in annual velocities $\left(-1.31 \mathrm{~m} \mathrm{yr}^{-2} ; \mathrm{R}^{2}=0.52, p=0.06\right)$ reported by Tedstone et al. [2015] from 2007-2013 (Figure 2-2 a). These least squares regression slopes hold when considering error on the velocities using a weighted least squares regression (Table 2-4).

We also find no statistically significant trend in runoff season magnitude, variability, or length, and/or the timing of North Lake drainage from 2007-2013 (Figure 2-2 b). Rather, these parameters are most notable for their significant year-to-year variability (Figure 2-2 b; Table 2-2). The largest magnitude season runoff in $2010\left(\boldsymbol{R}_{\boldsymbol{m a g}}=2.82 \mathrm{~m}\right.$ w.e. $)$ is $\sim 70 \%$ higher than that of the lowest runoff in $2013\left(\boldsymbol{R}_{\text {mag }}=1.66 \mathrm{~m}\right.$ w.e. $)$. Similar year-to-year variability is found in the longer-term runoff record, but in that case we do find an increasing trend of $0.02 \mathrm{~m} \mathrm{yr}^{-1}(p<0.005)$ from 1985-2014 (Figure 2-3 h). Thus, given the high inter-annual variability in runoff, the lack of any runoff trend at North Lake during our study period likely reflects our inability to detect the longer-term increase that has been observed across the ice sheet [van den Broeke et al., 2009] with only 7 years of data.

To investigate the relationship between annual velocity and runoff, we assessed the covariance between $\boldsymbol{V}_{\boldsymbol{A}}$ and seasonal runoff characteristics. We find no statistically significant correlation between $\boldsymbol{V}_{\boldsymbol{A}}$ and annual runoff parameters $\boldsymbol{R}_{\boldsymbol{m a g}}, \boldsymbol{R}_{\boldsymbol{v a r}}, \boldsymbol{R}_{\text {length }}, \boldsymbol{t}_{\boldsymbol{L D}}$, and $\boldsymbol{V}_{\boldsymbol{m i n}}$ (Table 2-1; Figures 2-3 a,b, 2$11 \mathrm{a}-\mathrm{d}$ ) even during the two extreme melt years in 2010 and 2012. These results are consistent with previous regional studies, which showed little correlation between annual velocity and runoff [Zwally et al., 2002; van de Wal 2008, 2015; Sole et al., 2013; Tedstone et al., 2013]. Furthermore, summer and winter velocities show no correlations with annual runoff parameters (Table 2-1; Figures 2-8-2-10 ae).

\subsubsection{Influence of past runoff magnitude on seasonal and annual ice-flow}

We next explored whether cumulative past runoff over multiple years has a control on ice-flow in our region. Following the analysis of Tedstone et al. [2015], we calculated two forms of past mean runoff magnitude. The first, $\overline{\boldsymbol{R}}_{\boldsymbol{m a g}}^{[-\boldsymbol{n} \boldsymbol{\boldsymbol { g }} \mathbf{0}]}$, represents runoff averaged over the $\boldsymbol{n}$ previous years including the present year (Figure 2-3 d). The second, $\overline{\boldsymbol{R}}_{\boldsymbol{m a g}}^{[-\boldsymbol{n} \boldsymbol{\boldsymbol { a g }}, \mathbf{1}]}$, is the mean runoff calculated from the $\boldsymbol{n}$ previous years, but not including the present year (Figure 2-3 d). Seasonal and annual velocities were then 
regressed against $\overline{\boldsymbol{R}}_{\boldsymbol{m a g}}^{[-\boldsymbol{n}, \mathbf{0}]}$ and $\overline{\boldsymbol{R}}_{\boldsymbol{m a g}}^{[-\boldsymbol{n},-\mathbf{1}]}$ for up to six years into the past $(0<\boldsymbol{n}<6)$ (Figures 2-3a-f, 2-9-2-11 f-q). The correlations between annual velocities and $\overline{\boldsymbol{R}}_{\boldsymbol{m a g}}^{[-\mathbf{4},-\mathbf{1}]}$ are shown in Figure 2-3c, and the $\mathrm{R}^{2}$ values calculated as a function of $\boldsymbol{n}$ years included in the runoff averages are shown in Figure $2-3 e$.

Both expressions for past mean runoff magnitude show improved and significant correlations with $\boldsymbol{V}_{\boldsymbol{A}}$ (Figures 2-4 e, 2-11 f-q) and $\boldsymbol{V}_{\boldsymbol{W}}$ (Figure 2-10 f-q) similar to that found by Tedstone et al. [2015]. The relationship between $\boldsymbol{V}_{\boldsymbol{A}}$ and past mean runoff magnitude is negative (higher runoff in past years results in a lower $\boldsymbol{V}_{\boldsymbol{A}}$ of the present year; Figure 2-3 c), with past runoff explaining up to $70 \%$ of the variance in $\boldsymbol{V}_{\boldsymbol{A}}$ (Figure $2-3$ e). The relationships between past mean runoff magnitude and $\boldsymbol{V}_{\boldsymbol{A}}$ generally strengthen with increasing values of $\boldsymbol{n}$ until $\boldsymbol{n} \approx \mathbf{4}$, with the exception of a particularly high correlation for $\boldsymbol{n}=1$ (Figure 2-3 e). The relationship between $\boldsymbol{V}_{\boldsymbol{W}}$ and past mean runoff magnitude is also negative and explains up to $82 \%$ of the variance in $\boldsymbol{V}_{\boldsymbol{W}}$ (Figure 2-10 i).

We stress that one must be careful not to over interpret these results. This regression assumes a fixed relationship between the variables (velocity and runoff) with time. Our data, however, display long-term temporal trends (Figure 2-3 g,h). Thus, to investigate the implications of our analysis for this study and others, we performed Monte Carlo simulations with correlated trends displaying similar magnitude year-to-year variability as observed (Appendix 2.E, Figure 2-14). These simulations show an improved correlation when multiple years of runoff are included, even when the variability in the data is not correlated on an annual time-scale as is the case in our data set (Figure 2-14). Thus, the improved correlation observed when multiple years of runoff are included is an expected outcome of analyzing two variables with long-term temporal trends, even if the mechanism generating these trends is unrelated to the annual variability.

\subsubsection{Variability in late-summer slowdown}

To gain further insight into the influence of runoff on the subglacial system, we take advantage of the high temporal resolution of our data to investigate variability in the amplitude of the late-summer slowdown $\left|\boldsymbol{V}_{\min }\right|$. The persistent presence of a late-summer velocity minimum (Figures 2-1 b-e, 2-4) supports the theory that the local subglacial hydrologic network undergoes seasonal reorganization, with increasing channelization throughout the summer resulting in increased frictional coupling that 
promotes this slowdown [Bartholomew et al., 2010; Colgan et al., 2011; Hoffman et al., 2011; Sundal et al., 2011; Sole et al., 2013; van de Wal et al., 2015]. Thus, larger $\left|\boldsymbol{V}_{\boldsymbol{m i n}}\right|$ has been proposed to represent more extensive subglacial channelization over the runoff season under higher melt conditions [Sundal et al., 2011]. While this relationship holds for 2010 (highest melt and largest $\left|\boldsymbol{V}_{\boldsymbol{m i n}}\right|$ ), over the 7-year study our data show that on an annual basis $\left|\boldsymbol{V}_{\min }\right|$ does not exhibit a statistically significant relationship with

$\boldsymbol{R}_{\text {mag }}\left(\mathrm{R}^{2}=0.22\right.$ [0.00-0.55] (95\% Confidence Interval), $p=0.28$ ) (Figures 2-1d, 2-3b) or any other present season runoff variables (Figure 2-11 a-c). This finding contrasts previous observations [Sundal et al., 2011] and theoretical studies [Schoof, 2010; Hewitt, 2013], which have shown higher summer runoff magnitude and variability lead to a larger magnitude late-summer slowdown due to increased efficiency in the subglacial drainage system.

\subsubsection{Mechanisms for a decadal or multi-year dependence of ice-flow on runoff}

Existing decadal records show a significant decreasing trend in Greenland ice sheet velocity and increasing trend in annual runoff (Figure 2-3 g,h). Our records exhibit similar trends, though neither of these trends are statistically significant given the high inter-annual variability in annual velocities and runoff over the 7-year record (Figure 2-3 g,h). While there is no correlation between velocity and runoff on annual timescales [Zwally et el., 2002; van de Wal et al., 2008, 2015; Sole et al., 2013; Tedstone et al., 2015], the negative relationship between past mean runoff magnitude and annual velocity has been invoked in previous studies [Tedstone et al., 2015] to suggest a causal relationship where increased runoff drives slower velocities on multiyear timescales. Indeed, all three records depict a similar negative relationship between past mean runoff magnitude and annual velocity that strengthens with increasing values of $\boldsymbol{n}$ (Figures 2-3 e, 2-13, 2-14). However, it remains unclear whether this negative relationship is the manifestation of hydrologic mechanisms acting at the bed over multiple years [e.g., Tedstone et al., 2015] or opposing decadal trends in velocity and melt caused by other factors.

The co-occurrence of an increasing runoff trend and a decreasing annual velocity trend (Figure 2-3 g,h) could arise for multiple reasons. Annual velocity and runoff could be changing independently of one another on decadal timescales, such that when comparing velocity and runoff annually they show no correlation (Figure 2-3 a). By integrating past runoff, the negative relationship with annual velocity emerges (Figures 2-3 c) as the variability in runoff is reduced (Figure 2-3 h, 2-14). Thus, in this scenario the correlation between the trends does not require causation. 
Alternatively, annual velocity and runoff could be directly related to one another, but through a physical mechanism that is weakly expressed on annual timescales. For example, as the ice-sheet thins, the response to small changes in driving stress $\left(\tau_{d}\right)$ at annual timescales is small, but the response over the longer term is enhanced due to the non-linearity of ice flow. A change in driving stress due to ice sheet thinning was found to account for up to a third of the velocity slowdown observed across the Western Margin [Tedstone et al. 2015].

Finally, annual velocity and runoff may be related through a hydraulic response whereby longterm evolution in the subglacial drainage system causes the annual velocity's response to melt to strengthen over multiple decades. While Tedstone et al. [2015] invoked this final mechanism to explain the majority of the slowdown, all three explanations could apply to the North Lake, K-transect, and Western Margin data.

Regardless of the co-occurrence of opposing decadal trends in velocity and runoff, annual velocities on the western margin are slowing down (Figure 2-3 g). As the changes in driving stress due to ice sheet thinning are insufficient to explain the observed decrease in annual velocities [Tedstone et al., 2015], other physical processes driving this slowdown should be considered. A slowdown driven by changes in internal deformation or basal motion through sliding and/or till deformation could be occurring independently of, or alongside, a change in subglacial hydrology. Additional observations of ice sheet velocity, geometry, internal structure, and basal properties are needed to determine the causal relationship between annual velocity and runoff and to understand the observed slowdown of the ice sheet margin. 

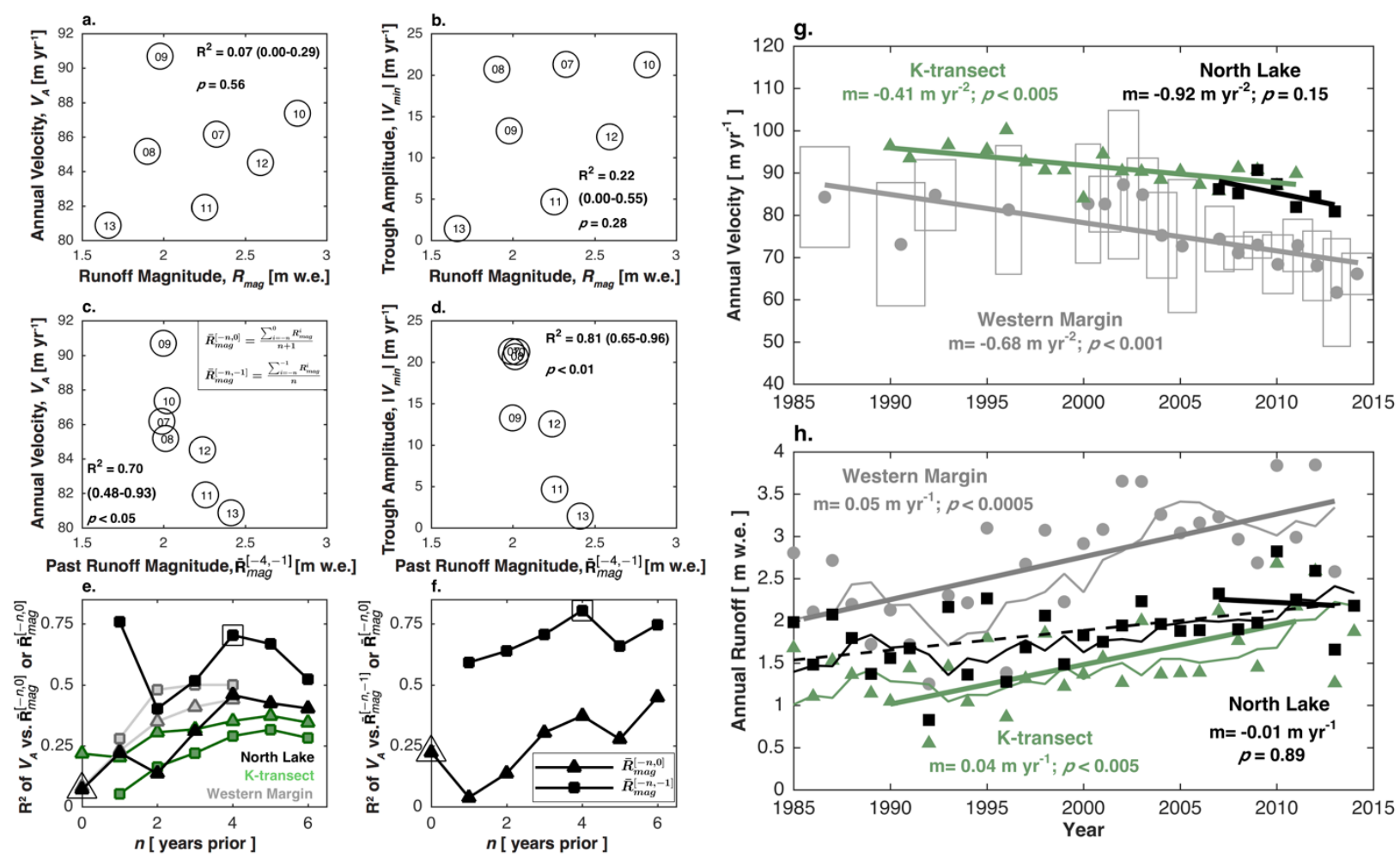

Figure 2-3: Annual ice velocity and past mean runoff magnitude relationships at North Lake, K-transect, and the Western Margin. (a) $\boldsymbol{V}_{\boldsymbol{A}}$ and (b) trough amplitude, $\left|\boldsymbol{V}_{\boldsymbol{m i n}}\right|$ for 2007-2013 versus runoff magnitude $\boldsymbol{R}_{\boldsymbol{m a g}}$. Error bars are smaller than circle diameter. (c) $\boldsymbol{V}_{\boldsymbol{A}}$ and (d) $\left|\boldsymbol{V}_{\boldsymbol{m i n}}\right|$ for 2007-2013 versus past runoff magnitude $\overline{\boldsymbol{R}}_{\mathbf{m a g}}^{[-\mathbf{4},-\mathbf{1}]}$ (see Appendix 2.C). $\mathrm{R}^{2}$ values for relationships between (e) $\boldsymbol{V}_{\boldsymbol{A}}$ or (f) $\left|\boldsymbol{V}_{\boldsymbol{m i n}}\right|$ and past runoff magnitude: $\overline{\boldsymbol{R}}_{\boldsymbol{m a g}}^{[-\boldsymbol{n}, \mathbf{0}]}$ (black triangles) or $\overline{\boldsymbol{R}}_{\boldsymbol{m a g}}^{[-\boldsymbol{n},-\mathbf{1}]}$ (black squares), where $\boldsymbol{n}$ extends from one to six years of past runoff. $\mathrm{R}^{2}$ values for relationships between past runoff magnitude and Western Margin velocities in grey [Tedstone et al., 2015]. $\mathrm{R}^{2}$ values for relationships between $\mathrm{K}$-transect annual velocities [van de W al et al., 2015] and past runoff magnitude calculated from local daily runoff in green. Open triangles in panels e and $\mathrm{f}$ correspond to relationships plotted in panels a and b, respectively. Open squares in panels e and $\mathrm{f}$ correspond the relationships plotted in panels $\mathrm{c}$ and d, respectively. (g) Trends through annual velocity measurements at North Lake (black), K-transect (green, van de Wal et al. [2015]), and the western margin (grey, Tedstone et al. [2015]). (h) Local runoff estimates for North Lake (black) and K-transect (green) are plotted alongside the trends (thick lines) through through these runoff values over the years in which annual velocities are available. Western margin runoff values and trend from Tedstone et al. [2015] are in grey. Runoff trend at North Lake from 1985-2014 shown in dashed black line. $\overline{\boldsymbol{R}}_{\boldsymbol{m a g}}^{[-\mathbf{4},-\mathbf{1}]}$ calculation plotted for all three locations as a thin line. 


\subsection{Implications for future predictions of ice-flow}

While hydrology and ice-flow models now capture the seasonal velocity structure of the ablation zone at a qualitative level [Schoof, 2010; Hewitt, 2013; Werder et al., 2013], our results suggest additional feedbacks must be considered in order to understand the details of how ice-flow is related to trends in runoff and runoff variability over longer timescales. Extrapolating the trends in runoff and velocity found in our study and earlier datasets suggests that a sustained increase in runoff would lead to a systematic decrease in ice-sheet velocities. However, we stress that the correlation between annual velocity and integrated past runoff is not necessarily evidence for a hydrologic mechanism acting on the basal system over timescales of a few years and could be related to other factors including changes in ice sheet thickness, internal deformation, or basal motion. Further, we find that in contrast to model predictions [Schoof, 2010; Hewitt, 2013] the magnitude of the late-summer velocity minimum is not the product of the present summer runoff (Figure 2-3 b). Thus, the mechanisms required to recreate seasonal ice-flow characteristics may not translate into accurate predictions of longer duration ice-flow variability. Observational studies targeted at long-term records of ice-sheet shape, subglacial hydrology, and basal motion are needed to better understand mechanisms controlling ice-sheet flow on annual to decadal timescales. Moreover, future modeling studies should be evaluated alongside the available measurements of ice-flow collected at North Lake, Swiss Camp, and the K-transect. 


\section{Appendices}

\section{A List of symbols}

\begin{tabular}{|c|c|}
\hline$n$ & Years of previous $\boldsymbol{R}_{\boldsymbol{m a g}}$ \\
\hline$R_{\text {length }}$ & Runoff season length (days) \\
\hline $\boldsymbol{R}_{\text {mag }}$ & Runoff season magnitude (mm w.e.) \\
\hline $\boldsymbol{R}_{\text {var }}$ & Runoff season variability ( $\mathrm{mm}$ w.e.) \\
\hline$\overline{\boldsymbol{R}}_{\text {mag }}^{[-n, 0]}$ & Past mean runoff magnitude including the present year ( $\mathrm{mm}$ w.e.) \\
\hline $\bar{R}_{m a g}^{[-n,-1]}$ & Past mean runoff magnitude excluding the present year (mm w.e.) \\
\hline$t_{L D}$ & Timing of North Lake drainage ( $\%$ through the runoff season) \\
\hline$t_{R 1}$ & $\begin{array}{l}\text { Runoff season start. Date of } 1^{\text {st }} \text { percentile of cumulative runoff curve (day of } \\
\text { year) }\end{array}$ \\
\hline$t_{V \min }$ & Runoff season end. Date of $\boldsymbol{V}_{\boldsymbol{m i n}}$ (day of year) \\
\hline $\boldsymbol{V}_{\boldsymbol{A}}$ & Annual velocity $\left(\mathrm{m} \mathrm{yr}^{-1}\right)$ \\
\hline$V_{\min }$ & End summer minimum velocity $\left(\mathrm{m} \mathrm{yr}^{-1}\right)$ \\
\hline$\left|V_{\min }\right|$ & End-summer minimum velocity trough amplitude $\left(\mathrm{m} \mathrm{yr}^{-1}\right)$ \\
\hline$V_{S}$ & Summer velocity $\left(\mathrm{m} \mathrm{yr}^{-1}\right)$ \\
\hline$V_{W}$ & Winter velocity $\left(\mathrm{m} \mathrm{yr}^{-1}\right)$ \\
\hline
\end{tabular}

\section{B Local meltwater runoff}

Daily 11-km resolution RACMO2.3 runoff estimates from 2007-2013 [Noël et al., 2015], statistically downscaled to 1-km resolution [Nö̈l et al., 2016], are selected for a 100- $\mathrm{km}^{2}$ region centered on North Lake. Here we use the version v.0.2 of the downscaled surface mass balance (SMB) product. The selected runoff values are averaged to obtain a daily time series of runoff estimates for the North Lake location (Figures 2-1c-e, 2-4, 2-7). The start of each year is defined as the date of the $1^{\text {st }}$ percentile of each year's cumulative runoff curve, $\boldsymbol{t}_{\boldsymbol{R} \mathbf{1}}$ (Figure 2-1 b-e). Summer velocities are calculated from $\boldsymbol{t}_{\boldsymbol{R} \mathbf{1}}$ to $\boldsymbol{t}_{\boldsymbol{V} \boldsymbol{m i n}}$, the later of which represents the midpoint within the characteristic velocity minimum at the 
end of the melt season (Figure 2-1 b-e). Winter velocities are calculated from $\boldsymbol{t}_{\boldsymbol{V} \boldsymbol{m i n}}$ to $\boldsymbol{t}_{\boldsymbol{R} \mathbf{1}}$ of the following year. As each year in the time series has different runoff characteristics, the start and end of the runoff season do not fall on consistent calendar dates from year to year (Figures 2-1 c-e, 2-4; Table 2-2). We test the impact of our season delineation method ( $\boldsymbol{t}_{\boldsymbol{R} \mathbf{1}}$ to $\left.\boldsymbol{t}_{\boldsymbol{V} \mathbf{m i n}}\right)$ by also calculating seasonal and annual velocities over fixed calendar dates, with May $30^{\text {th }}$ (day of year 150) as the start of the year and September $7^{\text {th }}$ (day of year 250) as the end of summer. The resulting inter-annual trends (Section 2.4.1) and correlations with past mean runoff magnitude (Section 2.4.2) are nearly identical regardless of the method used to delineate seasons.

Runoff season statistics are calculated from the daily runoff estimates for each year in the time series (Figures 2-2 b, 2-7; Table 2-2). Total runoff season magnitude, $\boldsymbol{R}_{\boldsymbol{m a g}}$, is calculated by summing daily runoff estimates for the year (Figure 2-2 b, 2-7 b). Runoff season variability, $\boldsymbol{R}_{\boldsymbol{v a r}}$, is calculated by taking the root-mean-square of residuals (RMS error) between the daily runoff estimates and a single-term Gaussian model fitted to the daily runoff estimate for the dates $\boldsymbol{R}_{\mathbf{5}}<\boldsymbol{t}<\boldsymbol{R}_{\mathbf{9 5}}$ (Figures 2-2 b, 2-7 c,d). Across all years of the RACMO record, the Gaussian models poorly fit both the abrupt beginning of the runoff season and late summer runoff spikes (Figure $2-7 \mathrm{c}, \mathrm{d}$ ). Thus, residuals between daily runoff and the Gaussian model in the tails of daily runoff curve $\left(\boldsymbol{t}<\boldsymbol{R}_{5}\right.$ and $\left.\boldsymbol{t}>\boldsymbol{R}_{95}\right)$ are excluded from the $\boldsymbol{R}_{\boldsymbol{v a r}}$ calculation. The timing of North Lake drainage, $\boldsymbol{t}_{\boldsymbol{L D} \boldsymbol{D}}$, is expressed as the cumulative percentile of runoff that corresponds to the day of drainage for each year [Das et al., 2008; Stevens et al., 2015] (Table 2-2). Our analysis does not take into account other lake drainage characteristics that may be important including the style of North Lake drainage, the volume of North Lake at drainage, and the timing, volume, and style of other nearby lake drainages.

\section{C Past mean runoff magnitude}

Following Tedstone et al. [2015], we calculate two forms of past mean runoff magnitude. The first, $\overline{\boldsymbol{R}}_{\boldsymbol{m a g}}^{[-\boldsymbol{n} \boldsymbol{\mathbf { g }}]}$, is the mean of up to $\boldsymbol{n}$ years of previous $\boldsymbol{R}_{\boldsymbol{m a g}}$ including the present year as follows:

$$
\bar{R}_{m a g}^{[-n, 0]}=\frac{\sum_{i=-n}^{0} R_{m a g}^{i}}{n+1}
$$

The second, $\overline{\boldsymbol{R}}_{\boldsymbol{m a g}}^{[-\boldsymbol{n},-\mathbf{1}]}$, is the mean of up to $\boldsymbol{n}$ years of previous $\boldsymbol{R}_{\boldsymbol{m a g}}$ not including the present year as follows: 


$$
\bar{R}_{m a g}^{[-n,-1]}=\frac{\sum_{i=-n}^{-1} R_{m a g}^{i}}{n}
$$

We extend these calculations from one to six years of past melt magnitude $(1<\boldsymbol{n}<6)$ (Figures 2-3, 2-8-2-11). In addition, we tested calculations forward in time using up to two years of future melt

magnitude (Table 2-4). $\overline{\boldsymbol{R}}_{\boldsymbol{m a g}}^{[-\mathbf{4},-\mathbf{1}]}$ from 1985-2014 for North Lake, K-transect, and the western margin is plotted in Figure 2-3 h.

\section{D Seasonal and annual ice-flow}

A GPS array consisting of 1-16 receivers was maintained around North Lake from July 2006 through July 2014 (Figure 2-1 a inset) [Das et al., 2008; Joughin et al., 2008; Stevens et al., 2015]. From July 2006 to July 2009, a single dual-frequency Trimble NetR7 receiver located at NLBS collected continuous 30-s resolution data for one day each week. From July 2009 to December 2010, a single dual-frequency Trimble NetRS receiver collected continuous 30-s resolution data at NLBS. From June 2011 to July 2014, up to 16 dual-frequency Trimble NetR9 receivers located around North Lake collected continuous 30-s resolution GPS data. GPS stations were powered by solar panels and small batteries and stations commonly turned off over the winter from late October to March. GPS data from all years were processed with Track software [Chen, 1998]. The stations were processed individually as kinematic sites relative to the 30-s resolution Greenland GPS Network (GNET) KAGA base station located on bedrock $\sim 55 \mathrm{~km}$ from North Lake [Bevis et al., 2012; Stevens et al., 2015]. The GPS position estimate vector $\mathbf{X}$ output from Track software is given as Cartesian coordinates relative to the KAGA base station for each GPS station $i$, at time $t$. The error estimate vector $\sigma_{i}(t)$ output from Track software defines 1-sigma errors for $\mathbf{X}_{i}(t)$, but not the full covariance matrix [Chen, 1998]. The horizontal components of $\sigma_{i}(t)$ are consistently $\pm 2 \mathrm{~cm}$, and the vertical component of $\sigma_{i}(t)$ is consistently $\pm 5 \mathrm{~cm}$ across all stations and all years.

Continuous velocities are calculated for both the weekly and 30-s resolution GPS data (Figures 2-1 c-e, 2-4). For the years with weekly GPS positions (2006-2009), the average position for the day of the week that the station was logging is calculated, and a weekly velocity is calculated at the midpoint between the days of data (Figures 2-1 c, 2-4 a-d). For the years with 30-s resolution GPS positions (2009-2014), continuous 24-hr velocities are calculated following the methodology described in 
Hoffman et al. [2011]. The horizontal components of a 6-hr moving average of $\mathbf{X}_{i}(t)$ are linearly regressed using a centered 24-hr time window at each data point to obtain a continuous velocity record (Figures 2-1 d,e, 2-4 d-i). The 24-hr window length of the linear regression removes velocity fluctuations on diurnal timescales, yet retains the velocity spikes from major single or multi-day speedup events associated with supraglacial lake drainages and days of extended high runoff, respectively [Hoffman et al., 2011]. While the 30-s resolution GPS data are capable of producing quality velocities at shorter time-resolutions [Stevens et al., 2015], we plot the 24-hr velocities here as they are not above the time-resolution of the daily RACMO runoff estimates and our primary objective is to understand seasonal and annual velocity variability. For the years with more than one 30-s resolution GPS receiver (2011-2014), 24-hr velocities of all available stations are averaged at each 30-s interval to calculate a composite velocity across the North Lake array (Figures 2-1 e, 2-4 f-i). The standard deviation of the mean velocity computed at each point in time across the four-year time series has an average standard deviation of $\pm 15.6 \mathrm{~m} \mathrm{yr}^{-1}$.

Summer, winter, and annual velocities $\left(\boldsymbol{V}_{(\boldsymbol{S}, \boldsymbol{W}, \boldsymbol{A})}\right)$ are calculated from the horizontal GPS displacement estimates (Figures 2-2 c, 2-4). $\mathbf{X}_{i}(t)$ and corresponding uncertainties, $\sigma_{i}(t)$, are selected for $\boldsymbol{t}_{\boldsymbol{R} \mathbf{1}}$ and $\boldsymbol{t}_{\boldsymbol{V} \boldsymbol{m i n}}: \mathbf{X}_{i}\left(\boldsymbol{t}_{\boldsymbol{R} \mathbf{1}}\right)$ and $\mathbf{X}_{i}\left(\boldsymbol{t}_{\boldsymbol{V} \min }\right)$, respectively. A single, daily mean position and standard deviation are calculated for these two days for all viable stations: $\overline{\mathbf{x}}_{i}\left(\boldsymbol{t}_{\boldsymbol{R} \mathbf{1}}\right) \pm \boldsymbol{\sigma}_{i}\left(\boldsymbol{t}_{\boldsymbol{R} \mathbf{1}}\right)$, and $\overline{\mathbf{x}}_{i}\left(\boldsymbol{t}_{\boldsymbol{V} \boldsymbol{m i n}}\right) \pm$ $\boldsymbol{\sigma}_{i}\left(\boldsymbol{t}_{\boldsymbol{V} \boldsymbol{m i n}}\right)$. Summer velocities $\boldsymbol{V}_{\boldsymbol{S}}^{\boldsymbol{Y E A R}}$ (Figure 2-2 a) are calculated by differencing $\overline{\mathbf{x}}_{i}\left(\boldsymbol{t}_{\boldsymbol{V m i n}}\right)$ and $\overline{\mathbf{x}}_{i}\left(\boldsymbol{t}_{\boldsymbol{R} \mathbf{1}}\right)$ of the same year divided by the runoff season length as follows:

$$
V_{S}^{Y E A R}=\frac{\left(\bar{X}_{i}\left(t_{V m i n}^{Y E A R}\right) \pm \sigma_{i}\left(t_{V \min }^{Y E A R}\right)\right)-\left(\bar{X}_{i}\left(t_{R 1}^{Y E A R}\right) \mp \sigma_{i}\left(t_{R 1}^{Y E A R}\right)\right)}{R_{\text {length }}}
$$

Winter velocities $\boldsymbol{V}_{\boldsymbol{W}}^{\boldsymbol{Y E A R}}$ (Figure 2-2 a) are calculated by differencing $\overline{\mathbf{x}}_{i}\left(\boldsymbol{t}_{\boldsymbol{R} \mathbf{1}}\right.$ ) of the next year and $\overline{\mathbf{x}}_{i}\left(\boldsymbol{t}_{\boldsymbol{V} \boldsymbol{m i n}}\right)$ of the present year and dividing by the length of the winter season as follows:

$$
V_{W}^{Y E A R}=\frac{\left(\bar{X}_{i}\left(t_{R 1}^{Y E A R+1}\right) \pm \sigma_{i}\left(t_{R 1}^{Y E A R+1}\right)\right)-\left(\bar{X}_{i}\left(t_{V \min }^{Y E A R}\right) \mp \sigma_{i}\left(t_{V \min }^{Y E A R}\right)\right)}{\left(t_{R 1}^{Y E A R+1}-t_{V_{\min }}^{Y E A R}\right)}
$$

Annual velocities $\boldsymbol{V}_{\boldsymbol{A}}^{\boldsymbol{Y E A R}}$ (Figure 2-2 a) are calculated from the start of each runoff season by differencing $\overline{\mathbf{x}}_{i}\left(\boldsymbol{t}_{\boldsymbol{R} \mathbf{1}}\right)$ of the next year and $\overline{\mathbf{x}}_{i}\left(\boldsymbol{t}_{\boldsymbol{R} \mathbf{1}}\right)$ of the present year and dividing by the number of days between $\boldsymbol{t}_{\boldsymbol{R} \mathbf{1}}$ of the two years as follows: 


$$
V_{A}^{Y E A R}=\frac{\left(\bar{X}_{i}\left(t_{R 1}^{Y E A R+1}\right) \pm \sigma_{i}\left(t_{R 1}^{Y E A R+1}\right)\right)-\left(\bar{X}_{i}\left(t_{R 1}^{Y E A R}\right) \mp \sigma_{i}\left(t_{R 1}^{Y E A R}\right)\right)}{\left(t_{R 1}^{Y E A R+1}-t_{R 1}^{Y E A R}\right)}
$$

As each year in the time series has different runoff characteristics, the start and end of the runoff season do not fall on consistent calendar dates from year to year (Figures 2-1 c-e, 2a, 2-4; Table 2-2). Error estimates are calculated for $\boldsymbol{V}_{(\boldsymbol{S}, \boldsymbol{W}, \boldsymbol{A})}$ by translating the standard propagation of error for differences of the two $\overline{\mathbf{x}}_{i}(t)$ values into a percentage error. The percentage error is then applied to $\boldsymbol{V}_{(\boldsymbol{S}, \boldsymbol{W}, \boldsymbol{A})}$, resulting in errors on the order of $\sim 0.4 \mathrm{~m} \mathrm{yr}^{-1}$ for $\boldsymbol{V}_{\boldsymbol{S}}$ and $\sim 0.2 \mathrm{~m} \mathrm{yr}^{-1}$ for $\boldsymbol{V}_{\boldsymbol{W}}$ and $\boldsymbol{V}_{\boldsymbol{A}}$ (Figures $2-2,2-3)$.

Our seasonal delineation method allows annual and seasonal time periods to be defined more precisely than previous Greenland ice sheet studies, permitting a more rigorous evaluation of the seasonal component. In contrast, in the remotely-sensed Tedstone et al. [2015] study annual velocities are calculated over inconsistent temporal baselines that only sometimes contain portions of the summer, and thereby may capture a higher percentage of the winter than summer in their annual velocities. Moreover, previous GPS studies [Sole et al., 2013; van de W al et al., 2008; 2015] define seasons based on calendar dates, which may or may not align with the occurrence of runoff. In order to improve comparisons of our results to these few prior studies, though, we tested the impact of our season delineation method $\left(\boldsymbol{t}_{\boldsymbol{R} \mathbf{1}}\right.$ to $\left.\boldsymbol{t}_{\boldsymbol{V} \boldsymbol{m i n}}\right)$ by also calculating seasonal and annual velocities over fixed calendar dates, using May $30^{\text {th }}$ (day of year 150) as the start of each year and September $7^{\text {th }}$ (day of year 250) as the end of each summer (Table 2-3). The resulting inter-annual trends and correlations with past mean runoff magnitude are nearly identical regardless of the method used to delineate seasons (Figure 2-5).

The seasonal and annual displacements and velocities represent a quasi-Eulerian record of local ice-flow that contains data gaps and combines measurements from different stations in the final two years of the time series. The record is not a truly Eulerian measurement, as North Lake Base Station (NLBS) was reset to its approximate summer 2006 position during mid-summer station maintenance for most (2007-2010), but not all (2011-2013), of the years of the record. We bridge summer data gaps during station maintenance and resetting of NLBS in mid-summer of 2007-2010 by taking the average of the velocity of the week leading up to and the velocity of the week following 
the station move as the velocity over the data gap. For our data gaps on order of 1-2 weeks (20072009), the estimated displacement over the data gap is on order $\sim 2-4 \mathrm{~m}$.

From 2007 to the beginning of the 2012 summer, we use station NLBS to calculate seasonal and annual velocities. Due to the failure of NLBS in 2012 and 2013, we continue the time series of annual and seasonal velocities by correcting the displacements of other viable stations in the array that have the most similar summer and winter displacements to NLBS. We investigate the spread of summer and winter displacements across the array during 2011, the only year when all stations were recording (Figure 2-6). From the 2011 data, we observe that stations nearest to NLBS (NL04-NL09) have annual displacements within $\pm 1 \mathrm{~m}$ of NLBS (Figure 2-6). Station FL03 has an annual displacement within $\pm 2 \mathrm{~m}$ of NLBS (Figure 2-6). Stations outside of this group have annual displacements within 5-10 m of NLBS. For the 2012 velocity calculations, the only stations with sufficient data are NL04, NL08, NL02, and NL13. As stations NL02 and NL13 have differences in annual displacement of $\sim 8 \mathrm{~m}$ and $\sim 5 \mathrm{~m}$, respectively, in comparison to NLBS in 2011, we select stations NL04 and NL08 to calculate the seasonal and annual velocities in 2012. For the 2013 velocity calculations, the only stations with sufficient data are FL03 and FL04. We select station FL03 to calculate the seasonal and annual velocities in 2013, as station FL04 has a difference in annual displacement of $\sim 10 \mathrm{~m}$ in comparison to NLBS in 2011 .

To perform the correction, we calculate the difference in displacement between NLBS and stations over the 2011 summer (Figure 2-3 a) and winter (Figure 2-6 b). We then calculate a summer and winter difference in daily displacement between NLBS and the substituted station in 2011, and apply that difference to the number of days in the 2012 or 2013 summer and winter. For example, NL04 moves $0.006 \mathrm{~m} \mathrm{day}^{-1}$ faster than NLBS in the 2011 summer, resulting in a correction of -0.56 $\mathrm{m}$ to the NL04 displacement over the 92 days of the 2012 summer. For winter, NL04 moves $0.004 \mathrm{~m}$ day $^{-1}$ slower than NLBS in 2011 the winter, resulting in a correction of $+1.10 \mathrm{~m}$ to the NL04 displacement over the 270 days of the 2012 winter. Thus, while NLBS station failure in 2012 and 2013 prevents us from using a single station measurement for the entire time series, the use of additional stations in the array in 2012 and 2013 likely changes annual velocity measurements by at most $1 \mathrm{~m} \mathrm{yr}^{-}$ ${ }^{1}$, which is less than the overall variability of $\pm 3.3 \mathrm{~m} \mathrm{yr}^{-1}$ in $\boldsymbol{V}_{\boldsymbol{A}}$ (Figure 2-2 a). 
Finally, the trough amplitude of the late summer minimum velocity $\left|\boldsymbol{V}_{\mathbf{m i n}}^{\boldsymbol{Y E A R}}\right|$ is calculated as follows:

$$
\left|V_{\min }^{Y E A R}\right|=\left|V_{\min }^{Y E A R}-V_{W}^{Y E A R}\right|
$$

\section{E Time series statistics}

To investigate drivers of seasonal and annual ice-flow we asses the covariance between $\boldsymbol{V}_{(\boldsymbol{S}, \boldsymbol{W}, \boldsymbol{A})}$ and runoff variables based on the coefficient of determination $\left(\mathrm{R}^{2}\right)$ and $p$-value of linear trends between

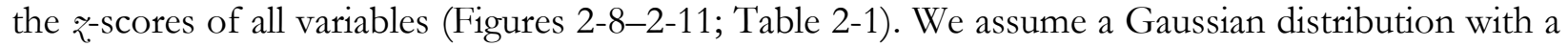
sample size of 7 . We calculate 5-95\% confidence interval bounds for all $\mathrm{R}^{2}$ values presented to illustrate the limitations of our small sample size.

To further investigate the observed relationship between past mean runoff magnitude and annual velocity (Section 2.4.2) at North Lake, the K-transect, and across the Western Margin we performed Monte Carlo simulations for each location with similar trends and amplitude variability in $\boldsymbol{V}_{\boldsymbol{A}}$ and $\boldsymbol{R}_{\boldsymbol{m a g}}$ as is observed (Figure 2-14). Synthetic annual velocities and runoff values were created for each location using the observed trends for both variables presented in Figure 2-3 $\mathrm{g}$ and h. Figure S11 shows two examples from the 20,000 computed realizations for synthetic $\boldsymbol{R}_{\boldsymbol{m a g}}$ values with high $\left(\mathrm{R}^{2} \sim 0.30\right.$; Figure 2-14 a-c) and low $\left(\mathrm{R}^{2} \sim 0.70\right.$; Figure 2-14 e-f) amplitude year-to-year variability. Both the high and low variability cases show an improved correlation between $\boldsymbol{R}_{\boldsymbol{m a g}}$ and $\boldsymbol{V}_{\boldsymbol{A}}$ when multiple years of runoff are included, even when the imposed variability in $\boldsymbol{R}_{\boldsymbol{m a g}}$ and $\boldsymbol{V}_{\boldsymbol{A}}$ is not correlated on an annual time-scale (Figure 2-14 c,f). Thus, the improved correlation observed when multiple years of runoff are included is an expected outcome of analyzing two variables with long-term temporal trends, even if the mechanism generating these trends is unrelated to the annual variability. The observed relationship between past mean runoff magnitude and $\left|\boldsymbol{V}_{\boldsymbol{m i n}}\right|$ (Figure 2-3 f) can be explained by an equivalent Monte Carlo simulation by varying the slope. 


\section{F Comparison to K-transect and Western Margin}

We reanalyze previously published data to compare annual velocity and past mean runoff magnitude relationships at North Lake to those found along the K-transect [van de Wal et al., 2015] and over the Western Margin [Tedstone et al., 2015]. For the K-transect, annual velocities presented in Figure 2-3 g were obtained from Figure 8 of van de Wal et al. [2015]. Runoff estimates for the K-transect were calculated in a method identical to the North Lake runoff estimates. Daily $11-\mathrm{km}$ resolution RACMO2.3 runoff estimates from 1985-2014 [Noël et al., 2015], statistically downscaled to 1-km resolution (v0.2 in Nö̈l et al., [2016]), are selected for a 100- $\mathrm{km}^{2}$ region centered on K-transect GPS Station S7. The selected runoff values are averaged to obtain a daily time series of runoff estimates for the S7 location. The S7 location was chosen as it represents roughly the middle elevation of the Ktransect, and the K-transect annual velocity record used here is a proportionally weighted average of individual stations along the transect [van de $W$ al et al., 2015]. Values of $\mathrm{R}^{2}$ for the K-transect presented in Figure 2-3 e were calculated in a method identical to North Lake past mean runoff magnitude calculations; the sample size of the K-transect distribution is 20 . Values of annual velocity and annual runoff for the Western Margin were obtained from Figure 2 of Tedstone et al., [2015]. Values of $\mathrm{R}^{2}$ for the Western margin presented in Figure 2-3 e were obtained from Extended Data Table 1 of Tedstone et al., [2015]. 


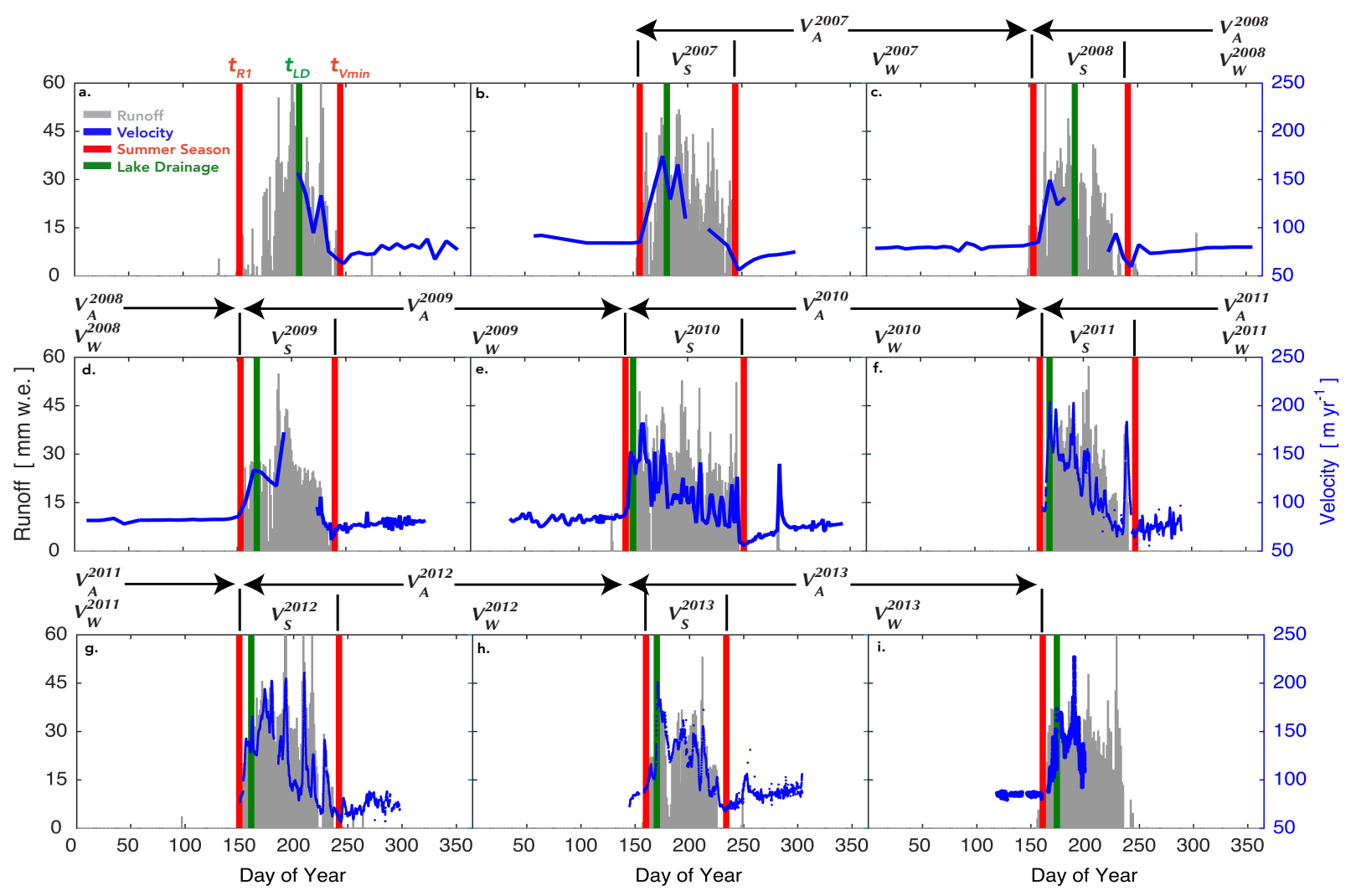

Figure 2-4: Daily ice velocity and runoff time series. (a-d) Weekly resolution or (d-i) 24-hr resolution ice velocities of the GPS array (blue) against RACMO2.3 downscaled daily runoff estimates v0.2 (grey bars) for the North Lake region from 2006-2014. The dates of the start and end of the runoff season used to calculate seasonal velocities are shown with red bars. North Lake drainages are shown with green bars. Time duration of seasonal velocity calculations shown above panels. 


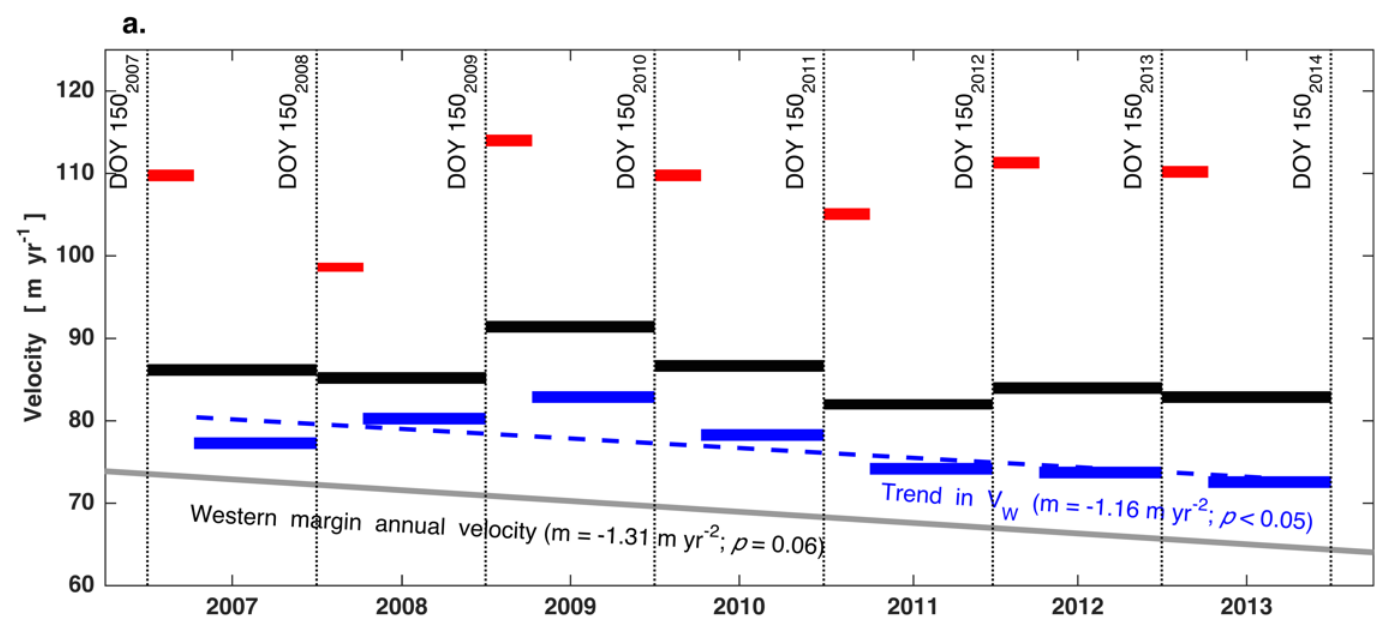

b.
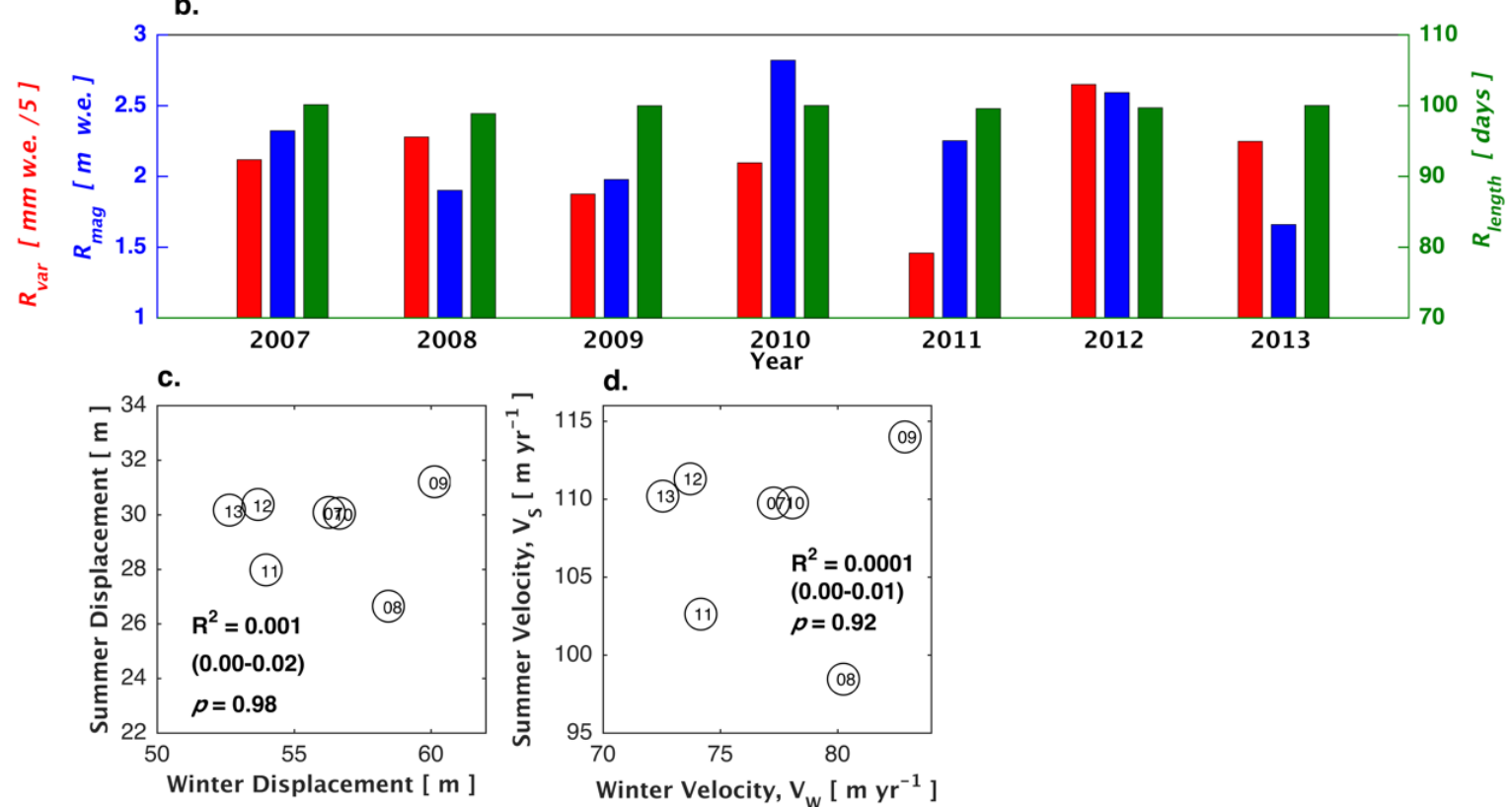

d.

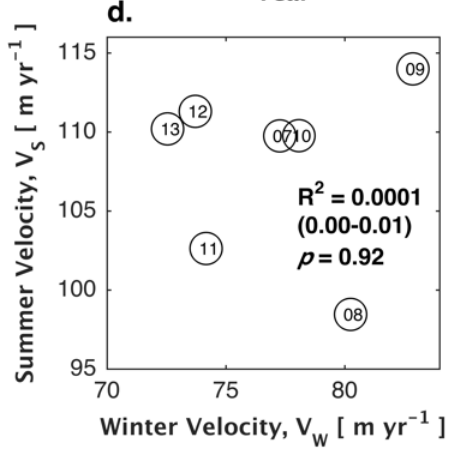

Figure 2-5. Seasonal ice velocity and runoff time series for the fixed calendar date seasonal delineation method. (a) $\boldsymbol{V}_{\boldsymbol{S}}$ (red), $\boldsymbol{V}_{\boldsymbol{W}}$ (blue), and $\boldsymbol{V}_{\boldsymbol{A}}$ (black) \pm uncertainty (error bars smaller than bar width) across the North Lake array from 2007-2013. Time along the x-axis is plotted in days, with vertical dashed lines marking the start of summer (DOY 150) and each year (subscript). The bar width in x- represents the length of time over which velocities were calculated. Trend in North Lake $\boldsymbol{V}_{\boldsymbol{W}}$ from 2007-2013 is shown in dashed blue line (no significant trends were found for $\boldsymbol{V}_{\boldsymbol{S}}$ or $\boldsymbol{V}_{\boldsymbol{A}}$ ). Grey line shows annual velocity trend from 2007-2013 of the western margin as calculated by Tedstone et al. [2015]. (b) $\boldsymbol{R}_{\boldsymbol{m a g}}$ (blue), $\boldsymbol{R}_{\boldsymbol{v a r}}$ (red), and $\boldsymbol{R}_{\text {length }}$ (green) in the North Lake region from 2007-2013. (c) Summer versus winter displacements and (d) $\boldsymbol{V}_{\boldsymbol{S}}$ versus $\boldsymbol{V}_{\boldsymbol{W}}$ (error bars smaller than circle diameter) for 2007-2013. 
a.

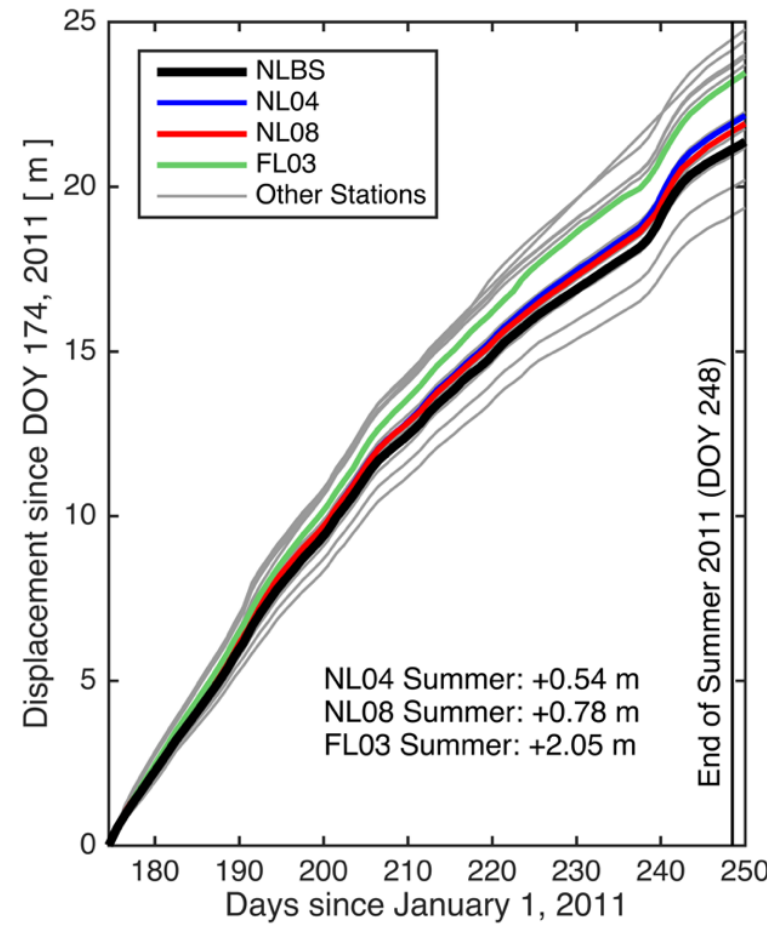

b.

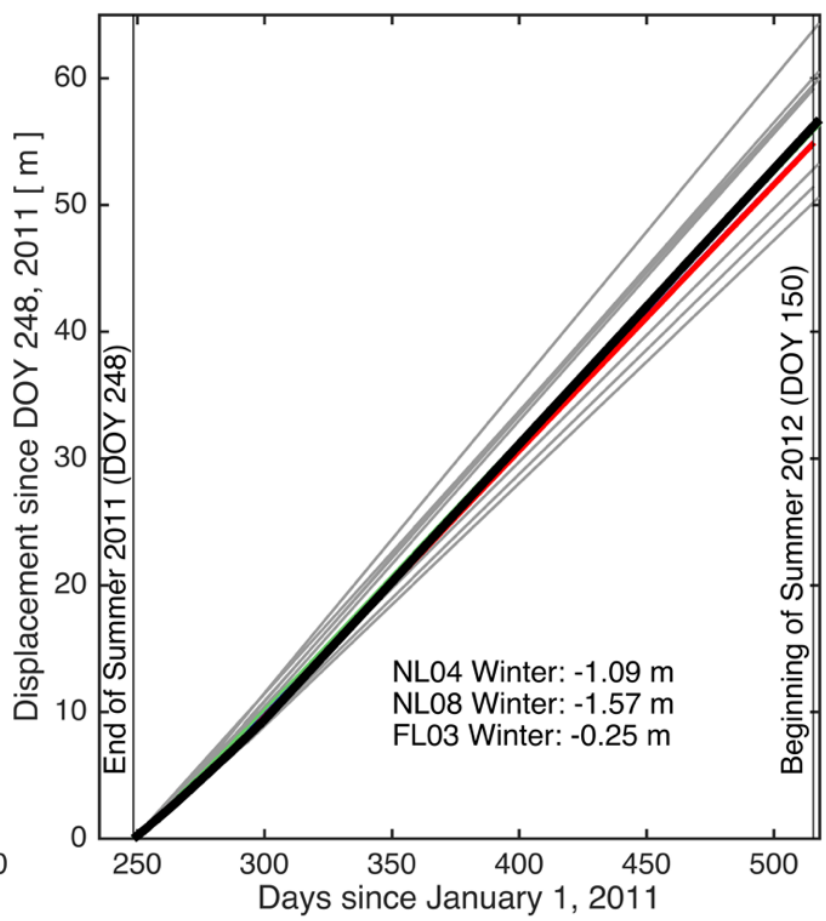

Figure 2-6. Variation in displacement across the 16 GPS stations in 2011. (a) Cumulative displacement of GPS stations over the summer of 2011. Station displacements are zeroed at DOY 174, 2011. (b) Cumulative displacement of GPS stations over the winter of 2011 (end of the 2011 summer (DOY 248, 2011) until the beginning of the following summer in 2012 (DOY 150, 2012)). Station displacements are zeroed at DOY 248, 2011. Summer (a) and winter (b) difference in displacement between NLBS and the stations used in the 2012 (NL04, NL08) and 2013 (FL03) calculations of annual and seasonal velocities are noted. 

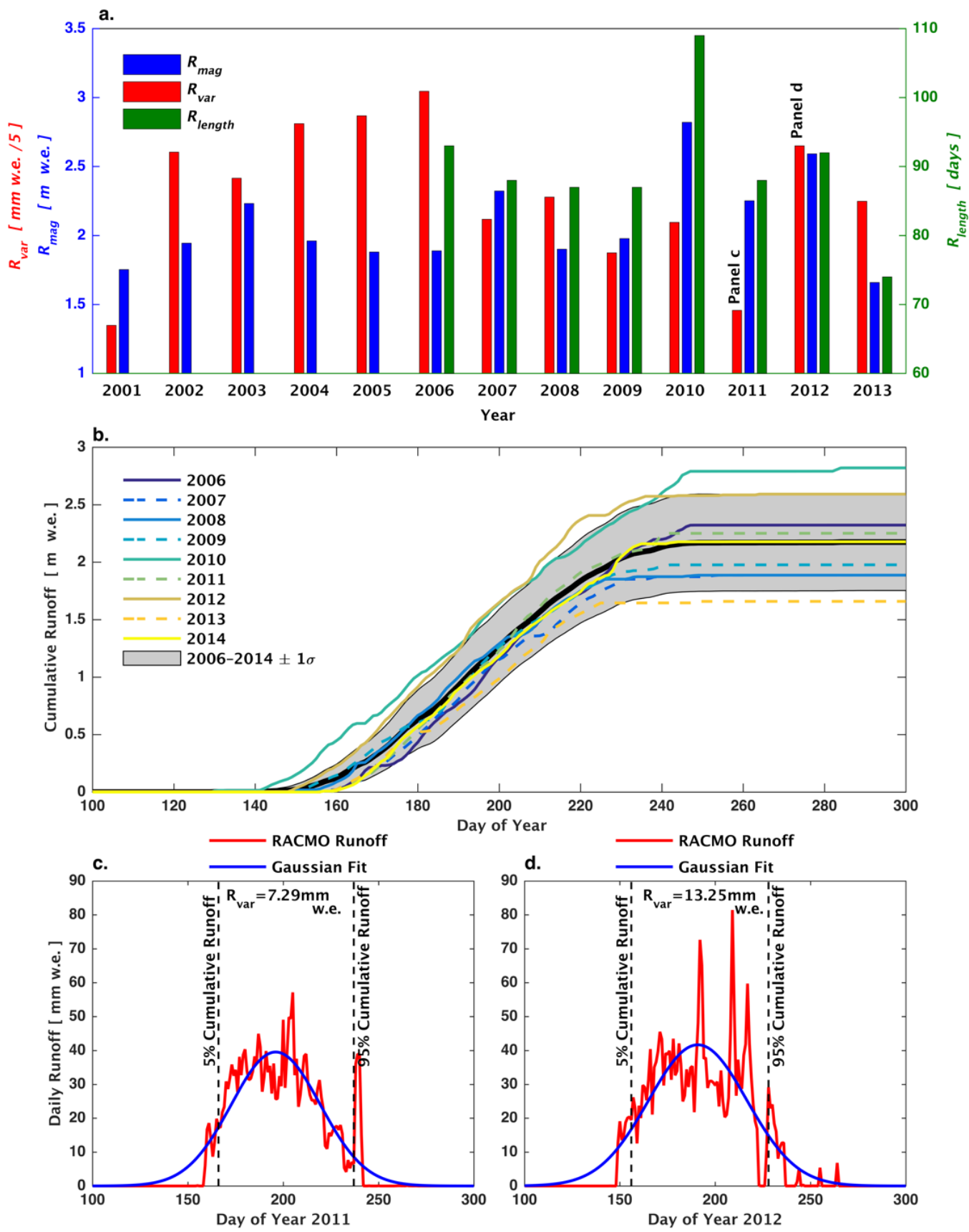

Figure 2-7. Runoff magnitude and variability at North Lake. (a) $\boldsymbol{R}_{\text {mag }}$ (blue), $\boldsymbol{R}_{\text {var }}$ (red), and $\boldsymbol{R}_{\text {length }}$ (green) in the North Lake region from 2001-2013. $\boldsymbol{R}_{\text {length }}$ record begins in 2006 with first fall of GPS record available to constrain $\boldsymbol{t}_{\boldsymbol{V} \text { min }}$. (b) Annual cumulative daily runoff curves from 20062014 (colors), with the mean cumulative runoff (black) $\pm 1 \boldsymbol{\sigma}$ (grey) from 2006-2014 for the North Lake region. (c) Example of year (2011) with low $\boldsymbol{R}_{\boldsymbol{v a r}}$. $\boldsymbol{R}_{\boldsymbol{v} \boldsymbol{a r}}$ is calculated as root-mean-square of the residuals between the daily runoff curve (red) and a single-term Gaussian model fit (blue) over the period from 5-95\% of cumulative runoff (vertical lines). (d) Same as in panel c, but with example year (2012) of high $\boldsymbol{R}_{\text {var }}$. 

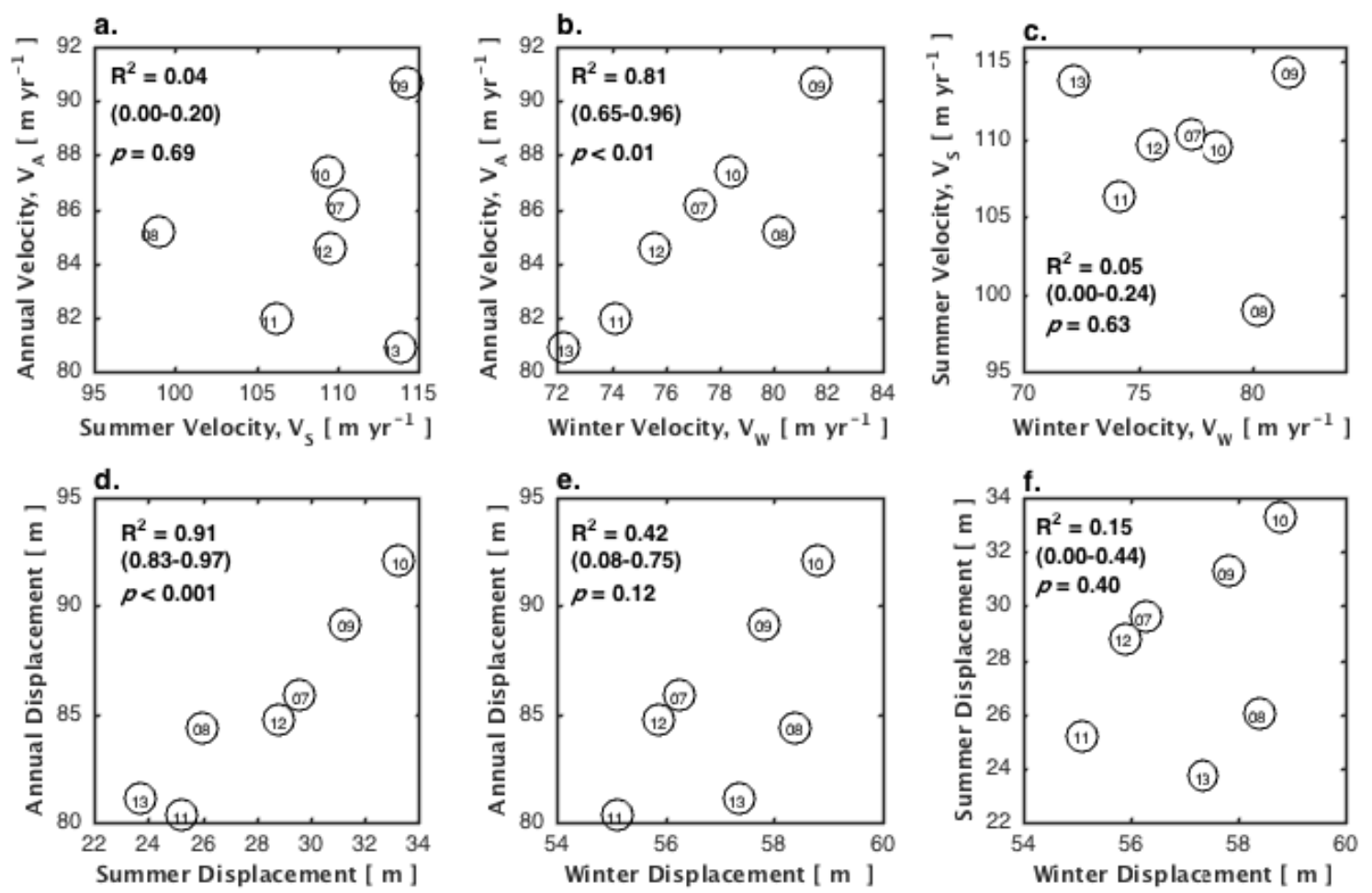

Figure 2-8. Seasonal and annual velocities at North Lake. (a) $\boldsymbol{V}_{S}$ versus $\boldsymbol{V}_{\boldsymbol{A}}$, (b) $\boldsymbol{V}_{W}$ versus $\boldsymbol{V}_{\boldsymbol{A}}$, and (c) $\boldsymbol{V}_{\boldsymbol{S}}$ versus $\boldsymbol{V}_{\boldsymbol{W}} \pm$ uncertainty (error bars smaller than circle diameter) for 2007-2013. (d) Summer versus annual displacement, (e) winter versus annual displacement, and (f) winter versus summer displacement \pm uncertainty (error bars smaller than circle diameter) for 2007-2013. 

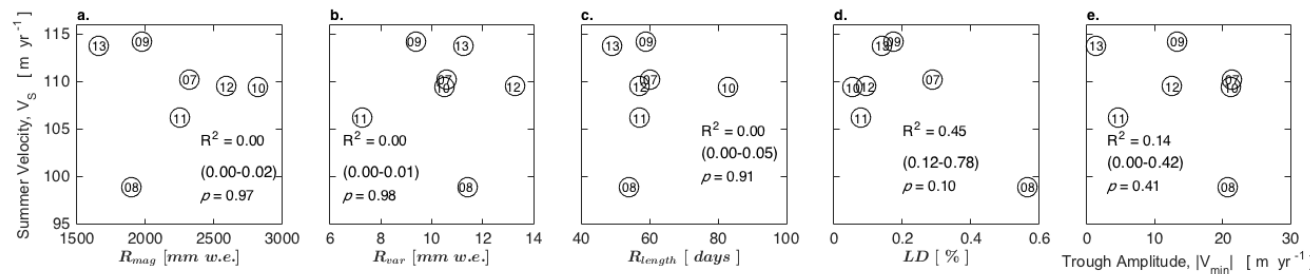

First Row : Present Year
Variables

Second Row :

$\bar{R}_{m a g}^{[-n,-1]}=\frac{\sum_{i=-n}^{-1} R_{\text {mas }}^{i}}{n}$

Third Row :

$\bar{R}_{m a g}^{[-n, 0]}=\frac{\sum_{i=-n}^{0} R_{\text {mag }}^{i}}{n+1}$
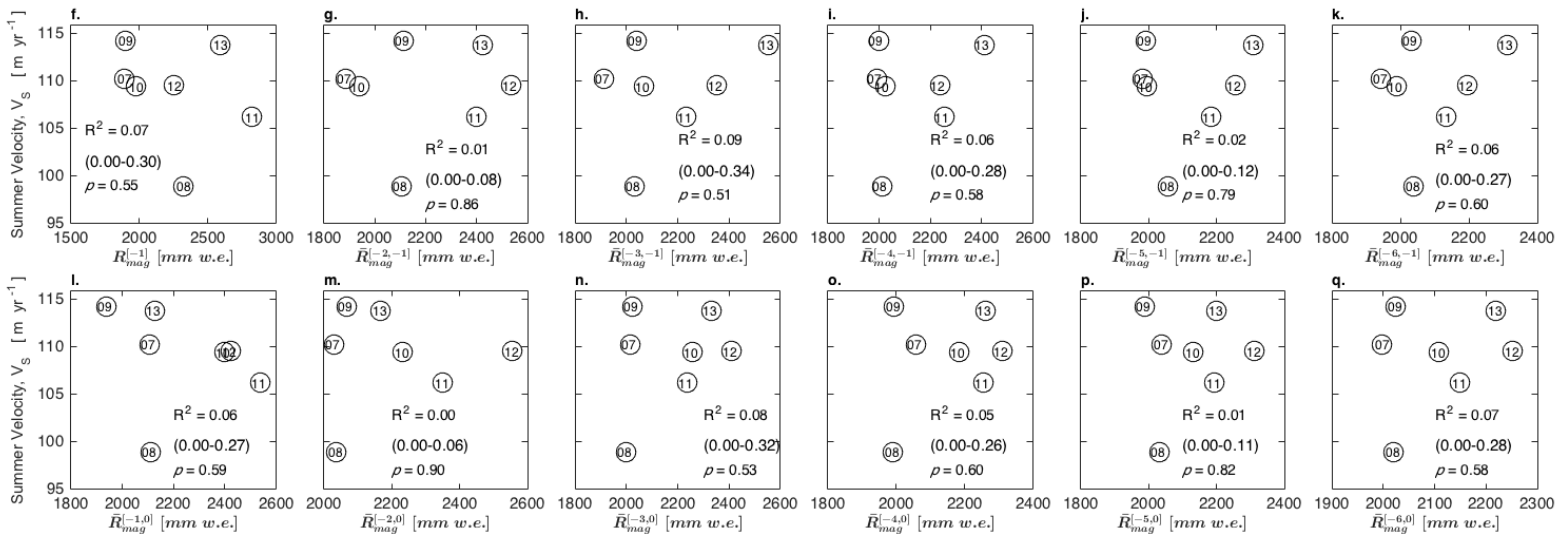

Figure 2-9. Summer velocity versus single and multiyear runoff. Summer velocities plotted against (a-e) present year runoff season characteristics, (f-h) $\overline{\boldsymbol{R}}_{\boldsymbol{m} \boldsymbol{a g}}^{[-\boldsymbol{n},-\mathbf{1}]}$ from $1<\boldsymbol{n}<6$, and (i-q) $\overline{\boldsymbol{R}}_{\boldsymbol{m a g}}^{[-\boldsymbol{n}, \mathbf{0}]}$ from $1<\boldsymbol{n}<6$. 

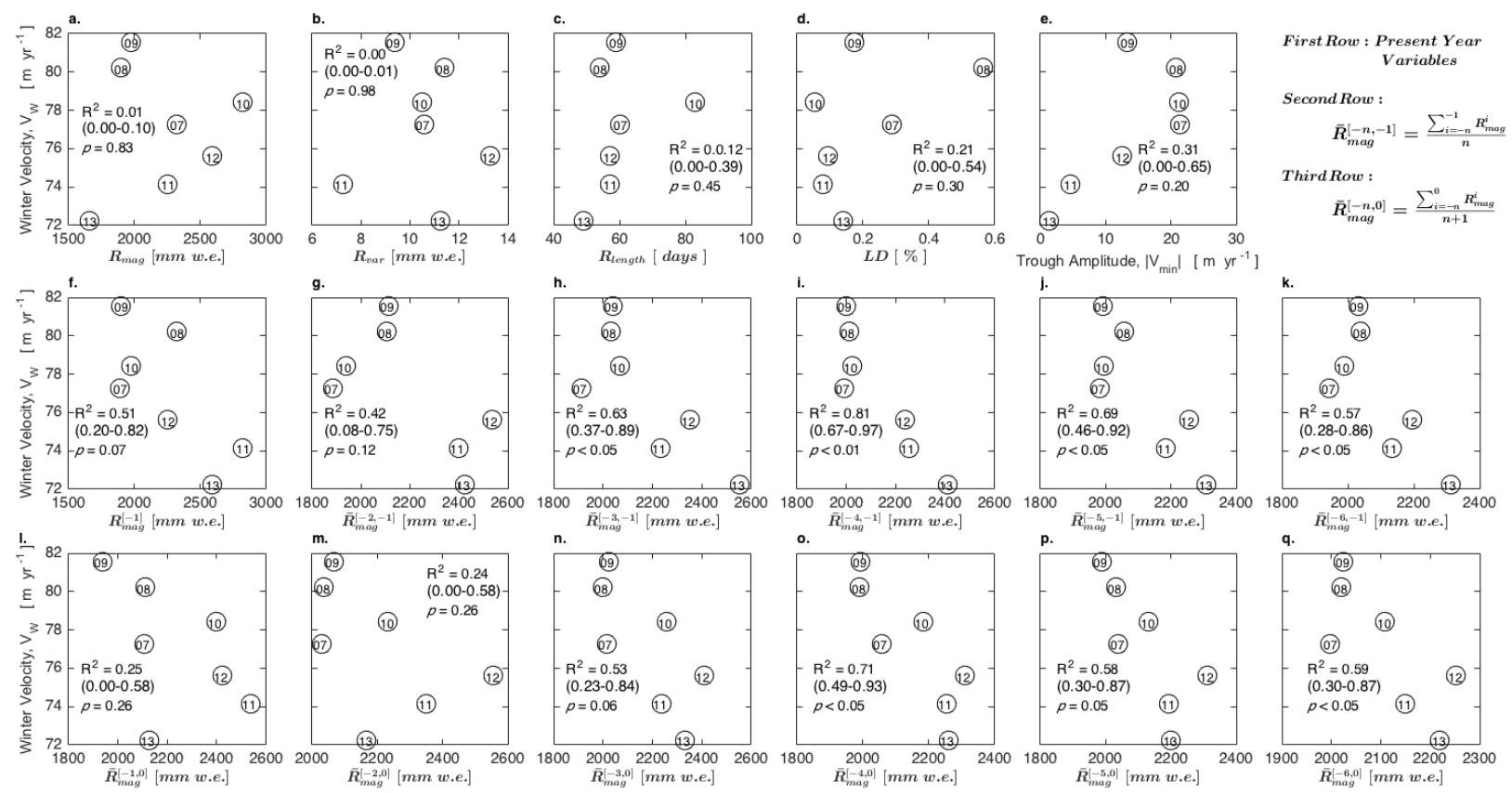

Figure 2-10. Winter velocity versus single and multiyear runoff. Winter velocities plotted against (a-e) present year runoff season characteristics, (f-h) $\overline{\boldsymbol{R}}_{\boldsymbol{m a g}}^{[-\boldsymbol{n},-\mathbf{1}]}$ from $1<\boldsymbol{n}<6$, and (i-q) $\overline{\boldsymbol{R}}_{\boldsymbol{m a g}}^{[-\boldsymbol{n} \boldsymbol{g} \mathbf{0}]}$ from $1<\boldsymbol{n}<6$. 

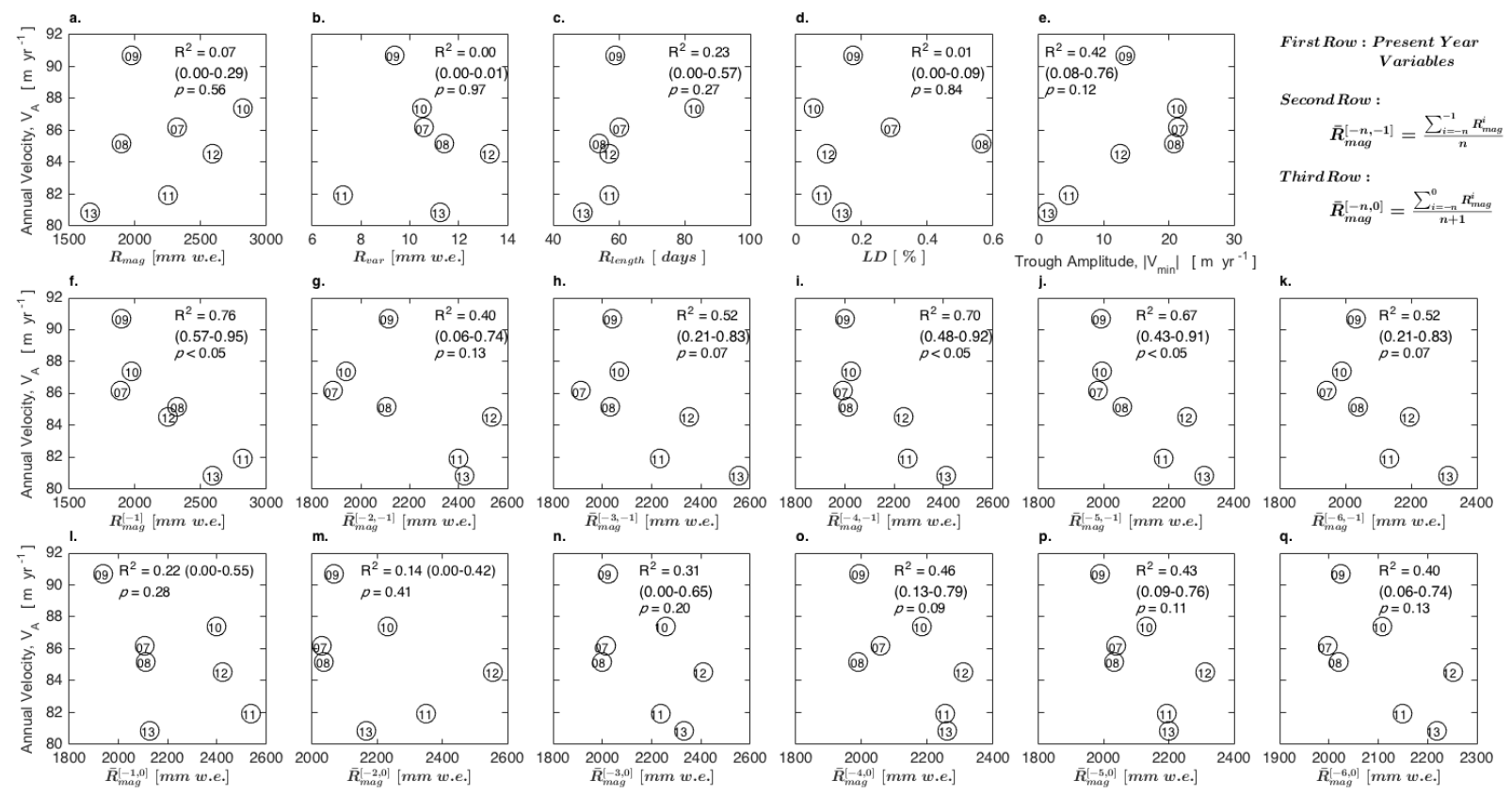

Figure 2-11. Annual velocity versus single and multiyear runoff. Annual velocities plotted against present year runoff season characteristics $(\mathbf{a}-\mathrm{e}), \overline{\boldsymbol{R}}_{\boldsymbol{m a g}}^{[-\boldsymbol{n},-\mathbf{1}]}$ from $1<\boldsymbol{n}<6(\mathbf{f}-\mathbf{h})$, and $\overline{\boldsymbol{R}}_{\boldsymbol{m a g}}^{[-\boldsymbol{n}, \mathbf{0}]}$ from $1<\boldsymbol{n}<6$ (i-q). 

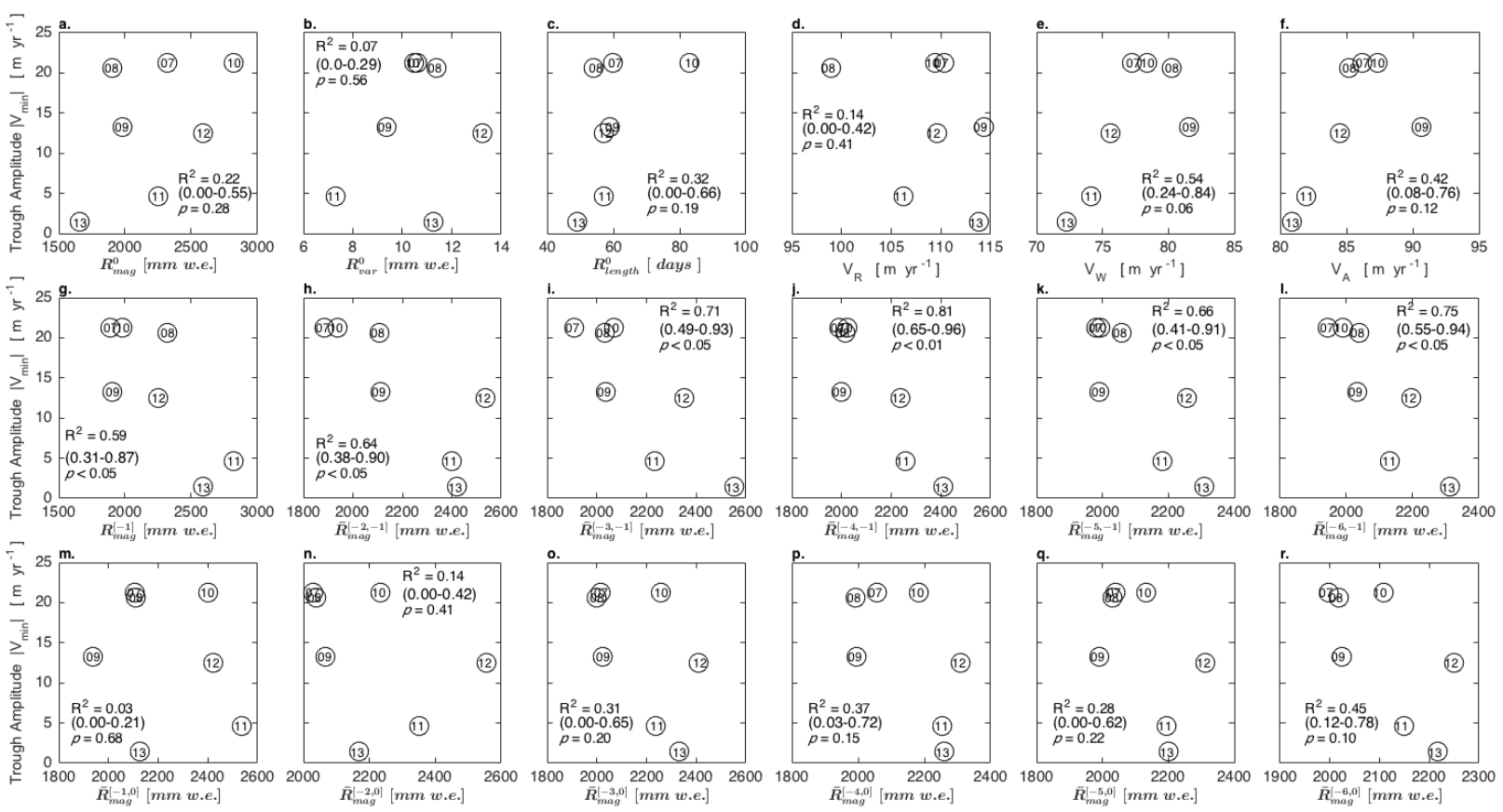

Figure 2-12. Trough amplitude, $\left|\boldsymbol{V}_{\min }\right|$, versus single and multiyear runoff. Trough amplitude, $\left|\boldsymbol{V}_{\min }\right|$, plotted against present year runoff season characteristics $(\mathbf{a}-\mathbf{c})$, seasonal velocities $(\mathbf{d}-\mathbf{f})$, $\overline{\boldsymbol{R}}_{\boldsymbol{m a g}}^{[-\boldsymbol{n},-1]}$ from $1<\boldsymbol{n}<6(\mathrm{~g}-\mathrm{i})$, and $\overline{\boldsymbol{R}}_{\boldsymbol{m a g}}^{[-\boldsymbol{n}, \mathbf{0}]}$ from $1<\boldsymbol{n}<6(\mathrm{~m}-\mathrm{r})$. 


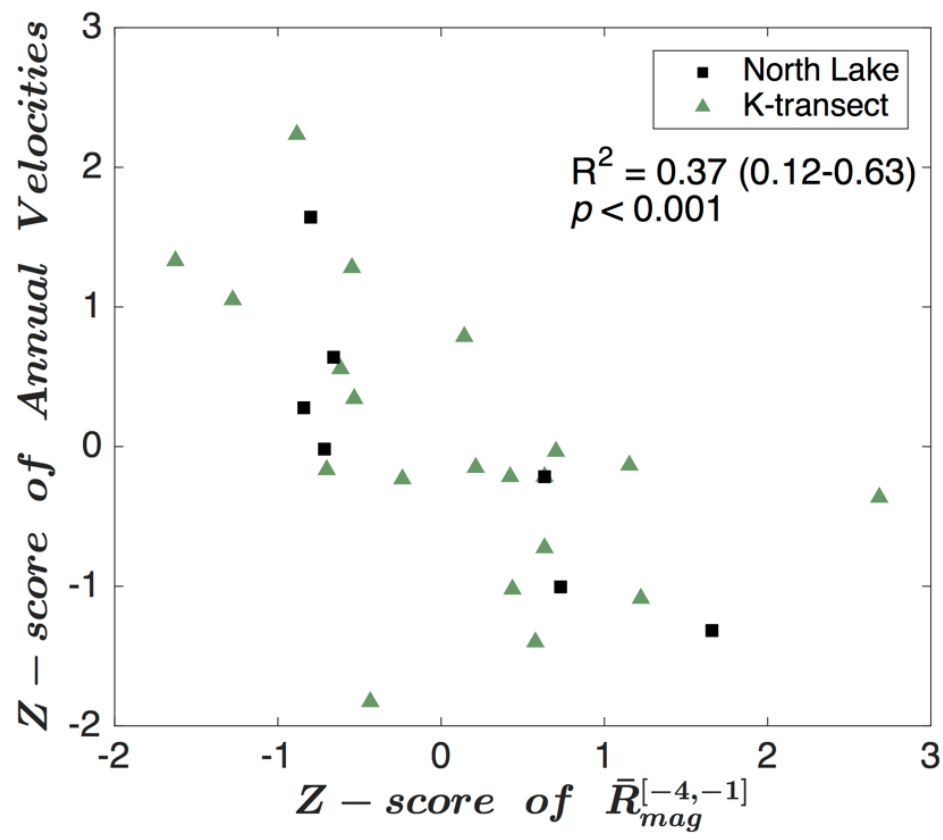

Figure 2-13. Annual velocities versus $\overline{\boldsymbol{R}}_{\text {mag }}^{[-4,-1]}$ for North Lake and the K-transect. Z-score of $\overline{\boldsymbol{R}}_{\boldsymbol{m a g}}^{[-\mathbf{4},-\mathbf{1}]}$ versus the $\mathrm{Z}$-score of annual velocities for North Lake (black squares) and the K-transect (green triangles). North Lake time series extends from 2007-2013 (n=7). The K-transect time series extends from 1990-2011 ( $\mathrm{n}=20)$. Annual velocity data for the $\mathrm{K}$-transect are published in van de Wal et al. [2015]. Local annual runoff estimates used to calculate $\overline{\boldsymbol{R}}_{\boldsymbol{m a g}}^{[-\mathbf{4}, \mathbf{- 1}]}$ are derived from RACMO2.3 downscaled daily runoff v0.2 at North Lake and K-transect station S7. $\mathrm{R}^{2}$ and $p$-values are given for the linear relationship including both North Lake and K-transect $z$-scores $(n=27)$. 

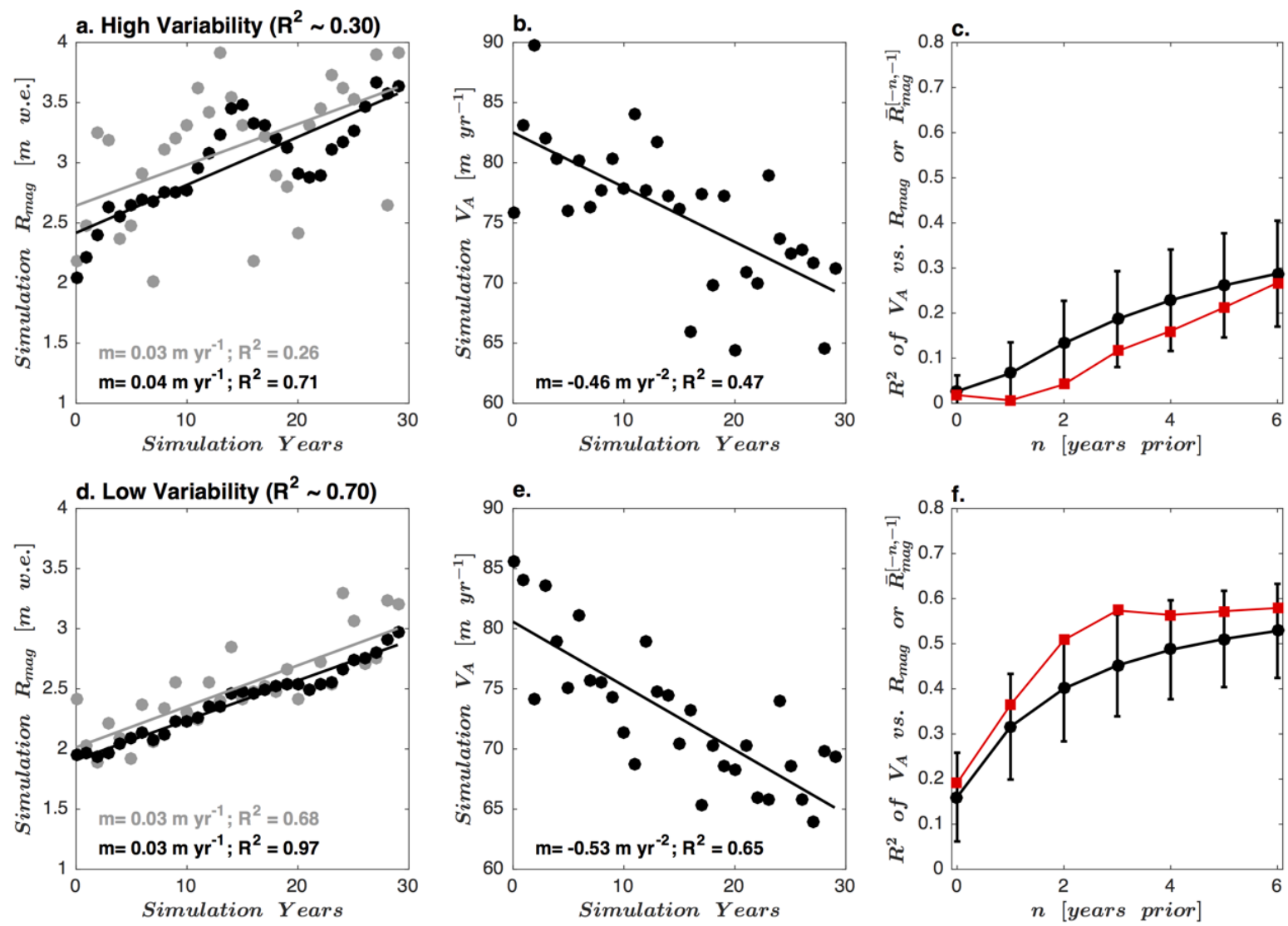

Figure 2-14. Monte Carlo simulations for synthetic $\boldsymbol{R}_{\boldsymbol{m a g}}$ and $\boldsymbol{V}_{\boldsymbol{A}}$ values. (a) Simulated $\boldsymbol{R}_{\text {mag }}$ (grey circles) and $\overline{\boldsymbol{R}}_{\boldsymbol{m a g}}^{[-\mathbf{4},-\mathbf{1}]}$ (black circles) values for a realization where $\boldsymbol{R}_{\boldsymbol{m a g}}$ has high variability $\left(\mathrm{R}^{2} \sim 0.30\right)$. Trend lines, slope, and $\mathrm{R}^{2}$ shown for both $\boldsymbol{R}_{\boldsymbol{m a g}}$ and $\overline{\boldsymbol{R}}_{\boldsymbol{m a g}}^{[-\mathbf{6},-\mathbf{1}]}$ in grey and black, respectively. (b) Simulated $\boldsymbol{V}_{\boldsymbol{A}}$ values (black circles) for an example realization where $\boldsymbol{V}_{\boldsymbol{A}}$ has variability roughly equivalent to observed $\left(\mathrm{R}^{2} \sim 0.50\right)$. Trend line, slope, and $\mathrm{R}^{2}$ shown for $\boldsymbol{V}_{\boldsymbol{A}}$ in black. (c) Mean value across all 10,000 high variability realizations of the $\mathrm{R}^{2}$ of the relationship between $\boldsymbol{V}_{\boldsymbol{A}}$ and $\overline{\boldsymbol{R}}_{\boldsymbol{m a g}}^{[-\boldsymbol{n},-1]}$, where $\boldsymbol{n}$ extends from one to six years of past runoff magnitude, in black. Error bars are 1sigma. Red values show $\mathrm{R}^{2}$ of the relationship between $\boldsymbol{V}_{\boldsymbol{A}}$ and $\overline{\boldsymbol{R}}_{\boldsymbol{m a g}}^{[-\boldsymbol{n}, \boldsymbol{- 1}]}$ for the example simulation shown in panels $\mathbf{a}$ and $\mathbf{b}$. Panels $\mathbf{d}-\mathbf{f}$ show the equivalent results as panels $\mathbf{a}-\mathbf{c}$ for 10,000 realizations with low variability $\left(\mathrm{R}^{2} \sim 0.70\right)$ in $\boldsymbol{R}_{\boldsymbol{m a g}}(\mathbf{d})$. 
Table 2-1. $\mathbf{R}^{2}$ (5-95\% confidence intervals) and $p$-values for linear trends between velocities and runoff season characteristics. Relationship shaded if $p<0.10$.

\begin{tabular}{c|ccc} 
& \multicolumn{1}{|c}{$\boldsymbol{V}_{\boldsymbol{S}}$} & $\boldsymbol{V}_{\boldsymbol{W}}$ & $\boldsymbol{V}_{\boldsymbol{A}}$ \\
\hline $\boldsymbol{R}_{\boldsymbol{m a g}}$ & $\mathrm{R}^{2}=0.00(0.00-0.02) ; p=0.97$ & $\mathrm{R}^{2}=0.01(0.00-0.10) ;$ & $\mathrm{R}^{2}=0.07(0.00-0.29) ;$ \\
& & $p=0.83$ & $p=0.56$ \\
\hline $\boldsymbol{R}_{\boldsymbol{v a r}}$ & $\mathrm{R}^{2}=0.00(0.00-0.01) ; p=0.98$ & $\mathrm{R}^{2}=0.00(0.00-0.01) ;$ & $\mathrm{R}^{2}=0.00(0.00-0.02) ;$ \\
& & $p=0.98$ & $p=0.97$ \\
\hline $\boldsymbol{R}_{\text {length }}$ & $\mathrm{R}^{2}=0.00(0.00-0.05) ; p=0.91$ & $\mathrm{R}^{2}=0.12(0.00-0.39) ;$ & $\mathrm{R}^{2}=0.23(0.00-0.51) ;$ \\
& & $p=0.45$ & $p=0.27$ \\
\hline $\boldsymbol{t}_{\boldsymbol{L} \boldsymbol{D}}$ & $\mathrm{R}^{2}=0.45(0.12-0.78) ; p=0.10$ & $\mathrm{R}^{2}=0.21(0.00-0.53) ;$ & $\mathrm{R}^{2}=0.01(0.00-0.10) ;$ \\
& & $p=0.30$ & $p=0.84$ \\
\hline $\boldsymbol{V}_{\boldsymbol{m i n}}$ & $\mathrm{R}^{2}=0.14(0.00-0.43) ; p=0.41$ & $\mathrm{R}^{2}=0.19(0.00-0.51) ;$ & $\mathrm{R}^{2}=0.14(0.00-0.43) ;$ \\
& & $p=0.33$ & $p=0.41$ \\
\hline $\boldsymbol{V}_{\boldsymbol{m i n}} \mid$ & $\mathrm{R}^{2}=0.14(0.00-0.43) ; p=0.41$ & $\mathrm{R}^{2}=0.54(0.24-0.84) ;$ & $\mathrm{R}^{2}=0.42(0.08-0.76) ;$ \\
& & $p=0.06$ & $p=0.12$ \\
\hline $\boldsymbol{R}_{\boldsymbol{m a g}}^{[-1]}$ & $\mathrm{R}^{2}=0.08(0.00-0.31) ; p=0.55$ & $\mathrm{R}^{2}=0.51(0.20-0.82) ;$ & $\mathrm{R}^{2}=0.76(0.57-0.95) ;$ \\
& & $p=0.07$ & $p<0.05$ \\
\hline $\boldsymbol{V}_{\boldsymbol{S}}$ & & $\mathrm{R}^{2}=0.05(0.00-0.24) ;$ & $\mathrm{R}^{2}=0.04(0.00-0.21) ;$ \\
& & $p=0.63$ & $p=0.69$ \\
\hline $\boldsymbol{V}_{\boldsymbol{W}}$ & & & $\mathrm{R}^{2}=0.81(0.66-0.96) ;$ \\
& & & $p<0.01$ \\
\hline & & &
\end{tabular}


Table 2-2. Runoff season and lake drainage timing characteristics.

\begin{tabular}{|c|c|c|c|c|c|c|c|}
\hline & $\begin{array}{l}t_{R 1} \\
\text { (DOY) }\end{array}$ & $\begin{array}{l}t_{V \min } \\
\text { (DOY) }\end{array}$ & $\begin{array}{l}R_{\text {length }} \\
\text { (days) }\end{array}$ & $\begin{array}{c}\text { mag } \\
\text { (m w.e.) }\end{array}$ & $\begin{array}{l}\boldsymbol{R}_{\text {var }} \\
\text { (mm w.e.) }\end{array}$ & $\begin{array}{l}t_{L D} \\
(\% \text { through } \\
\text { runoff season) }\end{array}$ & $\begin{array}{l}\left|V_{\min }\right|, \\
\text { trough } \\
\text { amplitude } \\
\left(\mathrm{m} \mathrm{yr}^{-1}\right)\end{array}$ \\
\hline 2007 & 156 & 244 & 88 & 2.32 & 10.59 & $28.83 \%$ & 21.27 \\
\hline 2008 & 154 & 241 & 87 & 1.90 & 11.39 & $56.50 \%$ & 20.67 \\
\hline 2009 & 153 & 240 & 87 & 1.98 & 9.37 & $17.45 \%$ & 13.27 \\
\hline 2010 & 143 & 252 & 109 & 2.82 & 10.48 & $5.37 \%$ & 21.24 \\
\hline 2011 & 160 & 248 & 88 & 2.25 & 7.29 & $7.87 \%$ & 4.66 \\
\hline 2012 & 150 & 242 & 92 & 2.59 & 13.25 & $9.57 \%$ & 10.71 \\
\hline 2013 & 160 & 234 & 74 & 1.66 & 11.24 & $14.17 \%$ & 1.59 \\
\hline
\end{tabular}

Table 2-3. Summer, winter, and annual displacements for the $t_{R 1}$ to $t_{V \min }$ seasonal delineation method and the fixed calendar date seasonal delineation method. The $\boldsymbol{t}_{R 1}$ to $\boldsymbol{t}_{V \min }$ method defines the start of each year as the date of the $1^{\text {st }}$ percentile of each year's cumulative runoff curve, $\boldsymbol{t}_{\boldsymbol{R} \mathbf{1}}$. The $\boldsymbol{t}_{\boldsymbol{R} \mathbf{1}}$ to $\boldsymbol{t}_{\boldsymbol{V} \min }$ method defines the end of each summer as $\boldsymbol{t}_{\boldsymbol{V m i n}}$, the midpoint within the characteristic velocity minimum at the end of the melt season. The fixed calendar date method defines May $30^{\text {th }}$ (day of year 150) as the start of each year (and the start of the summer) and September $7^{\text {th }}$ (day of year 250) as the end of each summer. The length of summer $\left(\boldsymbol{R}_{\text {length }}\right)$ in days is also noted for each delineation method.

\begin{tabular}{|c|c|c|c|c|c|c|c|c|}
\hline & \multicolumn{4}{|c|}{$\boldsymbol{t}_{\boldsymbol{R} 1}$ to $\boldsymbol{t}_{\boldsymbol{V} \min }$} & \multicolumn{4}{|c|}{ DOY 150 to 250} \\
\hline & $\begin{array}{l}\text { Summer } \\
(\mathrm{m})\end{array}$ & $\begin{array}{l}\text { Winter } \\
\text { (m) }\end{array}$ & $\begin{array}{l}\text { Annual } \\
(\mathrm{m})\end{array}$ & $\begin{array}{c}R_{\text {length }} \\
\text { (days) }\end{array}$ & $\begin{array}{l}\text { Summer } \\
(\mathrm{m})\end{array}$ & $\begin{array}{l}\text { Winter } \\
\text { (m) }\end{array}$ & $\begin{array}{l}\text { Annual } \\
\text { (m) }\end{array}$ & $\begin{array}{c}R_{\text {length }} \\
\text { (days) }\end{array}$ \\
\hline 2007 & $29.60 \pm 0.07$ & $56.27 \pm 0.07$ & $85.86 \pm 0.14$ & 88 & $30.07 \pm 0.08$ & $56.27 \pm 0.07$ & $86.36 \pm 0.15$ & 100 \\
\hline 2008 & $25.98 \pm 0.07$ & $58.41 \pm 0.07$ & $84.39 \pm 0.14$ & 87 & $26.65 \pm 0.07$ & $58.44 \pm 0.07$ & $85.09 \pm 0.14$ & 100 \\
\hline 2009 & $31.29 \pm 0.06$ & $57.84 \pm 0.07$ & $89.13 \pm 0.13$ & 87 & $31.21 \pm 0.06$ & $60.12 \pm 0.07$ & $91.33 \pm 0.13$ & 100 \\
\hline 2010 & $33.26 \pm 0.07$ & $58.81 \pm 0.06$ & $92.08 \pm 0.13$ & 109 & $30.05 \pm 0.07$ & $59.12 \pm 0.06$ & $89.17 \pm 0.13$ & 100 \\
\hline 2011 & $25.20 \pm 0.06$ & $55.11 \pm 0.07$ & $80.31 \pm 0.13$ & 88 & $25.50 \pm 0.06$ & $53.97 \pm 0.08$ & $79.46 \pm 0.14$ & 100 \\
\hline 2012 & $28.80 \pm 0.07$ & $55.89 \pm 0.07$ & $84.69 \pm 0.15$ & 92 & $30.07 \pm 0.08$ & $53.68 \pm 0.07$ & $84.05 \pm 0.15$ & 100 \\
\hline 2013 & $23.69 \pm 0.10$ & $57.36 \pm 0.10$ & $81.05 \pm 0.21$ & 74 & $30.17 \pm 0.07$ & $52.63 \pm 0.08$ & $82.80 \pm 0.15$ & 100 \\
\hline
\end{tabular}


Table 2-4. Trends in the seasonal and annual velocities from 2007-2013. Computed slopes with their 95\% (2-sigma) confidence intervals for $\boldsymbol{V}_{\boldsymbol{S}}, \boldsymbol{V}_{\boldsymbol{W}}$, and $\boldsymbol{V}_{\boldsymbol{A}}$ from 2007-2013 for a least squares regression and a weighted least squares regression. The least squares regression does not consider error on the velocity measurements. The weighted least squares regression considers error on the velocity measurements by weighting the individual velocity measurements as $\frac{1}{\text { error }^{2}}$.

\begin{tabular}{c|cc} 
& Least Squares Regression & $\begin{array}{c}\text { Weighted Least Squares } \\
\text { Regression }\end{array}$ \\
\hline $\boldsymbol{V}_{\boldsymbol{S}}$ & $0.85(-1.74,3.44)$ & $0.57(-2.53,3.69)$ \\
$\boldsymbol{V}_{\boldsymbol{W}}$ & $-1.13(-2.32,0.06)$ & $-1.09(-2.33,0.14)$ \\
$\boldsymbol{V}_{\boldsymbol{A}}$ & $-0.92(-2.33,0.48)$ & $-0.96(-2.46,0.53)$ \\
\hline
\end{tabular}

Table 2-5. $\mathbf{R}^{2}$ (5-95\% confidence intervals) and $p$-values for linear trends between velocities and future mean runoff magnitude. The range of years averaged is detailed in the superscript of $\bar{R}_{\text {mag }}^{\text {[year range }]}$, such that $\bar{R}_{\text {mag }}^{[-1,+1]}$ is the mean of the past year's melt magnitude, the present year's melt magnitude, and the melt magnitude of one year in the future. The RACMO2.3 record extends to 2014, thus $\bar{R}_{m a g}^{[0,+2]}$ is calculated excluding velocities from 2013.

\begin{tabular}{c|ccc} 
& $\boldsymbol{V}_{\boldsymbol{S}}$ & $\boldsymbol{V}_{\boldsymbol{W}}$ & $\boldsymbol{V}_{\boldsymbol{A}}$ \\
\hline$\overline{\boldsymbol{R}}_{\boldsymbol{m a g}}^{[-\mathbf{2 , + 1}]}$ & $\mathrm{R}^{2}=0.04(0.00-0.21) ;$ & $\mathrm{R}^{2}=0.16(0.00-0.46) ;$ & $\mathrm{R}^{2}=0.05(0.00-0.24) ;$ \\
& $p=0.68$ & $p=0.40$ & $p=0.64$ \\
\hline$\overline{\boldsymbol{R}}_{\boldsymbol{m a g}}^{[-\mathbf{1},+\mathbf{1}]}$ & $\mathrm{R}^{2}=0.01(0.00-0.10) ;$ & $\mathrm{R}^{2}=0.04(0.00-0.21) ;$ & $\mathrm{R}^{2}=0.04(0.00-0.21) ;$ \\
& $p=0.84$ & $p=0.67$ & $p=0.66$ \\
\hline$\overline{\boldsymbol{R}}_{\boldsymbol{m a g}}^{[\mathbf{0 , + 1}]}$ & $\mathrm{R}^{2}=0.01(0.00-0.10) ;$ & $\mathrm{R}^{2}=0.07(0.00-0.29) ;$ & $\mathrm{R}^{2}=0.16(0.00-0.46) ;$ \\
& $p=0.84$ & $p=0.55$ & $p=0.37$ \\
\hline$\overline{\boldsymbol{R}}_{\boldsymbol{m a g}}^{[\mathbf{0 , + 2}]}$ & $\mathrm{R}^{2}=0.01(0.00-0.10) ;$ & $\mathrm{R}^{2}=0.24(0.00-0.57) ;$ & $\mathrm{R}^{2}=0.29(0.00-0.63) ;$ \\
& $p=0.85$ & $p=0.33$ & $p=0.27$
\end{tabular}




\section{Chapter 3}

\section{Greenland supraglacial lake drainages triggered by hydrologically induced basal slip}

This chapter was originally published as: Stevens, L. A., M. D. Behn, J. J. McGuire, S. B. Das, I. Joughin, T. Herring, D. E. Shean, and M. A. King (2015), Greenland supraglacial lake drainages triggered by hydrologically induced basal slip, Nature, 522(7554), 73-76. Used with permission as granted in the original copyright agreement.

\subsection{Abstract:}

Water-driven fracture propagation beneath supraglacial lakes rapidly transports large volumes of surface melt-water to the base of the Greenland Ice Sheet [Das et al., 2008]. These drainage events drive transient ice-sheet acceleration [Das et al., 2008; Doyle et al., 2013; Tedesco et al., 2013] and establish conduits for additional surface-to-bed melt-water transport for the remainder of the melt season [Das et al., 2008; Joughin et al., 2008, 2013; Andrews et al., 2015]. While it is well established that cracks must remain water-filled to propagate to the bed [Krawcsynski et al., 2009; Weertman, 1973; Van Der Veen, 2007], the precise mechanisms that initiate hydro-fracture events beneath lakes are unknown. Here we show that, for a lake on the western Greenland Ice Sheet, drainage events are preceded by a 6-12 hour period of ice-sheet uplift and/or enhanced basal slip. Our observations from a dense GPS network allow us to determine the distribution of melt-water at the ice-sheet bed before, during, and after three rapid drainages in 2011-2013, each of which generates tensile stresses that promote hydro fracture beneath the lake. We hypothesize that these precursors are associated with the introduction of melt-water to the bed through neighboring moulin systems (vertical conduits connecting the surface and base of the ice sheet). Our results imply that as lakes form in less crevassed, interior regions of the ice sheet [Sundal et al., 2009; Howat et al., 2013; Fitzpatrick et al., 2014; Parizek and Alley, 2004; Leeson et al., 2015], where water at the bed is currently less pervasive [Joughin et al., 2013; Leeson et al., 2015; Bartholomew et al., 2011; Doyle et al., 2014], the creation of new surface-to-bed conduits caused by lakedraining hydro-fractures may be limited. 


\subsection{Main text}

Greenland ice sheet flow accelerates at the beginning of the melt-season [Joughin et al., 2008; Bartholomew et al., 2011], when surface melt-water reaches the bed via conduits [Das et al., 2008; Joughin et al., 2008, 2013; Andrews et al., 2015; Zwally et al., 2002; Batholomew et al., 2012]. Inland from the ice margin, this process is often associated with the drainage of supraglacial lakes [Das et al., 2008; Joughin et al., 2013; Hoffman et al., 2011]. The majority of supraglacial lakes drain slowly, overfilling their banks and routing lake water via surficial streams to nearby crevasses and/or moulins [Tedesco et al., 2013; Selmes et al., 2011; Smith et al., 2015]. A smaller fraction ( 13\%) of lakes drain rapidly (<1 day) [Selmes et al., 2011], in some cases as rapidly as a few hours [Das et al., 2008; Doyle et al., 2013; Tedesco et al., 2013], through large (kilometer-scale length) hydro-fractures that form directly beneath the lake basin. These hydrofractures subsequently close except where continued stream flow keeps moulins open for the remainder of the melt season [Das et al., 2008; Doyle et al., 2013; Tedesco et al., 2013]. While the former style of drainage requires the presence of pre-existing crevasses and/or moulins, the latter style has the potential to create new surface-to-bed melt-water pathways through the ice sheet, and is thus an area of intense study [Das et al., 2008; Doyle et al., 2013; Tedesco et al., 2013; Joughin et al., 2013; Hoffman et al., 2011; Pimentel and Flowers, 2010; Tsai and Rice, 2010].

While the basic principles of hydro-fracture through glacial ice are well understood [Krawczynski et al., 2009; Weertman, 1973; Van Der Veen, 2007], the mechanism that triggers the formation of kilometer-scale length hydro-fractures in compressional basins where lakes form is unknown [Doyle et al., 2013]. A necessary condition for generating through-ice hydro-fractures is that a supraglacial lake must contain a sufficient volume of water to keep a fracture filled as it propagates from the surface to the bed [Krawcsynski et al., 2009; Weertman, 1973; Van Der Veen, 2007]. However, large lakes with volumes well above this threshold often do not drain over multiple summers [Fitspatrick et al., 2014]. Additionally, lakes repeatedly fill basins containing numerous healed hydro-fracture cracks and moulins created during prior years' drainage events [Das et al., 2008; Doyle et al., 2013; Krawczynski et al., 2009], implying that the presence of pre-existing cracks does not necessarily lead to immediate drainage. Thus, identifying the first-order control on hydro-fracture initiation preceding rapid lake drainages has remained elusive. 
In this study, we investigate hydro-fracture initiation and rapid drainage at North Lake $\left(68.72^{\circ} \mathrm{N},-49.50^{\circ} \mathrm{W}\right), \mathrm{a} \sim 2.5-\mathrm{km}$ diameter supraglacial lake located south of the Jakobshavn-Isbrae catchment on thick ice $(\sim 980 \mathrm{~m})$ (Figure $3-1)$. This site has been the focus of in-depth study since 2006, when the first detailed evidence for hydro-fracture to the bed of the Greenland ice sheet was collected using Global Positioning System (GPS) measurements from North Lake base station (NLBS) (Figure 3-1) [Das et al., 2008]. During the 2006 event, a slow, steady lake-level drop was observed over a 16-hour pre-drainage stage followed by the rapid $(<2 \mathrm{hr})$ drainage coincident with vertical and horizontal ice displacement [Das et al., 2008. Subsequent modeling of the NLBS data collected during this event found that vertical uplift was caused almost entirely by a horizontal cavity opening at the ice-bed interface due to rapid injection of melt-water, whereas opening of the through-ice vertical crack was the principal contributor to the horizontal surface displacements [Tsai and Rice, 2010]. Similar observations have since been made at other west Greenland Ice Sheet supraglacial lakes [Doyle et al., 2013; Tedesco et al., 2013] all providing definitive evidence for rapid melt-water drainage to the bed during hydrofracture events.

A limitation of these prior studies was insufficiently dense observations of surface motion required to directly constrain the mechanism and location of hydro-fracture initiation and the spatial distribution of melt-water at the ice-sheet bed. Here we present results from a spatially-dense array of 16 GPS stations positioned around North Lake between 2011 and 2013 (Figure 3-1). This array captured the dynamic response of the ice sheet to rapid lake drainages in each of the three years of the study, allowing us to infer the evolving hydro-fracture geometry and spatial distribution of meltwater at the ice-sheet bed before, during, and after drainages.

From these GPS data, we identify a period of precursory ice motion, indicative of the presence of an increased volume of water reaching the bed within the GPS array, hours before each years' local hydro-fracture initiation and rapid lake drainage (Table 3-1). The displacement anomalies (Figures 3$2 \mathrm{a}-\mathrm{c})$ show the along-flowline, crack-normal, and vertical displacement histories for two days prior to and one day following each drainage event at stations NL08 and NL01 or NL03 (Figures 3-1, Appendix 3.A). We pick three time points for each drainage (using all available stations) that designate the start of the precursor, hydro-fracture initiation, and the maximum hydro-fracture opening (Figure 3-2; Table 3-1). 
The 2011 precursor is manifested as vertical uplift followed by increased displacement in the flow-line direction at stations southwest of moulin M1 (NL07, NL08, NL10) over the 10 hours leading up to rapid lake drainage (Figures 3-1, 3-2 a, 3-3 a). This is consistent with field observations that suggest as North Lake filled over the preceding days the western shoreline reached M1, allowing meltwater to begin pooling in and reactivating M1 prior to lake drainage, thus permitting increased basal slip (Figures 3-5, 3-6). Similarly, we observe increased displacement in the flow-line direction prior to the 2012 and 2013 hydro-fracture events, which we also interpret to be hydrologically induced (Figure 3-2 b, c) (Appendix 3.I, Appendix 3.J). In 2012 the precursor is manifested as anomalous alongflowline displacements at stations in the northern end of the array (e.g., NL01 and NL02), but shows little signal at the southern stations (Figure 3-8 a). The 2013 precursor is manifested as enhanced flowline displacements at all western stations (FL03, NL04, NL07, NL08, NL10), as well as vertical uplift focused just west of the lake basin (Figure 3-9 a). All three precursors have similar durations (6-12 hours), but they occur in different subsets of the spatial array. Following each precursor there is clear evidence of the main 4-km long hydro-fracture opening and subsequent rapid lake drainage, as indicated by the $\sim 3$ hour long, 5-10 cm excursion of NL08 in the crack-normal (southward) direction, which is rapidly recovered due to closing of the fracture (Figures 3-2 a-c). In all three years the hydro-fracture opening phase is accompanied by considerable $(>20 \mathrm{~cm})$ uplift and enhanced along-flowline motion across many stations in the network.

To quantitatively constrain the processes responsible for these surface motions, we exploit the high spatial density of our GPS data to invert for the space-time history of deformation surrounding the lake drainages. We use the Network Inversion Filter (NIF) algorithm [Segall and Matthews, 1997] to model the GPS time series of drainage-related surface motion as the summation of three deformation sources: (1) hydro-fracture opening, (2) basal cavity opening (due to the rapid injection of melt-water), and (3) extra basal slip above the background rate (due to enhanced basal lubrication) (Appendix 3.C) (Figures 3-10-3-12). The NIF utilizes Green's functions for an elastic half-space to relate the surface displacement time series to the space-time history of opening and slip along prescribed planes describing each of these deformation sources [Segall and Matthews, 1997] (Appendix 3.C). 
The NIF results provide estimates of the spatial distribution of melt-water at the ice-sheet bed before, during, and after drainages. Figures 3-2 d-f show spatially integrated results from 2011-2013 for the three deformation sources: hydro-fracture crack volume, basal cavity volume, and basal slip (shown as moment $\mathrm{M}_{0}$; see Appendix 3.D). For the 2011 event, we identify basal cavity opening and slip associated with the precursor southeast and southwest of M1, respectively, before the hydrofracture opens (Figures 3-2 d, 3-3 a-c) -indicating the injection of melt-water at the ice-sheet bed prior to local hydro-fracture initiation. Immediately following the precursor, the hydro-fracture opens first at M1, and then propagates east beneath the basin. At the time of maximum hydro-fracture opening (Figures 3-3 d-f), the basal cavity volume (Figure 3-2 d) is nearly equivalent to the North Lake pre-drainage volume estimate of $0.007 \pm 0.001 \mathrm{~km}^{3}$ (Appendix 3.B) (Table 3-1; Figures 3-6, 37). The agreement between lake volume calculations and NIF estimates of basal cavity volume validates our inversion results. Basal slip is focused within, and a few $\mathrm{km}$ south of, the lake basin, but not northward possibly due to a known ridge in the basal topography (Figure 3-3 d) [Joughin et al., 2013; Bamber et al., 2013].

Inversion results for the rapid drainage events in 2012 and 2013 also suggest precursory activity (Appendices 3.I, 3.J). The 2012 precursor is associated with basal slip $3 \mathrm{~km}$ north of the hydrofracture, possibly due to enhanced lubrication from nearby melt-water input to the bed (Figure 3-7 a). The 2013 precursor was the most extensive, producing enhanced basal slip over a $5 \times 5 \mathrm{~km}$ area as well as significant basal uplift (Figure 3-8 a,b). In both 2012 and 2013, the hydro-fracture opening and lake drainage produce $\sim 50 \mathrm{~cm}$ of basal cavity opening beneath the lake basin and enhanced basal slip over a wide area (Figures 3-8 d-f, 3-9 d-f).

Previous work on the 2006 North Lake drainage event identified a slow steady drop in lake level in the 16 hours prior to the rapid hydro-fracture induced drainage, and it was hypothesized that this pre-drainage may have been due to the initial filling of a slowly propagating hydro-fracture directly beneath the lake basin, or water over-spilling into an adjacent crack system [Das et al., 2008]. However, the observations in 2006 were insufficient to distinguish between these (or alternative) mechanisms. Our NIF results show no evidence for the slow downward propagation of a hydro-fracture prior to lake drainage, which would be manifest as crack-normal horizontal displacements. Rather, the inversions clearly demonstrate that each drainage is preceded by a period of enhanced basal slip and/or 
uplift, that is likely caused by the injection of melt-water at the bed via neighboring hydro-fractures and moulins. Intriguingly, precursor motion was also observed prior to other lake drainages [Das et al., 2008; Doyle et al., 2013], though it was not identified as a triggering mechanism for hydro-fracture initiation (Appendix 3.G). The observation of a precursor before rapid lake drainages strongly suggests that they play an important role in triggering hydro-fractures, possibly by inducing local stress perturbations that overcome the background compressive stresses found in lake basins [Joughin et al., 2013; Catania et al., 2008].

To test the hypothesis that local stress perturbations play an important role in triggering hydrofractures, we compared the background viscous stresses in the lake basin to the elastic stress change induced by the precursory basal slip and cavity opening (Appendix 3.F). We calculated background compressive stresses of order $-70 \pm 40 \mathrm{kPa}$ within the lake basin, comparable to other west Greenland lake basin estimates [Catania et al., 2008]. Prior to the start of the precursor, changes in crack-normal stress $\left(\Delta \sigma_{\mathrm{n}}\right)$ on the hydro-fracture are $\Delta \sigma_{\mathrm{n}}=0 \pm 40 \mathrm{kPa}$. However, throughout the precursor $\Delta \sigma_{\mathrm{n}}$ increases, attaining maxima tensile stresses of +100 to $+600 \mathrm{kPa}$ at the top of the hydro-fracture at the onset of rapid drainage (Figure 3-4 a-c). These calculations confirm that the drainage precursors can generate tensile crack-normal stresses near the surface with sufficient magnitude to temporarily overcome the compressive background stress and promote hydro-fracture initiation.

Our results and reinterpretation of previous studies (Appendix 3.G) indicate that injection of surface melt-water, routed from supraglacial lakes to the bed through pre-existing crevasses or conduits, is required to trigger hydro-fracture initiation and subsequent rapid lake drainage in an otherwise compressional basin. As shown previously, a necessary condition for hydro-fracture propagation is a sufficient volume of water to keep the fracture filled [Krawcsynski et al., 2009; Van Der Veen, 2007]. Lacking a known triggering mechanism, prior studies used only this volume threshold to predict that lake drainages would occur [Leeson et al., 2015; Clason et al., 2012; Arnold et al., 2014]. However, we do not find that lakes spontaneously hydro-fracture once they surpass this threshold [Fitzpatrick et al., 2014]. In all 3 years, North Lake contained $~ 5 x$ the critical volume of water necessary to keep a $4 \mathrm{~km}$ long crack open to the bed (Appendix 3.E) before hydro-fracture occurred. Thus, we argue against the exclusive use of a volume threshold for triggering supraglacial lake drainage in regional ice sheet modeling studies. 
We hypothesize that if stress transients associated with enhanced melt-water transport to the bed beneath lakes are required to initiate surface-to-bed hydro-fractures in compressional lake basins, then lakes are less likely to create large-scale hydro-fractures in interior regions of the Greenland Ice Sheet where melt-water access to the bed is limited by lack of pre-existing crevasses [Joughin et al., 2013; Leeson et al., 2014; Bartholomew et al., 2011; Doyle et al., 2014; Poinar et al., 2015]. As new lakes form at higher elevations in a warming climate [Sundal et al., 2009; Howat et al., 2013; Fitzpatrick et al., 2014; Parizek and Alley, 2004; Leeson et al., 2015] they will encounter longer wavelength surface topography [Joughin et al., 2013; Sergienko, 2013; Lampkin and VanderBerg, 2011], resulting in greater distances between compressive lake basins and extensional crevasse-forming regions. Thus, lake water must be routed greater distances in surface streams down the ice sheet before encountering crevasses where through-ice drainage conduits can be established, minimizing local stress transients and potentially obstructing in situ rapid drainage of high elevation lakes and the formation of new surface-to-bed hydro-fractures beneath lake basins [Poinar et al., 2015]. This indicates that while lake drainages may be important for inland expansion of enhanced flow at mid-elevations [Doyle et al., 2014], such expansions are more likely influenced by longitudinal coupling at high elevations [Price et al., 2008] (Appendix 3.H). Finally, the supply of melt-water to the bed may not be well correlated with the location, abundance, and size of high elevation supraglacial lakes. 


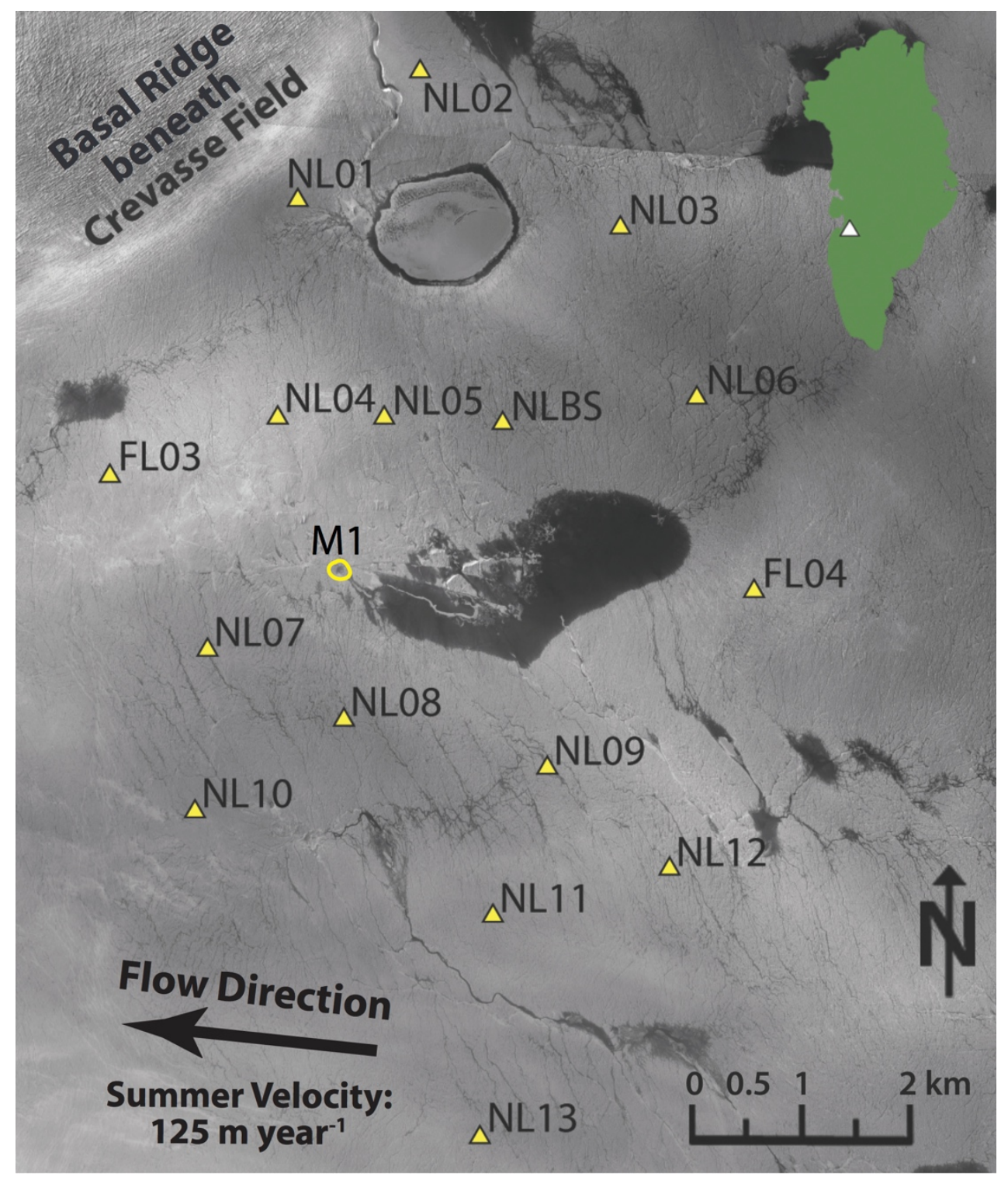

Figure 3-1. June 17, 2011 Synthetic Aperture Radar (SAR) image showing the extent of North Lake (center) and surrounding lakes one day before the 2011 rapid North Lake drainage. Yellow triangles show GPS locations. The M1 moulin is also shown. 


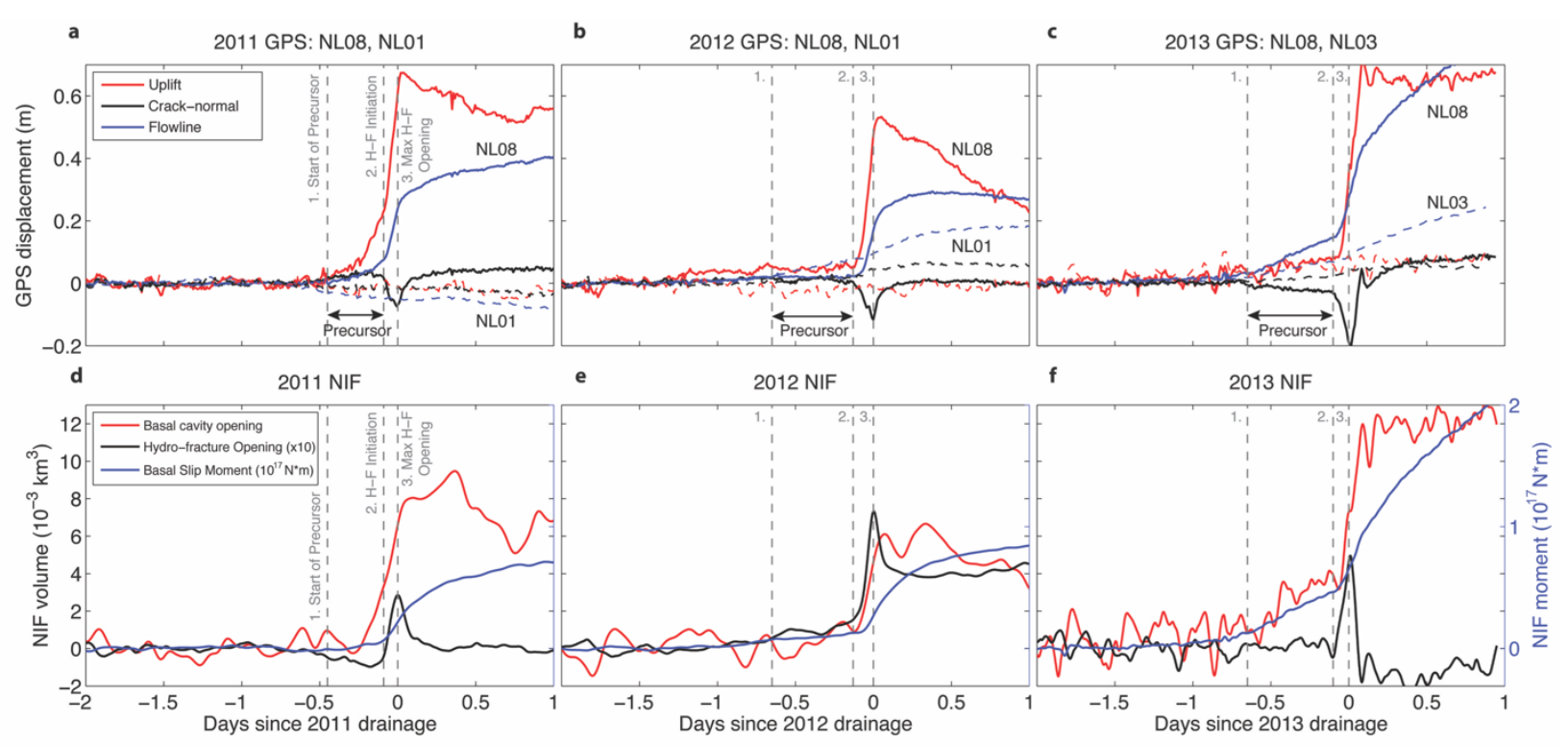

Figure 3-2. 2011, 2012, and 2013 North Lake Drainages. GPS station displacement less background velocities shown in solid (dashed) lines for station NL08 (NL01 or NL03) flowline displacement (blue), crack-normal displacement (black), and relative vertical uplift (red) over the two days prior and one day following the (a) 2011, (b) 2012, (c) 2013 drainage events. The bottom row shows NIF-derived hydro-fracture opening volume (black), basal cavity opening volume (red), and basal slip moment (blue) across the domain for the two days prior to and one day following the (d) 2011, (e) 2012, (f) 2013 drainage events. The coordinate system is orientated such that hydro-fracture opening is expressed primarily in the horizontal crack-normal component, while basal slip is primarily expressed in the horizontal flowline component, and basal cavity opening is primarily reflected in the vertical component data. The precursor and rapid lake drainage periods are designated by three time points across the drainages: (1) the start of the precursor at the time of first distinguishable deviation of station vertical uplift, crack-normal, or flowline displacement from the background velocity field (" 1 . Start of Precursor"); (2) hydro-fracture initiation at the time of maximum NL08 southward cracknormal acceleration ("2. H-F Initiation"); and, (3) the maximum hydro-fracture opening at the time of maximum southward NL08 crack-normal displacement (“3. Max H-F Opening”) (Table 3-1). 
a

2011 Hydro-fracture Initiation DOY 169.21

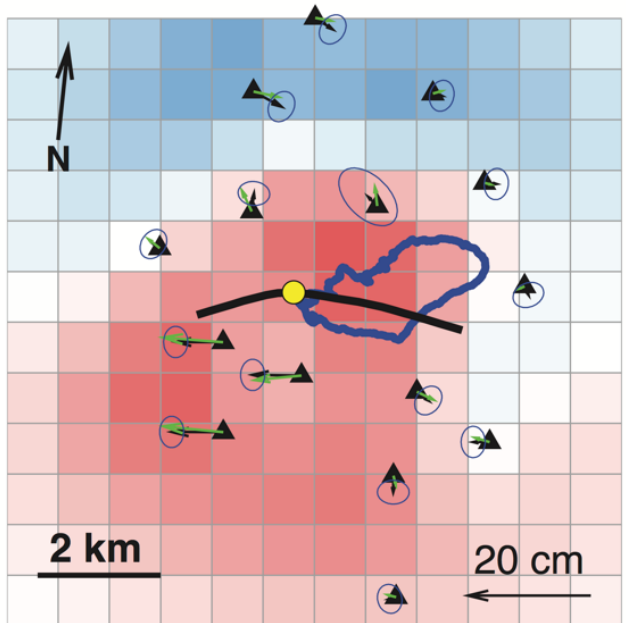

b
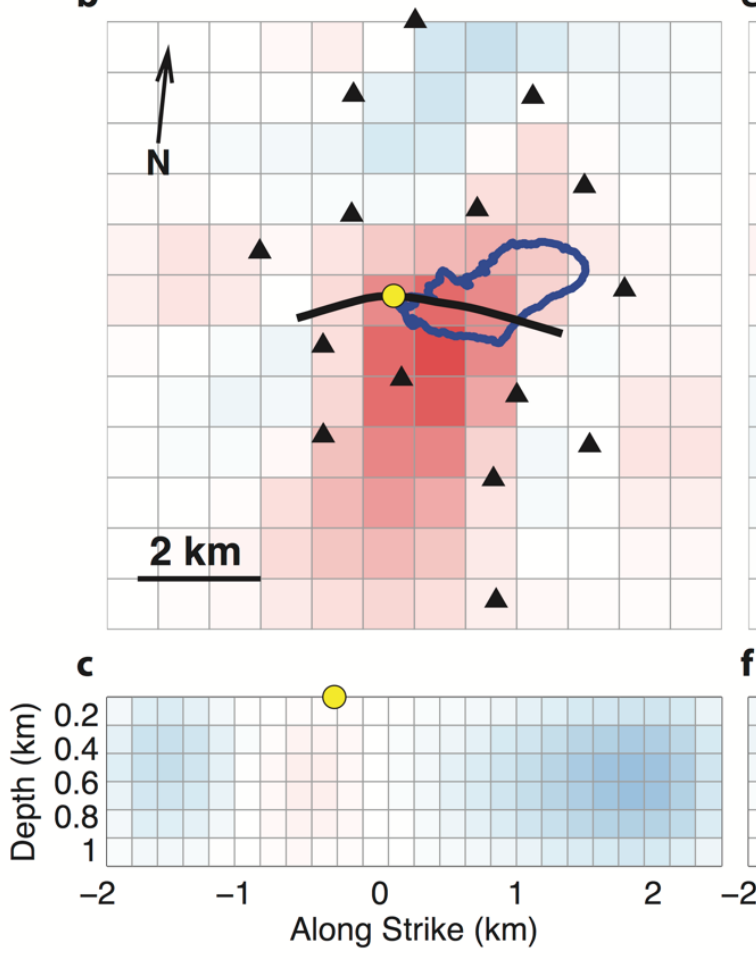

2011 Max Hydro-fracture Opening DOY 169.32

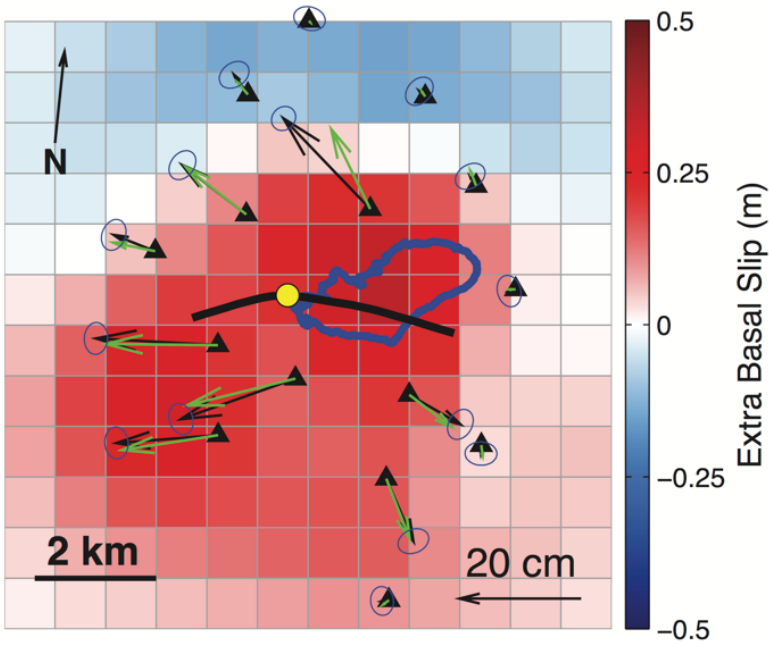

e
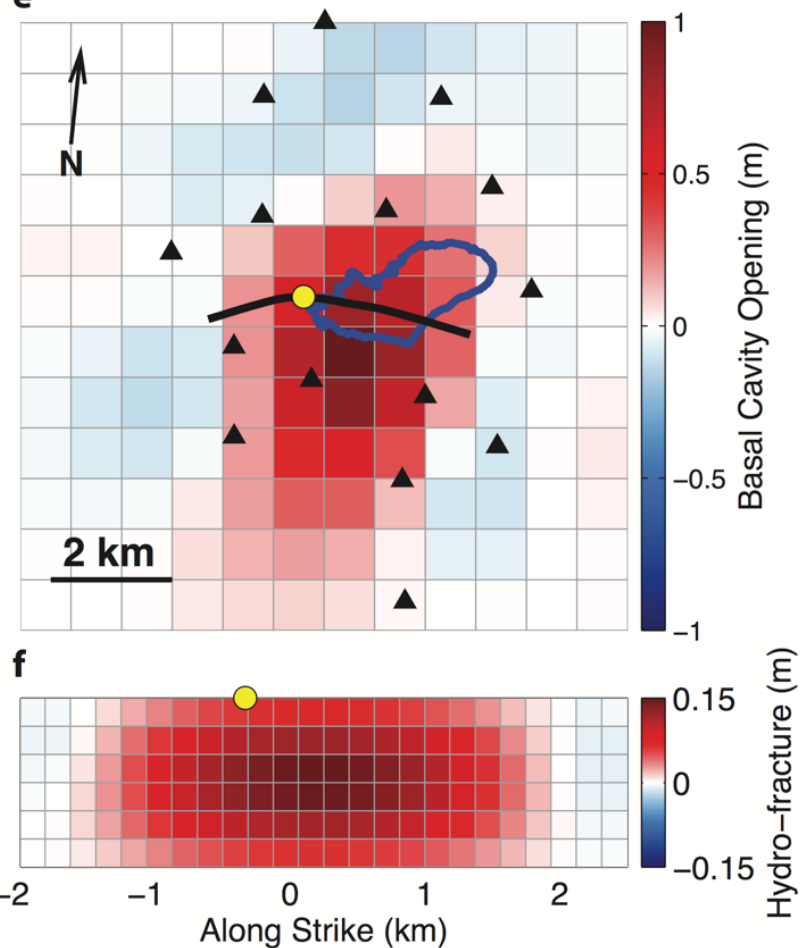

Figure 3-3. 2011 Basal slip and cavity opening at hydro-fracture initiation and maximum hydro-fracture opening. NIF-calculated (a) extra basal slip accumulated, (b) basal cavity opening, and (c) hydro-fracture crack opening at the time of the $2011(\mathrm{a}-\mathrm{c})$ hydro-fracture initiation and $(\mathrm{d}-\mathrm{f})$ maximum hydro-fracture opening (time points shown in Fig. 2a). Moulin location, last known lake shoreline, GPS stations, and NIF vertical crack surface trace derived from SAR imagery are shown as a yellow circle, blue line, black triangles, and black line, respectively. Vector fields show GPS (NIF) displacement less background velocities in black (green) for (a) the period between the start of the precursor and hydro-fracture initiation, and (d) the period between hydro-fracture initiation and maximum hydro-fracture opening. Error ellipses of 1 sigma are shown for the GPS displacements (blue ellipses). Basal subelements are $0.83 \mathrm{~km}$ by $0.83 \mathrm{~km}$, resulting in 144 subelements over a $10 \mathrm{~km}$ by $10 \mathrm{~km}$ region. 
a

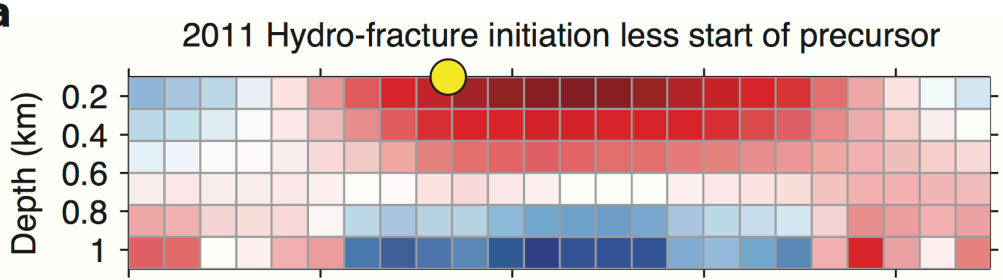

b 2012 Hydro-fracture initiation less start of precursor

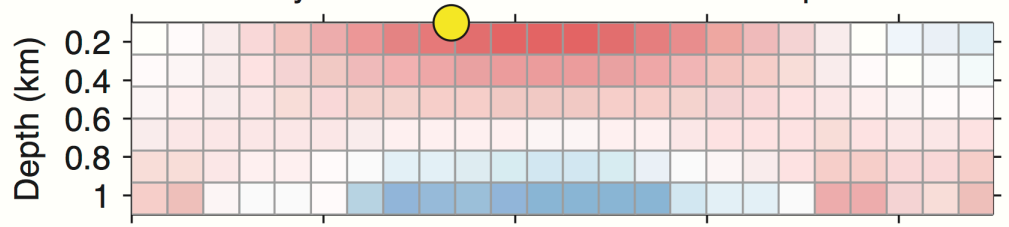

C 2013 Hydro-fracture initiation less start of precursor

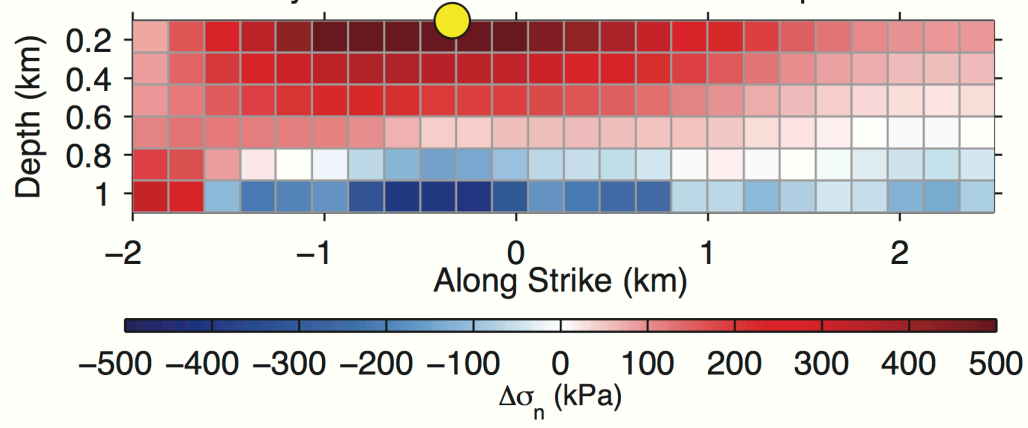

Figure 3-4. Change in Crack-normal Stress during the Precursor. Changes in the crack-normal elastic stresses $\left(\Delta \sigma_{\mathrm{n}}\right)(\mathrm{kPa})$ (compressive $=$ negative; tensile $=$ positive $)$ on the hydro-fracture crack as a result of basal cavity opening and accumulated extra basal slip during the (a) 2011, (b) 2012, and (c) 2013 precursor. Stresses are calculated at the start of the precursor and hydro-fracture initiation, coinciding with the times noted in Table 3-1, and then differenced to show the change in elastic stress that occurs during the precursor. 


\section{Appendices}

\section{A GPS Data}

Continuous 30-s resolution GPS data collected by dual-frequency Trimble NetR9 receivers were processed with Track software [Chen, 1998]. GPS data for each station were processed individually relative to the 30-s resolution Greenland GPS Network (GNET) KAGA base station located on bedrock $\sim 55 \mathrm{~km}$ from North Lake [Bevis et al., 2012]. The 30-s resolution position estimates and corresponding uncertainties from Track were used in the NIF and plotted in Figures 3-10 and 3-11. For plotting purposes, the data in Figure 3-2 were smoothed over a 2-minute window with a fivepoint central moving average. Error output from Track software is given as 1-sigma errors for East, North, and Up offsets from the coordinates of the first position in the time series, but not the full covariance matrix [Chen, 1998]. Horizontal (vertical) 1 -sigma errors are consistently $\pm 2 \mathrm{~cm}( \pm 5 \mathrm{~cm})$ across all stations and years.

Of the 16 GPS stations in the North Lake array, stations NL08, NL01 and/or NL03 best capture differences between the precursors over the three drainage events (Figure 3-2). NL08 is consistently the most responsive station during lake drainage events, and proves to be the best single station indicator of the drainage event as a whole. NL08 captures the 2011 and 2013 precursor well (Figure 3-2 a,c). In 2012, the precursor is manifested as anomalous along-flowline displacements observed at stations NL01 and NL02. Thus, we show of these northern stations (NL01) alongside the NL08 timeseries to show the along flowline speed up in the northern portion of the array during the 2012 precursor (Figure 3-2b). In 2013, NL01 and NL02 stations were not recording during the drainage, leaving NL03 as the closest station in the northern portion of the array to NL01/NL02 (Figure 3-2 c). Lake drainage duration is calculated based on NL08 crack-normal motion from the start of the hydro-fracture opening to when NL08 crack-normal motion regains its southward displacement as the crack closes ( 1-2 hours after time of maximum hydro-fracture opening) (Figure 3-2, Table 3-1). 


\section{B Lake Volume}

The NASA Ames Stereo Pipeline [Moratto et al., 2010] stereographic software was used to generate $\sim 2$ m per pixel digital elevation models (DEMs) of the empty, post-drainage North Lake basin using a WorldView-1 stereopair acquired on 7/21/2011 and a WorldView-2 stereopair acquired on 7/5/2013 (Figure 3-5). Orthorectified $\sim 0.5 \mathrm{~m}$ per pixel WorldView images depicting the last available predrainage North Lake shoreline were used to constrain the lake shoreline position and thus, lake depth and volume from the DEM. The 2011 lower bound on the lake volume estimate for North Lake was calculated from the shoreline position on a 6/17/2011 WorldView-1 image obtained 1 day before the 2011 drainage. The 2013 lower bound for lake volume for North Lake was calculated from the shoreline position on a 6/17/2013 WorldView-2 image obtained 2 days before the 2013 drainage. While small-scale surface features (moulins, supraglacial stream channels) advect $\sim 100 \mathrm{~m} \mathrm{yr}^{-1}$ to the WNW, the North Lake basin geometry is the result of fixed bed topography, and does not change significantly between summers (Figure 3-7). Lake volume estimates are given in Table 3-1.

In 2012, a lack of satellite images of North Lake basin during the days leading up to drainage prevented lake volume calculation via shoreline position and DEM methods. Output from the Regional Atmospheric Climate Model for the Greenland Ice Sheet (RACMO2/GR) [V an Angelen et al., 2013] for 2011 and 2012 was used to compare estimated cumulated runoff in the North Lake region $\left(68.66^{\circ} \mathrm{N},-49.52^{\circ} \mathrm{W}\right)$ at the day of lake drainage between the two years. We found that RACMO2/GR values of cumulative runoff at DOY 1692011 and DOY 1612012 are very similar at $0.0030 \mathrm{~kg} \mathrm{~m}^{-2}$ and $0.0031 \mathrm{~kg} \mathrm{~m}^{-2}$, respectively. Average daily runoff values at this location during midJune are on the order $0.0003 \mathrm{~kg} \mathrm{~m}^{-2} \mathrm{day}^{-1}$. Thus, we conclude the pre-drainage 2012 North Lake volume is on the order of the pre-drainage $2011 \mathrm{NL}$ volume: $0.007 \pm 0.001 \mathrm{~km}^{3}$. We hypothesize that the pre-drainage 2012 North Lake shoreline reached M1 at the time of drainage.

\section{C Network Inversion Filter}

We implemented the Network Inversion Filter (NIF) algorithm [Segall and Matthews, 1997] to determine the amount of opening along a vertical crack and slip and opening along a basal crack during the 2011, 2012, and 2013 North Lake rapid drainage events. The NIF utilizes Green's functions for an elastic half-space [Okada, 1985] to relate surface displacement time series to the space-time history of opening and slip along prescribed planes [Segall and Matthews, 1997]. The North Lake basin is modeled using 
an isotropic elastic half-space with the GPS stations at the surface. Three deformation sources are included: (1) hydro-fracture opening, (2) basal cavity opening (due to the rapid injection of melt-water), and (3) extra basal slip above the background rate (due to enhanced basal lubrication). The NIF assumes linear elastic behavior for the ice sheet, and treats hydro-fracture as a horizontal elastic dislocation along a vertical crack within the ice [Weertman, 1973]. These assumptions are justified by vertical-crack propagation timescales (seconds to minutes) that are shorter than the Maxwell time of ice (6 to 24 hours) [Krawczynski et al., 2009; Van der Veen, 2007; Pimentel and Flowers, 2010; Tsai and Rice, 2010].

We model the GPS position vector $\mathbf{X}$ for each GPS station $i$, as a function of time $t$ relative to the starting time $t_{0}$ as follows [Segall and Matthews, 1997; Miyazaki, 2003]:

$$
\mathbf{X}_{i}(t)-\mathbf{X}_{i}\left(t_{0}\right)-\mathbf{V}_{i}\left(t-t_{0}\right)=\mathbf{G}_{i} \mathbf{s}(t)+\mathbf{L}_{\mathrm{i}}(t)+\mathrm{F} \mathbf{f}(t)+\varepsilon(t)
$$

where the left hand side represents the drainage-related surface motion of the GPS stations obtained by removing the station background velocity field V [Miyazaki, 2003]. V is determined for each station by calculating station velocity over the 2 days of data available prior to the start of the precursor. On the right hand side of Equation 3.1, G represents the matrix of elastic Green's functions [Okada, 1985], $\mathbf{s}(t)$ is a vector of slip (or opening) on each deformation plane subfault at time $t, \mathrm{~L}_{\mathrm{i}}(t)$ is component specific colored noise, $\mathrm{F} f(t)$ represents reference frame errors [Miyazaki, 2003] at time $t$, and $\varepsilon(t)$ represents normally distributed white noise observation error at time $t$. We model $\mathrm{L}(t)$ with a Brownian random walk model as has been done in previous studies of high-rate GPS data [Miyazaki et al., 2011]. This term is necessary to absorb colored noise in the time series due to unmodeled errors in the position estimates and possibly local benchmark instabilities. The random walk is described by a scale parameter $\tau$, which we estimated to be $5 \mathrm{~cm} \mathrm{day}^{-1 / 2}$ by modeling data prior to the start of the precursor as a combination of a background velocity and random walk $\left(5 \mathrm{~cm} \mathrm{day}^{-1 / 2}\right.$ was the smallest value that resulted in white residuals for such a model). We use three perpendicular translations for $\operatorname{Ff}(t)$ due to the small size of our network [Miyazaki, 2003]. The data vector in the Kalman filter is given by the GPS position data $\mathbf{X}_{i}(t)$ minus the background velocity $\left(\mathrm{D}_{i}(t)=\mathbf{X}_{i}(t)-\mathrm{X}_{\mathrm{i}}\left(t_{0}\right)-\mathbf{V}_{i}\left(t-t_{0}\right)\right)$. The data covariance matrix is assumed to be diagonal and derived from the individual component errors from the Track processing modified appropriately given the uncertainty in our estimate of $\mathbf{V}$ [Miyazaki, 2003]. 
The vertical plane for the hydro-fracture extends from 100 to $1100 \mathrm{~m}$ depth striking along the surface expression of the most substantial recurring hydro-fracture crack intersecting M1 on the western edge of the lake basin (Figure 3-5). The vertical plane does not start at the surface of the elastic half-space because the Green's Functions used in the NIF algorithm are for dislocations within the halfspace [Okada, 1985]. This approximation is sufficient because the vertical crack is located within the lake and our GPS stations are located $>1 \mathrm{~km}$ outside the lake basin and thus, are not sensitive to the shallowest $100 \mathrm{~m}$ of crack opening. On the vertical plane we solve only for mode-I tensile motion corresponding to opening of the crack [V an der Veen, 1998]. The vertical plane is subdivided into 24 subfaults along strike and 6 subfaults along dip; each vertical subfault is $0.19 \mathrm{~km}$ wide and 0.16 $\mathrm{km}$ tall.

The basal plane is defined as a $100-\mathrm{km}^{2}$ sub-horizontal plane at $1100 \mathrm{~m}$ depth, dipping $0.01^{\circ}$ to the west, and centered beneath the North Lake basin $(68.723 \mathrm{~N},-49.53 \mathrm{~W})$. The basal plane strikes 186 degrees from North, perpendicular to the direction of average ice velocity as determined from the average of all GPS stations' velocity in the days leading up to each year's drainage event. We estimate both mode-I tensile and dip-slip motion in the direction of ice flow on the basal plane. The basal plane is subdivided into 12 subfaults along dip and 12 subfaults along strike; each subfault is a $0.83 \times 0.83 \mathrm{~km}$ square. The shallow depth of the basal plane within the half-space results in Green's function magnitudes above 0.95 for the uplift response at GPS stations to basal plane opening. Therefore, we neglect the material property contrast at the ice sheet-bedrock interface in our model because it would only modify the Green's function magnitude by a few percent [Okada, 1985]. The geometry of our array, with a 10:1 ratio of horizontal distance across the GPS array to ice thickness, allows us to resolve slip and opening on the basal plane on the length scale of the station spacing (1$3 \mathrm{~km})$.

Our choice of a nearly horizontal basal plane is motivated by the presence of a relatively flat basin in the bedrock topography centered directly beneath North Lake [Joughin et al., 2013; Bamber et al., 2013], which yields a nearly horizontal basal slope across the entire GPS array. Moreover, sensitivity tests show that our NIF results are robust for basal plane dips up to $5^{\circ}$. This value is greater than the maximum bedrock slope $\left(3.4^{\circ}\right)$ measured from the bedrock basin center beneath North Lake to the bedrock ridge $5 \mathrm{~km}$ to the west of the lake basin [Joughin et al., 2013; Bamber et al., 2013]. Thus, we find 
no reason to add complexity associated with small variations in basal topography and/or to correct the GPS displacements for the vertical distance gained as the stations move up and out of the basin.

We used a Maximum likelihood estimation (MLE) algorithm to determine appropriate ranges of values for the spatial $(\boldsymbol{\gamma})$ and temporal $(\alpha)$ hyperparameters for both the vertical and basal planes [Segall and Matthews, 1997]. We determined the final hyperparameter values based on a combination of MLE estimates and analysis of NIF output to identify hyperparameter values low enough to provide significant model smoothing, but high enough to still track station displacements during the few hours of rapid drainage in the timeseries. The MLE estimates provide an average value that is appropriate over the entire time series, but therefore, oversmoothes the time periods of rapid deformation when higher values of and are warranted by the data. The MLE calculations of the vertical-plane temporal hyperparameter suggest values of $\alpha$ of 100 (2011), 200 (2012), and 1000 (2013); however, slightly higher or lower $\alpha$ values of 150 (2011), 250 (2012), and 500 (2013) were used based on NIF ability to track station displacements during the rapid drainage (Figure 3-12). The vertical-plane spatial smoothing parameter, $\gamma$, could not be constrained based on MLE calculations. The MLE calculations suggest a higher than necessary value of the spatial hyperparameter for the vertical crack, resulting in unrealistic vertical plane opening and closing on spatial scales of $<0.5 \mathrm{~km}$ along strike. Therefore, we set the vertical plane spatial parameter to $\gamma=450$ for the 2011 and 2012 inversions, resulting in vertical plane opening and closing on scales of $1 \mathrm{~km}$ along strike.

The basal plane spatial and temporal hyperparameters were also not satisfactorily constrained by MLE calculations for 2011 and 2012. The MLE calculations recommended higher than necessary spatial and temporal hyperparameters, resulting in unrealistic, over-fit solutions for the basal plane. The chosen basal plane temporal parameter $(\alpha=25)$ is substantially lower than the temporal parameter of the vertical plane, resulting in a smoother solution of bed opening and slip. The chosen basal plane spatial parameter $(\boldsymbol{\gamma}=50)$ resolves basal slip and opening on spatial scales of $2 \mathrm{~km}$, consistent with our 1 to $3 \mathrm{~km}$ GPS station spacing on the ice-sheet surface (Figure 3-1). For 2013, the rapid oscillatory variations in the crack-normal component of displacement (North) for several stations required a larger basal-plane spatial parameter $(\boldsymbol{\gamma}=500)$ in order to allow the migration of sufficiently compact slip patches required to fit the oscillations in the crack-normal data (Appendix 3.J). 


\section{D Basal Moment Calculations}

Basal slip moment $\mathrm{M}_{0}$, in $\mathrm{N} \cdot \mathrm{m}$, is calculated to provide an integrated measure of slip across the basal plane:

$$
\mathrm{M}_{0}=\mu \mathrm{AD}
$$

where $\mu$, the shear modulus for glacial ice, is taken to be $3.5 \mathrm{GPa}$ [Hobbs, 1974], A is the area of the basal plane in square meters, and $\mathrm{D}$ is the mean bed slip across the basal plane just after drainage in meters (Table 3-1). Moment magnitude $\left(\mathrm{M}_{\mathrm{w}}\right)$ is calculated from the basal slip moment [Kanamori, 1983]: $\mathrm{M}_{\mathrm{w}}=(2 / 3) \log \left(\mathrm{M}_{0}\right)-6.05$ (Table 3-1).

\section{E Critical Volume for Driving Water-filled Hydro-fracture to Bed.}

The critical volume of water necessary to keep a $4 \mathrm{~km}$ long crack open to the bed ranges from to 0.0008 to $0.0020 \mathrm{~km}^{3}$. This estimate is derived based on a mean crack opening of $0.2-0.5 \mathrm{~m}$ required to drive a $4 \mathrm{~km}$ long, 100\% water-filled vertical crack through $1 \mathrm{~km}$ of glacial ice with a shear modulus of 1.5-3.9 GPa [Krawcaynski et al., 2009].

\section{F North Lake Basin Stresses}

To calculate background viscous stresses in North Lake basin, we use Glen's flow law [Glen, 1955] to convert longitudinal (along flow) surface strain rates derived from TerraSAR-X 2009-2011 winter velocity measurements ${ }^{5}$ to longitudinal stresses, $\sigma_{j k}$ :

$$
\sigma_{j k}=A^{-[1 / n]} \stackrel{\circ}{\varepsilon}_{\mathrm{E}}^{[1-n] / n} \stackrel{\circ}{\varepsilon}_{j k}
$$

where the creep parameter, $A$, is $3.5 \times 10^{-25} \mathrm{~s}^{-1} \mathrm{~Pa}^{-3}{ }^{44}, n=3$ is the creep exponent, $\stackrel{\circ}{\mathrm{E}}_{\mathrm{E}}$ is the twodimensional effective strain rate, and $\check{\varepsilon}_{j k}$ is longitudinal strain rate. We use the same Green's functions from the $\mathrm{NIF}^{37}$ to calculate the change in crack-normal stress $\left(\Delta \sigma_{\mathrm{n}}\right)$ on the hydro-fracture that was induced by the basal cavity opening and accumulated extra basal slip during the two days leading up to each drainage event.

\section{G Precursors Observed in Previous Studies}

While our study is the first to interpret the cause and significance of precursors to rapid lake drainage, similar precursors have been observed prior to other recorded rapid supraglacial lake drainages on the western margin of the Greenland Ice Sheet in the form of GPS station uplift and steady lake level 
lowering in the hours before hydro-fracture [Das et al., 2008; Doyle et al., 2013]. During a rapid North Lake drainage in 2006, NLBS GPS station uplift and steady lake level lowering was observed prior to rapid lake level drop and northward ice motion indicative of hydro-fracture opening [Das et al., 2008]. Slow lake level lowering was also observed before a 2008 rapid drainage of South Lake (68.58 N, 49.39 W), another lake site in this region located $20 \mathrm{~km}$ south of North Lake [Joughin et al., 2013]. During the rapid drainage of Lake F (67.01 N, 48.74 W) in 2010, uplift of two GPS stations on the eastern side of the lake is observed over the 7 hours leading up to rapid drainage [Doyle et al., 2013]. Precursory motion was not observed during the rapid drainage of Lake Ponting in 2011 (69.57 N, 49.81 W); however, the four GPS stations used to record ice motion may have been located too far from the lake to record precursory motion [Tedesco et al., 2013]. The three rapid drainage precursors observed during 2011-2013 at North Lake allow us to reinterpret precursors of past rapid lake drainages as evidence of a hydrologically-induced trigger for hydro-fracture. Further, our results provide a possible mechanism by which a lake drainage could generate a melt-water pulse that could trigger additional lake drainages in the vicinity. Such regionally clustered lake drainages have been noted in previous lake drainage studies [Doyle et al., 2013; Fitapatrick et al., 2014].

\section{H Implications for Inland Expansion of Seasonal Acceleration}

The formation and drainage of high elevation lakes his been invoked to explain the inland expansion of seasonal acceleration (enhanced summer velocities up to $8 \%$ above winter velocities) during high melt summers now [Doyle et al., 2014] and in the future [Leeson et al., 2015]. The precursors observed here suggest enhanced melt-water transport to the bed beneath lakes is needed to generate tensile stress transients that promote the initiation of surface-to-bed hydro-fractures. For this proposed hydro-fracture initiation mechanism, there must exist both a sufficient reservoir of surface melt-water and a nearby surface-to-bed pathway to transport the melt-water to the bed beneath the lake. Our results inform our hypothesis that rapid lake drainages are unlikely to progress inland to areas of new surface melting based on the overall decline in tensile strain rates towards the ice sheet interior, which results in increasingly rare crevasses with elevation [Poinar et al., 2015]. Thus, much of the new surface melt in the interior likely drains via long $(10$ s of $\mathrm{km}$ ) supraglacial streams that eventually terminate in moulins in regions where surface melt-water already reaches the bed at present [Poinar et al., 2015]. While surface melt may continue to expand inland, much of this melt-water will only reach the bed in areas further downstream where seasonal lubrication already occurs [Bartholomew et al., 2011; Hoffman et al., 2011; Poinar et al., 2015]. An alternative explanation for the observed seasonal acceleration is 
longitudinal coupling of these higher elevations (above $\sim 1600 \mathrm{~m}$ a.s.l.) to lower elevation regions (below $\sim 1600 \mathrm{~m}$ a.s.l.) that are responding to increased melt input [Kamb and Echelmeyer, 1986; Hindmarsh, 2006; Price et al., 2008].

\section{I 2012 North Lake Drainage.}

In 2012, North Lake drained rapidly over a period of $\sim 5$ hours beginning at 22:12 local time on June 9, 2012 (DOY 161). Due to the lack of satellite images bracketing the North Lake drainage window, the maximum volume of North Lake in 2012 is unknown prior to drainage. Using RACMO runoff estimates, we conclude that the 2012 North Lake volume was similar to the 2011 volume based on a difference of $+0.00012 \mathrm{~kg} / \mathrm{m}^{2}$ of cumulative runoff between the two years (Appendix 3.B).

Regional basal slip prior to the 2012 North Lake hydro-fracture initiation indicates the presence of increased basal melt-water at the ice-sheet bed prior to North Lake hydro-fracture. Over the 16 hours leading up to North Lake hydro-fracture initiation, stations NL01 and NL02 experience an additional $5 \mathrm{~cm}$ of flowline-parallel displacement (Figures 3-2 b, 3-8 a). At the end of the precursor, slip in the northern portion of the array results in a basal moment $\left(\mathrm{M}_{0}\right)$ of $10^{7} \mathrm{~N}$ m (Figures 3-2 e, 38 a), though there is minimal basal cavity opening throughout the array (Figure 3-8 b). Over the following 3.5 hours, the hydro-fracture opens beneath the North Lake basin, reaching its maximum width 2.5 hours after hydro-fracture initiation. As in the 2011 North Lake rapid drainage, basal cavity opening is centered beneath and to the south of the North Lake basin during the 2012 drainage (Figure 3-8 e). During lake drainage, basal slip beneath and to the southwest of the North Lake basin occurs, while the basal slip initially accumulated to the north during the precursor (Figure 3-8 a) remains and expands south (Figure 3-8 d).

\section{J 2013 North Lake Drainage}

In 2013, GPS station attrition in the eastern half of the array precludes various array-scale NIF conclusions; however, precursory activity in the western half of the array is well resolved (Figure 3-9). In 2013, North Lake and a small lake (Small Lake, Figure 3-9) $2 \mathrm{~km}$ to the southwest of North Lake may have drained concurrently or in sequence. Positive crack-normal (approximately northward) motion during the North Lake hydro-fracture was observed at the three GPS stations located between Small Lake and North Lake (NL08, NL07, NL10). This can be seen in the positive crack-normal 
excursion of $0.1 \mathrm{~m}$ at station NL08, 0.25 days after the 2013 maximum North Lake hydro-fracture crack opening (Figure 3-2 c).

Available imagery does not capture the precise timings of the lakes' drainages. The last WorldView image obtained on 6/17/2013 (2 days before the 2013 North Lake drainage) shows a filled North Lake and Small Lake. The volume of North Lake (Small Lake) was at least $0.0036 \pm$ $0.001 \mathrm{~km}^{3}\left(0.0021 \pm 0.001 \mathrm{~km}^{3}\right)$ at the time of drainage based on the shoreline positions obtained two days prior to the North Lake drainage event (Figures 3-6 d, 3-7 b). The first post-drainage WorldView image available on 7/5/2013 (16 days after North Lake drainage, Figure 3-6 e) shows an empty North Lake and Small Lake, with a bright, linear crack running through the South Lake basin that could be the 2013 Small Lake hydro-fracture. July 2014 field surveys confirmed the existence and East-West strike of the Small Lake hydro-fracture.

In an attempt to distinguish 2013 North Lake and Small Lake hydro-fracture events, a NIF including an additional source of displacement as a vertical plane with tensile opening along the South Lake hydro-fracture crack trace was developed and run with the 2013 GPS data. The NIF with the additional Small Lake hydro-fracture ("four-source") did not accurately capture opening and closing along the Small Lake hydro-fracture. While including the Small Lake hydro-fracture more completely fits NL07, NL08, and NL10 station motion during the 1.5 hours following the North Lake rapid drainage, the NIF results for the Small Lake hydro-fracture exhibit unrealistic behavior by continuing to widen throughout the day after North Lake drainage. We attribute this result to the nonuniquness inherent in the inversion due to the lack of stations between North and Small Lake. Because the NIF results including the Small Lake source produce a physically unlikely result (a crack that continues widening after drainage) we favor the alternate solution which fits the data equally well—namely no Small Lake hydro-fracture and a rougher distribution of basal slip/opening $(\boldsymbol{\gamma}=500)$ that accounts for the crack-normal component oscillations at NL07 and NL08 via the spatial propagation of the basal slip patch (Figure 3-2 c).

For a NIF that does not include the additional Small Lake vertical plane ("three-source"), individual station motion can be mapped onto the three original deformation sources (vertical opening, basal cavity opening, and basal slip) with a highly spatially resolved basal plane $(\boldsymbol{\gamma}=500)$ and associated highly temporally resolved vertical plane $(\alpha=500)$. The three-source 2013 NIF yields 
realistic opening and closing North Lake hydro-fracture behavior. We present the three-source 2013 NIF results here, since we cannot sufficiently distinguish between the North and Small Lake drainages from the available station spatial density.

Independent of the NIF setup ( 3 or 4 sources of displacement), precursory activity in the western half of the array is well resolved in the GPS data. North Lake drained rapidly over a period of $\sim 5$ hours beginning at 15:00 local time on June 19, 2013 (DOY 170) (Figures 3-2 c, f). From analysis of WorldView imagery, the 2013 west North Lake shoreline had not reached M1 two days before the drainage event (Figure 3-3 b), though, in the absence of a snow-dam, water could have reached the moulin via a deeply incised surface melt-water channel (Figure 3-2 d). During the 16 hours leading up to hydro-fracture initiation, flowline parallel speed up of western stations (Figure 32 c) generates considerable $\mathrm{M}_{0}$ (Figure 3-2 $\mathrm{f}$ ), and is coincident with a basal cavity opening of $\sim 0.002$ $\mathrm{km}^{3}$ beneath the North Lake and Small Lake basins (Figures 3-2 f, 3-9 a-c). Inversion results suggest that hydro-fracture opening begins in the region of M1; however, opening along the eastern portion of the vertical plane is not well constrained due to a lack of GPS stations to the immediate northeast of North Lake basin (e.g. NL05, NL06, and NLBS). As in previous years, during the North Lake rapid drainage basal cavity opening occurs beneath the lake basin, while extra basal slip extends further afield (Figure 3-9 d-f). A ground survey of North Lake basin a month after the 2013 NL drainage identified post-drainage supraglacial melt-water routing through M2 (Figure 3-5). 
Table 3-1. 2011, 2012, and 2013 North Lake Drainage Environmental, GPS, and Network Inversion Filter observations. Time of start of precursor, start of hydro-fracture crack opening, and maximum hydro-fracture crack opening equivalent to time delineations in Fig. 2.

\begin{tabular}{|c|c|c|c|}
\hline Environmental & 2011 & 2012 & 2013 \\
\hline Day of Year & $\begin{array}{c}\text { June 18, } 2011 \text { (DOY } \\
169)\end{array}$ & $\begin{array}{l}\text { June 9, } 2012 \\
\text { (DOY 161) }\end{array}$ & $\begin{array}{c}\text { June 19, } 2013 \\
\text { (DOY 170) }\end{array}$ \\
\hline $\begin{array}{l}\text { Start of Precursor (decimal } \\
\text { DOY GMT }+0 \text { ) }\end{array}$ & 168.85 & 161.20 & 169.90 \\
\hline Hydro-fracture Initiation & 169.21 & 161.72 & 170.45 \\
\hline $\begin{array}{l}\text { Maximum Hydro-fracture } \\
\text { Opening }\end{array}$ & 169.32 & 161.85 & 170.55 \\
\hline Drainage Duration* & $\sim 3$ hours & $\sim 5$ hours & $\sim 5$ hours \\
\hline Lake Volume (DEM) $\left(\mathrm{km}^{3}\right)$ & $0.0077 \pm 0.001$ & approx. same as 2011 & $\begin{array}{c}0.0036 \pm 0.001 \\
\text { Small Lake: } 0.0021 \pm \\
0.001\end{array}$ \\
\hline $\begin{array}{l}\text { Lake Shoreline Location at } \\
\text { Drainage }\end{array}$ & Meets M1 & approx. same as 2011 & $\begin{array}{l}\text { May fill channel } \\
\text { trough to M1 }\end{array}$ \\
\hline \multicolumn{4}{|l|}{ GPS } \\
\hline $\begin{array}{l}\text { Background velocity magnitude } \\
\text { average across all stations } \\
\text { (m/year) }\end{array}$ & $162 \mathrm{~m} /$ year & $125 \mathrm{~m} /$ year & $94 \mathrm{~m} /$ year \\
\hline $\begin{array}{l}\text { Background velocity direction } \\
\text { average across all stations (deg) }\end{array}$ & $276^{\circ}$ & $277^{\circ}$ & $277^{\circ}$ \\
\hline Precursor type & $\begin{array}{l}\text { Uplift in lake basin, } \\
\text { followed by speed up } \\
\text { in lake basin }\end{array}$ & $\begin{array}{l}\text { Speed up NL01 and } \\
\text { NL02 stations; minor } \\
\text { uplift in basin }\end{array}$ & $\begin{array}{c}\text { Speed up of western } \\
\text { stations (FL03, } \\
\text { NL04, NL07, NL08, } \\
\text { NL10); uplift in } \\
\text { basin }\end{array}$ \\
\hline $\begin{array}{l}\text { Duration of Precursor before } \\
\text { Drainage starts (hours) }\end{array}$ & 10 (uplift); 5 (speed up) & $\begin{array}{l}16 \text { (N speed up); } 24 \\
\text { (minor uplift in basin) }\end{array}$ & $\begin{array}{l}16 \text { (possibly as early } \\
\text { as } 24 \text { hours before) }\end{array}$ \\
\hline \multicolumn{4}{|l|}{ Network Inversion Filter } \\
\hline $\begin{array}{l}\text { Vertical Crack Initiation } \\
\text { Location }\end{array}$ & M1 & Center of lake basin & M1 \\
\hline $\begin{array}{l}\text { Vertical Crack Propagation } \\
\text { History }\end{array}$ & $\begin{array}{c}\text { Propagates from M1 to } \\
\text { Lake Basin }\end{array}$ & $\begin{array}{l}\text { Stays in center of lake } \\
\text { basin }\end{array}$ & $\begin{array}{l}\text { Stays at M1 (east } \\
\text { unresolved) }\end{array}$ \\
\hline $\begin{array}{l}\text { Max. Vertical Crack Opening } \\
\text { Width (m) }\end{array}$ & 0.16 & 0.36 & 0.40 \\
\hline Max. Vertical Crack Volume $\left(\mathrm{km}^{3}\right.$ & $2.9 \times 10^{-4}$ & $7.3 \times 10^{-4}$ & $4.9 \times 10^{-4}$ \\
\hline $\begin{array}{l}\text { Max. Basal Cavity Opening } \\
\text { Location }\end{array}$ & Lake Basin & Lake Basin & Lake Basin \\
\hline Max. Basal Cavity Volume $\left(\mathrm{km}^{3}\right)$ & 0.0095 & 0.0067 & 0.012 \\
\hline Max. Extra Basal Slip Locations & $\begin{array}{c}\text { Lake Basin, SW of } \\
\text { Lake Basin }\end{array}$ & $\begin{array}{c}\text { Lake Basin, SW \& NW } \\
\text { of Lake Basin }\end{array}$ & $\begin{array}{l}\text { Lake Basin and } \\
\text { Western Stations }\end{array}$ \\
\hline $\begin{array}{l}\text { Average extra basal slip across } \\
\text { basal plane just after drainage } \\
(\mathrm{m})\end{array}$ & 0.13 (DOY 169.5) & 0.15 (DOY 162.0) & 0.31 (DOY 170.7) \\
\hline $\begin{array}{l}\mathrm{M}_{0} \text { (basal moment) }\left(\mathrm{N}^{*} \mathrm{~m}\right) \text { just } \\
\text { after drainage }\end{array}$ & $4.6 \times 10^{16}$ & $5.3 \times 10^{16}$ & $1.1 \times 10^{17}$ \\
\hline $\begin{array}{l}\mathrm{M}_{\mathrm{W}} \text { (moment magnitude) just } \\
\text { after drainage }\end{array}$ & 5.1 & 5.1 & 5.3 \\
\hline
\end{tabular}

*Drainage duration calculated as duration of southward anomaly in the NL08 crack-normal timeseries (see Appendix 3.A: GPS Data). 


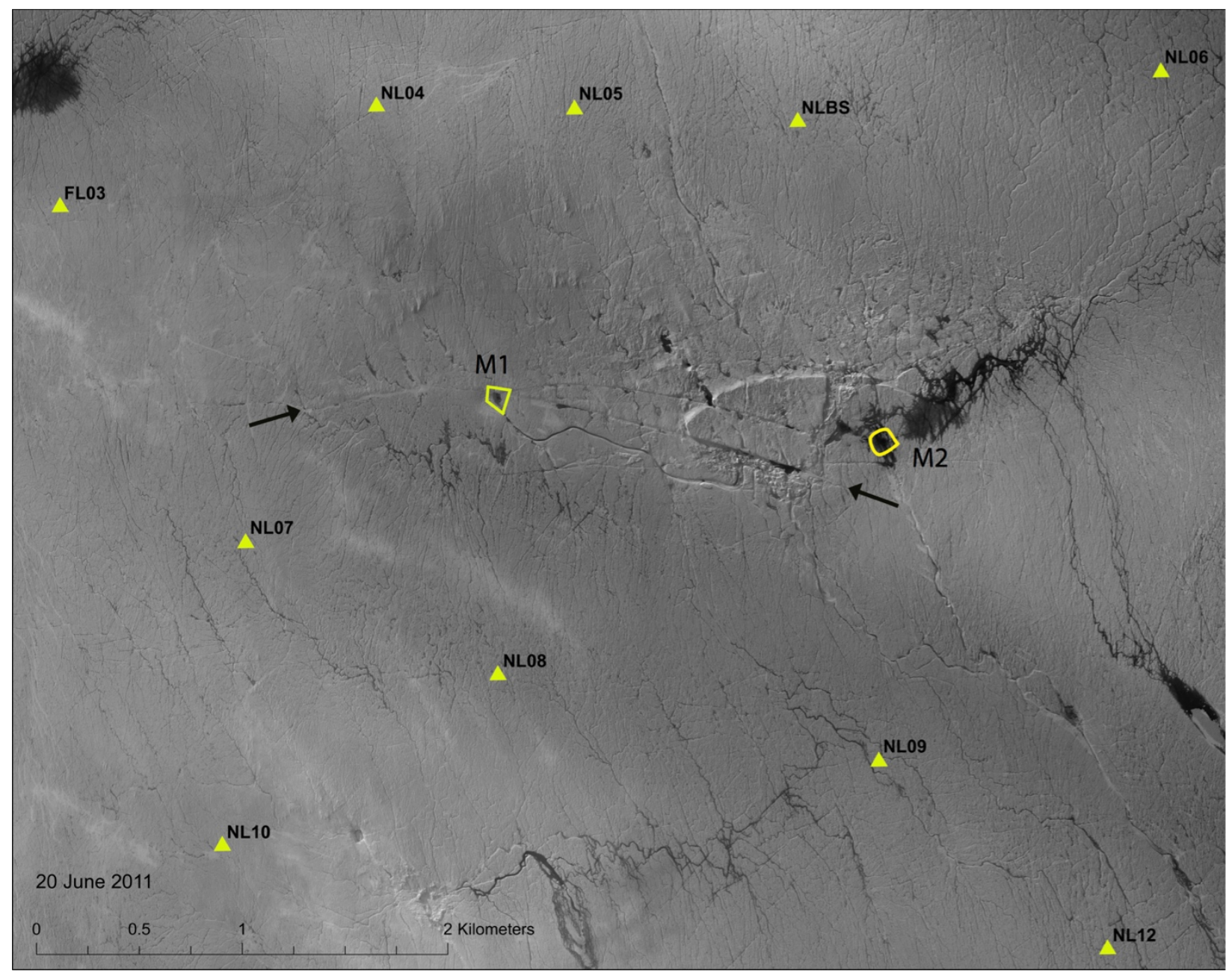

Figure 3-5. July 21, 2011 WorldView image of an empty North Lake basin after the 2011 rapid drainage event. Yellow outline shows M1 and M2 location along the hydro-fracture trace (endpoints marked by black arrows). Yellow triangles mark GPS stations within the map area. Image (C) 2011 DigitalGlobe, Inc. 


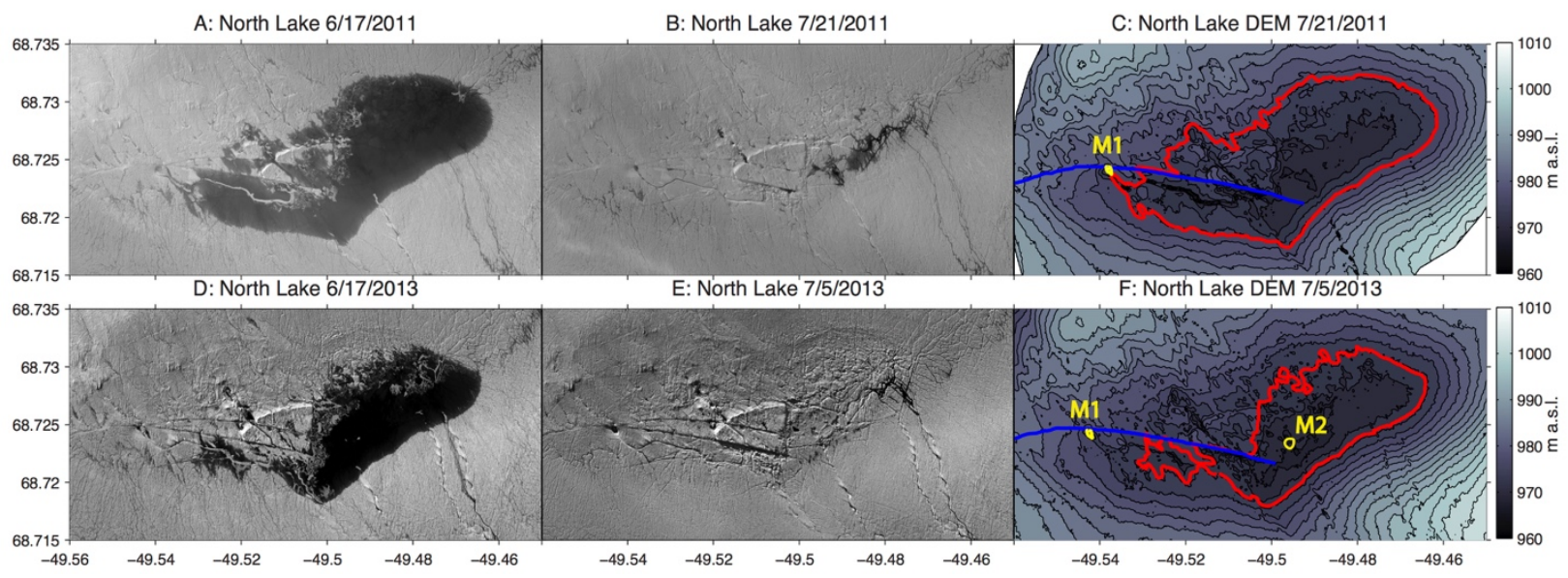

Figure 3-6. Images and Digital Elevation Model (DEM) of 2011 and 2013 North Lake basin. Panel a (d) shows the WorldView image chosen to map the 2011 (2013) North Lake pre-drainage shoreline position. Panel b (e) shows the WorldView image of an empty North Lake basin obtained July 21, 2011 (July 5, 2013) used to create the 2011 (2013) North Lake DEM. Panel c (f) shows the 2meter horizontal resolution DEM (2-m vertical contours in black) for the North Lake region, with the North Lake shoreline (red), M1 (yellow), and hydro-fracture trace (blue) mapped over contours. Images (C) 2011 and 2013 DigitalGlobe, Inc. 
a

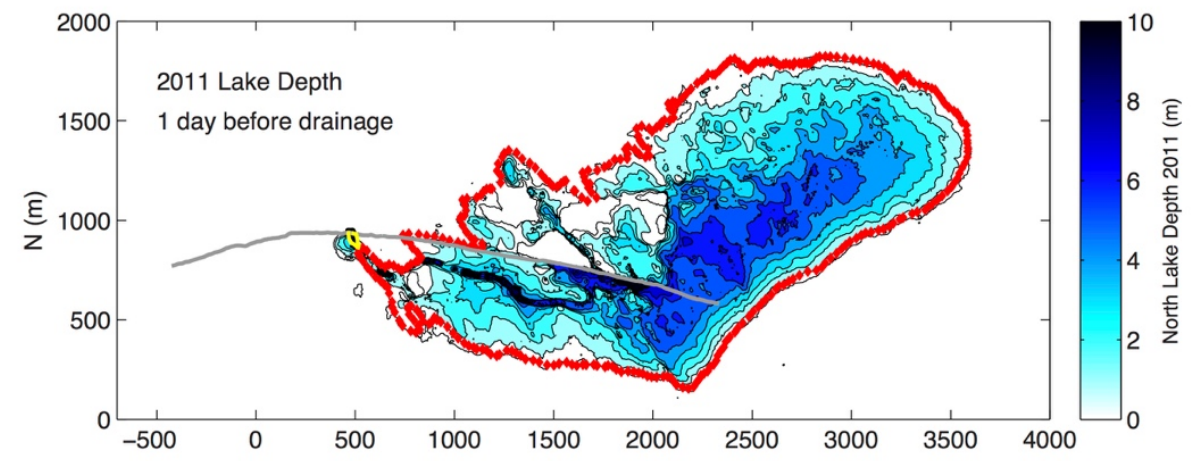

b

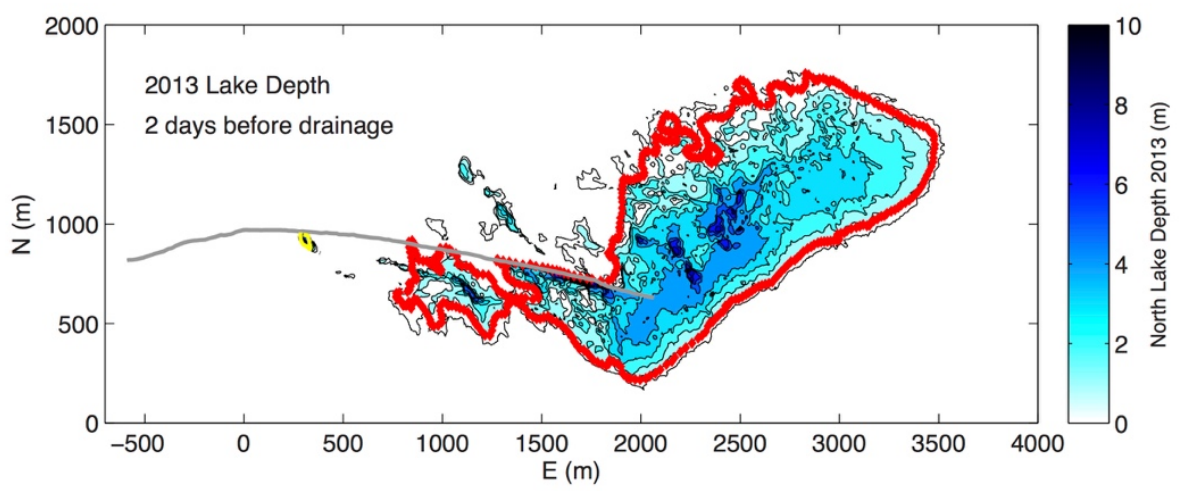

Figure 3-7. 2011 and 2013 North Lake Depths. 2-m resolution Digital Elevation Models (DEM) were created from the first available post-drainage WorldView stereo pair obtained of the region in (a) 2011 and (b) 2013. Shoreline positions from 2011 and 2013 derived from last pre-drainage WorldView or TerraSAR-X images obtained over the region are shown in red. The last pre-drainage WorldView image for 2011 occurs 2 days prior to the drainage event on June 17, 2011; the last predrainage SAR image for 2013 occurs 1 day before the event on June 17, 2013. Filling the empty basin DEM up to the greatest known pre-drainage shoreline extent generates North Lake depths (1-m vertical contours in black) are generated in relation to the greatest known pre-drainage shoreline extents and are used to calculate minimum 2011 and 2013 North Lake pre-drainage volumes. The trace of the vertical hydro-fracture crack is shown in grey; M1 is outlined in yellow. 

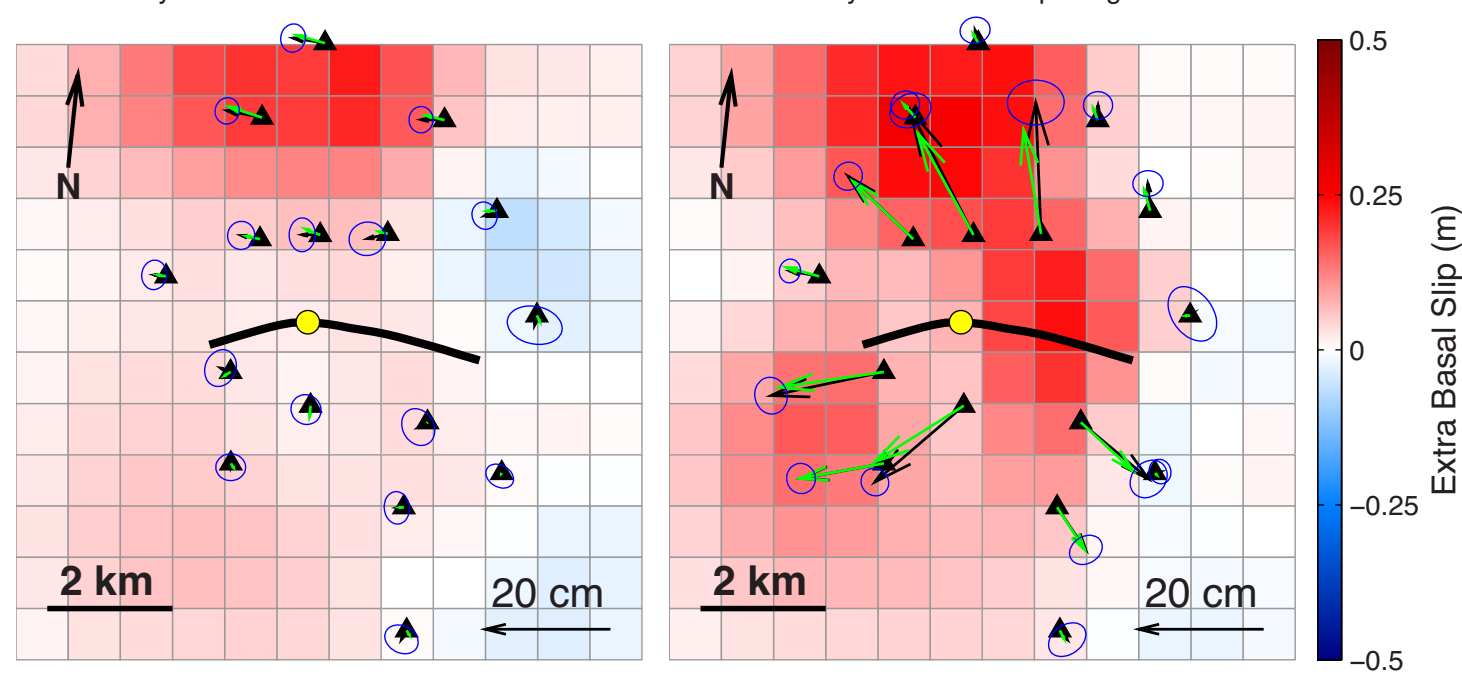

b

e
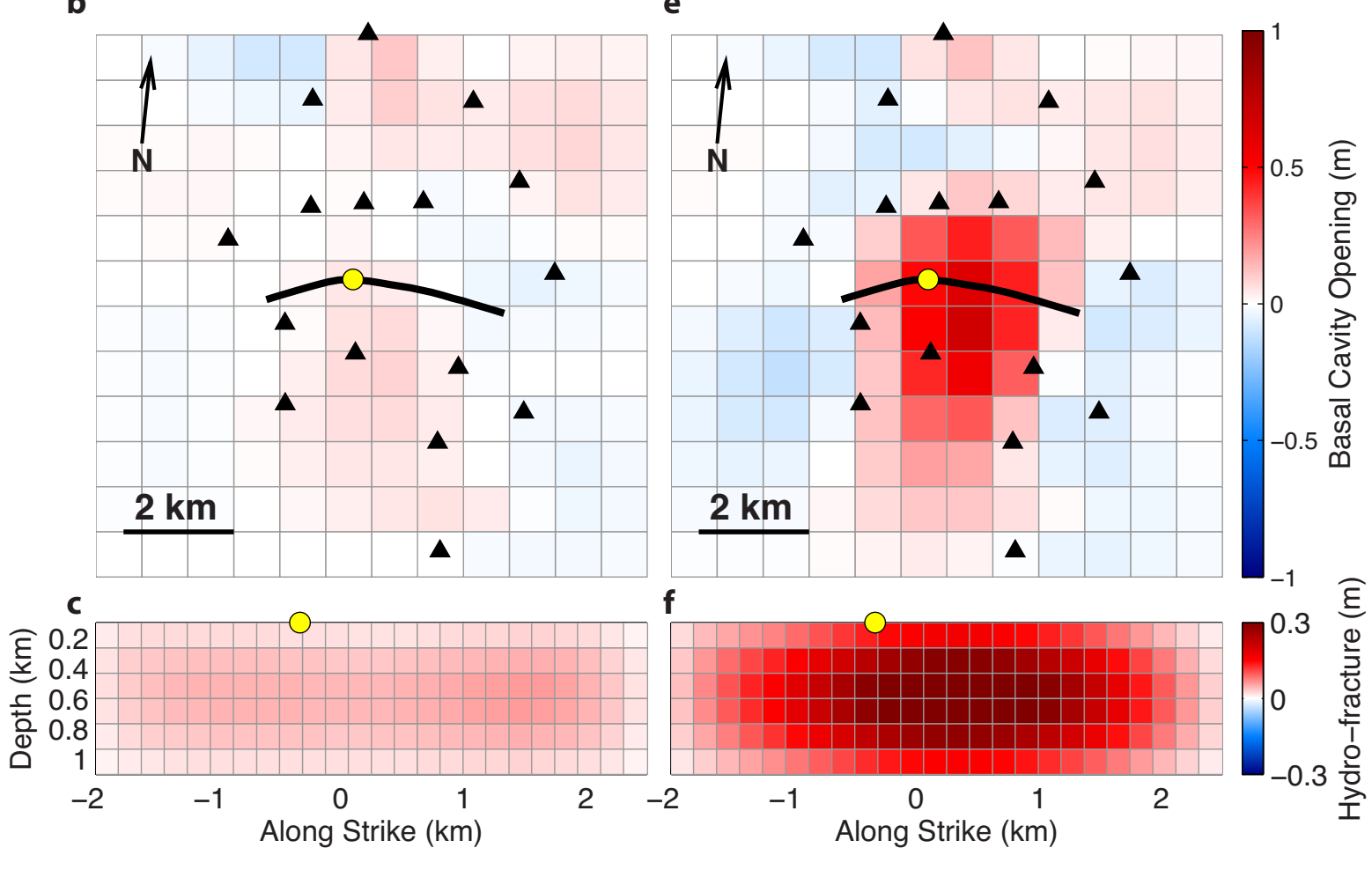

Figure 3-8. 2012 Basal slip and cavity opening at hydro-fracture initiation and maximum hydro-fracture opening. NIF-calculated (a) extra basal slip accumulated, (b) basal cavity opening, and (c) hydro-fracture crack opening at the time of the $2012(\mathrm{a}-\mathrm{c})$ hydro-fracture initiation and $(\mathrm{d}-\mathrm{f})$ maximum hydro-fracture opening (time points shown in Figure 3-2 a). Moulin location, last known lake shoreline, GPS stations, and NIF vertical crack surface trace derived from SAR imagery are shown as a yellow circle, blue line, black triangles, and black line, respectively. Vector fields show GPS (NIF) displacement less background velocities in black (green) for (a) the period between the start of the precursor and hydro-fracture initiation, and (d) the period between hydro-fracture initiation and maximum hydro-fracture opening. Error ellipses of 1 sigma are shown for the GPS displacements (blue ellipses). Basal subelements are $0.83 \mathrm{~km}$ by $0.83 \mathrm{~km}$, resulting in 144 subelements over a $10 \mathrm{~km}$ by $10 \mathrm{~km}$ region. 
a

2013 Hydro-fracture Initiation DOY 170.45

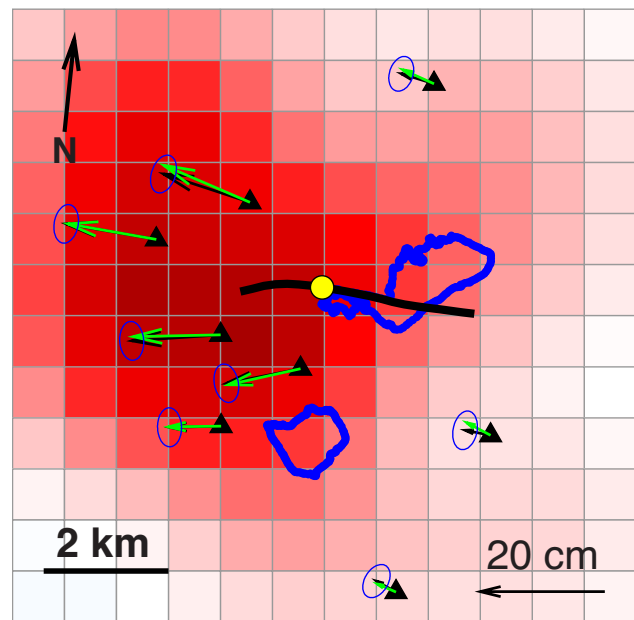

b
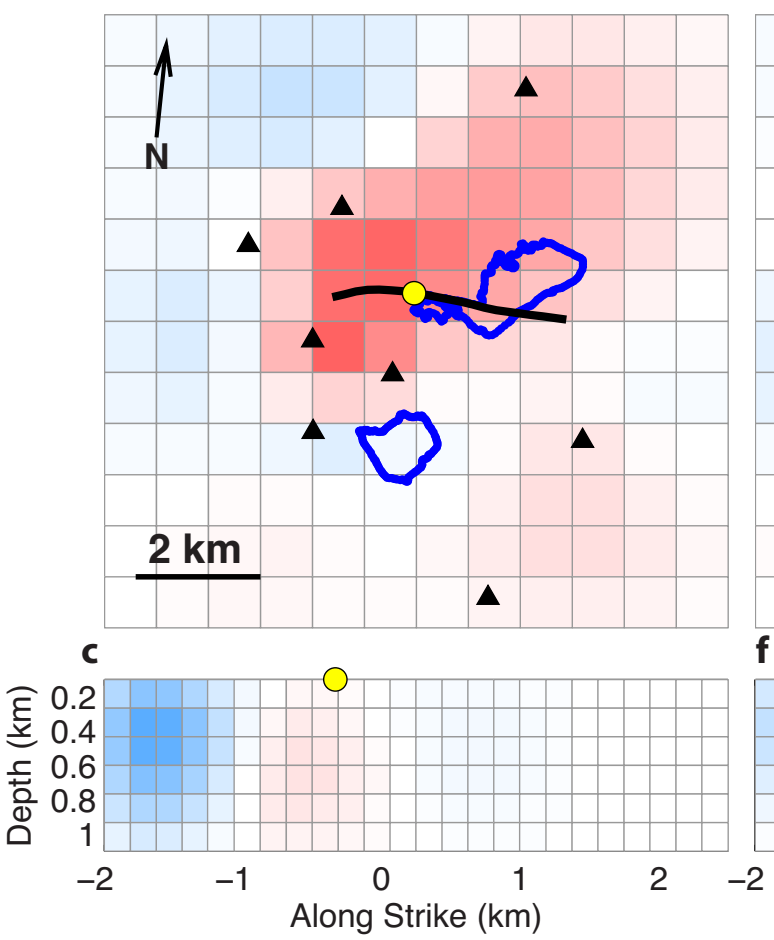

Figure 3-9. 2013 Basal slip and cavity opening at hydro-fracture initiation and maximum hydro-fracture opening. NIF-calculated (a) extra basal slip accumulated, (b) basal cavity opening, and (c) hydro-fracture crack opening at the time of the $2013(\mathrm{a}-\mathrm{c})$ hydro-fracture initiation and (d-f) maximum hydro-fracture opening (time points shown in Figure 3-2 a). Moulin location, last known lake shoreline, GPS stations, and NIF vertical crack surface trace derived from SAR imagery are shown as a yellow circle, blue line, black triangles, and black line, respectively. Vector fields show GPS (NIF) displacement less background velocities in black (green) for (a) the period between the start of the precursor and hydro-fracture initiation, and (d) the period between hydro-fracture initiation and maximum hydro-fracture opening. Error ellipses of 1 sigma are shown for the GPS displacements (blue ellipses). Basal subelements are $0.83 \mathrm{~km}$ by $0.83 \mathrm{~km}$, resulting in 144 subelements over a $10 \mathrm{~km}$ by $10 \mathrm{~km}$ region. 


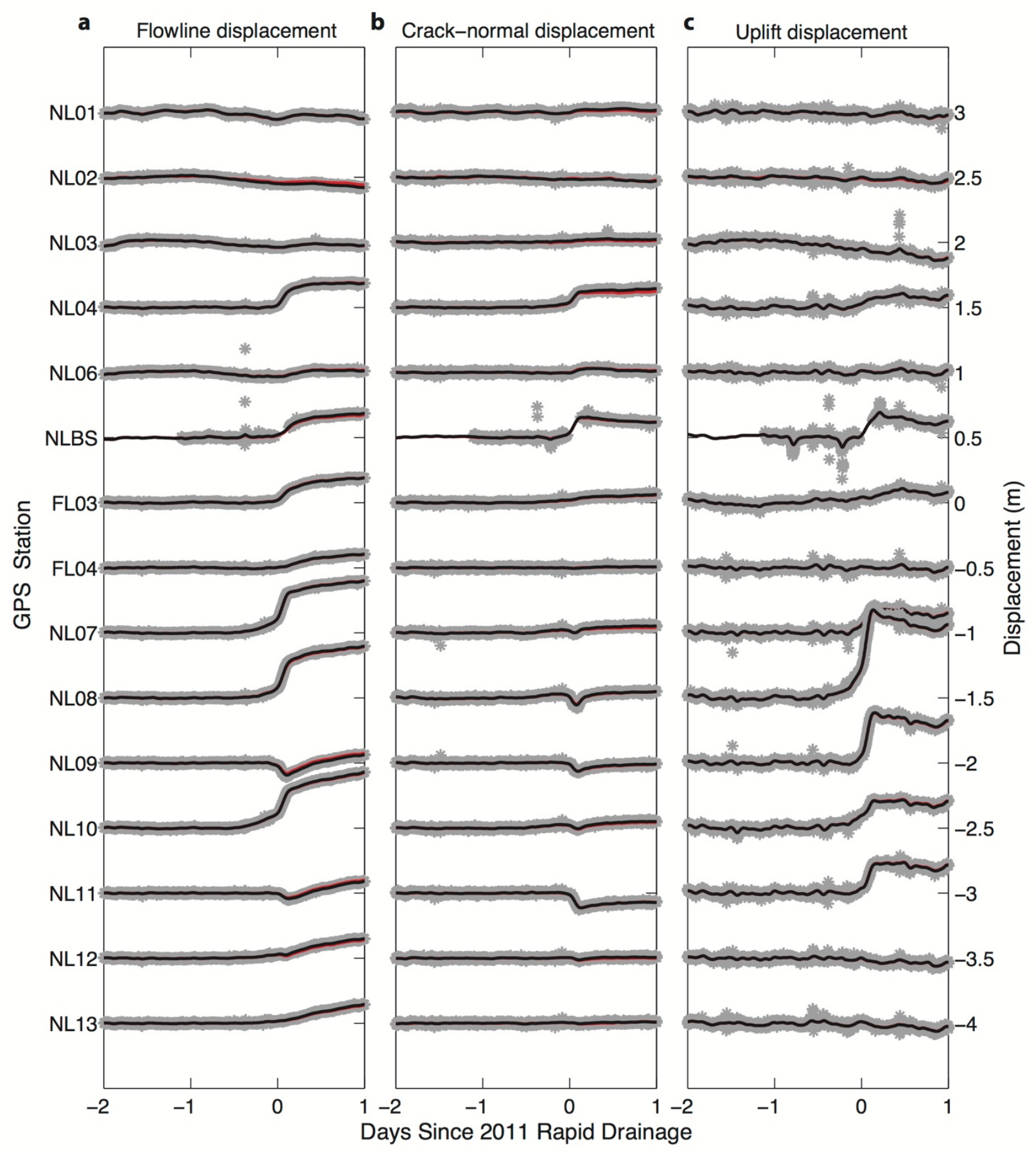

Figure 3-10. 2011 Station Timeseries. (a) Flowline, (b) crack-normal, and (c) uplift GPS displacements (meters) (grey stars) for stations used in the 2011 NIF. NIF station fits from the three displacement sources (Figure 3-11) shown in red, and NIF station fits including $\mathrm{L}(\mathrm{t})$ (random benchmark wobble term) are shown in black. Stations are ordered roughly north to south on the yaxis, offset by 0.5 meters. 
a

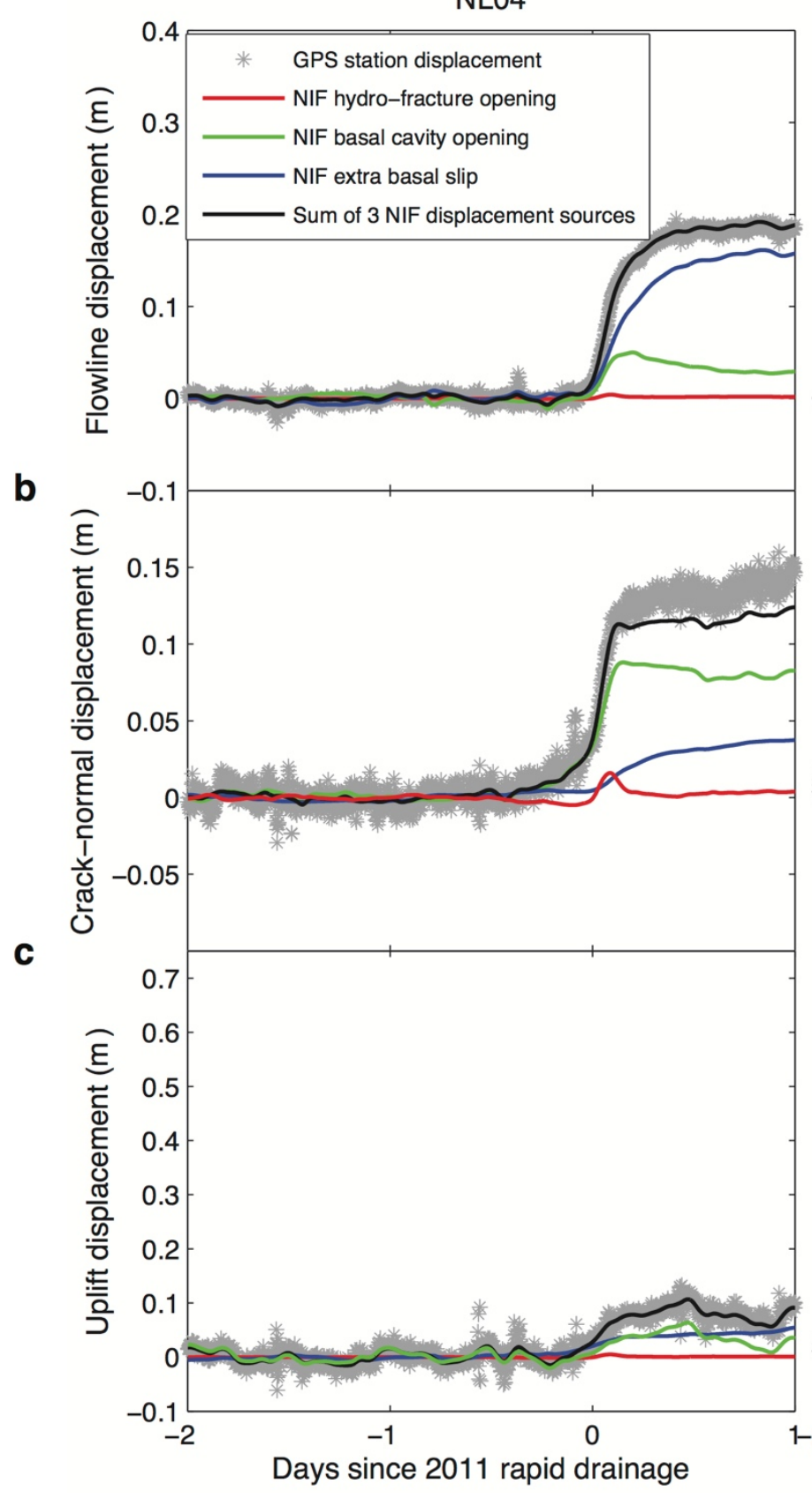

C

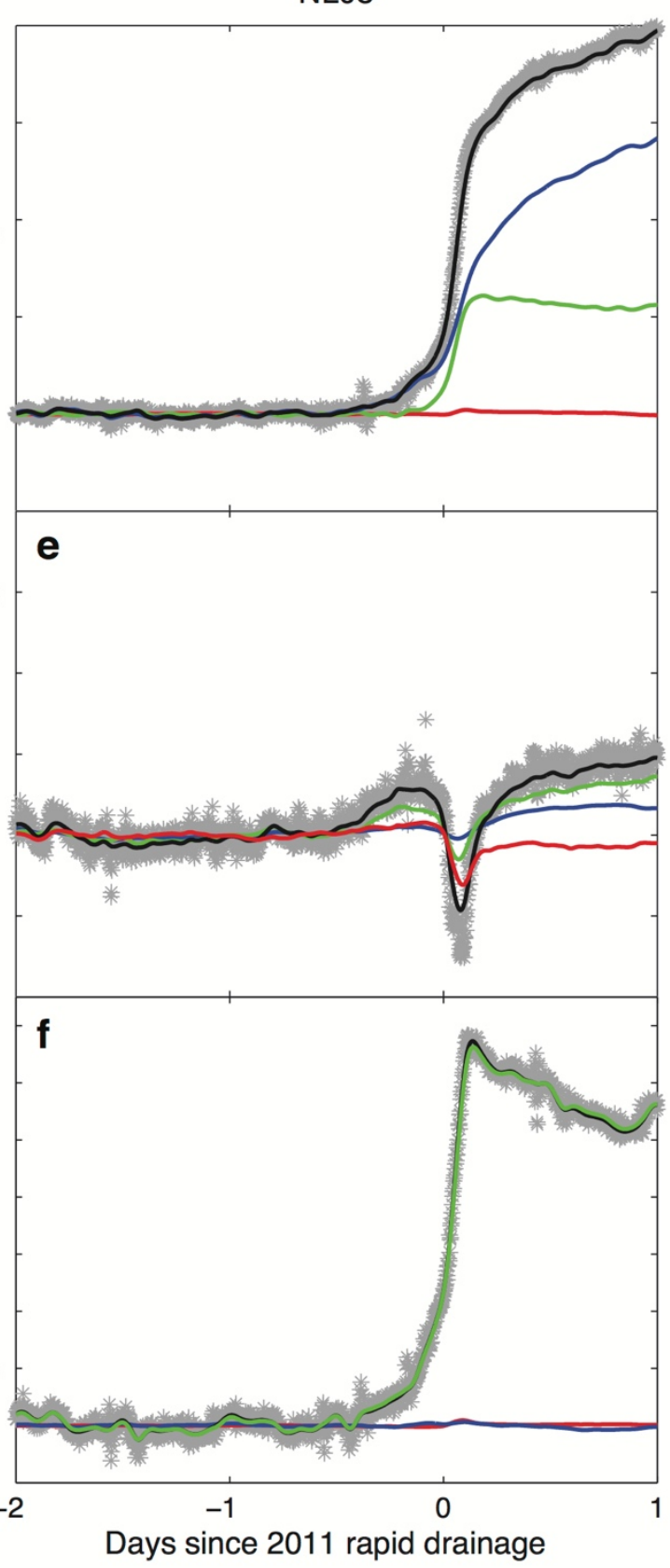

Figure 3-11. 2011 NL08 and NL04 Station flowline, crack-normal, and uplift displacements computed from NIF displacement sources. Flowline, crack-normal, and uplift GPS displacements less background velocity field (grey stars) are plotted the for (a-c) NL04 and (d-f) NL08 over the two days before and one day following the 2011 rapid NL drainage. These stations are two examples chosen from the full array because they capture displacement on both the northern (NL04) and southern (NL08) side of the lake, are located at roughly the same longitude as M1, and are within 2 $\mathrm{km}$ of the lake. NIF calculated surface ice displacements at NL04 and NL08 stations from the three displacement sources are plotted for the (red) hydro-fracture crack opening, (green) basal cavity opening, and (blue) extra basal slip. The sum of all three NIF displacement sources is shown in black. 

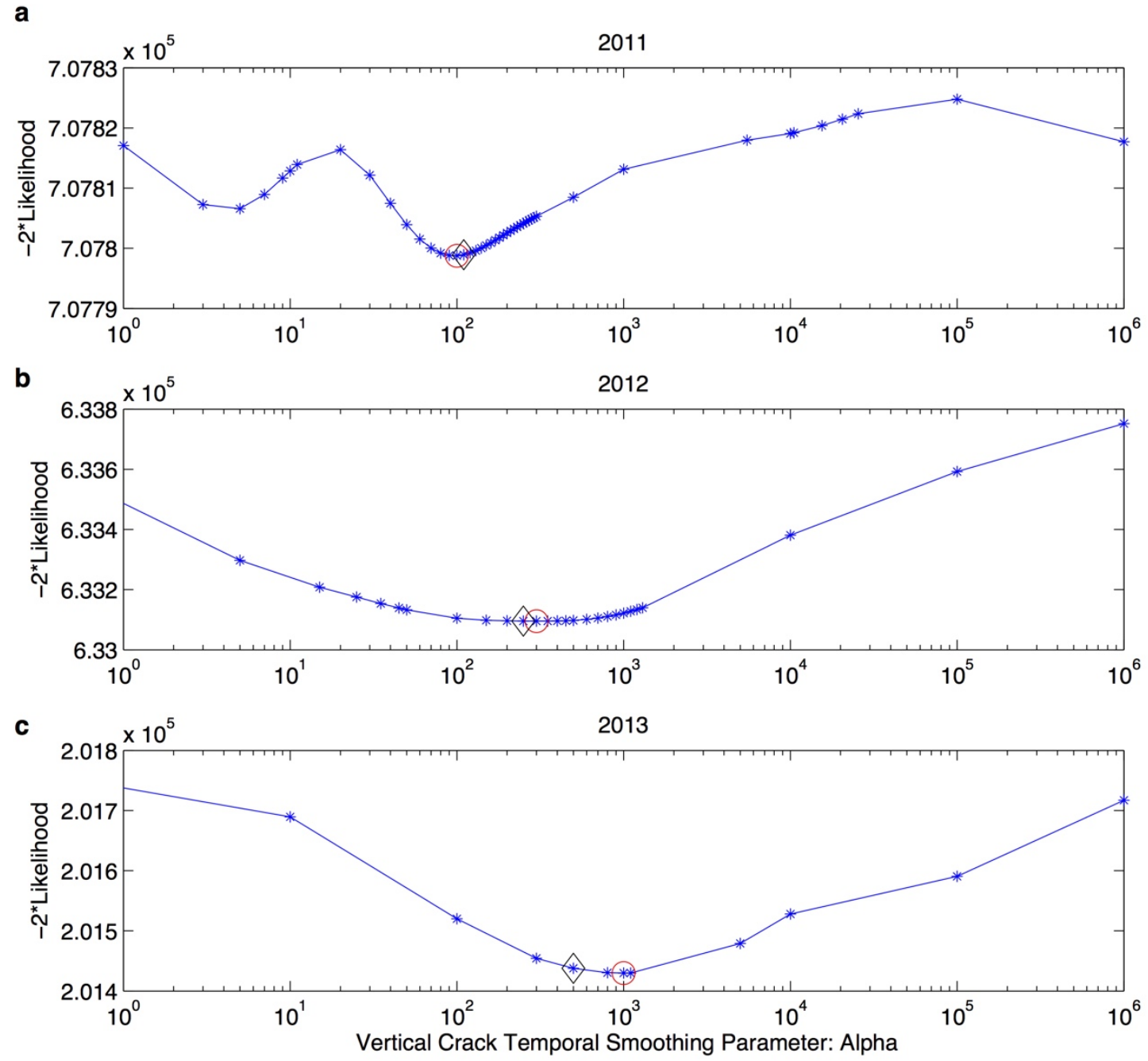

Figure 3-12. Maximum Likelihood Estimation of NIF hyperparameters. Maximum likelihood estimation of the vertical hydro-fracture plane temporal smoothing parameter, $\alpha$, for (a) 2011, (b) 2012, and (c) 2013 NIF. The maximum likelihood estimation corresponds with the minimum value on the $-2^{*}$ Likelihood plots ${ }^{19}$. Minimum likelihood estimates are outlined in red circles, with the value used in each year's inversion outlined indicated with a black diamond (Appendix 3.C). 
a. Supraglacial Lake Formation

A supraglacial lake forms on the surface of the Greenland Ice Sheet when surface runoff fills a compressive basin.

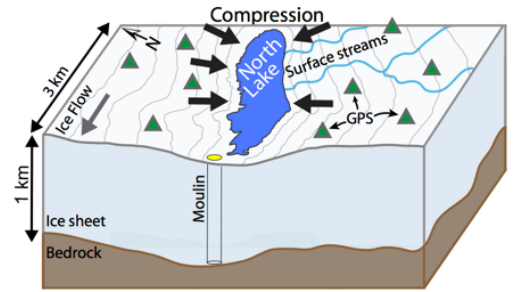

b. A Precursor to Rapid Lake Drainage

Substantial melt-water is routed to the bed via a moulin

causing uplift and tension at the ice sheet surface.

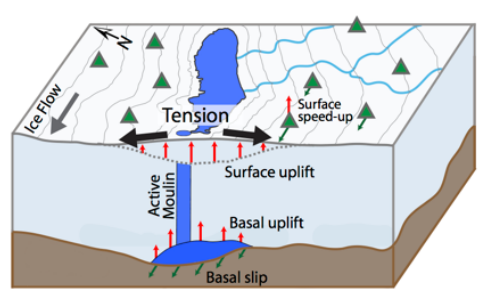

c. Hydro-fracture Opening and Rapid Drainage A hydro-fracture opens through the lake basin, draining water in the lake to the bed within a few hours.

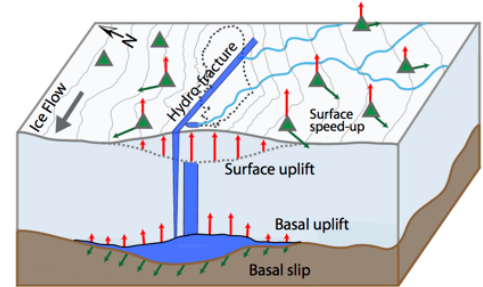

Figure 3-13. Stress changes across North Lake basin during (a) supraglacial lake formation, (b) rapid drainage precursor, and (c) hydro-fracture opening. 


\section{Chapter 4}

\section{Varying relationships between Greenland Ice Sheet melt season surface speeds and modeled effective pressures}

\subsection{Abstract}

In this study, we use a numerical model of subglacial hydrology to test whether model-derived effective pressures exhibit the theorized inverse relationship with melt-season ice surface velocities in an $\sim 8,000$ $\mathrm{km}^{2}$ area on the western margin of the Greenland Ice Sheet. Using a realistic ice sheet and basal geometry, we force a 900-m spatial resolution subglacial hydrology model with daily temporal resolution runoff estimates over multiple years from 2008-2010. Overall drainage system morphology is equivalent in both years, with robust subglacial pathways forming over bedrock ridges and minimal englacial or basal water storage outside of the melt season. Model predictions of effective pressure are compared to the spatiotemporal pattern of regional surface speed over the 2009 and 2010 melt seasons derived from TerraSAR-X imagery. Across both years, our results show the expected inverse relationship between effective pressure and ice velocity when surface speeds in the mid-melt season are at least $150 \%$ above the average winter velocity. In the early- and late-melt season, effective pressures and speed have a positive relationship, inconsistent with the general basal sliding modelsuggesting that effective pressure may be less important than driving stress in controlling ice velocities outside of the mid-melt season. These results suggest that the canonical basal sliding model may need to be modified to explain these observations. 


\subsection{Introduction}

Understanding the physical processes driving variability in ice sheet flow is a persistent challenge that hinders our prediction of sea level rise contributions from Greenland Ice Sheet mass loss [Pritchard et al., 2009; Vaughan et al., 2013]. Outside of the fast-flowing trunks of outlet glaciers, seasonal accelerations of ice sheet ablation zones are observed across the Greenland Ice Sheet in concert with surface melting, though the amount of net annual ice motion is largely insensitive to (or in some cases inversely related to) the magnitude of annual melt [Zwally et al., 2002; Joughin et al., 2008, 2013; van de Wal et al., 2008, 2015; Sole et al., 2013; Tedstone et al., 2015; Stevens et al., 2016a]. The spatiotemporal variability of surface meltwater reaching and traveling along the ice-bed interface is frequently hypothesized to play a major role in controlling ice sheet velocities through its ability to "lubricate" the ice-bed interface [Das et al., 2008; Shepherd et al., 2009; Schoof, 2010; Hoffman et al., 2011; Smith et al., 2015; Stevens et al., 2015]. However, because the ice-bed interface is a difficult place at which to make direct geophysical observations, numerical models paired with surface observations provide a means to test theories relating subglacial water routing to ice flow [Flowers, 2015].

In recent years, numerical model development has progressed more rapidly than has data acquisition for model calibration, resulting in increasingly detailed numerical models that lack realistic basal topography maps and regional measurements of ice surface velocities for comparison [Flowers, 2015]. Currently, subglacial hydrology models often use idealized ice sheet geometries [Schoof, 2010; Hoffman et al., 2011, 2016; Hewitt, 2013]; prescribe time- and space-invariant hydraulic potential fields [Lindbäck et al., 2015; Chu et al., 2016b; Stevens et al., 2016b]; and/or calibrate models that are thousands of square kilometers in area to a few point-source GPS velocity, GPS uplift, or borehole measurements [de Fleurian et al., 2016; Hoffman et al., 2016]. While regional observations and measurements are most useful for model calibration [Flowers, 2015], just three regional observations of the spatiotemporal evolution of ice flow through the melt season exist for the Greenland margin [Palmer et al., 2011; Joughin et al., 2013; Bougamont et al., 2014]. From these few regional observations, the location of surface speedup has been shown to align with observed supraglacial catchments [Palmer et al., 2011; Joughin et al., 2013] and modeled subglacial drainage pathways [Chu et al., 2016b]. However, continued data calibration is needed to adequately validate these models that include an increasing range of parameters [Flowers, 2015]. 
Further, pairing subglacial hydrology models with surface velocity observations provides a test of theoretical parameterizations for basal sliding. Most models for basal sliding, $u_{b}$, take the general form:

$$
\tau_{b}=u_{b}^{p} N^{q}, \quad p, q>0
$$

where $\tau_{b}$ is basal shear stress, $N$ is effective pressure (ice overburden pressure minus the water pressure), and $p$ and $q$ are positive constants [Iken and Bindschadler, 1986; Fowler, 1987; Cuffey and Patterson, 2010; Schoof, 2010]. In interior regions of the ice sheet, $\tau_{b}$ is approximately equal to the driving stress, $\tau_{d}$, as longitudinal and wall stresses provide little resistance to flow in these regions, leaving basal drag to offset almost all of the driving stress [Cuffey and Patterson, 2010]. In the ablation area of the Greenland Ice Sheet, basal sliding makes up roughly $90 \%$ of the motion in the melt season [Ryser et al., 2014], such that driving stress and effective pressure combine to control melt season surface velocities. However, while some ice sheet flow models couple subglacial hydrology to ice dynamics through model-derived effective pressures [Schoof, 2010; Hewitt, 2013], the relationship between effective pressure and regional melt season surface speeds has not been tested using available observational data sets.

In this study, we use a regional subglacial hydrology model to test whether model-derived effective pressures exhibit the predicted inverse relationship with surface speeds during the summer melt season. Improving on idealized models, we use a sub-kilometer resolution subglacial hydrology model that incorporates: (1) distributed and channelized drainage components, (2) realistic ice sheet geometries, and (3) daily-resolved surface runoff inputs. We model a region of the Greenland Ice Sheet south of Jakoshavn Isbræ that exhibits spatiotemporally complex seasonal surface speeds as observed by 11-day resolution TerraSAR-X images over the 2009 and 2010 melt seasons (Figure 4-1) [Joughin et al., 2013]. By comparing our subglacial hydrology model with regional surface speed observations, we find the expected inverse relationship between effective pressure and ice velocity in the mid-melt season but not in the early- and late- melt season, suggesting the canonical basal sliding model may need to be modified to explain these observations outside of the mid-melt season. 


\subsection{Methods}

\subsubsection{Study Region}

We focus our study on an $8,110 \mathrm{~km}^{2}$ area of both fjord- and land-terminating ice located immediately south of Jakobsahvn Isbræ in western Greenland (Figure 4-1 a). Within this region, three slow-moving $\left(\sim 150 \mathrm{~m} \mathrm{yr}^{-1}\right)$ marine-terminating outlet glaciers [Joughin et al., 2013] at the margin transition into a region of shallow ice sheet surface slopes and numerous supraglacial lakes [Yang et al., 2015]. This study area region $\sim 100 \mathrm{~km}$ inland from the ice margin over a range in ice thicknesses from 0-1758 $\mathrm{m}$ (Figure 4-1 b). The entirety of the region is within the ablation zone, with the local equilibrium line altitude at $\sim 1500 \mathrm{~m}$ a.s.l. [Poinar et al., 2016].

The region was chosen based on availability of in situ and remotely-sensed ice sheet velocity data [Das et al., 2008; Joughin et al., 2008, 2013, Stevens et al., 2015, 2016a, 2016b] and high resolution basal topography derived from radar datasets [Bamber et al., 2013; Morlighem et al., 2014]. Regional surface velocity measurements over the 2009 and 2010 melt season derived from 11-day repeat TerraSAR-X images reveal a spatiotemporally complex pattern of speedup (Figure 4-1 d, e) [Joughin et al., 2013]. These velocity maps cover $1,700 \mathrm{~km}^{2}$ ( 20\%) of the study region (Figure 4-1 c), and provide a unique set of spatially-extensive ice sheet surface speeds that can be compared with the outputs of our subglacial hydrology model. A previous time-invariant model of subglacial water flow in the region calculated using theoretical, static hydraulic potential fields by Chu et al. [2016b] provides an additional model comparison study.

\subsubsection{Subglacial hydrology model}

\subsubsection{Governing equations}

The subglacial water flow model is the two-dimensional model of the subglacial drainage system used by Banwell et al. [2016] and originally developed by Hewitt [2013]. The model routes ice sheet surface meltwater input into a continuous "sheet" connected to discrete "channels" melted upwards into the base of the ice sheet [Hewitt, 2013]. A schematic of model parameters is given in Figure 4-2. Water

moves between the continuous sheet of some average thickness $h$, and discharge, $\boldsymbol{q}$; channels of 
cross-sectional area $S$ and discharge $Q$; and englacial storage $\Sigma$, to maintain a continuous hydraulic potential $\phi$ given by

$$
\phi=\rho_{w} g b+p_{w}
$$

where $\rho_{w}$ is the water density, $g$ is the gravitational acceleration, $b$ is the basal elevation, and $p_{w}$ is the water pressure. Water discharge in the sheet $\boldsymbol{q}$ is dependent on sheet thickness $h$, through

$$
\boldsymbol{q}=-\frac{K_{S} h^{3}}{\rho_{w} g} \nabla \phi
$$

where $K_{S}$ is the sheet flux coefficient controlling the sheet permeability, making $K_{S} h^{3}$ an effective hydraulic transmisivity.

Water in the sheet is further divided into two components: a cavity sheet of thickness $h_{c a v}$ and an elastic sheet of thickness $h_{e l}$. The sum of the height of the cavity and elastic sheet is equal to total sheet thickness: $h=h_{c a v}+h_{e l}$. The thickness of the cavity sheet represents the height of waterfilled cavities [Schoof et al., 2012], and is a balance between the combined effects of basal ice melt and basal sliding opening cavities, and ice creep closing cavities according to

$$
\frac{\partial h_{\text {cav }}}{\partial t}=\frac{\rho_{w}}{\rho_{i}} m+\frac{U_{b}\left(h_{r}-h_{c a v}\right)}{l_{r}}-\frac{2 A}{n^{n}} h_{c a v}|N|^{n-1} N,
$$

where $\rho_{i}$ is the ice density, $m$ is the basal melting rate, $U_{b}$ is the basal sliding speed, $h_{r}$ is the bed roughness height scale, $l_{r}$ is the bed roughness length scale, $A$ is the creep parameter in Glen's law, $n$ is the creep exponent in Glen's law, and $N$ is the effective pressure $\left(N=p_{i}-p_{w}\right)$. Basal sliding speed $U_{b}$ is prescribed everywhere to be $100 \mathrm{~m} \mathrm{yr}^{-1}$ as an approximate median value of measured surface ice velocities in the region of $\sim 50-250 \mathrm{~m} \mathrm{yr}^{-1}$ (Figure 4-1 b) [Joughin et al., 2013]. Basal melting rate in the sheet, $m$, is prescribed everywhere to be $0.0059 \mathrm{~m} \mathrm{yr}^{-1}$ based on an average geothermal heat flux, $G$, beneath Greenland of $0.063 \mathrm{~W} \mathrm{~m}^{-2}$ [Rogozhina et al., 2012] according to the equation 


$$
m=\frac{G}{\rho_{w} L}
$$

where $L$ is the latent heat of melting.

The elastic sheet is included to represent the elastic uplift or "hydraulic jacking" of ice where $p_{w}>p$. Here $h_{e l}$ is related to effective pressure, $N$, through

$$
h_{e l}=\left\{\begin{array}{cl}
-C_{e l}\left(N-\frac{1}{2} N_{0}\right), N<0 \\
C_{e l} \frac{\left(N_{0}-N\right)^{2}}{2 N_{0}}, & 0<N<N_{0} \\
0, & N>N_{0}
\end{array}\right.
$$

where $C_{e l}$ is the uplift compliance rate and $N_{0}$ is a small regularizing pressure used to smooth this relationship. Based on this form, $h_{e l}$ is zero when $N$ is positive $\left(p_{i}>p_{w}\right)$, but increases rapidly when $p_{w}$ approaches or exceeds $p_{i}(N \leq 0)$. A constant value for $C_{e l}$ of $1.02 \times 10^{-6} \mathrm{~m} \mathrm{~Pa}^{-1}$ is set for all model runs, resulting in $1 \mathrm{~m}$ of uplift for $100 \mathrm{~m}$ of excess hydraulic head. While this treatment of $h_{e l}$ allows for the injection of a large amount of meltwater into the subglacial drainage system without generating unrealistically large water pressures in the cavity layer or channels, elastic bending stress in the ice is not accounted for. For example, a non-zero at one node does not cause its neighboring nodes to also become hydraulically jacked. Rather, the activation of the elastic sheet affects the pressure gradient between neighboring nodes. As stated above, the sum of the height of the cavity and elastic sheet is equal to total sheet thickness, which drives discharge in the sheet (Eq. 4.2).

Water in the sheet is connected to discrete channels. Water discharge in the channels, $Q$, is given by

$$
Q(s)=-K_{c} S^{\frac{5}{4}}\left|\frac{\partial \phi}{\partial \mathrm{s}}\right|^{-\frac{1}{2}} \frac{\partial \phi}{\partial \mathrm{s}},
$$

where $K_{c}$ is a turbulent flow coefficient for channel flow, and $S$ is the cross-sectional area of channel at a distance along the channel $\mathbf{s}$. The growth and decay of channel cross-sectional area is a 
competition between the melt back opening of channel walls and creep closure of channel walls given by

$$
\frac{\partial \mathrm{S}}{\partial t}=\frac{\rho_{w}}{\rho_{i}} M-\frac{2 A}{n^{n}} S|N|^{n-1} N
$$

where $M$ is the melting rate of channel walls. The melting rate of channel walls $M$, is expressed as

$$
M=\frac{\left|Q \frac{\partial \phi}{\partial s}\right|}{\rho_{w} L}+\frac{\lambda_{c}|\boldsymbol{q} \cdot \nabla \phi|}{\rho_{w} L}
$$

where $\lambda_{c}$ is the incipient sheet width contributing to channel melting (the length scale over which ice melting contributes to channel formation). The first term is the channel melting rate as a function of channel discharge and hydraulic potential along the channel, and the second term should be viewed as a parameterization of how small channels emerge from a sheet flow [Hewitt et al., 2012]. The appropriate value for $\lambda_{c}$ is rather uncertain and discussed in Section 4.4.1.

Finally, mass conservation is expressed as a balance between the sheet, channels, and englacial storage with basal melting, channel wall melting, and surface runoff inputs $E$ according to

$$
\left[\frac{\partial \mathrm{h}}{\partial t}+\nabla \cdot \boldsymbol{q}\right]+\left[\frac{\partial \mathrm{S}}{\partial t}+\frac{\partial \mathrm{Q}}{\partial s}\right] \delta\left(x_{c}\right)+\frac{\partial \Sigma}{\partial t}=m+M \delta\left(x_{c}\right)+E
$$

where $\Sigma$ is englacial storage, which represents the additional water storage in connected englacial void space [Harper et al., 2010; Bartholomaus et al., 2011; Hewitt, 2013]. Englacial storage is related to water pressure through

$$
\Sigma=\sigma \frac{p_{w}}{\rho_{w} g}+A_{m} \frac{p_{w}}{\rho_{w} g} \delta\left(x_{m}\right)
$$

where $\sigma$ is the connected void fraction of the ice and $A_{m}$ is the cross-sectional area of the moulin. For Eqs. 4.10 and 4.11, the delta functions only apply at the line positions of the channels, $x_{c}(s)$, and the point positions of moulins, $x_{m}$. 
In this study, we will primarily focus on the model predictions of sheet discharge $\boldsymbol{q}$ and effective pressure $N$, which are solved at every model grid point. The model is forced by daily surface runoff inputs ( $E$ in Eq. 4.10) derived from a regional climate model (Section 4.3.2.4). We will use $\boldsymbol{q}$ to determine whether the drainage system morphology is inefficient (majority of drainage through linked cavities) or efficient (majority of drainage through channels). Because the exact form of the sliding law (Eq. 4.1) is uncertain and can be highly non-linear, the ice flow model in Hewitt [2013] is not employed here. Instead, we compare ice surface speed directly to effective pressure $N$ in order to quantify this relationship both spatially and temporally over the melt season and multiple years.

\subsubsection{Numerical procedure}

The subglacial hydrology equations above are discretized onto a two-dimensional, regular rectangular mesh and solved using a finite difference approach [Hewitt, 2013]. Nodes are spaced 900-m apart. The continuous variables hydraulic potential $\phi$, water sheet thickness $h$, and water pressure $p_{w}$ are discretized onto the nodes of the grid. Every node on the grid is the center of a finite volume square over which discharge in the sheet, $\boldsymbol{q}$, is calculated. Eight potential channels connect every node to its closest surrounding eight nodes, with the midpoint of all channels crossing the finite volume dividing line between two neighboring nodes. Moulins are defined on a selection of the nodes $x_{m}$ chosen based on the surface runoff forcing as discussed in Section 4.3.2.4. The non-linear system for the evolution of $p_{w}, h$, and $\mathrm{S}$ described in Eqs. 4.2-11 is solved at each timestep using an iterative Newton method with variable time step length based on the success of the last iteration. The maximum time step the model can take is set to one day, with time steps decreasing to only a couple hours during periods of high surface runoff during the melt season. The model is forced with daily runoff estimates from January 1, 2008 until December 31 ${ }^{\text {st }}, 2010$ (see Section 4.3.2.3 below).

\subsubsection{Model geometry and boundary conditions}

Akin to the work of Banwell et al. [2016], the subglacial hydrology model has been modified to a specific region of the Greenland Ice Sheet to incorporate realistic ice sheet bed geometry and surface elevation (Figure 4-1 a,b); pressure boundary conditions; and surface melt magnitude, timing, and input locations (Section 4.3.2.4). Bedrock topography is calculated from the IceBridge BedMachine Greenland Version 2 bedmap available at the NASA National Snow and Ice Data Center 
(http://dx.doi.org/10.5067/AD7B0HQNSJ29) [Morlighem et al., 2014]. Bed elevations on the regularly-spaced, 900-m mesh of model nodes are determined by subsampling the Morlighem et al. [2014] bed at every $6^{\text {th }}$ point. Boundary conditions for ice sheet surface elevation are calculated from the Greenland Ice Mapping Project (GIMP) digital elevation model [Howat et al., 2014] with equivalent subsampling methods to that of the bed elevations. The bed and ice sheet surface geometry is treated as fixed, as bedrock and ice sheet shape changes minimally over the course of a few years [Hewitt, 2013].

The model is forced from January 1, 2008 until December 31 ${ }^{\text {st }}, 2010$. With the seasonal cycles of runoff forcing, the model never reaches a steady state that is in equilibrium with the background basal melt rate $m$. Moreover, for some parameter choices, regions of elevated sheet discharge $\boldsymbol{q}$ persist from the end of one runoff season until the beginnings of the following year's runoff season (Figure 4-3 a). Thus, we use 2008 as a spin-up year and focus on the evolution of the drainage system in 2009 and 2010. At the start of the model run (January 1, 2008), initial hydraulic potential $\phi$ conditions at the bed are set by prescribing $p_{w}$ such that $\phi$ is equivalent to $90 \%$ of overburden pressures. The initial condition for cavity sheet thickness $h_{c a v}$ is calculated from the steady state form of Eq. 4.3. Over the first 100 days of 2008, $h_{\text {cav }}$ averaged across the model domain decreases from an initial height of $0.039 \mathrm{~m}$ to $0.025 \mathrm{~m}$, which is balanced by the background basal melt rate $m$ until melt season surface runoff inputs begin.

At model boundary nodes that are located under interior ice, a no flux condition is applied. At both marine- and land-terminating margins of the ice sheet, we set $N=0$. This boundary condition is appropriate for land-terminating margins so long as ice sheet thickness tapers to zero at the margin (Figure 4-1 b) and approximates hydrostatic conditions at marine-terminating margins. Boundary nodes along the ice sheet margin are dynamically adjusted at each 1-day timestep. If there is inflow at the node, pressure is no longer prescribed at that node and a no flux condition is applied instead. This prevents water from getting sucked under the ice sheet from regions outside of the model domain. If the pressure predicted becomes larger than the boundary pressure, the condition is switched back to a pressure outlet condition. 


\subsubsection{Surface runoff forcing}

The model is forced with one of two forms of surface runoff input: distributed and discrete. As this is the first study to incorporate daily surface runoff inputs to the bed for this region, we tested runoff inputs to the bed using two simple cases: (1) the ice sheet bed receives distributed inputs at every model node (distributed) (Figure 4-3); and (2) the ice sheet receives discrete inputs at identified or randomly assigned moulins (discrete) (Figure 4-4). We do not attempt to route water along the surface of the ice sheet [Yang et al., 2015]; remotely observe when individual moulins open up or lakes drain; or estimate when lakes drain based on non-physical threshold lake volume parameterizations [Clason et al., 2012; Arnold et al., 2014; Leeson et al., 2015].

The total meltwater input to the bed is equivalent in both the discrete and distributed cases. In the distributed surface runoff input formation (Figure 4-3), surface runoff estimates from the daily, downscaled 1-km resolution Regional Atmospheric Climate Model (RACMO) v. 2.3 [Noël et al., 2015, 2016] are interpolated to the $900-\mathrm{m}$ mesh of model grid nodes. There is no surface storage, and runoff immediately transits to the bed. This scenario is effectively equivalent to having a moulin at every node of the model.

In the discrete surface runoff input formation (Figure 4-4), moulin locations within the TerraSAR-X scene footprint are defined based on moulins identified by Joughin et al. [2013]. Moulin positions outside of the TerraSAR-X scene footprint are randomly assigned, but adhere to a moulin density estimate derived from counting the number of moulins within 100-m surface ice elevation bands within the TerraSAR-X scene footprint, which extends over 500-1200 m a.s.l. (Figure 4-5 a). The density of moulins from $500-700 \mathrm{~m}$ a.s.l. is roughly half the density observed at equivalent elevations in the Paakitsoq region [Andrews, 2015], which likely speaks to the overall lower driving stresses in our shallower sloping region of lake basins. Over the 500-700 m a.s.l. elevation band of highest moulin density ( 1 moulin for every 5 grid nodes), the discrete surface runoff input has a fifth of the moulin density of the distributed surface runoff input scenario ( 1 moulin at every grid node). Moulin density for elevation bands outside of the TerraSAR-X frame is estimated based on the decline in moulin density observed in the lower and upper elevations of the Paakitsoq region (Figure 4-5 a). The surface area that drains into each moulin is determined by Voronoi tessellation (Figure 4-5 b), and the daily input into each moulin is the integral of the RACMO daily runoff values within the 
Voronoi cell. There is no surface storage, and runoff immediately transits to the bed at the location of the moulin within each Voronoi cell.

\subsubsection{Coherence and spectral estimation}

We employ coherence estimates to compare goodness of fit between surface speeds, static variables, and model output effective pressures. Coherence is a bivariate statistic in the spectral domain that is analogous to correlation in the spatial domain [Simons et al., 2000]. Coherence measures the phase relationship between two signals, with high coherence values indicating constructive interference at wavenumbers where the two signals are correlated [for review, see Kirby, 2014]. For geophysical problems, one-dimensional coherence was first used by Forsyth [1985] to estimate flexural rigidity of the lithosphere through coherence between topography and gravity anomalies along transects across continental rift valleys [Forsyth, 1985]. The approach was expanded by Simons et al. [2000] to investigate two-dimensional lithospheric loading from the coherence between two-dimensional fields of topography and gravity anomalies [Simons et al., 2000, 2003]. The coherence estimation between two two-dimensional fields yields information in the spectral, spatial, and azimuthal domains, which provides the wavelength, spatial, and directional dependence of the coherence between the two fields, respectively [Simons et al., 2003].

In this study, we follow the methodology and analysis routines of Simons et al. [2000] for estimating two-dimensional coherence of stationary fields. For two stochastic fields (e.g., surface ice velocity $(X)$ and bedrock topography $(Y)$ ) defined on $\boldsymbol{d}$ in the spatial domain and $\boldsymbol{k}$ in the Fourier

domain, the coherence-square function between the two fields, $\gamma_{X Y}^{2}$, is the ratio between the magnitude of the fields' cross-spectral density, $S_{X Y}$, and the power spectral density of the individual fields, $S_{X X}$ and $S_{Y Y}$ :

$$
\gamma_{X Y}^{2}(\boldsymbol{d}, \boldsymbol{k})=\frac{\left|S_{X Y}(\boldsymbol{d}, \boldsymbol{k})\right|^{2}}{S_{X X}(\boldsymbol{d}, \boldsymbol{k}) S_{Y Y}(\boldsymbol{d}, \boldsymbol{k})}
$$

Like correlation estimates, coherence-square estimates range from $0<\gamma_{X Y}^{2}<1$, with $\gamma_{X Y}^{2}=1$ indicating an entirely consistent phase relationship between both fields [Simons et al., 2003]. 
Some amount of averaging in the wavenumber domain must be completed prior to calculating $\gamma_{X Y}^{2}$ to prevent the ratio of periodograms expressed in Eq. 4.12 from always yielding $\gamma_{X Y}^{2}=1$ [Bendat and Piersol, 1993]. Following Simons et al. [2000], we use multitaper spectral estimation [Thomson, 1982] with two-dimensional Slepian tapers [Slepian, 1978] on a Cartesian plane to perform this wavenumber averaging. A weighted average of the spectra is created by multiplying the data by a set of several chosen tapers, taking the two-dimensional Fourier transform of these data-taper products, and finally taking a average in wavenumber space of the resulting power spectra [Kirby, 2014]. The result is a coherence-square estimation over the wavenumber domain, $\gamma_{X Y}^{2}\left(\boldsymbol{k}_{X}, \boldsymbol{k}_{Y}\right)$. Isotropic coherence-square estimates, $\gamma^{2}(|\boldsymbol{k}|)$, are calculated by averaging over $360^{\circ}$ of azimuth around logarithmically-spaced annuli in the wavenumber domain [Kirby, 2014]. A coherence-square estimation of synthetic data (two 2-D sine waves at right angles to one another) with some noise is provided in Figure 4-6 to illustrate this methodology.

The number and bandwidth of the chosen set of tapers determines the wavenumber resolution and variance of the coherence-square estimate [Simons et al., 2000]. A higher number of tapers and/or a wider taper bandwidth reduces the variance in the coherence-square estimate and reduces the waveband resolution [Kirby, 2014]. Most studies choose taper bandwidths to be the width of 2-5 wavenumber bands [Simons et al., 2000; Kirby, 2014]. For this study, we set the taper bandwidth, NW, to 3 and the number of tapers $K$ to 4 for all coherence-square estimates.

As the coherence-square estimate is a statistic, the variance of the isotropic coherence-square estimate is calculated following the Cramer-Rao lower bound:

$$
\sigma^{2}\left\{\gamma^{2}(|\boldsymbol{k}|)\right\}=\frac{2 \gamma^{2} \frac{\left(1-\gamma^{2}\right)^{2}}{J}}{\Lambda}
$$

which is a measurement of variance determined by maximum likelihood estimates [Seymour and Cumming, 1994; Simons et al., 2003], where $J$ is the number of uncorrelated spectral estimators over which the coherence-square estimate is made [Simons et al., 2003], and $\Lambda$ is the number of points in the wavenumber annuli [Simons et al., 2000]. In our two-dimensional case, $J=K^{2}$ [Simons et al., 2003]. As we have set $K=4, J=K^{2}=16$ uncorrelated spectral estimators. Error estimates of $\gamma^{2}(|\boldsymbol{k}|)$ 
presented throughout the paper are two standard deviations, $2 \sigma$. With $J=16$, the $2 \sigma$ values across all possible $\gamma^{2}(|\boldsymbol{k}|)$ values increases with increasing wavelength, from a minimum of 0.025 at $2 \mathrm{~km}$ wavelength to maximum of 0.96 at $30.9 \mathrm{~km}$ wavelength.

Finally, the range of wavelengths we can investigate in the spectral domain is set by our data length, $\left(N_{X}, N_{Y}\right)$, and data spacing, $(d x, d y)$, in the spatial domain. Our coherence-square estimates are constrained by surface velocity data from single-look complex TerraSAR-X radar images, which have $d x=d y=0.1 \mathrm{~km}, N_{X}=309$ data points, and $N_{Y}=552$ data points. The longest resolvable wavelength (the Rayleigh wavelength, $\lambda_{R}$ ) is set by the shorter $x$ dimension to be $\lambda_{R X}=N_{X} d x=$ $30.9 \mathrm{~km}$. The shortest resolvable wavelength in either direction is the Nyquist wavelength, $\lambda_{N}=$ $2 d x=0.2 \mathrm{~km}$.

\subsection{Results}

\subsubsection{Parameter Space Calibration}

All non-varying parameter values in the model are equivalent to the values used by Banwell et al. [2016] (Table 4-1). We perform model runs with different parameter combinations for the three parameters - $K_{s}, \lambda_{c}$, and $\sigma$ - that most greatly affect the timing and morphology of the inefficient and efficient subglacial drainage systems in previous studies using versions of this model [Hewitt, 2013; Werder et al., 2013; Banwell et al., 2016]. We vary $K_{s}$ by by factors of 10 across the range $10^{-4} \leq K_{s} \leq$ $10^{-2} \mathrm{~Pa}^{-1} S^{-1}$ to investigate the sensitivity of sheet permeability; $\lambda_{c}$ across the range $\lambda_{c}=$ $[100,1000,5000] \mathrm{m}$ to investigate the sensitivity of the width of the region that contributes to channel melting (Eqs. 4-10); and $\sigma$ by a factors of 10 across the range $10^{-4} \leq \sigma \leq 10^{-2}$ to investigate the sensitivity of englacial storage capacity on drainage system evolution. This results in 27 parameter combinations for each of the two surface melt forcing scenarios (distributed or discrete).

To test the relationship between model-derived effective pressures and observed surface speeds is the aim of our study, we need a way to calibrate the parameter space that is independent of surface velocity measurements. Differing from previous studies of land-terminating ice using this model [Hewitt, 2013; Werder et al., 2013; Banwell et al., 2016], we cannot assess parameter space fitness 
by comparing measured proglacial discharge at stream discharge stations because proglacial discharge along the margin of our region enters into unmonitored proglacial lakes and fjords. Instead, we use GPS records of surface ice uplift during rapid drainages of supraglacial lake North Lake $\left(68.72^{\circ} \mathrm{N}\right.$, 49.70 $\mathrm{W} ;(0,0) \mathrm{km}$ in model domain) [Das et al., 2008; Stevens et al., 2015; 2016a] to bracket a wide range of days over which the drainage system should become efficient at North Lake. In some years, uplift in the North Lake basin subsides to pre-drainage elevations within 24 hours of rapid drainage [e.g., 2006 drainage; Das et al., 2008]. In other years, ice sheet surface elevation remains elevated after the lake drainage for multiple days [e.g., 2011-2013 drainages; Stevens et al., 2015]. To first order, we interpret a longer period of sustained uplift to occur when the subglacial drainage system beneath the lake is inefficient and unable to quickly evacuate water away following a lake drainage event. This interpretation is theoretically supported by a numerical model of North Lake drainage where basal water pressures can subside to pre-drainage levels within 24 hours of the drainage event when sufficiently large pre-existing channels characteristic of an efficient drainage system are present [Pimentel and Flowers, 2010].

We use rapid drainage events in 2006 and 2009 to constrain the timing of the inefficient to efficient drainage system transition in the region. In 2009, North Lake drained rapidly on DOY 168 $2009\left(17^{\text {th }}\right.$ June) [Stevens et al. 2016a]. This was at least the fourth consecutive year of rapid drainage at North Lake, as constrained by GPS and pressure logger measurements [Das et al., 2008; Joughin et al., 2008; Stevens et al., 2015; 2016a]. A single GPS station located $\sim 1 \mathrm{~km}$ north of the lake recorded the ice sheet surface motion during the drainage, capturing an increase in along flowline motion and rapid uplift during the drainage (Figure 4-7). Similar sustained ice sheet surface elevations following earlysummer rapid lake drainages were observed in 2011-2013 [Stevens et al., 2015]. In contrast, ice sheet surface elevations subsided to pre-drainage elevations within 24 hours after the late melt season 2006 drainage on DOY 210 (July 29 ${ }^{\text {th }}$ ) [Das et al., 2008]. The 2006 and 2009 melt seasons at North Lake are similar in total melt-season runoff magnitude (1.89 and $1.98 \mathrm{~m}$ water equivalent (w.e.), respectively), and runoff onset occurs 3 calendar days apart between the two years [Stevens et al., 2016a]. Thus, we use the 2009 DOY 168 and 2006 DOY 210 lake drainage dates as bounds for the inland migration of an efficient drainage system in 2009. We acknowledge the 40 days between the calendar dates of the 2006 and 2009 lake drainage events comprises a large portion of the melt season, making this parameter space criteria rather imprecise. 
The transition from inefficient to channelized drainage travels inland and up elevation from the margin over the first half of the melt season at roughly the location of the $N=0 \mathrm{MPa}$ contour (Figures 4-3, 4-4). This drainage system transition reaches the position of North Lake when roughly $40 \%$ of the area of the TerraSAR-X region has become an efficient drainage system. We define nodes having an efficient drainage system where $N>0 \mathrm{MPa}$ and $\boldsymbol{q}>0.001 \mathrm{~m}^{2} \mathrm{~s}^{-1}$, based on the observation that effective pressures increase rapidly after channelization occurs.

The timing of the inefficient to efficient drainage system transition proves a discerning metric for model parameter space calibration for models with distributed surface runoff forcing (Figure 4-6 a-c). Over the course of the 2009 summer, the area of efficient drainage in the TerraSAR-X region increases at different rates based on model parameters, with higher sheet permeability $\left(K_{S}\right)$ and sheet width contributing to melting $\left(\lambda_{c}\right)$ leading to faster rates of channelization when englacial storage fraction $(\sigma)$ is 0.001 (Figure 4-8 a-c) and 0.0001 (Figure 4-9 d-f). We reject 9 of the 27 distributed runoff models that have that have achieved over $40 \%$ of efficient channelized area within the TerraSAR-X region by DOY 174 2009, as the transition from inefficient to efficient drainage in these model runs occurred too quickly to be in agreement with the 2009 lake drainage record (Figures 4-8, 4-9). We also reject an additional 5 of the 27 distributed runoff models that have not achieved at least $40 \%$ of efficient channelized area within the TerraSAR-X region by DOY 210 2009, as the transition from inefficient to efficient drainage system occurred too slowly to be in agreement with the 2006 lake drainage record in these cases (Figures 4-8, 4-9). The majority of rejected models employed the highest englacial void fraction of $\sigma=10^{-2}$, and also exhibit unrealistically long lags between surface runoff input and subglacial system channelization (Figure 4-9 a-c, Sections 4.4.5).

We keep all models that meet the lake drainage criterion (13 of the 27), and chose a model in the middle of the parameter space $\left(K_{s}=0.001 \mathrm{~Pa}^{-1} \mathrm{~s}^{-1}, \lambda_{c}=100 \mathrm{~m}\right.$, and $\left.\sigma=0.001\right)$ for plotting purposes in Figures 4-3, 4-13, 4-17, and 4-22. Channelization behavior in 2010 models with distributed surface runoff forcing exhibits less variability across $K_{s}$ and $\lambda_{c}$ parameter space, which may be due to the larger surface runoff forcing in 2010 (Figure 4-11). This reduced variability in 2010 is not due to preferred discharge morphology developing over multiple model year runs, as 2009 models run over one 2008 spin-up year have similar variability in timing of efficient drainage area to 2009 models run over two 2008 spin-up years. 
For models with discrete surface runoff forcing, the input of water at discrete moulin locations is far more important for controlling the transition speed from inefficient to efficient drainage than the wide range of $K_{s}, \lambda_{c}$, and $\sigma$ parameters we have chosen (Figures 4-8 d-f, 4-10, 4-12). We keep all models that meet the lake drainage criterion (18 of the 27 ), and chose a model in the middle of the parameter space $\left(K_{s}=0.001 \mathrm{~Pa}^{-1} \mathrm{~s}^{-1}, \lambda_{c}=100 \mathrm{~m}\right.$, and $\left.\sigma=0.001\right)$ for plotting purposes in Figures 4-4, 4-13, 4-17, and 4-22. All 9 of the 27 discrete runoff models that employ the highest englacial void fraction of $\sigma=0.01$ and are rejected (Figures 4-10) for the similar behavior of unrealistically long lags between surface runoff input and subglacial system channelization observed in the distributed runoff models with $\sigma=0.01$ (Figure 4-9). This channelization behavior across parameter space for models with discrete surface runoff forcing is approximately the same in 2010 (Figure 4-12), with slight variations in timing of efficient drainage area increases due to the earlier onset and higher runoff rates in the 2010 melt season (See Section 4.4.2 below).

\subsubsection{Distributed versus discrete surface runoff input}

Figures 4-3 and 4-4 show snapshots of the drainage system from the beginning of the year 2009 through the late melt season forced by distributed (Figure 4-3) and discrete (Figure 4-4) surface runoff inputs. Averages across the model domain of selected prescribed (runoff) and derived $\left(Q_{\text {all }}, b, S_{\text {all }}\right.$ and N) variables are shown as a function of time in Figure 4-13. The equivalent figures for 2010 are plotted in Figures 4-14-16. In general, sheet and channel behavior are similar between the distributed and discrete models, though there are notable differences in elastic sheet size, channelization rate, and channel morphology.

As surface runoff begins near the margins of the domain in 2009 on DOY 140 (Figures 4$3 \mathrm{~b}, 4-4$, and 4-13a), water is accommodated first in the sheet (Figure 4-13 b) and then in the the channels (Figure 4-13 c) as the efficient drainage system grows inland. The runoff inputs to the domain lead the outflow from the domain by roughly 10 days for the entire melt season, with the majority of outflow occurring in the latter half of the melt season (Figure 4-13 a). The runoff and outflow are not equivalent when integrated over the year in both 2009 and 2010 (Figures 4-13, 4-16 a). We think this failed closure of the mass conservation equation is due to errors in how outflow is counted along the discharge nodes. Effective pressures across the domain decrease in the early melt season (Figure 4-13 d), when the majority of water is accommodated in the sheet (Figure 4-13 b). As the amount of water 
accommodated in channels increases and the region of efficient drainage increases (Figure 4-13 c), effective pressures across the domain increase and eventually surpass their pre-melt season values (Figure 4-13 d). This transition can be observed spatially by tracking the contour of $0 \mathrm{MPa}$ effective pressure $N$ that moves inland from DOY 1742009 onwards (Figures 4-3 c-f, 4-4 c-f). Between the ice sheet margin and the $0 \mathrm{MPa}$ effective pressure contour, effective pressures are high $(N>0)$ and discharge morphology shows definitive channelization (Figures 4-3 d, 4-4 d). To the east of the $0 \mathrm{MPa}$ contour, effective pressures are low $(N<0)$ and discharge morphology shows minimal to moderate channelization (Figures 4-3 d, 4-4 d). This drainage system evolution upglacier is qualitatively similar to that found in the idealized model geometry of Hewitt [2013], with the main differences in system morphology due to flow paths being routed through topographic lows in the ice sheet bed (Figure 41 a) [Werder et al., 2013].

There are differences in the activation of the elastic sheet, channel area, and discharge morphology between the distributed and discrete models with equivalent $K_{s}, \lambda_{c}$, and $\sigma$ values. The height of the sheet layer $b$ averaged across the domain for the discrete model is roughly double that of the distributed model over the melt season, with the majority of the sheet layer height difference between the two models attributable to differences in elastic sheet height $h_{e l}$ (Figure 4-13 b). The larger elastic sheet height is due to the focused, point source input of water in the discrete model, which results in local activation of the elastic sheet layer and more negative effective pressures at moulin sites in the early melt season (e.g., low $N$ values at moulin locations on DOY 1522009 (Figure 4-4 b)). In contrast, the minimum effective pressures in the distributed model are greater than minimum effective pressures in the discrete model (Figure 4-3 c versus Figure 4-4 c), but negative effective pressures occur over a wider area in the distributed model. Thus, differences in surface runoff input between the two models affect the distribution and magnitude of local effective pressures (Figures 4-3, 4-4). However, these differences result in nearly equivalent minima in area-averaged effective pressures over the melt summer (Figure 4-13 d).

In the early melt-season, channel area increases faster in the distributed model compared to the discrete model for this parameter space combination (Figure 4-8, 4-13 c). At the equivalent $K_{s}$, $\lambda_{c}$, and $\sigma$ parameter values, the growth of channel layer area in the distributed model leads discrete model channel layer growth in the early- and mid-melt seasons by 10-15 days (Figure 4-13 c). The maximum channel layer area attained is larger in the distributed model (Figure 4-13 c). In the 
distributed model, small channels can start at every node that is receiving surface melt, while channel formation in the discrete model is limited to nodes that are moulins or nodes that are down hydraulic potential from moulins. Thus, while the rate of channel area growth is limited by sheet layer permeability $K_{s}$ and sheet layer width available for melting $\lambda_{c}$ for both surface input types (Eq. 9), the rate of channel area growth in the discrete input model is further limited by the larger distance between surface-to-bed meltwater pathways.

While locations of high discharge are equivalent between the two input types by mid-melt season, routes of high discharge are more numerous and geographically focused in the discrete surface input model (Figures 4-3, 4-4). By DOY 218 2009, the discrete surface input model drainage system has $\sim 10$ routes to the margin with $\boldsymbol{q}>0.1 \mathrm{~m}^{2} \mathrm{~s}^{-1}$ (Figure 4-4 e), while the distributed surface input model drainage system has $\sim 6$ routes with $\boldsymbol{q}>0.1 \mathrm{~m}^{2} \mathrm{~s}^{-1}$ (Figure 4-3 e). Similar to differences in channel area between the two models, this difference may also be attributable to the need for the distributed surface input model drainage system to move water across all nodes, whereas the discrete surface input model drainage system only needs to move water at and down hydraulic potential of moulins. Relatedly, there are more discharge outlet locations along the margin for the discrete input model. Both static [Chu et al., 2016a] and evolving (this study) treatments of subglacial water routing predict no major subglacial flow or discharge outlet down the terminus of Nordenskiöld Gletscher (position (-40 km, -70 km) in model domain) (Figures 4-1, 4-3, 4-4). Channel routes instead favor ice sheet margin discharge locations to the south and north of the outlet glacier, and are likely steered to these outlet locations by the steeper ice sheet surface gradients and small basal topographic valleys in these areas (Figure 4-1 a-b).

Overall drainage system evolution and morphology are equivalent in 2010, with differences in channelization timing and extent driven by the longer duration melt season that year (Figures 4-1416). A larger total runoff in 2010 results in greater height of the sheet layer $b$ and lower area-averaged effective pressures compared to 2009 (Figures 4-13 b,d, 4-16 b,d). Area-averaged effective pressures are negative during the early and mid-melt season in the 2010 distributed model (Figure 4-16 d) when runoff occurs across the entire model domain (Figure 4-14 c-e). While both distributed and discrete 2010 models rapidly increase the height of the cavity layer in the early melt-season (Figure 4-16 b), channel area increases faster and the maximum channel layer area is attained in the discrete model in 2010 (Figure 4-16 c). 


\subsubsection{Controls on 2009 melt-season surface speed and speedup compared to winter}

The primary aim of this study is to determine the dominant control on melt-season surface speeds in the region. This is investigated through weighted linear regression (Figures 4-17-20) and coherence estimation (Figure 4-21) of the 2009 and 2010 TerraSAR-X surface ice speeds against static (driving stress, bed elevation, surface slope, ice sheet thickness) and evolving (effective pressure) variables (Figures 4-22, 4-23). For the weighted linear regression analysis, 11-day averages of $E, \boldsymbol{q}$, and $N$ are calculated for each node within the TerraSAR-X region over the equivalent time intervals of the TerraSAR-X data (Figures 4-3, 4-4). The 11-day averages of $N$ are interpolated to the 100 -m resolution TerraSAR-X grid and plotted against the TerraSAR-X ice sheet surface speed (Figures 4-17-20). Scatter plots are linearly discretized along the $N$-and speed-axis; speed averages (circles) are calculated within each bin along $N$ (Figures 4-17-20). A weighted linear least squares regression is performed, using two standard deviations of the binned surface speed measurement as the weight on the $y$-values (Figures 4-17-20). The correlation coefficient, $r$, of the weighted least squares regression is taken as a measurement of strength and direction of a linear relationship between $N$ and speed (Figures 4-22 c, 4-23 c).

The equivalent procedure is used to quantify the relationships between driving stress $\tau_{d}$ and speed, bed elevation and speed, ice sheet surface slope and speed, and ice sheet thickness and speed (Figures 4-17-20). $\tau_{d}$ is calculated according to

$$
\tau_{d}=\rho_{i} g H \sin (\alpha)=\rho_{i} g\left(Z_{s}-Z_{b}\right) \sin (\alpha)
$$

where $H$ is the ice sheet thickness (the difference between the surface elevation $Z_{s}$ and the bed elevation $\left.Z_{b}\right)$ and $\alpha$ is the ice sheet surface slope averaged over $6 \mathrm{~km}(\sim 4$ ice thicknesses) [Cuffey and Patterson, 2010].

In 2009, there is a significant positive relationship between speed and driving stress $\tau_{d}$ throughout the winter and melt season (Figures 4-17, 4-22 c). The strength and direction of the relationships between surface ice speed and bed elevation, surface slope, and ice sheet thickness 
change over the melt season (Figures 4-17, 4-22 c). Bed elevation and surface slope exhibit a negative relationship with surface speeds in the mid-melt season (Figures 4-17 c,d, 4-18 c,d, 4-22 c), while ice thickness exhibits a positive relationship with surface speed in the mid-melt season (Figures 4-18 c,d, 4-22 c).

The strength and direction of the relationships between surface speed and effective pressures for both distributed and discrete surface input models also show variable strength and direction over the melt season (Figures 4-17, 4-22 c). For both distributed and discrete surface inputs, effective pressures and speed have a positive relationship in the early and late melt season and an inverse relationship in the mid-melt season (Figures 4-17, 4-22 c). In winter, effective pressures and surface speed have a positive relationship, though the range of effective pressures over this time is very small $(0.02<N<0.06 \mathrm{MPa}$ ) (Figure 4-17 a) compared to the average melt season range $(-1.5<N<2.0$ MPa) (Figure 4-17 b-e). Discrete surface input models that meet the lake drainage criterion have highly similar relationships between effective pressures and surface speed, while the equivalent relationships are more diverse for the distributed surface input models that meet the lake drainage criterion (Figure 4-22 c). In general, the distributed surface input models that more quickly transition to efficient drainage systems (Figure 4-8) depict the mid-melt season negative relationship between effective pressures and speed observed in all discrete surface input models (Figure 4-22 c).

Coherence estimation between speed and effective pressures (Figure 4-21 a-e) and speedup and effective pressures (Figure 4-21 $\mathrm{f}-\mathrm{j}$ ) yields information on the wavelength and directional dependence of coherence between the two fields. High coherence $(>0.6)$ is observed in the flowline direction (Figures 4-1 c, 4-12 c) between speed and effective pressures on 2009 DOY 185 and 196, with a peak in azimuthally averaged coherence at $5 \mathrm{~km}$ wavelengths (Figure 4-21 e). For the relationship between speedup and effective pressures, high coherence is observed weakly in the flowline direction (Figure 4-21 h) at longer 10-30 km wavelengths (Figure 4-21 j). The highest azimuthally averaged coherences for surface speedup and effective pressures are observed at the beginning of the mid-melt season on 2009 DOY 185 and 196 (Figure 4-22 d). These two highest coherence time intervals coincide with a speedup spatial pattern that is orthogonal to flowline direction (Figure2 4-1 e, 4-22 f) in a region of bedrock lows [Joughin et al., 2013]. While azimuthally averaged coherence is strongest between effective pressures and speedup in mid-summer (Figure 4-22 d), directionality in the flowline direction is observed for coherence estimates between effective pressures 
and all 11-day surface speed intervals in the 2009 mid- and late-melt season and winter (Figure 4-21 c).

There is little coherence between driving stress and surface speedup (Figure 4-22 d). However, three terms used to compute driving stress (Eq. 12) -ice sheet thickness, bed elevation, and surface slope-show moderate coherence with surface speedup at the beginning of the mid-melt season (Figure 4-22 d).

\subsubsection{Controls on 2010 melt-season surface speed and speedup compared to winter}

There are differences between the two years that are independent of the model. The 2010 melt season was three weeks longer than the 2009 season, and annual runoff integrated over the model domain was $5.52 \mathrm{~km}^{3}$ larger (25\% higher) in 2010 than in 2009 [Stevens et al., 2016a] (Figures 4-22 a, 4-23 a). Additionally, surface melt extended and persisted at higher elevations in 2010 than in 2009 over the mid- and late-melt season (Figures 4-3 c-f, 4-14 c-f). The greatest surface speeds in the TerraSAR-X region occurred in the early-melt season in 2010 (Figure 4-23 a), whereas 2009 maximum speeds occurred in the mid-melt season (Figures 4-1 d, 4-22 a) [Joughin et al., 2013].

The relationships between surface speed and modeled effective pressures observed in 2010 (Figure 4-23 c) are overall consistent with those seen in 2009 (Figure 4-22 c) with a few differences noted here. Again in 2010, there is a significant positive relationship between speed and driving stress throughout the winter and mid-melt season (Figures 4-19 a, 4-23 c). This relationship is insignificant during the early- and late-melt season (Figure 4-23 c). The relationships between speed and bed elevation and speed and ice thickness are again equal in strength and opposite in direction for the entire year (Figures 4-19, 4-20, 4-23 c). The strength and direction of the relationships between speed and surface slope is weakly negative over the year (Figures 4-20, 4-23 c).

In 2010, the strength and direction of the relationships between surface speed and effective pressures for both distributed and discrete surface input models again show variable strength and direction over the melt season (Figures 4-19, 4-23 c). The relationships in both distributed and discrete surface input models show negative relationships with surface speed in the early- and mid-melt season, before switching to a positive relationship in the late melt season and winter (Figures 4-19, 4-23 c). In 
general, the main difference between the two years is a lack of the positive relationships between effective pressures and speed seen in the 2009 early melt season in 2010. In contrast to 2009, low coherence $(<0.3)$ is observed between speedup and effective pressures across the 2010 melt season. Ice thickness and surface slope show moderate coherence (0.3-0.6) with speedup in the early and middle melt season, while the remaining static variables show low coherence.

\subsubsection{Model Curiosities 1: Oscillatory behavior at high englacial void fraction}

When englacial storage fraction is its highest value of 0.01 , both distributed and discrete surface runoff models exhibit unrealistically high discharge under interior ice outside of the melt season (Figures 49-12). The models with high englacial storage miss melt season onset and termination timing when englacial voids dampen the response of basal water pressure to runoff inputs and delay drainage system transition timing [Hewitt, 2013]. While models with lower englacial storage fractions exhibit a clear transition from efficient to inefficient drainage at $800 \mathrm{~m}$ a.s.l. in tandem with the beginning of the mid-melt season (2010 DOY 174) (Figure 4-4 c), models with high englacial storage fraction do not exhibit this transition until the late melt season (2010 DOY 211) (Figure 4-24 e).

At melt season termination, models with high englacial storage fraction store enough water to maintain subglacial routing in the interior for months after the melt season ends (Figure 4-24 a). Similar behavior was observed on a surge-type valley glacier in the St Elias Mountains, Canada, where spontaneous water pressure oscillations correlated in time across several boreholes were observed well after the end of the melt season [Schoof et al., 2014]. These pressure oscillations can be driven by englacial or subglacial water storage that supplies water to a remnant drainage system at rates beneath some critical threshold [Schoof et al., 2014], which produces an instability equivalent to the instability that triggers jökuhlaups [Nye, 1976].

\subsubsection{Model Curiosities 2: Effects of a pressure dependent melting point}

The pressure dependence of the melting point is often neglected when solving for the evolution of subglacial channel size (Eq. 4.8) [Flowers, 2015], though this term may become important when water flowing up significant bed slopes can freeze [Röthlisberger, 1972; Creyts and Clarke, 2010]. We neglected the pressure dependence of the melting point to decrease computational expenditure. To test the 
effect of including the pressure dependence of the melting point on drainage system morphology, we ran one discrete and one distributed model over 2009 with a pressure-dependent melting point and parameter values in the middle of the parameter space $\left(K_{s}=0.001 \mathrm{~Pa}^{-1} \mathrm{~s}^{-1}, \lambda_{c}=100 \mathrm{~m}\right.$, and $\sigma=$ $0.001)$.

For the distributed surface runoff input, the inclusion of the pressure dependence of the meting point results in a slower rate of channelization, with areas of negative effective pressures in the TerraSAR-X region through DOY 218 (Figure 4-25). The rate of channelization for the discrete runoff input does not change depending on the inclusion of the pressure dependence of the melting point. The major drainage system pathways do not vary when including the pressure dependence of the melting point (Figure 4-25). Though inclusion of the pressure dependence of melting makes it harder for subglacial water to flow up bedrock ridges, both the distributed and discrete models grow channels across the major bedrock ridge separating the margin from the inland ice (Figures 4-1 a, 4-25). We address the implications of these robust subglacial flow pathways in Section 4.5.3.

\subsection{Discussion}

\subsubsection{Controls on ice sheet margin surface speed dynamics}

Based on the general form of models of basal sliding for glacial ice (Eq. 4.1), driving stress $\tau_{d}$ and effective pressure $N$ should control surface speeds in our region. Since driving stress is a product of ice sheet thickness, surface slope, and bed elevation (Eq. 4.14), these variables may also show some level of control on surface speeds. As we do not have a way to test if the model predictions of effective pressure are accurate, we take model-derived effective pressures to be true in order to test the relationship between effective pressure and surface speeds. Additionally, equating surface speed to basal sliding velocity is most reliable in the melt season, with internal ice deformation from borehole measurements in the Greenland Ice Sheet ablation area suggesting basal sliding makes up roughly $90 \%$ of the motion in the melt season [Ryser et al., 2014].

Consistently across 2009 and 2010, our results depict an effective pressure and speed relationship that is most akin to the model for basal sliding when surface speeds are high in the midmelt season. Outside of these periods, the basal sliding model (Eq. 4.1) may be incorrect or effective 
pressure may be less important for speed in comparison to the driving stress. We find similar relationship direction and strength between effective pressures and speed for models with different surface runoff input conditions, though the relationships observed are slightly different between the two years of available surface speed data (Figures 4-22 c, 4-23 c). In both 2009 and 2010, effective pressure and speed exhibit the expected inverse relationship (Eq. 4.1) in the mid-melt season (Figures 4-22 c, 4-23 c). In both 2009 and 2010, effective pressures have an unexpectedly positive relationship with speed during the winter and the late melt season (Figures 4-22 c, 4-23 c). The main difference between the two years is effective pressure and speed exhibiting a positive relationship in the earlymelt season in 2009, whereas this relationship is significantly negative (2010 distributed models) or insignificantly negative (2010 discrete models) in the 2010 early melt season. This difference may be related to the magnitude of surface speed itself, as periods of high $\left(>150 \mathrm{~m} \mathrm{yr}^{-1}\right)$ surface speeds across the TerraSAR-X region (Figures 4-22 a, 4-23 a) yield the expected inverse relationship between effective pressures and speed in both 2009 and 2010 (Figures 4-22 c, 4-23 c). In 2009, the expected inverse relationship between effective pressures and speed only occurs after surface speeds across the TerraSAR-X region have risen above $150 \mathrm{~m} \mathrm{yr}^{-1}$ in the mid-melt season (Figures 4-22 c). Alternatively, the basal sliding model may be incorrect for the time periods with step changes in meltwater supply at the start and end of the melt season (Figures 4-22 a, 4-23 a).

Our results suggest a shifting importance of driving stress and effective pressures on ice flow over the melt season. Effective pressures are most important for surface speeds in the mid-melt season when they enhance the driving stress contribution to ice flow, while the constant driving stressinfluenced mainly by ice sheet thickness - provides more equivalent contributions to ice flow over the entire year. For 2009 and most of 2010, the relationship between driving stress depicts the expected positive relationship with surface speed for the winter and melt season (Figures 4-22 c, 4-23 c). Again, the divergence from the expected relationship occurs in the 2010 early- and late-melt seasons (Figure 4-23 c). This positive relationship in both years is mostly a result of the expected positive relationship between ice thickness and speed (and the expected inverse relationship between bed elevation (dependent on ice thickness) and speed), as the relationship between surface slope and speed is insignificant and weakly negative over the melt season (Figures 4-22 c, 4-23 c). These relationships for driving stress and ice thickness weaken or switch directions most often when there is a positive relationship between effective pressures and speed in the early- and late-melt seasons of 2009 and 
2010 (Figures 4-22 c, 4-23 c). This again suggests the basal sliding model may be incorrect for predicting ice flow in the early- and late-melt seasons.

The inconsistency we observe in the late-melt season between the model for basal sliding and the relationships between effective pressures and speed may be consistent with the hypothesis that changes in connectivity to the unchannelized portion of the subglacial drainage system controls latesummer ice flow [Andrews et al., 2014]. Importantly, these changes in connectivity to the unchannelized portion of the subglacial drainage system occur on daily timescales with a diurnal signal of runoff [Andrews et al., 2014; Hoffman et al., 2016]. We do not vary runoff input on diurnal timescales in our model, and effective pressures are entirely positive in the late-melt season when averaged over 11 days (Figures 4-17 e, 4-19 e). Thus, model-derived effective pressures as we have averaged them here may be inconsistent with the sliding law if velocities in this portion of the melt season are more dependent on daily fluctuations in effective pressures [Andrews et al., 2014].

The coherence estimates presented here place a wavelength dependence on the influence of bed topography and ice sheet thickness on melt season surface speedup by Joughin et al. [2013] of 10$30 \mathrm{~km}$ in the 2009 mid-melt season when speedup exceeds $100 \%$ of the winter speed (Figure 4-1 e). The equivalent 10-30 km wavelength dependence over the same time intervals has higher estimates of coherence for effective pressures (Figures 4-21, 4-22 d). At least in 2009, the results presented here indicate that effective pressures driven by subglacial hydrology can at times more fully explain melt season speedup compared to bed topography alone. In contrast, high coherence between effective pressures and speed up is not observed at all in the 2010 melt-season, and low to mid coherence estimates are observed between ice thickness and surface slope in the early- to mid-melt season (Figure 4-23 d).

Finally, we will make a brief comment on the difference in effective pressures averaged across the entire model domain between the average (2009) and high (2010) runoff years as it relates to observations of annual ice flow variability. Though we did not test the evolution of the model over decadal timescales, area-averaged effective pressures are lower in 2010 than in 2009 over both the melt season (Figures 4-13 d, 4-16 d) and the entire year $\left(N_{2009}=1.27 \mathrm{MPa} ; N_{2010}=1.08 \mathrm{MPa}\right.$ ) for distributed surface runoff input. This disparity also holds for discrete surface runoff input models. Taking driving stress as constant over the two years, lower effective pressures would promote higher 
basal sliding in both the 2010 melt season and year as compared to 2009 based on Eq. 4.1. In contrast, GPS observations in the model domain observed higher melt season and annual velocities in 2009 than in 2010 [Stevens et al., 2016a]. Furthermore, if Eq. 4.1 is correct, our results are inconsistent with long-term trends of annual ice velocity decrease and annual runoff increase on the Greenland Ice Sheet margin over the past three decades [Tedstone et al., 2015; van de Wal et al., 2015; Stevens et al., 2016a]. This suggests that the model for basal sliding combined with model-derived effective pressures is not a good predictor of annual variability in ice flow and that there are likely other processes acting to affect ice flow not included in the model.

\subsubsection{Robust subglacial flow pathways}

Overall drainage system morphology in 2009 and 2010 is equivalent across surface runoff input scenarios, with robust locations of high discharge at the margin and under inland ice (Figures 4-3, 44, 4-14, 4-15, 4-25). Both distributed and discrete models grow channels across the major bedrock ridge in the model domain, and this behavior is impartial to the inclusion of a pressure-dependent melting point (Figures 4-1 a, 4-3, 4-4, 4-14, 4-15, 4-25). This is contradictory to the static subglacial modeling of this area done by Stevens et al. [2016b] and Chu et al. [2016b], where subglacial drainage catchments are determined by steady state hydraulic potential fields. Catchments with outlets at the terminus of Sarqardleq or Alángordliup glaciers do not extend inland across the bedrock ridge except for when the water pressures are, perhaps unrealistically, set to above flotation across the entire region [Chu et al., 2016b].

Two key difference between the calculations of static subglacial catchments [Lewis and Smith, 2009; Lindbäck et al., 2015; Chu et al., 2016b; Stevens et al., 2016b] and the subglacial drainage development in this model and are an evolving hydraulic potential field and the inland growth of subglacial channels [Hewitt, 2013; Banwell et al., 2016]. In our model, channels grow perpendicular to the hydraulic potential field and inland from the ice sheet margin towards bedrock ridges (4-3, 4-4, 414, 4-15, 4-25). Local pressure lows around the channels affect the hydraulic potential and steer water in the sheet layer towards the closest channel [Hewitt, 2013; Werder et al., 2013]. How easily a channel can grow in the model depends partially on the term $\lambda_{c}$ (Eq. 4.9), a width-scale along the bed over which sheet discharge contributes to channel initiation. Though $\lambda_{c}$ is difficult to estimate empirically, major drainage pathways develop across bedrock ridges for the wide range of $\lambda_{c}$ we tested (100-5000 
m) (Figure 4-8). Thus, in this model, the evolving subglacial water pressure field's sensitivity to channels may result in the ability for major drainage pathways to develop across bedrock ridges.

In contrast to interior subglacial catchments switching ice margin outlet locations or notions of "water piracy" [Lindbäck et al., 2015; Chu et al., 2016b], the positions of major drainage system pathways in the model are robust and do not switch over the melt season. Again, inland growth of subglacial channels and the time it takes to develop the channel networks likely prevents switching or redirecting of major drainage system pathways over the melt season.

Subglacial drainage models with evolving hydraulic potential fields likely yield more realistic subglacial flow pathways than calculations of subglacial catchments with static and/or spatially invariant water pressures. A physical interpretation of subglacial catchments that best aligns with our results is as follows: there is an interior region of low discharge velocities $\left(0.001-0.01 \mathrm{~m}^{2} \mathrm{~s}^{-1}(\sim 9-90\right.$ $\mathrm{m}^{2}$ day $\left.^{-1}\right)$ ), where water is mostly stored in the sheet layer until a channel growing from the margin into this interior region modifies the local hydraulic potential field to drive channelization and fast discharge velocities $\left(0.1-1 \mathrm{~m}^{2} \mathrm{~s}^{-1}\left(\sim 9,000-90,000 \mathrm{~m}^{2}\right.\right.$ day $\left.\left.{ }^{-1}\right)\right)$. As discharge velocities in the sheet layer are small, water in these inefficient systems may not travel far during the $\sim 10-20$ days that elapse before the onset of channelization (Figure 4-13 b,c). Thus, catchment area delineation is likely more important for regions of the bed that develop efficient drainage, as this drainage system has a much greater ability to evacuate large amounts of water.

\subsubsection{Model limitations and future directions}

The relationships between effective pressures and speed are roughly equivalent between the best-fit distributed and discrete surface runoff input scenarios. However, the model could be improved by making the timing and rate of surface runoff inputs to the bed increasingly more realistic. The model could be improved by testing the effect of diurnal runoff input oscillations on subglacial drainage system development [Banwell et al., 2016; Hoffman et al., 2016]. One could also prescribe storage time of supraglacial runoff, effectively lagging the time that meltwater first reaches the bed [de Fleurian et al., 2016]. Additionally, supraglacial meltwater input based on a regional lake drainage record could be implemented to investigate how the system responds to large impulses of meltwater [Banwell et al., 
2013; 2016]. To do this, elastic bending in the elastic sheet layer $h_{e l}$ must be added to prevent unrealistically high water pressures at moulin nodes where lake drainages occur.

Though endless modifications can be made to model supraglacial inputs and the model itself, efforts may be better spent validating coupled subglacial hydrology and ice flow models against observations [Flowers, 2015]. The subglacial hydrology model for this specific Greenland geometry could be coupled to the ice flow model of Hewitt [2013] to test if the relationships between subglacial drainage and surface speed we have shown are also upheld by the model's sliding law. Ice sheet surface speed measurements at increasingly high temporal resolution are available with the launch of the Sentinel-1 and Landsat-8 satellites [Fabnestock et al., 2015; Mouginot et al., 2017]. These measurements provide abundant opportunities to further test and muddy our theoretical ideas of how ice flows.

\subsection{Conclusions}

Using a numerical model of subglacial hydrology, we investigate how model-derived effective pressures relate to a complex spatiotemporal pattern of surface speed over the 2009 and 2010 melt seasons. We find equivalent relationships between effective pressure and speed for both distributed and discrete surface runoff input across a wide range of model parameters. Overall drainage system morphology is equivalent in both years, with robust subglacial pathways forming over bedrock ridges and minimal englacial or basal water storage outside of the melt season.

The results presented here indicate that subglacial hydrology can at times more fully explain melt season speedup compared to bed topography alone, especially during intervals in the mid-melt season when speeds exceed $150 \mathrm{~m} \mathrm{yr}^{-1}$. Consistently across 2009 and 2010, our results depict the expected inverse relationship between effective pressure and speed when surface speeds are high in the mid-melt season. Outside of these periods in the early- and late-melt season, effective pressures and speed have a positive relationship inconsistent with the basal sliding model, suggesting the basal sliding model may be incorrect or effective pressure may be less important for speed in comparison to the driving stress. Either subglacial hydrology models still need to improve to better predict effective pressures, or the models are lacking other processes affecting ice flow than effective pressure and driving stress. Future work should continue to calibrate models regional observations and 
investigate what further model advances are necessary for improving effective pressure estimates before coupling the subglacial hydrology model to an ice flow model.

Table 4-1: Values and ranges used for model parameters.

\begin{tabular}{cll}
\hline$\rho_{w}$ & Water density & $1000 \mathrm{~kg} \mathrm{~m}^{-3}$ \\
$\rho_{i}$ & Ice density & $910 \mathrm{~kg} \mathrm{~m}^{-3}$ \\
$g$ & Gravitational acceleration & $9.8 \mathrm{~m} \mathrm{~s}^{-2}$ \\
$A$ & Glen's law fluidity coefficient & $6.8 \times 10^{-24} \mathrm{~Pa}^{-3} \mathrm{~s}^{-1}$ \\
$n$ & Glen's law exponent & 3 \\
$L$ & Latent heat of melting & $3.5 \times 10^{5} \mathrm{~J} \mathrm{~kg}^{-3}$ \\
$G$ & Greenland geothermal heat flux & $0.063 \mathrm{~W} \mathrm{~m}^{-2} * *$ \\
$\sigma$ & Englacial void fraction & {$\left[10^{-4}, 10^{-3}, 10^{-2}\right]$} \\
$K_{c}$ & Turbulent flow coefficient for channel flow & $0.1 \mathrm{~m} \mathrm{~s}^{-1} \mathrm{~Pa}^{-1 / 2}$ \\
$K_{s}$ & Sheet flux coefficient (sheet permeability) & {$\left[10^{-4}, 10^{-3}, 10^{-2}\right] \mathrm{m}^{-1} \mathrm{~s}^{-1} *$} \\
$\lambda_{c}$ & Sheet width contributing to melting & {$[100 ; 1000 ; 5000] \mathrm{m}^{*}$} \\
$c$ & Specific heat capacity of water & $4200 \mathrm{~J} \mathrm{~kg}^{-1} \mathrm{~K}^{-1}$ \\
$\beta$ & Melting point pressure gradient & $7.8 \times 10^{-8} \mathrm{~K} \mathrm{~Pa}^{-1}$ \\
$h_{r}$ & Bed roughness height scale & $0.1 \mathrm{~m}^{-1}$ \\
$l_{r}$ & Bed roughness length scale & $10 \mathrm{~m}^{-1}$ \\
$U_{b}$ & Basal sliding speed & $100 \mathrm{~m} \mathrm{yr}^{-1}$ \\
$C_{e l}$ & Uplift regularization rate & $1.02 \times 10^{-6} \mathrm{~m} \mathrm{~Pa}^{-1}$ \\
$A_{m}$ & Moulin cross-sectional area & $10 \mathrm{~m}^{2}$ \\
\hline
\end{tabular}

* range of values that differs from Banwell et al. (2016)

** value from Rogozhina et al. [2012] 

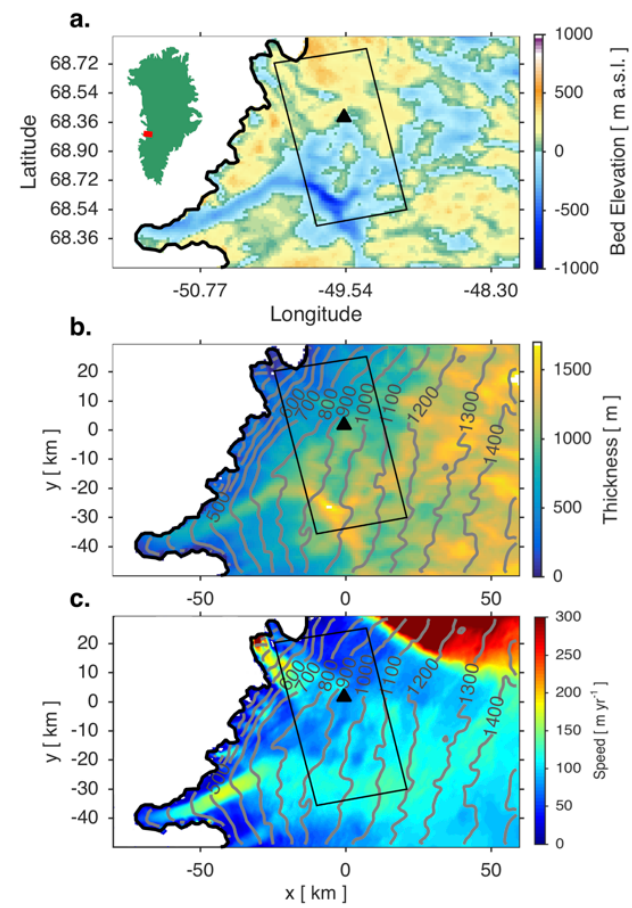

d.

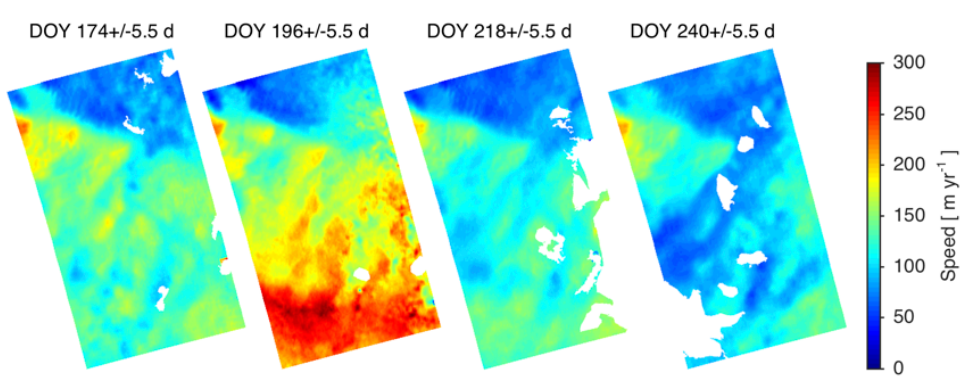

e.

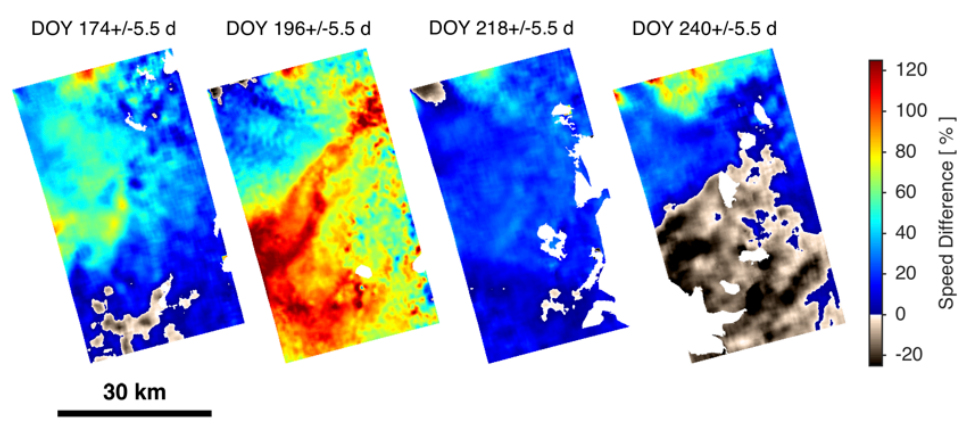

Figure 4-1. Model domain and ice sheet velocities. (a) Bedrock topography of the model domain, with ice sheet margin outlined in black. Black triangle marks the location of North Lake. Black rectangle is the area outline of the flow speed maps displayed in Figs. 1c-e. (b) Ice sheet thickness of the model domain. Grey contour lines show 100-m surface ice elevation contours. (c) Average winter flow speed from the MEaSUREs Multi-year Greenland Ice Sheet Velocity Mosaic (Version 1) from Joughin et al. [2010, 2016]. (d) From Joughin et al. [2013], summer 2009 flow speeds from 11-day interval TerraSAR-X images. The date at the top of the panel corresponds to the central date for the 11-day interval over which the velocity was determined. (e) From Joughin et al. [2013], increase in summer 2009 flow speeds relative to the 2007-2009 winter speed (c) plotted as a percentage difference of the winter speed. The date at the top of the panel corresponds to the central date for the 11-day interval over which the velocity was determined. 


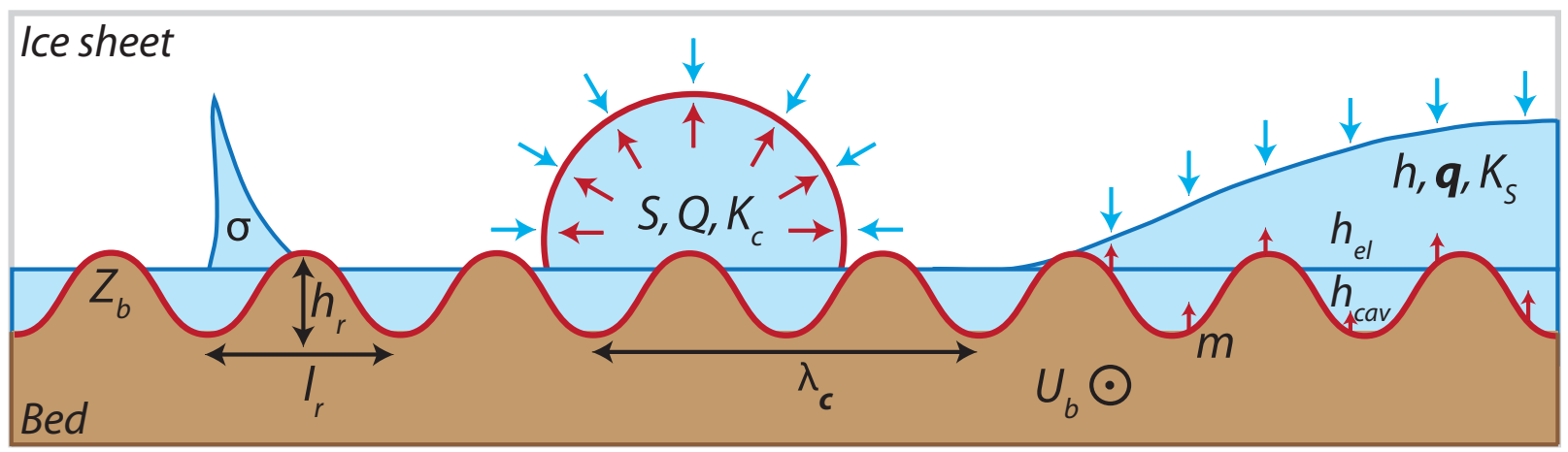

Figure 4-2. Cross-section schematic of subglacial hydrology model. From left to right, the schematic depicts englacial voids $\sigma$, channels, and cavities of the subglacial hydrology model. The cavity sheet $h_{c a v}$ and elastic sheet $h_{e l}$ sum to the thickness of the continuous sheet $h$. The cavity layer $h_{c a v}$ is bounded by bed undulations of height scale $h_{r}$ and length scale $l_{r}$. Melt (red arrows) and creep closure (blue arrows) control the growth and decay of channel and cavity elements. The schematic is not to scale. 

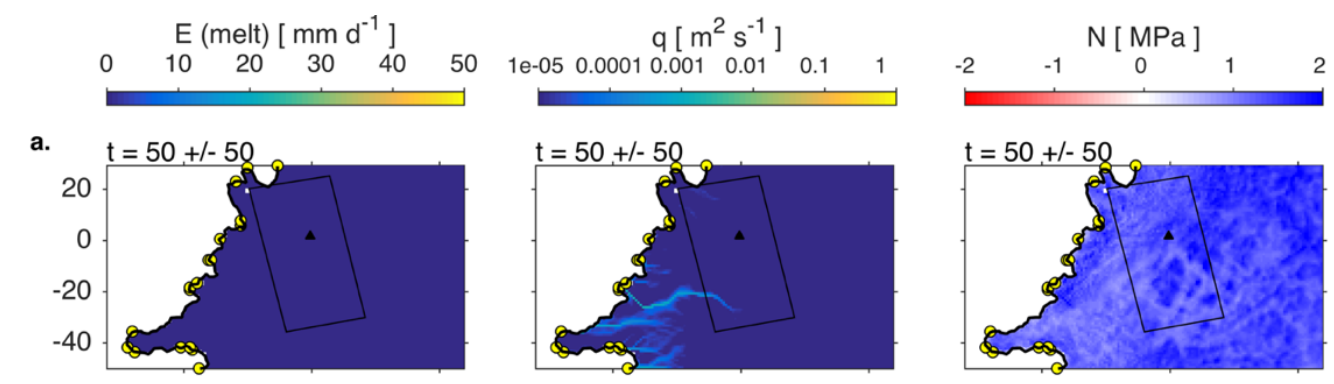

b.
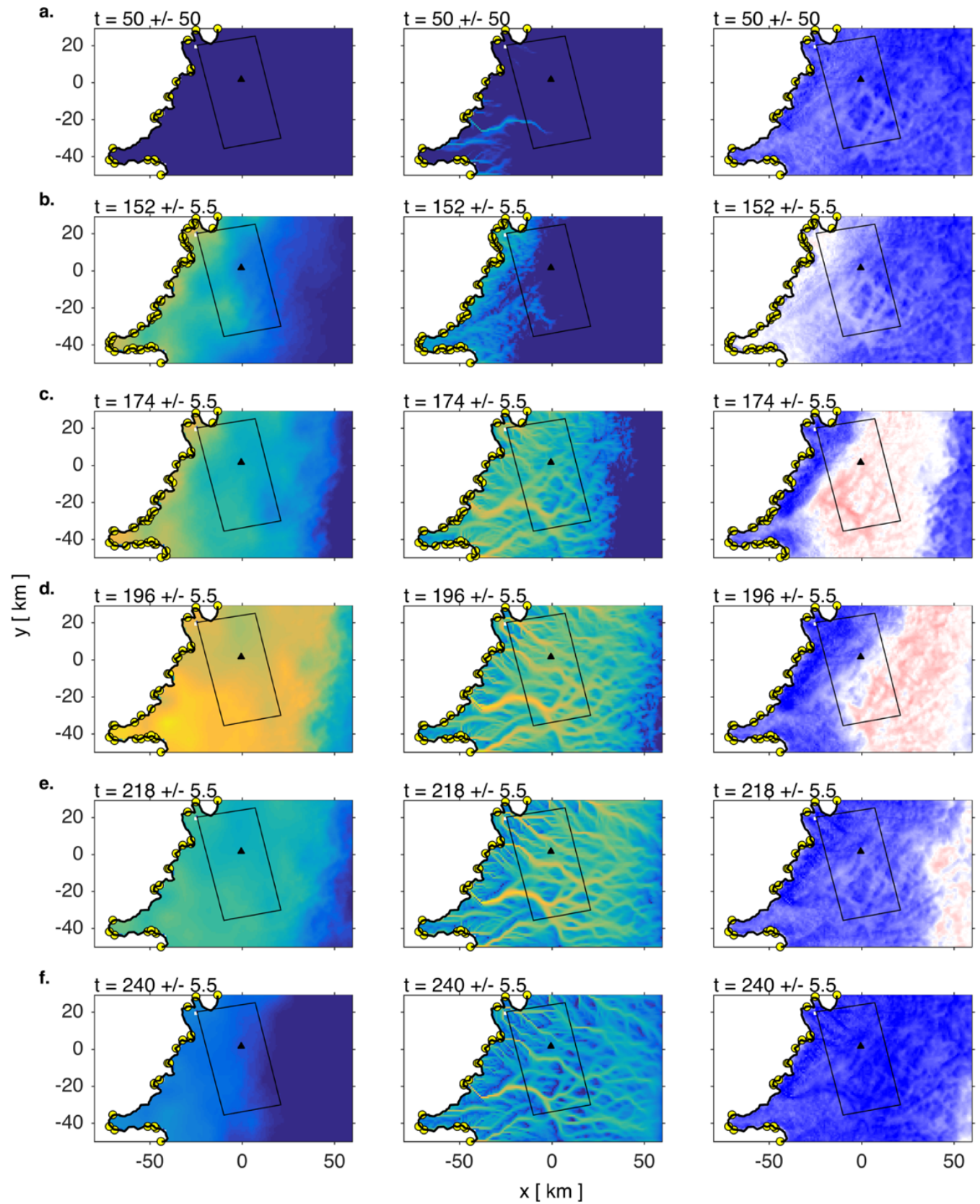

Figure 4-3. Averages of surface melt forcing, $\mathrm{E}\left(\mathrm{mm} \mathrm{day}^{-1}\right)$ (left column), subglacial water discharge, $\mathrm{q}\left(\mathrm{m}^{2} \mathrm{~s}^{-1}\right)$ (middle column), and effective pressure, $\mathrm{N}(\mathrm{MPa})$ (right column), over the 2009 melt season for a distributed surface input scenario. The date at the top of the panel corresponds to the central date for the interval over which the model outputs were determined. The top panels (a) are averages over the first 100 days of the year. The middle four rows of panels $(\mathbf{b}-\mathbf{e})$ are 11-day averages corresponding to the dates of summer flow speeds in Figs. $1 \mathrm{~d}$ and $1 \mathrm{e}$. For this model run, $\mathrm{K}_{\mathrm{s}}=0.001$ $\mathrm{Pa}^{-1} \mathrm{~s}^{-1}, \sigma=0.001$, and $\lambda_{c}=1000 \mathrm{~m}$. Black rectangle is the area outline of the ice flow maps in Figs. 1c-e. Black triangle marks the location of North Lake. Yellow circles mark discharge outlet locations along the ice sheet margin. 

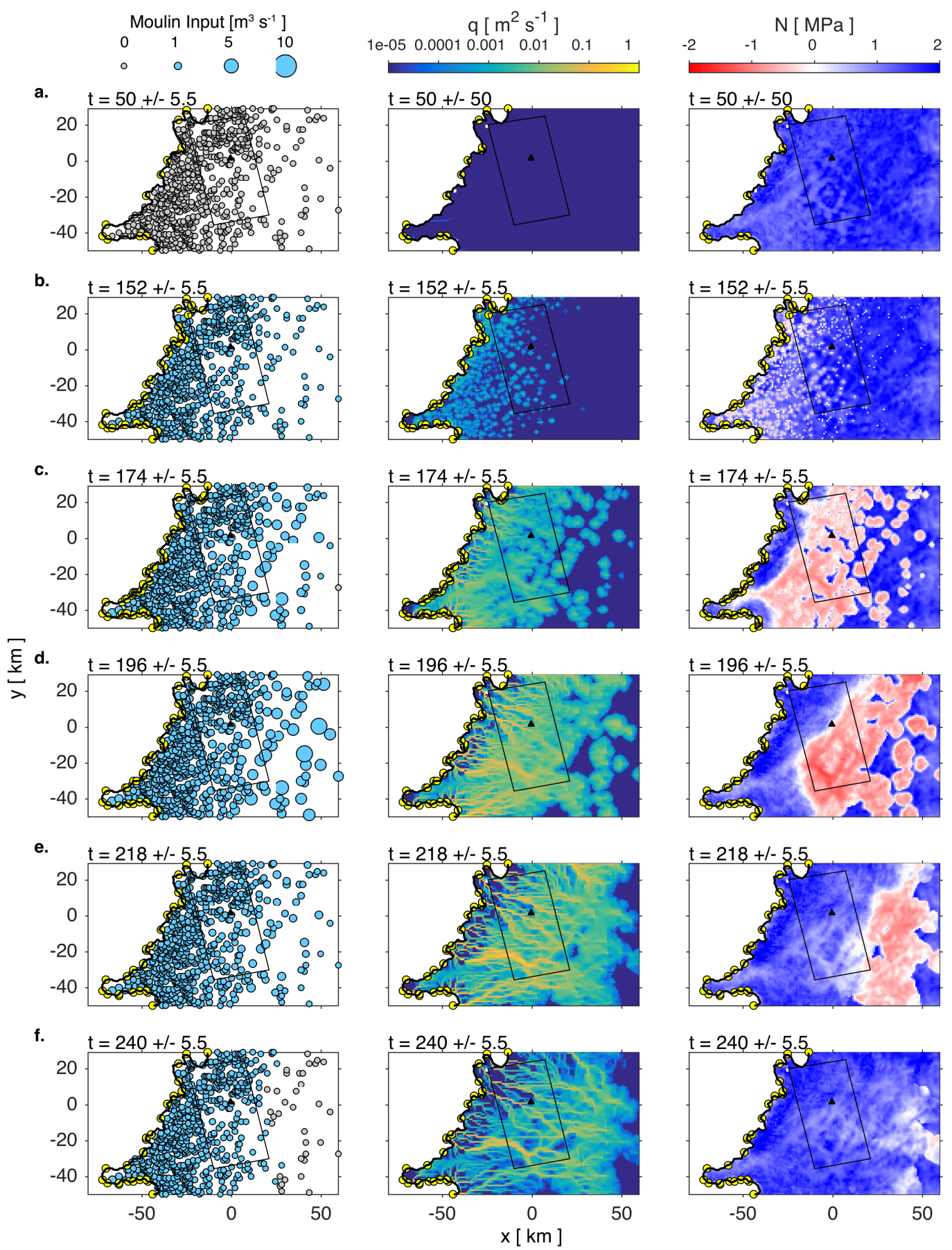

Figure 4-3. Averages of moulin input $\left(\mathrm{m}^{3} \mathrm{~s}^{-1}\right)$ (left column), subglacial water discharge, $\mathrm{q}\left(\mathrm{m}^{2} \mathrm{~s}^{-1}\right)$ (middle column), and effective pressure, N (MPa) (right column), over the 2009 melt season for a discrete surface input scenario. The date at the top of the panel corresponds to the central date for the interval over which the model outputs were determined. The top panels (a) are averages over the first 100 days of the year. The middle four rows of panels $(\mathbf{b}-\mathbf{e})$ are 11-day averages corresponding to the dates of summer flow speeds in Figs. $1 \mathrm{~d}$ and $1 \mathrm{e}$. For this model run, $\mathrm{K}_{\mathrm{s}}=0.001 \mathrm{~Pa}^{-1} \mathrm{~s}^{-1}, \sigma=0.001$, and $\lambda_{c}=1000 \mathrm{~m}$. Black rectangle is the area outline of the ice flow maps in Figs. 1c-e. Black triangle marks the location of North Lake. Yellow circles mark discharge outlet locations along the ice sheet margin. 
a.
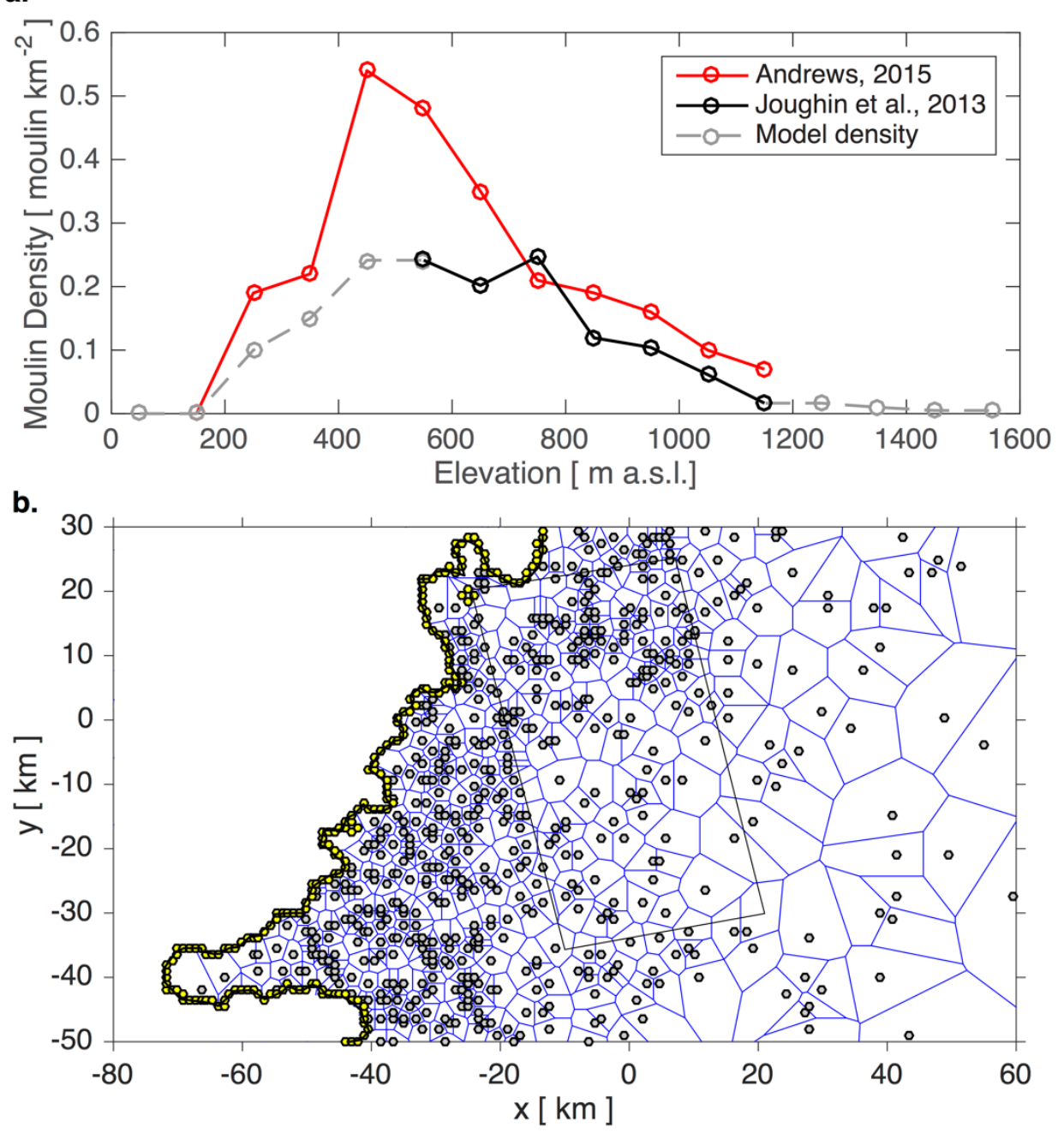

Figure 4-5. Moulin density and discrete surface runoff catchment delineation. (a) Moulin density versus elevation from Joughin et al. [2013] map (black), the Paakitsoq region (red) [Andrews, 2015], and the model domain (grey). (b) Vonronoi cells calculated for discrete moulin locations $\boldsymbol{x}_{\boldsymbol{m}}$ (grey circles). Yellow circles denote all potential ice margin discharge locations at the initial timestep. 

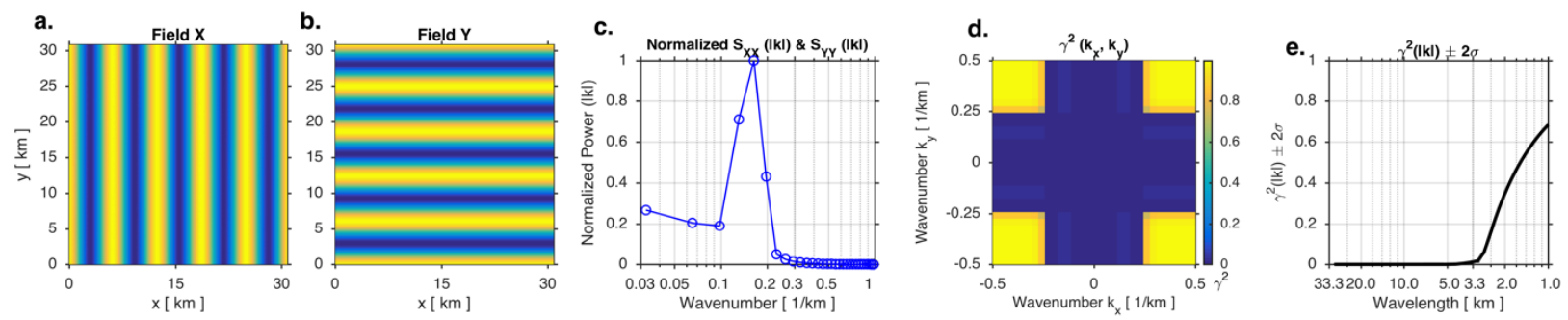

Figure 4-6. Coherence-square estimation of synthetic data. 2-dimensional, 6-km wavelength sine wave along the (a) x-axis and (b) y-axis. c) Isotropically averaged power of the two fields' power spectral densities, $\boldsymbol{S}_{\boldsymbol{X} \boldsymbol{X}}$ and $\boldsymbol{S}_{\boldsymbol{Y} \boldsymbol{Y}}$, plotted by wavenumber. Power is plotted normalized to the maximum value in each fields' isotropically averaged power. Power for each field peaks at $0.1 \overline{6}$ wavenumber, which is at $6-\mathrm{km}$ wavelength (wavenumber $=1$ /wavelength). $\mathbf{d}$ ) The coherence-square estimates between fields X (a) and Y (b) in wavenumber space, $\gamma^{2}\left(\boldsymbol{k}_{\boldsymbol{X}}, \boldsymbol{k}_{\boldsymbol{Y}}\right)$, where the smallest wavenumbers (largest, Rayleigh wavelengths) plot in the center of $\operatorname{plot}\left(\boldsymbol{k}_{\boldsymbol{X}}=\lambda_{R}, \boldsymbol{k}_{\boldsymbol{Y}}=\lambda_{R}\right)$, and the largest wavenumbers (smallest, Nyquist wavelengths) plot at the edges of the plot. The scale for the $\boldsymbol{k}_{\boldsymbol{X}}$ and $\boldsymbol{k}_{\boldsymbol{Y}}$ axes are linear in wavenumber. Wavenumber axis is log scale. Zero coherence is observed along the $\boldsymbol{k}_{\boldsymbol{X}}$ and $\boldsymbol{k}_{\boldsymbol{Y}}$ axes where the two fields have destructive interference. Coherence between the two fields switches to 1 at wavenumbers above 0.25 and wavelengths smaller than $4 \mathrm{~km}$. e) The isotropically averaged coherence-square estimate, $\gamma^{2}(|\boldsymbol{k}|) \pm 2 \sigma$, between fields $\mathbf{a}$ and $\mathbf{b}$. The $\log \mathrm{x}$ axis is equivalent to the axis in panel $\mathbf{c}$, but $\mathrm{x}$-axis tickmarks are now labeled in wavelength. 
a.

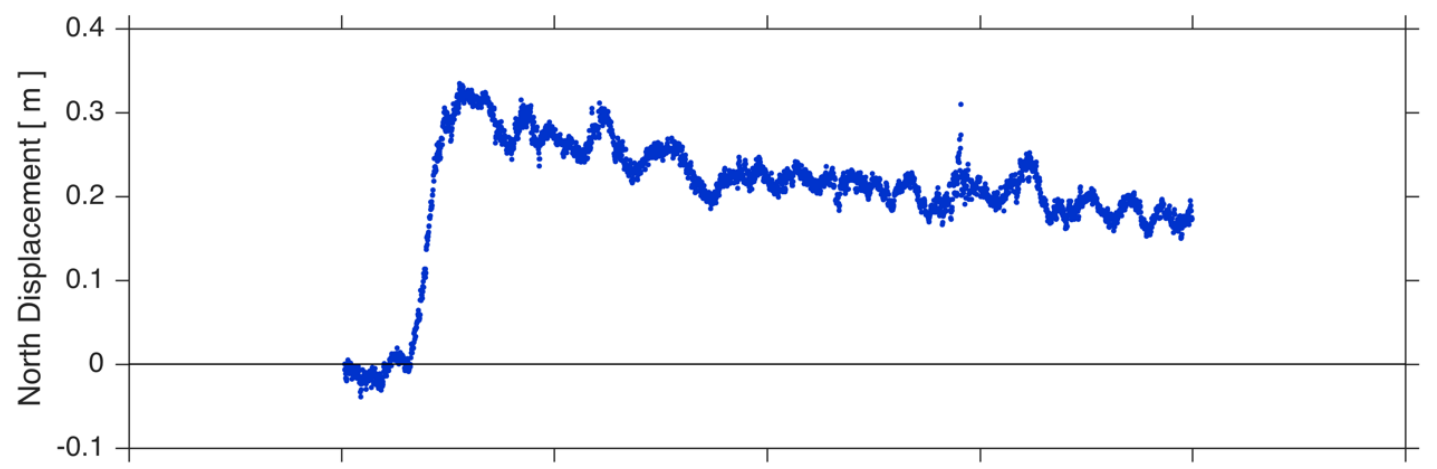

b.

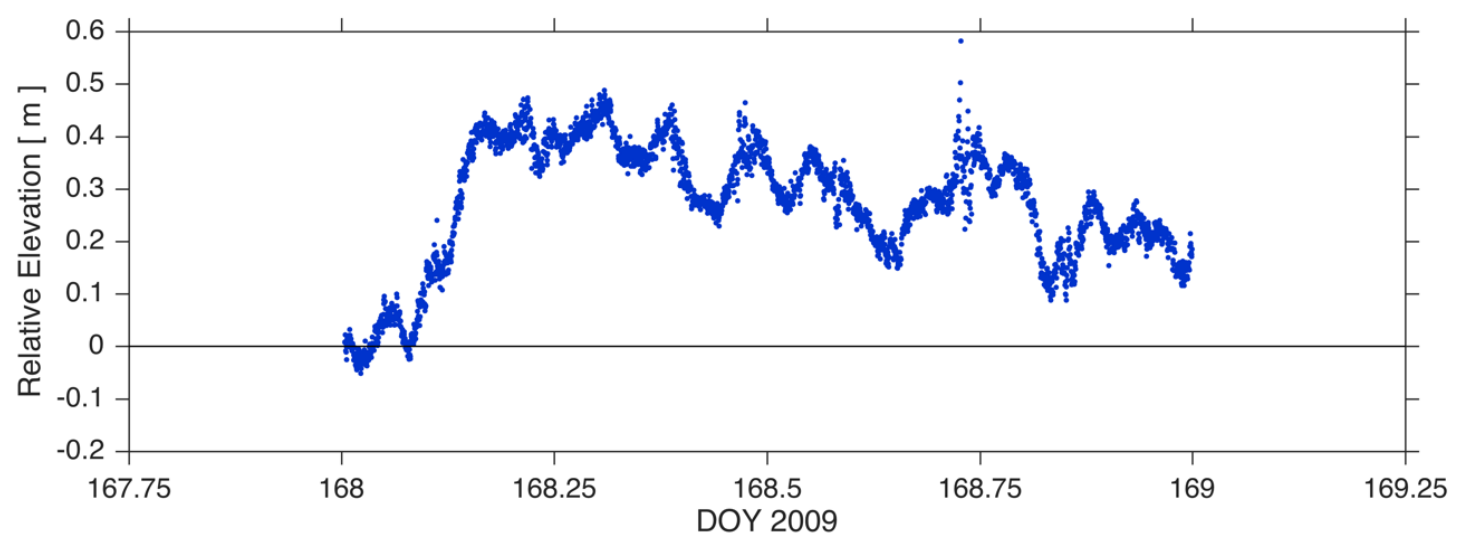

Figure 4-7: Surface ice displacement during the rapid drainage of North Lake on 2009 DOY 168. (a) North and (b) uplift displacement of the "Scooby" GPS station $\left(68.74^{\circ} \mathrm{N}-49.50^{\circ} \mathrm{W}\right)$ during a North Lake rapid drainage event. Scooby is $\sim 1 \mathrm{~km}$ north of the lake margin. Mean station northing $\left(0.044 \mathrm{~m} \mathrm{day}^{-1}\right)$ and elevation $\left(0.024 \mathrm{~m} \mathrm{day}^{-1}\right)$ rate over DOY 161-162 are subtracted to remove background eastward movement and elevation gain from station advection through North Lake basin. 
Distributed Surface Input $(\sigma=0.001)$

a. 2009 DOY 174

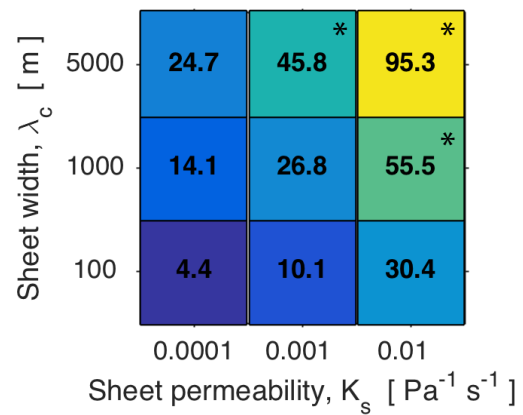

b. 2009 DOY 196

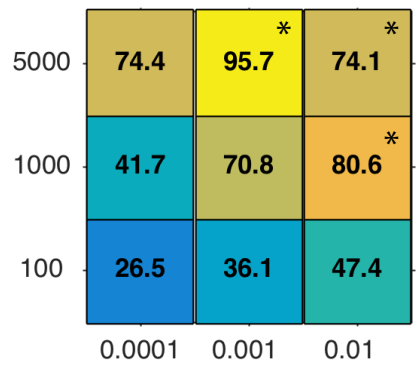

Sheet permeability, $\mathrm{K}_{\mathrm{s}}\left[\mathrm{Pa}^{-1} \mathrm{~s}^{-1}\right]$

\section{2009 DOY 218}

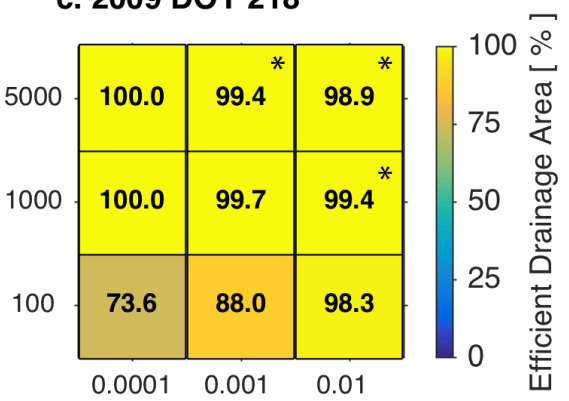

Sheet permeability, $\mathrm{K}_{\mathrm{s}}\left[\mathrm{Pa}^{-1} \mathrm{~s}^{-1}\right]$

Discrete (Moulin) Surface Input $(\sigma=0.001)$

\section{d. 2009 DOY 174}

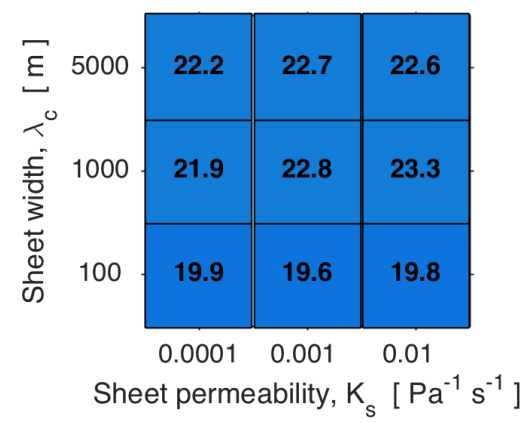

e. 2009 DOY 196

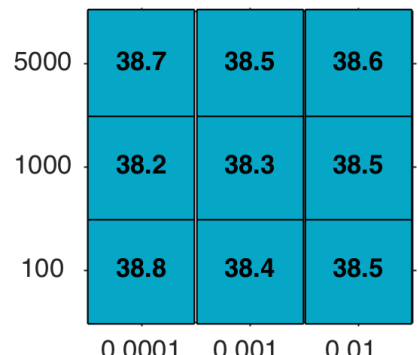

Sheet permeability, $\mathrm{K}_{\mathrm{s}}\left[\mathrm{Pa}^{-1} \mathrm{~s}^{-1}\right]$

\section{f. 2009 DOY 218}

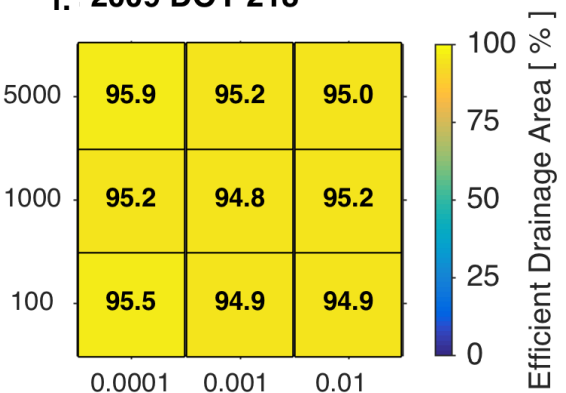

Sheet permeability, $\mathrm{K}_{\mathrm{s}}\left[\mathrm{Pa}^{-1} \mathrm{~s}^{-1}\right]$

Figure 4-8. Region of efficient drainage area increases at different rates across model parameter space. Percentage of efficient drainage area across $K_{s}$ and $\lambda_{c}$ parameter space for distributed surface input models on DOY (a) 174, (b) 196, and (c) 218 of 2009. Percentage of efficient drainage area across $\mathrm{K}_{\mathrm{s}}$ and $\lambda_{c}$ parameter space for discrete surface input models on DOY (d) 174 , (e) 196, and (f) 218 of 2009. Efficient drainage area (EDA) is defined as the area within the TerraSAR$\mathrm{X}$ region where $\mathrm{N}>0$ and $\boldsymbol{q}>0.001 \mathrm{~m}^{2} \mathrm{~s}^{-1} . \sigma=0.001$ for all models. Asterisks mark models that fail to meet 2009 lake drainage criterion (EDA < 40\% on DOY 1742009 and EDA > 40\% on DOY 218 2009). 
Distributed Surface Input $(\sigma=0.01)$

a. 2009 DOY 174

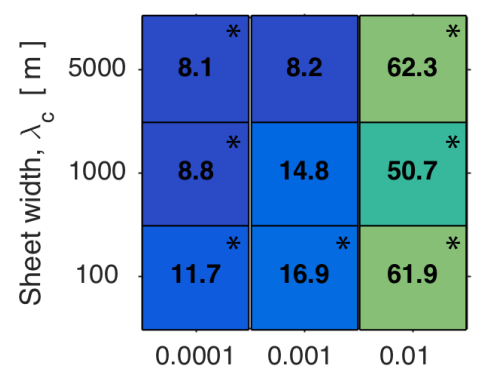

Sheet permeability, $\mathrm{K}_{\mathrm{s}}\left[\mathrm{Pa}^{-1} \mathrm{~s}^{-1}\right]$ b. 2009 DOY 196

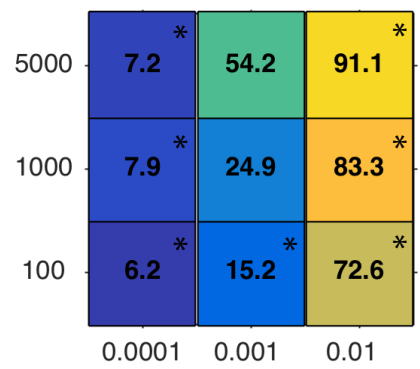

Sheet permeability, $\mathrm{K}_{\mathrm{s}}\left[\mathrm{Pa}^{-1} \mathrm{~s}^{-1}\right]$ c. 2009 DOY 218

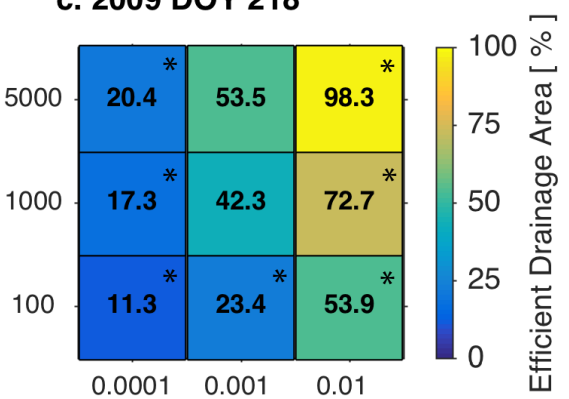

Sheet permeability, $\mathrm{K}_{\mathrm{s}}\left[\mathrm{Pa}^{-1} \mathrm{~s}^{-1}\right]$

Distributed Surface Input $(\sigma=0.0001)$

d. 2009 DOY 174

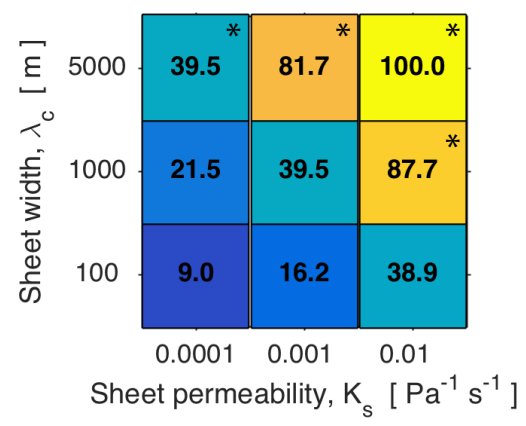

e. 2009 DOY 196

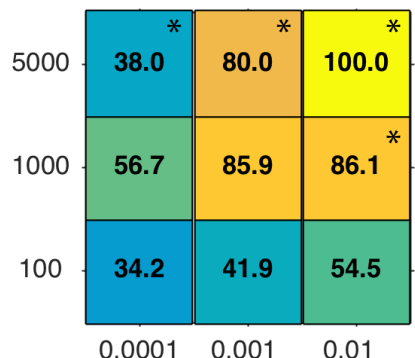

Sheet permeability, $\mathrm{K}_{\mathrm{s}}\left[\mathrm{Pa}^{-1} \mathrm{~s}^{-1}\right]$ f. 2009 DOY 218

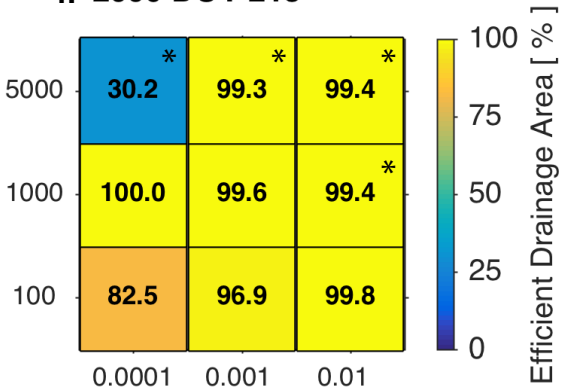

Sheet permeability, $\mathrm{K}_{\mathrm{s}}\left[\mathrm{Pa}^{-1} \mathrm{~s}^{-1}\right]$

Figure 4-9. Region of efficient drainage area for 2009 distributed surface runoff input at $\sigma=$ 0.01 and $\boldsymbol{\sigma}=\mathbf{0 . 0 0 0 1}$. Percentage of efficient drainage area across $K_{s}$ and $\lambda_{c}$ parameter space for distributed surface input models on $\operatorname{DOY}$ (a) 174, (b) 196, and (c) 218 of 2009 with $\sigma=0.01$. Percentage of efficient drainage area across $\mathrm{K}_{\mathrm{s}}$ and $\lambda_{c}$ parameter space for distributed surface input models on DOY (d) 174, (e) 196, and (f) 218 of 2009 with $\sigma=0.0001$. Efficient drainage area is defined as the area within the TerraSAR-X region where $N>0$ and $\boldsymbol{q}>0.001 \mathrm{~m}^{2} \mathrm{~s}^{-1}$. Asterisks mark models that fail to meet lake drainage criterion. 
Discrete (Moulin) Surface Input $(\sigma=0.01)$

a. 2009 DOY 174

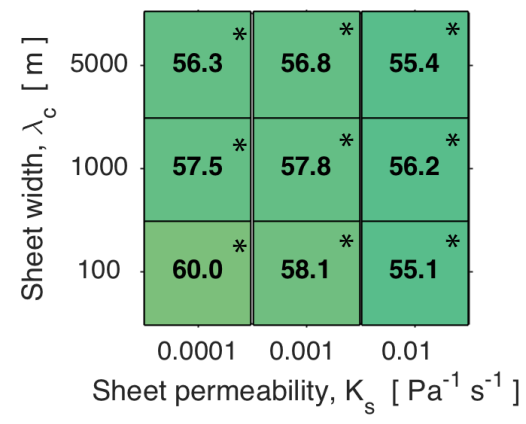

b. 2009 DOY 196

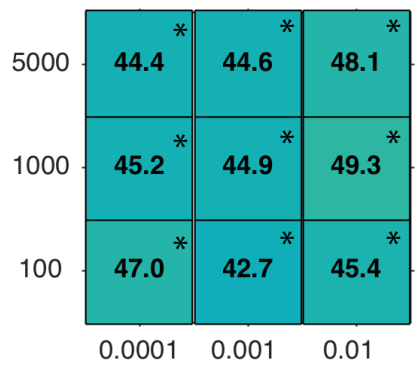

Sheet permeability, $\mathrm{K}_{\mathrm{s}}\left[\mathrm{Pa}^{-1} \mathrm{~s}^{-1}\right]$ c. 2009 DOY 218

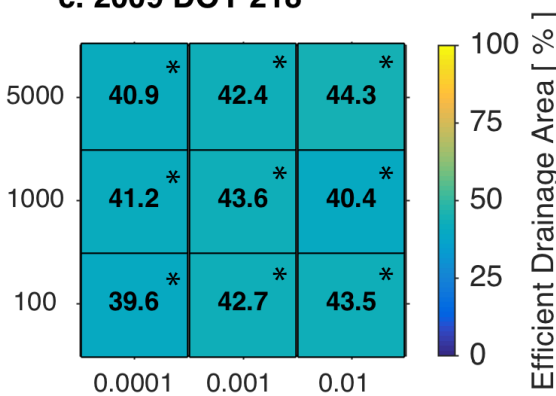

Sheet permeability, $\mathrm{K}_{\mathrm{s}}\left[\mathrm{Pa}^{-1} \mathrm{~s}^{-1}\right]$

Discrete (Moulin) Surface Input ( $\sigma=0.0001)$

\section{d. 2009 DOY 174}

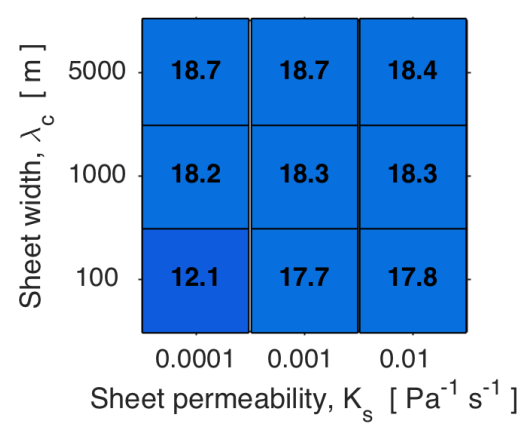

e. 2009 DOY 196

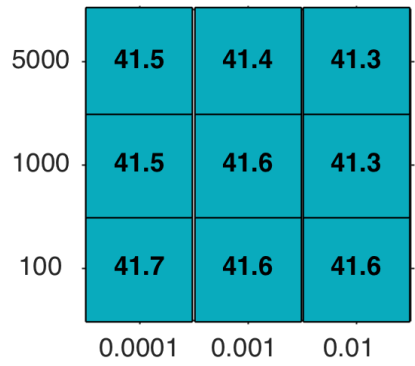

Sheet permeability, $\mathrm{K}_{\mathrm{s}}\left[\mathrm{Pa}^{-1} \mathrm{~s}^{-1}\right]$ f. 2009 DOY 218

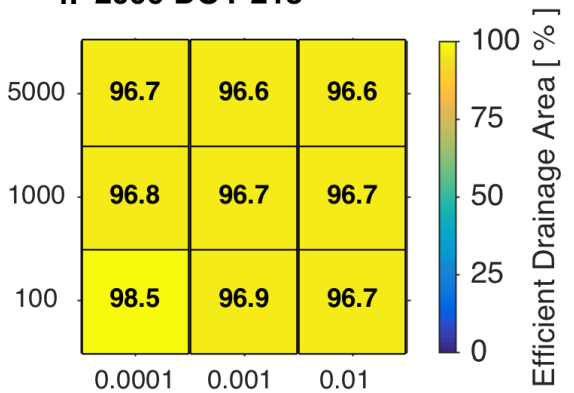

Sheet permeability, $\mathrm{K}_{\mathrm{s}}\left[\mathrm{Pa}^{-1} \mathrm{~s}^{-1}\right]$

Figure 4-10. Region of efficient drainage area for 2009 discrete surface runoff input at $\sigma=$ 0.01 and $\boldsymbol{\sigma}=\mathbf{0 . 0 0 0 1}$. Percentage of efficient drainage area across $K_{s}$ and $\lambda_{c}$ parameter space for discrete surface input models on DOY (a) 174, (b) 196, and (c) 218 of 2009 with $\sigma=0.01$. Percentage of efficient drainage area across $\mathrm{K}_{\mathrm{s}}$ and $\lambda_{c}$ parameter space for discrete surface input models on DOY (d) 174, (e) 196, and (f) 218 of 2009 with $\sigma=0.0001$. Efficient drainage area is defined as the area within the TerraSAR-X region where $N>0$ and $\boldsymbol{q}>0.001 \mathrm{~m}^{2} \mathrm{~s}^{-1}$. Asterisks mark models that fail to meet lake drainage criterion. 
High Englacial Storage Volume $(\sigma=0.01)$
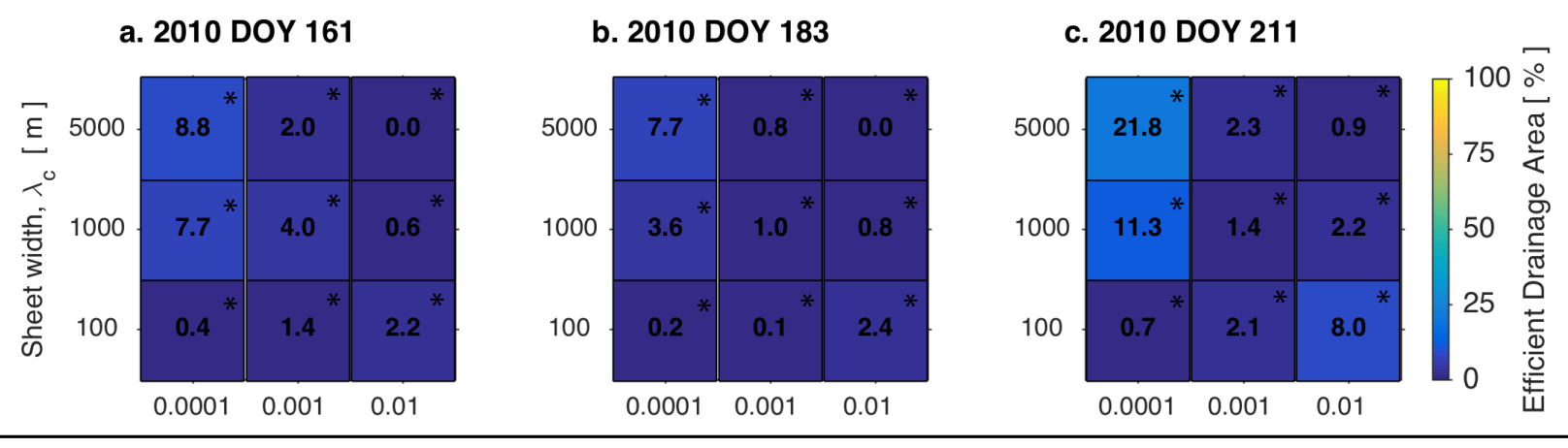

Medium Englacial Storage Volume $(\sigma=0.001)$

d. 2010 DOY 161

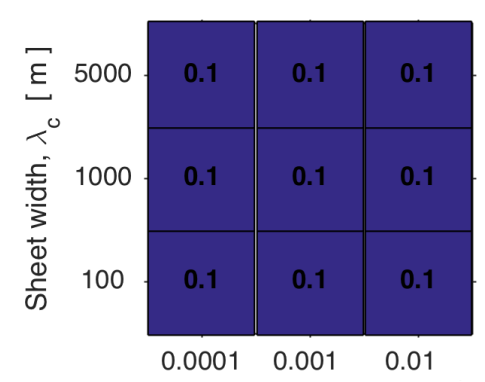

e. 2010 DOY 183

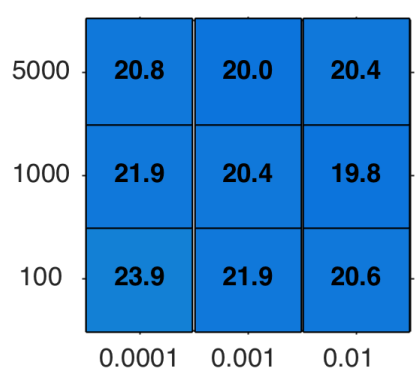

g. 2010 DOY 161

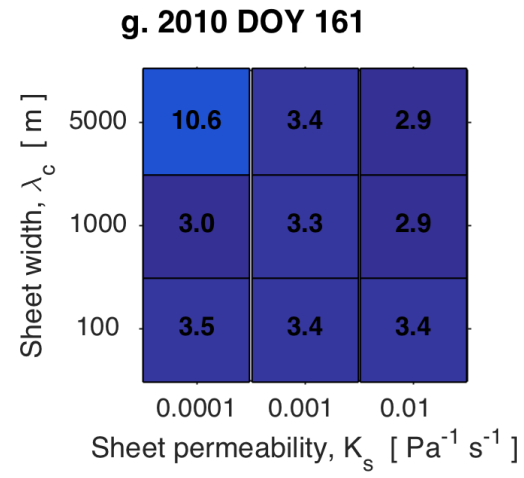

Sheet permeability, $\mathrm{K}_{\mathrm{s}}\left[\mathrm{Pa}^{-1} \mathrm{~s}^{-1}\right]$ h. 2010 DOY 183

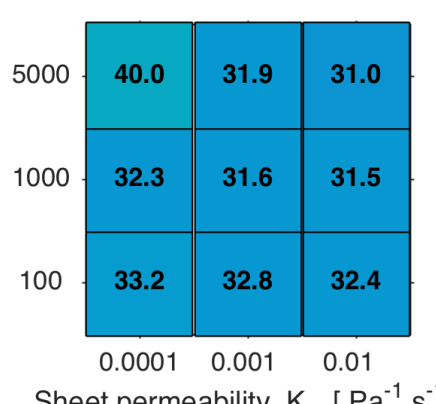

Sheet permeability, $\mathrm{K}_{\mathrm{s}}\left[\mathrm{Pa}^{-1} \mathrm{~s}^{-1}\right]$
Low Englacial Storage Volume $(\sigma=0.0001)$

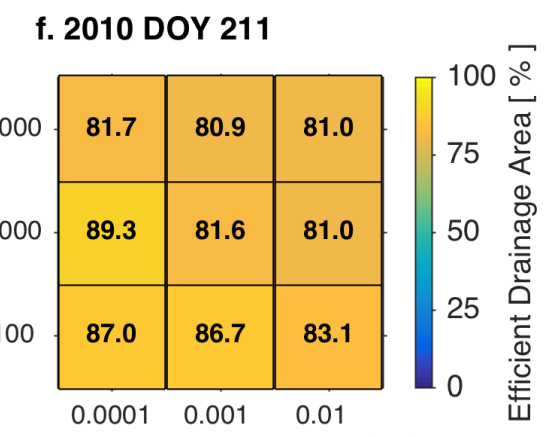

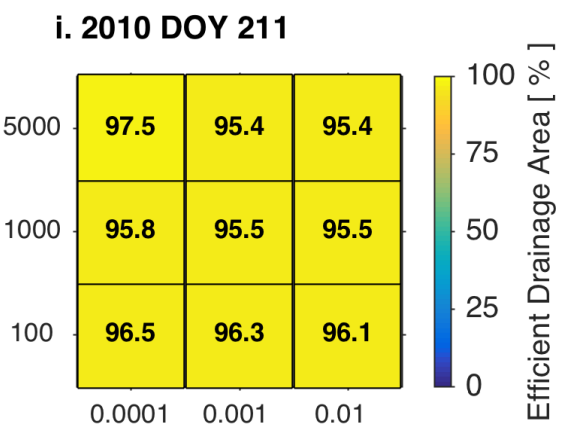

Sheet permeability, $\mathrm{K}_{\mathrm{s}}\left[\mathrm{Pa}^{-1} \mathrm{~s}^{-1}\right]$

Figure 4-11. Region of efficient drainage area for 2010 distributed surface runoff input. Percentage of efficient drainage area across $K_{s}$ and $\lambda_{c}$ parameter space for distributed surface input models on DOY 161, 183, and 211 of 2010. Efficient drainage area (EDA) is defined as the area within the TerraSAR-X region where $\mathrm{N}>0$ and $\mathrm{q}>0.001 \mathrm{~m}^{2} \mathrm{~s}^{-1}$. Englacial void fraction $\sigma$ decreases down the three rows of the figure from $\sigma=0.01(\mathrm{a}-\mathrm{c})$, to $\sigma=0.001(\mathrm{~d}-\mathrm{f})$, to $\sigma=0.0001(\mathrm{~g}-\mathrm{i})$. Asterisks mark models that fail to meet 2009 lake drainage criterion $(\mathrm{EDA}<40 \%$ on DOY 174 and EDA $>$ $40 \%$ on DOY 218 ). 
High Englacial Storage Volume $(\sigma=0.01)$

a. 2010 DOY 161

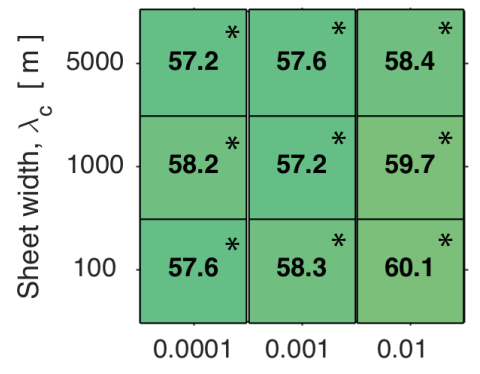

b. 2010 DOY 183

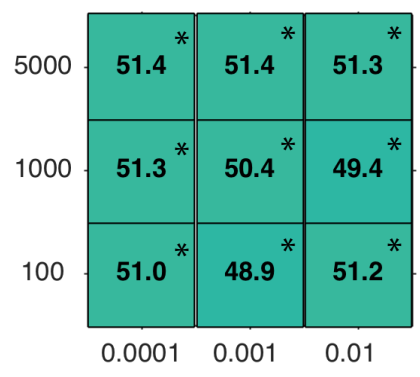

c. 2010 DOY 211

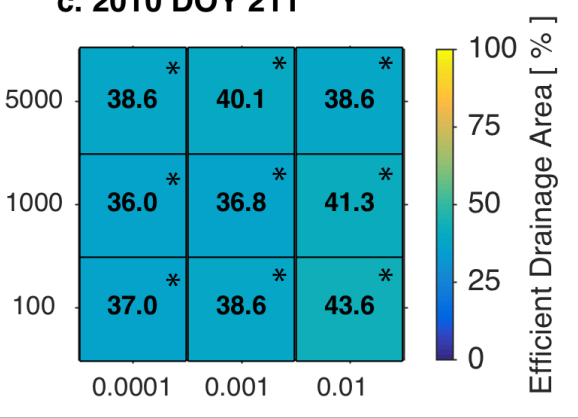

Medium Englacial Storage Volume $(\sigma=0.001)$

d. 2010 DOY 161

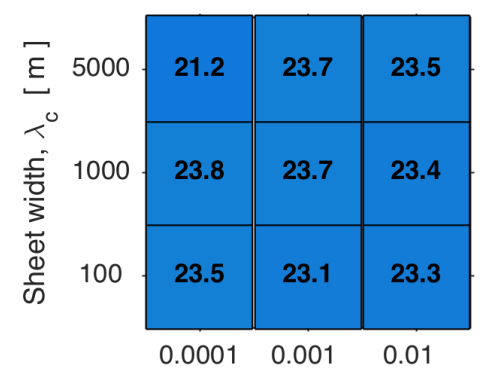

e. 2010 DOY 183

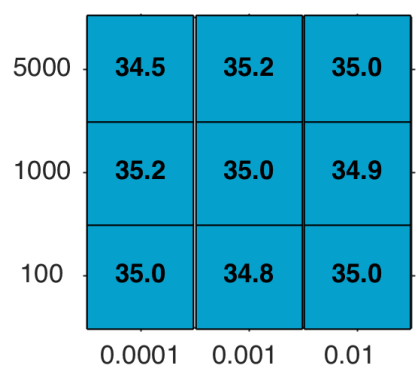

\section{f. 2010 DOY 211}

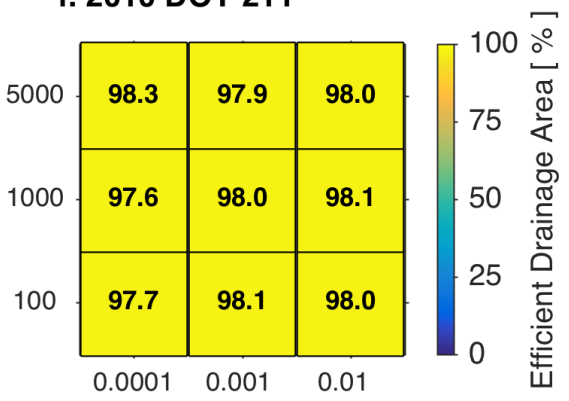

Low Englacial Storage Volume ( $\sigma=0.0001)$

g. 2010 DOY 161

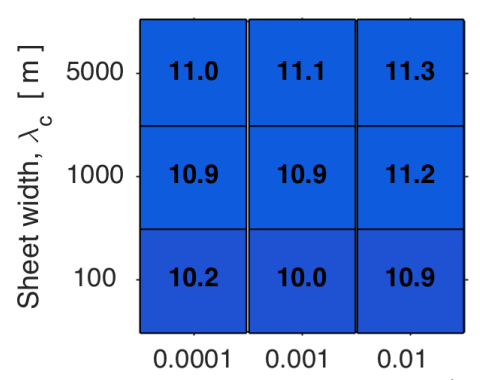

Sheet permeability, $\mathrm{K}_{\mathrm{s}}\left[\mathrm{Pa}^{-1} \mathrm{~s}^{-1}\right]$ h. 2010 DOY 183

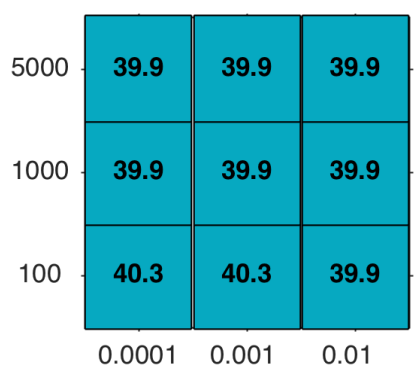

Sheet permeability, $\mathrm{K}_{\mathrm{s}}\left[\mathrm{Pa}^{-1} \mathrm{~s}^{-1}\right]$

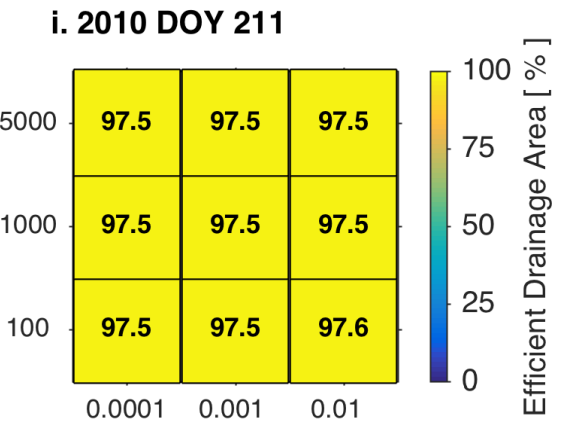

Sheet permeability, $\mathrm{K}_{\mathrm{s}}\left[\mathrm{Pa}^{-1} \mathrm{~s}^{-1}\right]$

Figure 4-12. Region of efficient drainage area for 2010 discrete surface runoff input. Percentage of efficient drainage area across $\mathrm{K}_{\mathrm{s}}$ and $\lambda_{c}$ parameter space for discrete surface input models on DOY 161, 183, and 211 of 2010. Efficient drainage area (EDA) is defined as the area within the TerraSAR$\mathrm{X}$ region where $\mathrm{N}>0$ and $\boldsymbol{q}>0.001 \mathrm{~m}^{2} \mathrm{~s}^{-1}$. Englacial void fraction $\sigma$ decreases down the three rows of the figure from $\sigma=0.01(\mathrm{a}-\mathrm{c})$, to $\sigma=0.001(\mathrm{~d}-\mathrm{f})$, to $\sigma=0.0001(\mathrm{~g}-\mathrm{i})$. Asterisks mark models that fail to meet 2009 lake drainage criterion (EDA $<40 \%$ on DOY 174 and EDA $>40 \%$ on DOY 218). 

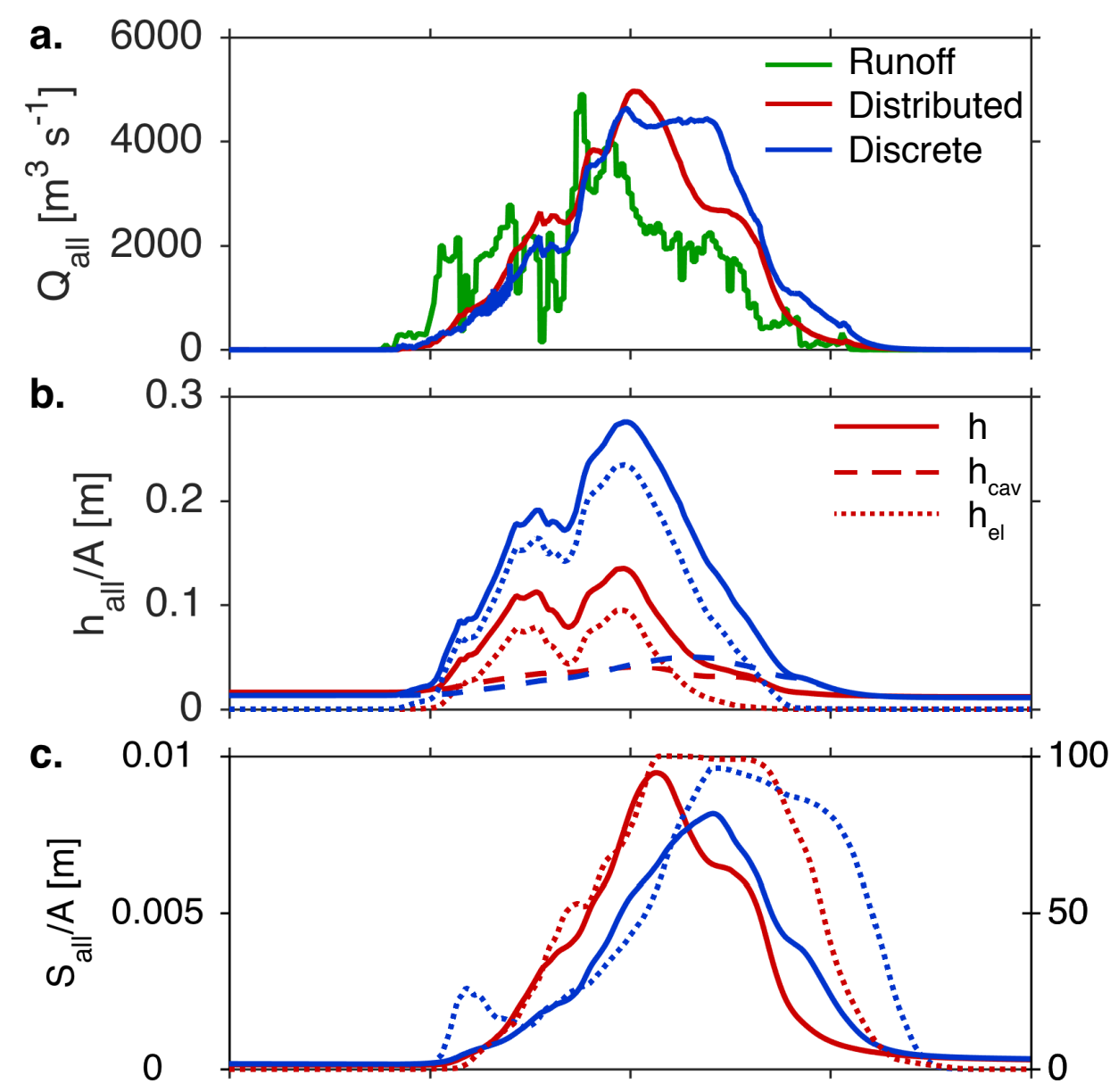

d.

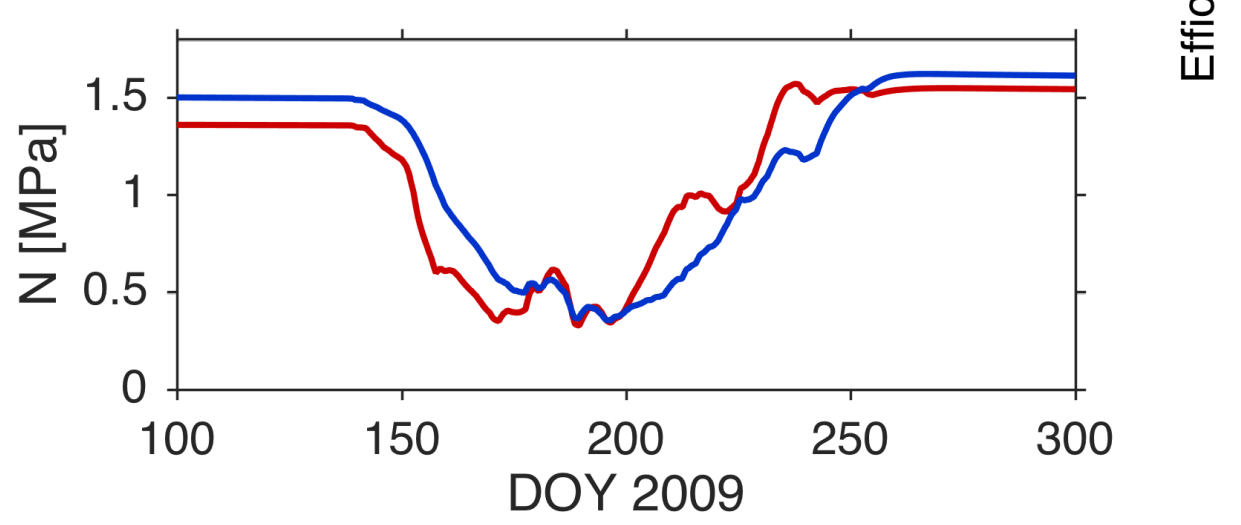

Figure 4-13. Differences in area-integrated model variables between the 2009 distributed (red) and discrete (blue) surface runoff input scenarios. (a) Surface runoff input across the domain (green) and discharge outflow at distributed (red) and discrete (blue) discharge outlet locations (yellow circles in Figs. 2 and 3). (b) Average sheet height $b$ across domain area $A$, with additional showing the contribution from the average cavity sheet height $h_{\text {cav }}$ (dashed) the and average elastic sheet height $h_{e l}$ (dotted) across the domain area $A$. (c) Average "height" of the channel layer across the domain area $A$ and the percentage of efficient drainage area of the TerraSAR-X region. Efficient drainage area (EDA) defined as the area within the TerraSAR-X region where $N>0 \mathrm{MPa}$ and $\boldsymbol{q}>0.001 \mathrm{~m}^{2} \mathrm{~s}^{-1}$. (d) Area-averaged effective pressures $N$. 

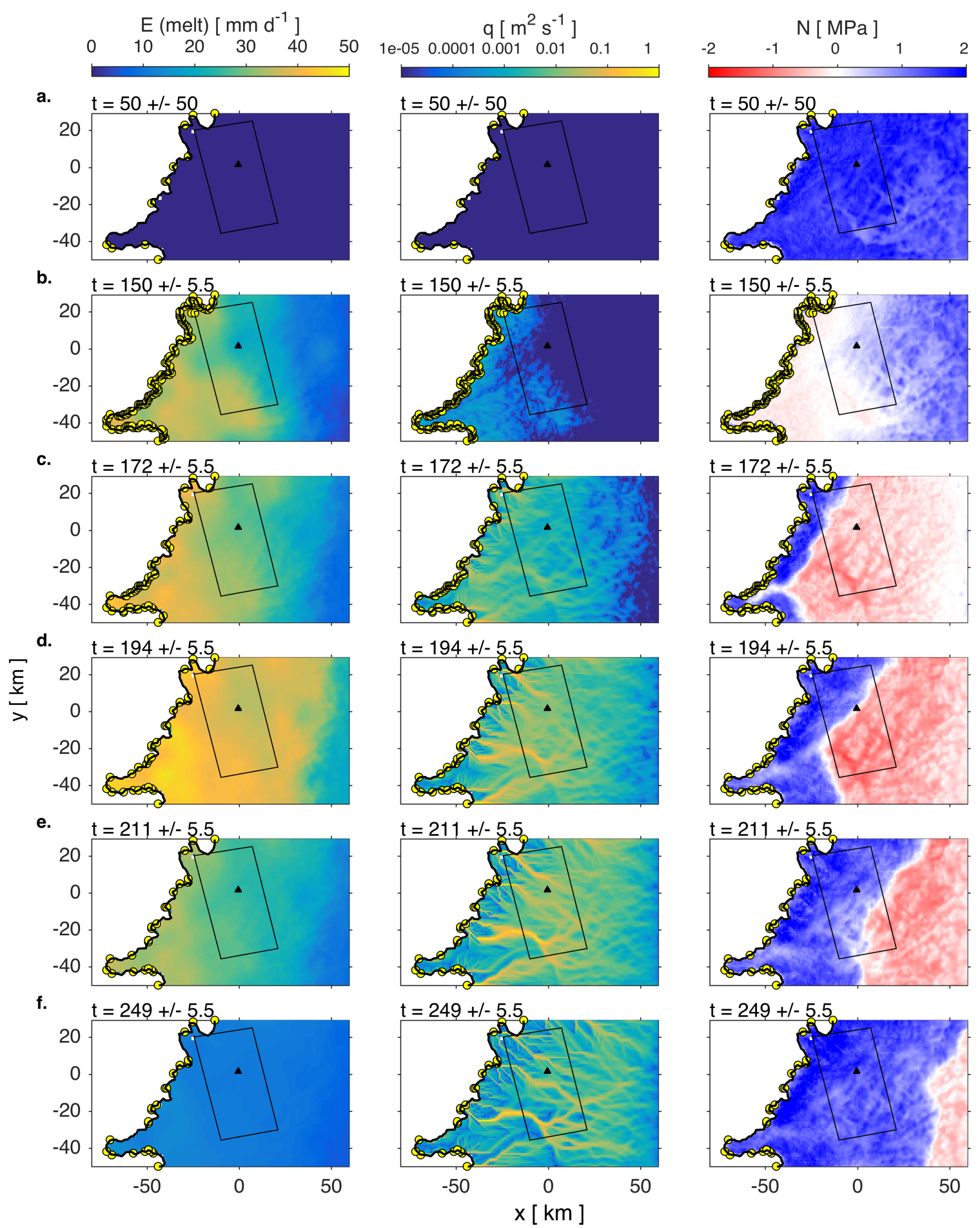

Figure 4-14. Averages of surface melt forcing, $\mathrm{E}\left(\mathrm{mm} \mathrm{day}^{-1}\right)$ (left column), subglacial water discharge, $\mathrm{q}\left(\mathrm{m}^{2} \mathrm{~s}^{-1}\right)$ (middle column), and effective pressure, $\mathrm{N}(\mathrm{MPa})$ (right column), over the 2010 melt season for a distributed surface input scenario. The date at the top of the panel corresponds to the central date for the interval over which the model outputs were determined. For this model run, $\mathrm{K}_{\mathrm{s}}=0.001$ $\mathrm{Pa}^{-1} \mathrm{~s}^{-1}, \sigma=0.001$, and $\lambda_{c}=1000 \mathrm{~m}$. Black rectangle is the area outline of the ice flow maps in Figs. 1c-e. Black triangle marks the location of North Lake. Yellow circles mark discharge outlet locations along the ice sheet margin. 

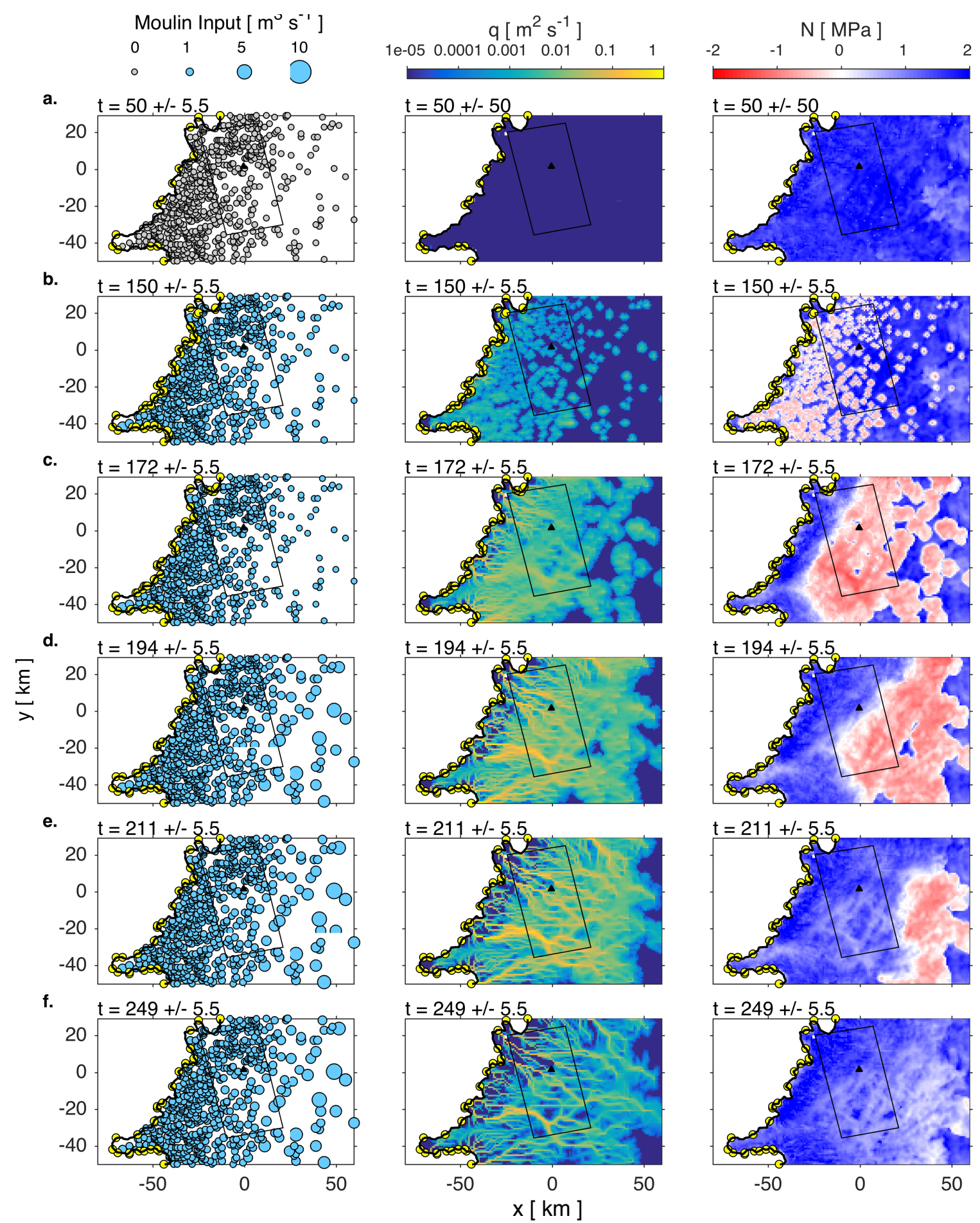

Figure 4-15. Averages of moulin input $\left(\mathrm{m}^{3} \mathrm{~s}^{-1}\right)$ (left column), subglacial water discharge, $\mathrm{q}\left(\mathrm{m}^{2} \mathrm{~s}^{-1}\right)$ (middle column), and effective pressure, $\mathrm{N}$ (MPa) (right column), over the 2010 melt season for a discrete surface input scenario. The date at the top of the panel corresponds to the central date for the interval over which the model outputs were determined. For this model run, $\mathrm{K}_{\mathrm{s}}=0.001 \mathrm{~Pa}^{-1} \mathrm{~s}^{-1}$, $\sigma=0.001$, and $\lambda_{c}=1000 \mathrm{~m}$. Black rectangle is the area outline of the ice flow maps in Figs. 1c-e. Black triangle marks the location of North Lake. Yellow circles mark discharge outlet locations along the ice sheet margin. 

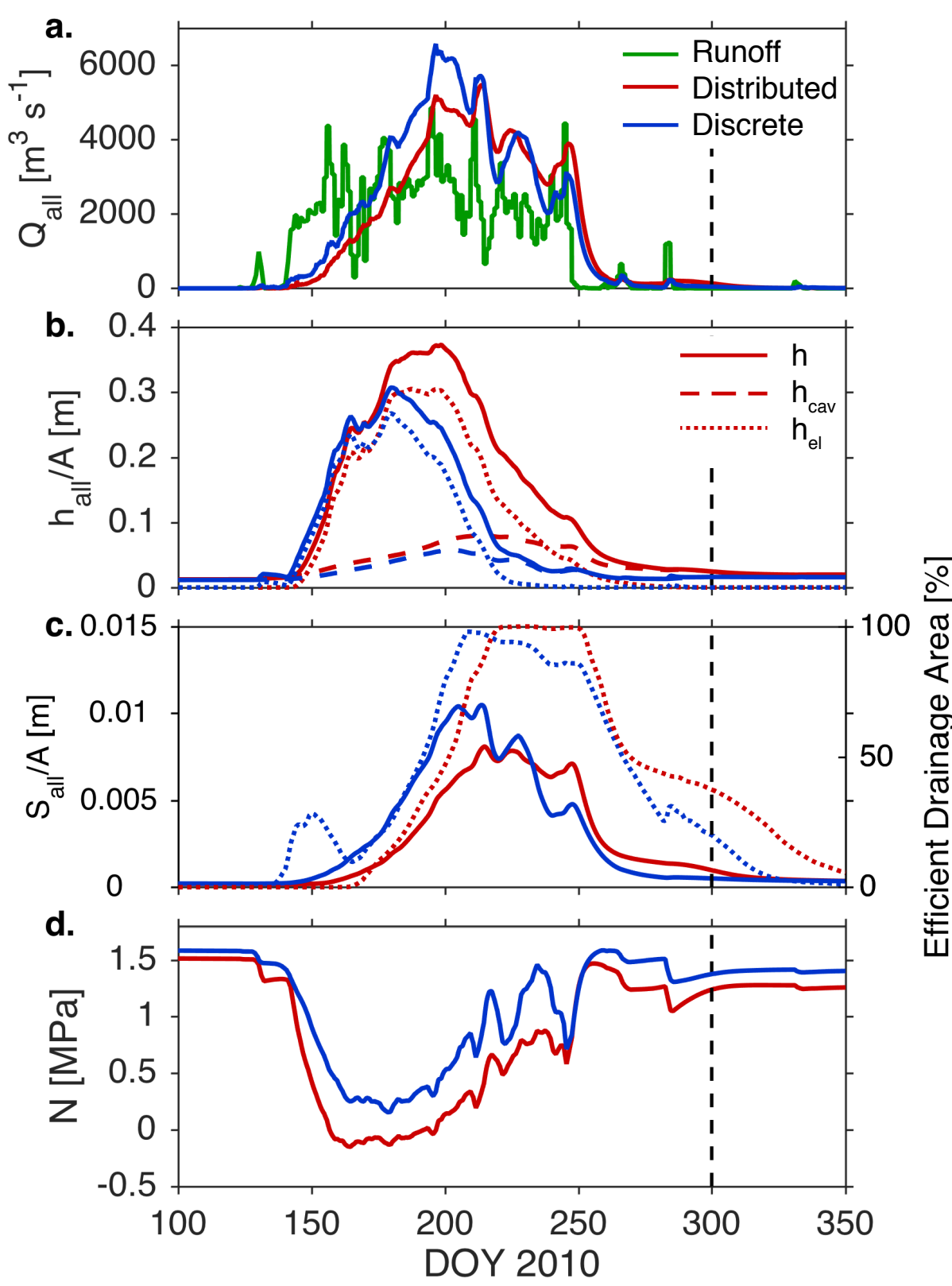

Figure 4-16. Differences in area-integrated model variables between the 2010 distributed (red) and discrete (blue) surface runoff input scenarios. (a) Surface runoff input across the domain (green) and discharge outflow at distributed (red) and discrete (blue) discharge outlet locations (yellow circles in Supplementary Figs. 6 and 7). (b) Average sheet height $h$ across domain area $A$, with additional showing the contribution from the average cavity sheet height $h_{\text {cav }}$ (dashed) the and average elastic sheet height $h_{e l}$ (dotted) across the domain area $A$. (c) Average "height" of the channel layer across the domain area $A$ and the percentage of efficient drainage area of the TerraSAR-X region. Efficient drainage area (EDA) defined as the area within the TerraSAR-X region where $N>0 \mathrm{MPa}$ and $\boldsymbol{q}>0.001 \mathrm{~m}^{2} \mathrm{~s}^{-1}$. (d) Area-averaged effective pressures $N$. Note axes limits for all panels differ from the 2009 area-integrated model variables shown in Figure 4-13. Vertical dashed line through all plots marks limit of the 2009 timeseries shown in Figure 4-13. 


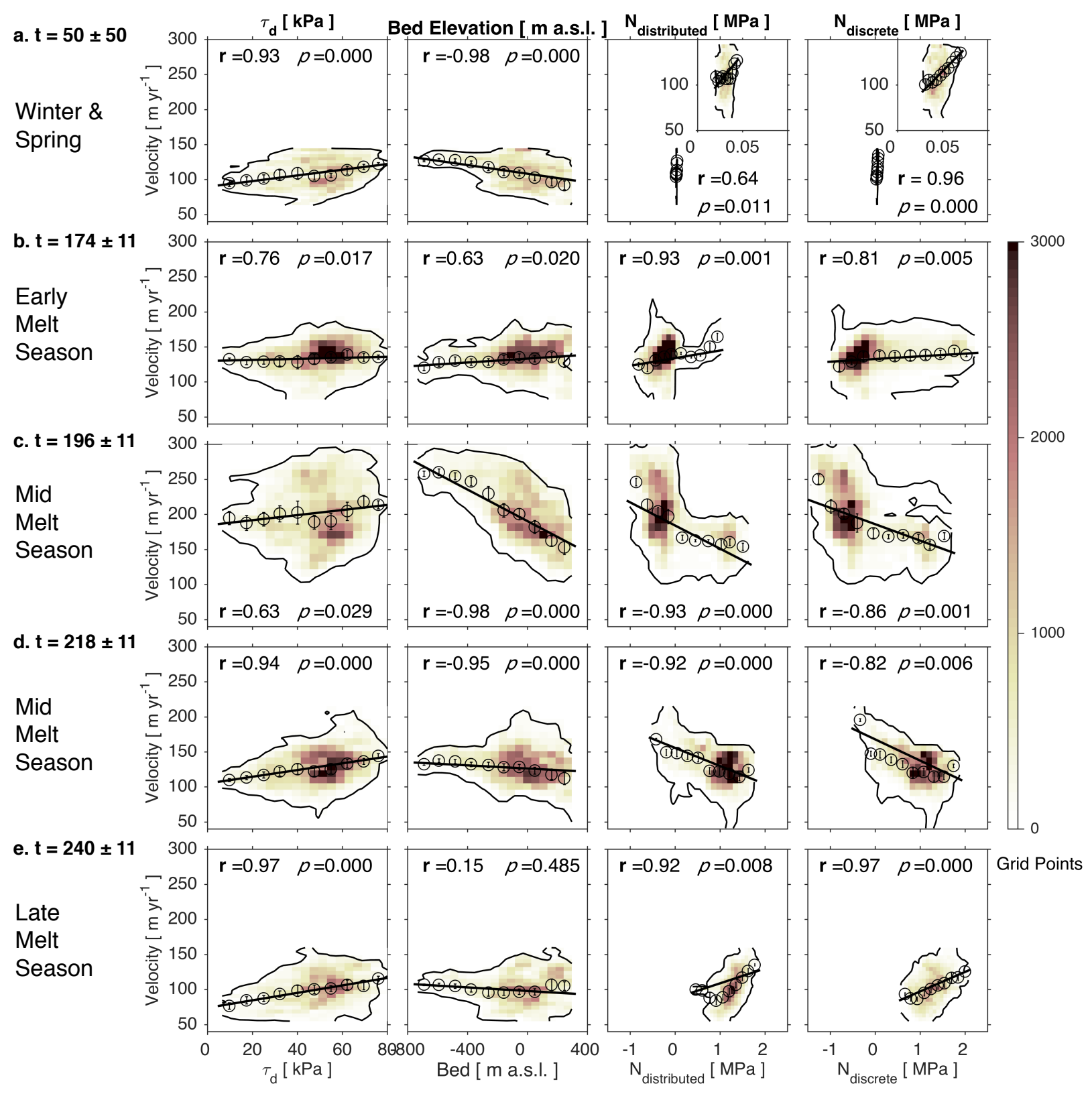

Figure 4-17. Correlations with surface speeds evolve through the 2009 melt season. Driving stress $\tau_{d}$, bed elevation, and model-derived 11-day averages of effective pressure $N$ for a distributed and discrete input of surface forcing against the winter RADARSAT and melt-season TerraSAR-X surface speed measurements. Data are linearly binned along the $\mathrm{x}$ - and $\mathrm{y}$-axis, and the color of the bin represents the number of model grid points within that bin. Black contour surrounds data region with more than 10 model grid points. Surface speeds are averaged within each x-axis bin (circles), and are fit with a weighted linear regression (black line), where the y-value weights are 2 standard deviations (error bars). The weighted correlation coefficient $\mathbf{r}$ and the $p$-value are derived from the weighted linear regression. Inset in effective pressure row a panels shows detail view of 50-150 $\mathrm{m} \mathrm{yr}^{-1}$ winter surface speeds and 0-0.1 MPa effective pressures. 


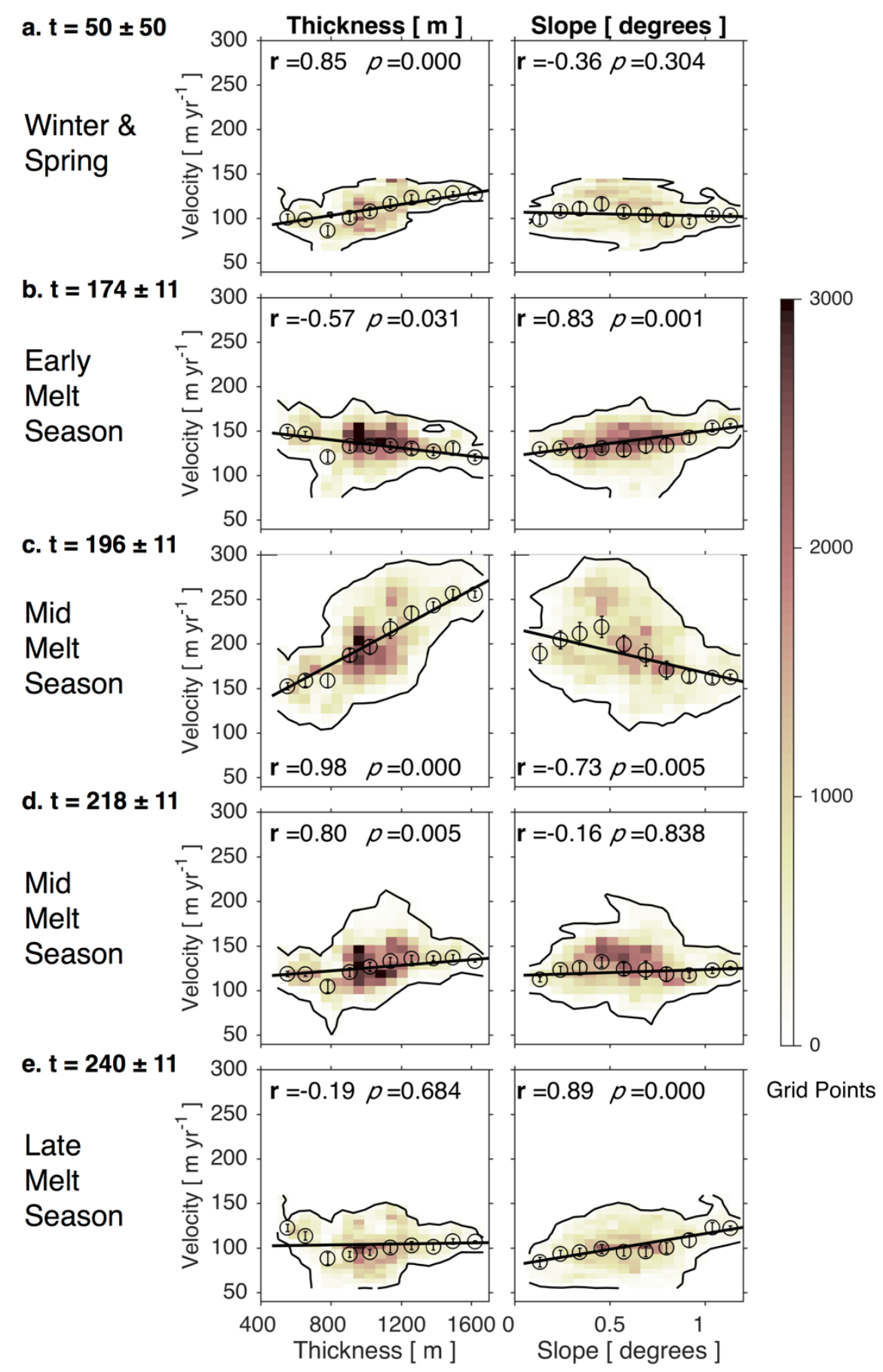

Figure 4-18. Correlations with ice sheet thickness, surface slope, and surface speeds through the 2009 melt season. Ice sheet thickness and surface slope against the winter RADARSAT and melt-season TerraSAR-X surface speed measurements. Data are linearly binned along the $\mathrm{x}$ - and $\mathrm{y}$ axis, and the color of the bin represents the number of model grid points within that bin. Black contour surrounds data region with more than 10 model grid points. Surface speeds are averaged within each $\mathrm{x}$-axis bin (circles), and are fit with a weighted linear regression (black line), where the $\mathrm{y}$-value weights are 2 standard deviations (error bars). The weighted correlation coefficient $\mathbf{r}$ and the $p$-value are derived from the weighted linear regression. 


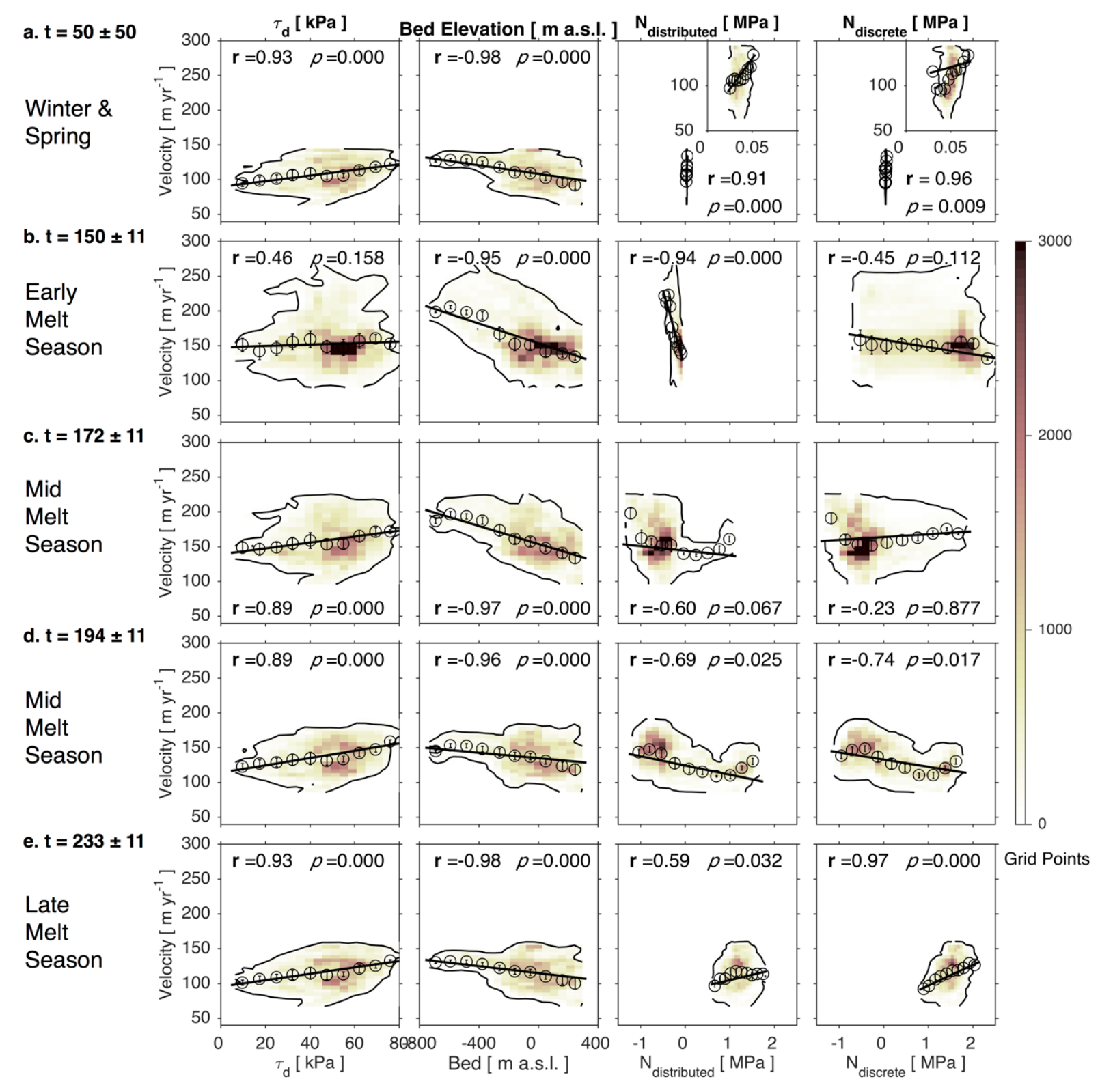

Figure 4-19. Correlations with surface speeds evolve through the 2010 melt season. Driving stress $\tau_{d}$, bed elevation, and model-derived 11-day averages of effective pressure $N$ for a distributed and discrete input of surface forcing against the winter RADARSAT and melt-season TerraSAR-X surface speed measurements. Data are linearly binned along the $\mathrm{x}$ - and $\mathrm{y}$-axis, and the color of the bin represents the number of model grid points within that bin. Black contour surrounds data region with more than 10 model grid points. Surface speeds are averaged within each $\mathrm{x}$-axis bin (circles), and are fit with a weighted linear regression (black line), where the y-value weights are 2 standard deviations (error bars). The weighted correlation coefficient $\mathbf{r}$ and the $p$-value are derived from the weighted linear regression. Inset in effective pressure row a panels shows detail view of $50-150 \mathrm{~m} \mathrm{yr}^{-1}$ winter surface speeds and 0-0.1 MPa effective pressures. 


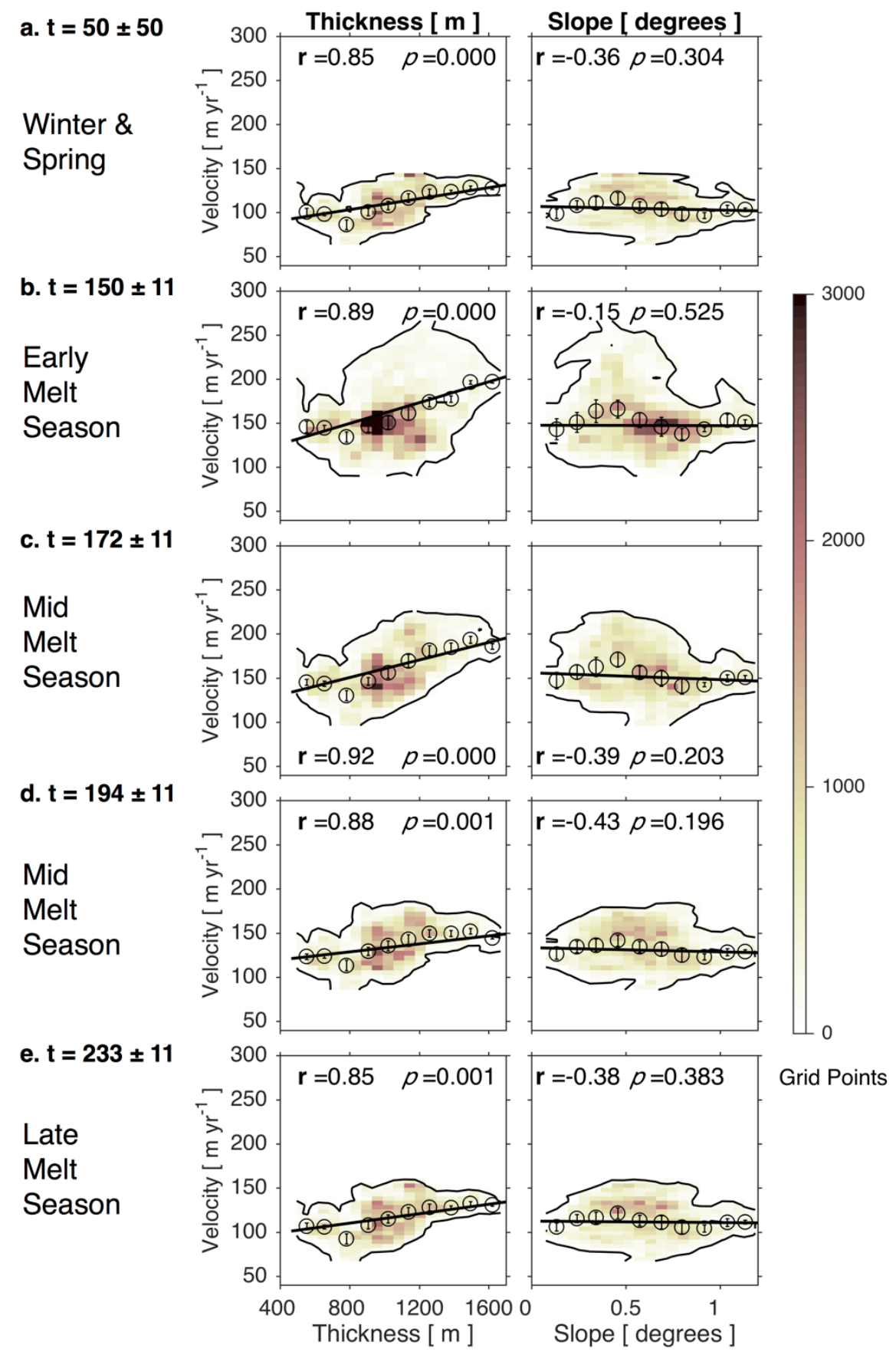

Figure 4-20. Correlations with ice sheet thickness, surface slope, and surface speeds through the $\mathbf{2 0 1 0}$ melt season. Ice sheet thickness and surface slope against the winter RADARSAT and meltseason TerraSAR-X surface speed measurements. Data are linearly binned along the $\mathrm{x}$ - and $\mathrm{y}$-axis, and the color of the bin represents the number of model grid points within that bin. Black contour surrounds data region with more than 10 model grid points. Surface speeds are averaged within each $\mathrm{x}$-axis bin (circles), and are fit with a weighted linear regression (black line), where the $\mathrm{y}$-value weights are 2 standard deviations (error bars). The weighted correlation coefficient $\mathbf{r}$ and the $p$-value are derived from the weighted linear regression. 

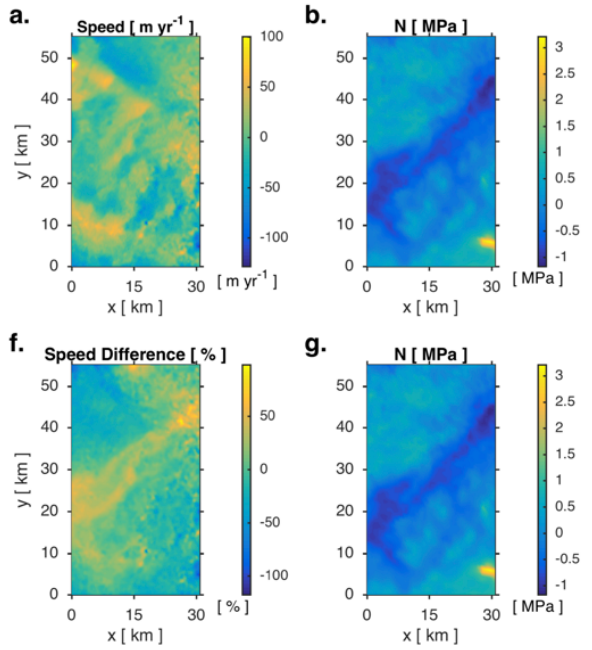
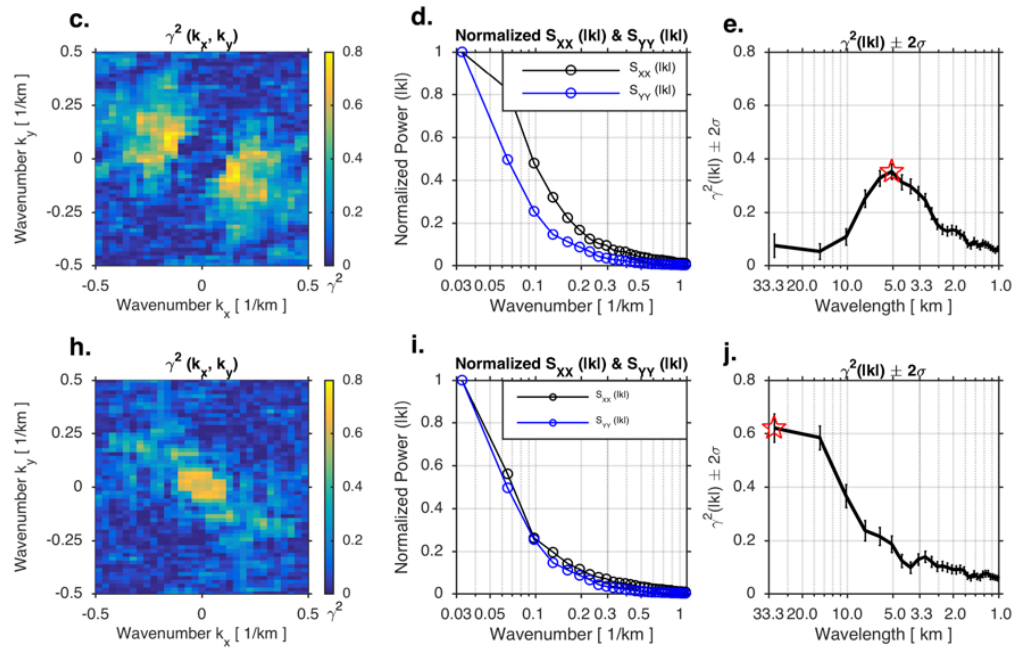
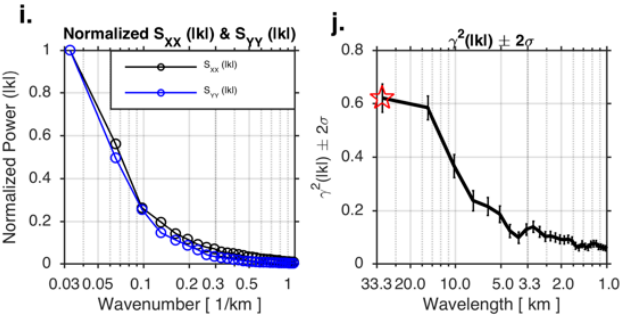

Figure 4-21. Coherence between Speed and Effective Pressure on DOY 196 of 2009. Detrended and demeaned fields of 11-day averages centered on DOY 196 of 2009 of (a) surface ice speed and (b) modeled effective pressure $(\mathrm{N})$ for the TerraSAR-X region outside of outlet glacier trunks. c) The coherence-square estimates between fields $\mathbf{a}$ and $\mathbf{b}$ in wavenumber space, $\gamma^{2}\left(\boldsymbol{k}_{\boldsymbol{X}}, \boldsymbol{k}_{\boldsymbol{Y}}\right)$, where the smallest wavenumbers (largest, Rayleigh wavelengths) plot in the center of $\operatorname{plot}\left(\boldsymbol{k}_{\boldsymbol{X}}=\lambda_{R}, \boldsymbol{k}_{\boldsymbol{Y}}=\lambda_{R}\right)$, and the largest wavenumbers (smallest, Nyquist wavelengths) plot at the edges of the plot. The scale for the $\boldsymbol{k}_{\boldsymbol{X}}$ and $\boldsymbol{k}_{\boldsymbol{Y}}$ axes are linear in wavenumber. d) Isotropically averaged power of the surface ice speed and effective pressure fields' power spectral densities plotted by wavenumber. Power is plotted normalized to the maximum value in each fields' isotropically averaged power. Wavenumber axis is $\log$ scale. e) The isotropically averaged coherence-square estimate, $\gamma^{2}(|\boldsymbol{k}|) \pm 2 \sigma$, between fields a and $\mathbf{b}$. The $\log \mathbf{x}$-axis is equivalent to the axis in panel $\mathbf{d}$, but $\mathbf{x}$-axis tickmarks are now labeled in wavelength. Red star marks maximum value plotted in Figure 4-22 c. (f-j) The equivalent coherence analysis as the first row of panels with detrended and demeaned fields of 11-day averages centered on DOY 196 of 2009 for (f) flow speeds as a percentage of the winter speed instead of the speed itself. 


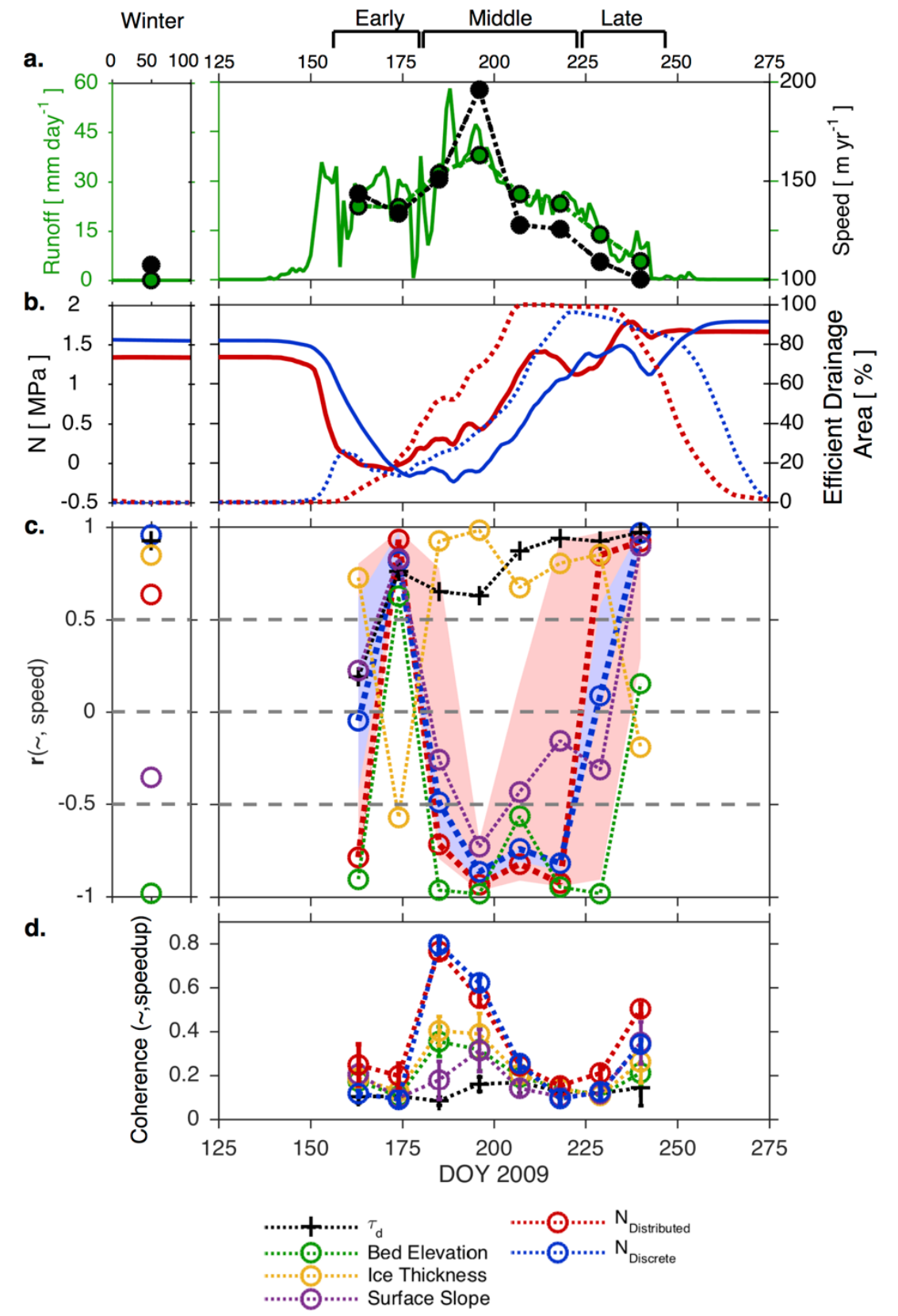

Figure 4-22. Linear and spectral relationships between $\tau_{d}$, bed elevation, effective pressure, and surface speed evolve over the 2009 winter and melt season. (a) Daily (green line) and 11-day averages (green circle) of runoff over the TerraSAR-X region. Black circles are 11-day averages of TerraSAR-X surface speeds. (b) Daily effective pressure $N$ and efficient drainage area over the TerraSAR-X region for models with distributed (red) and discrete (blue) surface runoff input. (c) Correlation coefficient, $r$, between TerraSAR-X speeds and effective pressure $N$ for the distributed (red range) and discrete (blue range) surface input model runs. Additional lines represent the correlation coefficient between TerraSAR-X speeds and static model parameters: $\tau_{d}$, bed elevation, ice sheet thickness, and ice sheet surface slope (see legend). (d) Maximum magnitude of isotropically averaged coherence-square estimates, $\gamma_{\max }^{2}(|\boldsymbol{k}|) \pm 2 \sigma$, between each variable. Colors are equivalent to panel $\mathbf{c}$ as noted in the legend. 


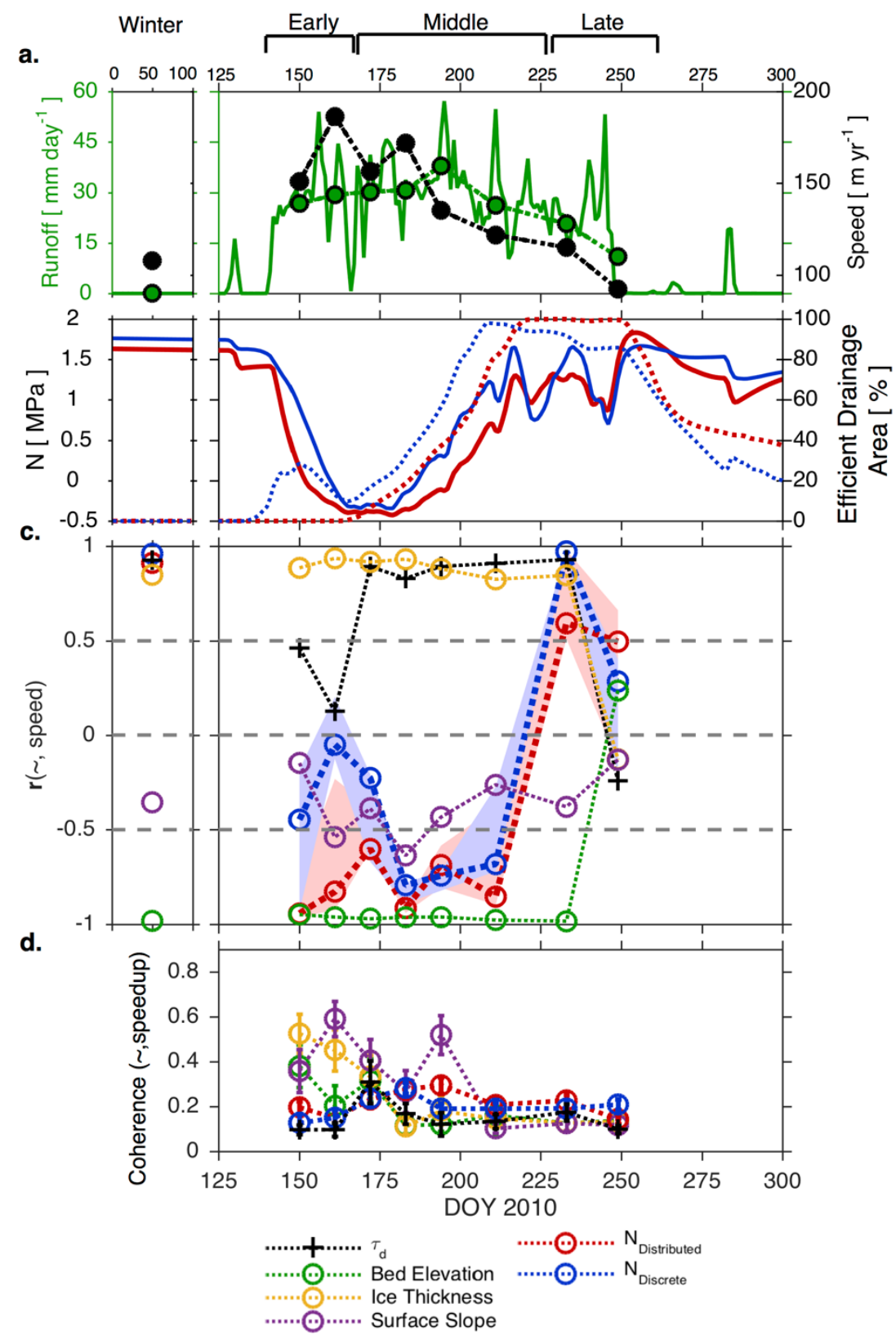

Figure 4-23. Linear and spectral relationships between $\tau_{d}$, bed elevation, effective pressure, and surface speed evolve over the 2010 winter and melt season. (a) Daily (green line) and 11-day averages (green circle) of runoff over the TerraSAR-X region. Black circles are 11-day averages of TerraSAR-X surface speeds. (b) Daily effective pressure $N$ and efficient drainage area over the TerraSAR-X region for models with distributed (red) and discrete (blue) surface runoff input. (c) Correlation coefficient, $r$, between TerraSAR-X speeds and effective pressure $N$ for the distributed (red range) and discrete (blue range) surface input model runs. Additional lines represent the correlation coefficient between TerraSAR-X speeds and static model parameters: $\tau_{d}$, bed elevation, ice sheet thickness, and ice sheet surface slope (see legend). (d) Maximum magnitude of isotropically averaged coherence-square estimates, $\gamma_{\max }^{2}(|\boldsymbol{k}|) \pm 2 \sigma$, between each variable. Colors are equivalent to panel $\mathbf{c}$ as noted in the legend. 


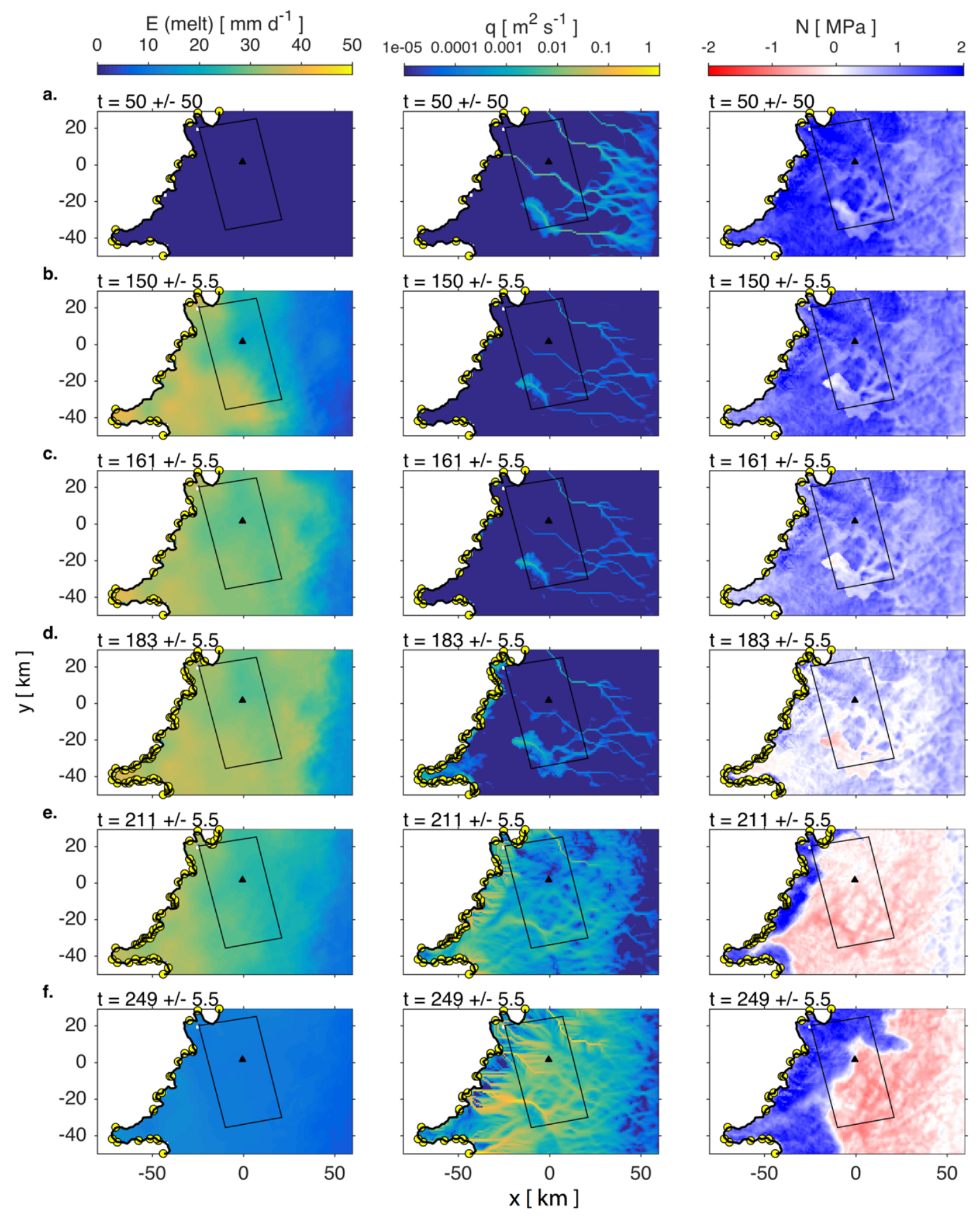

Figure 4-24. Averages of surface melt forcing, $\mathrm{E}\left(\mathrm{mm} \mathrm{day}^{-1}\right)$ (left column), subglacial water discharge, $\mathrm{q}\left(\mathrm{m}^{2} \mathrm{~s}^{-1}\right)$ (middle column), and effective pressure, $\mathrm{N}(\mathrm{MPa})$ (right column), over the 2010 melt season for a distributed surface input scenario with high englacial void fraction $(\sigma=0.01)$. The date at the top of the panel corresponds to the central date for the interval over which the model outputs were determined. For this model run, $\mathrm{K}_{\mathrm{s}}=0.001 \mathrm{~Pa}^{-1} \mathrm{~s}^{-1}, \sigma=0.01$, and $\lambda_{c}=1000 \mathrm{~m}$. Black rectangle is the area outline of the ice flow maps in Figure 4-1 c-e. Black triangle marks the location of North Lake. Yellow circles mark discharge outlet locations along the ice sheet margin. 

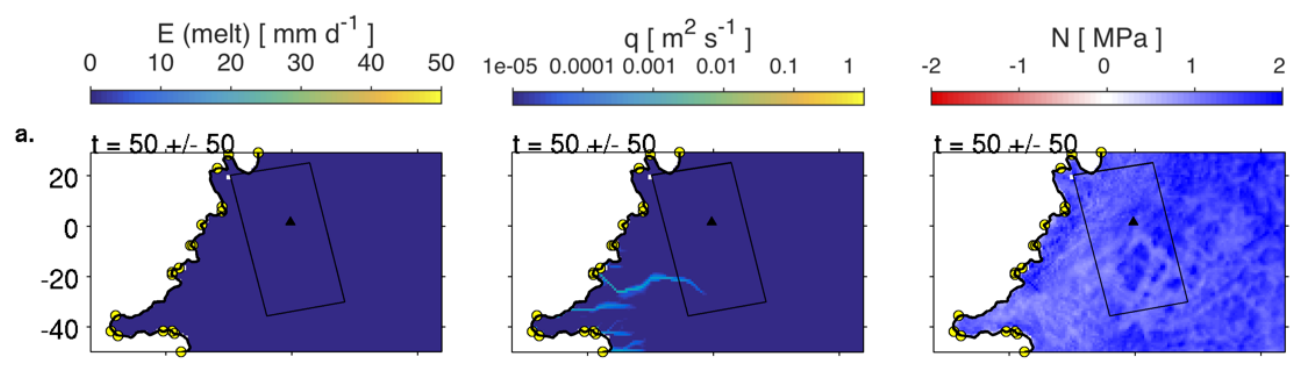

b.
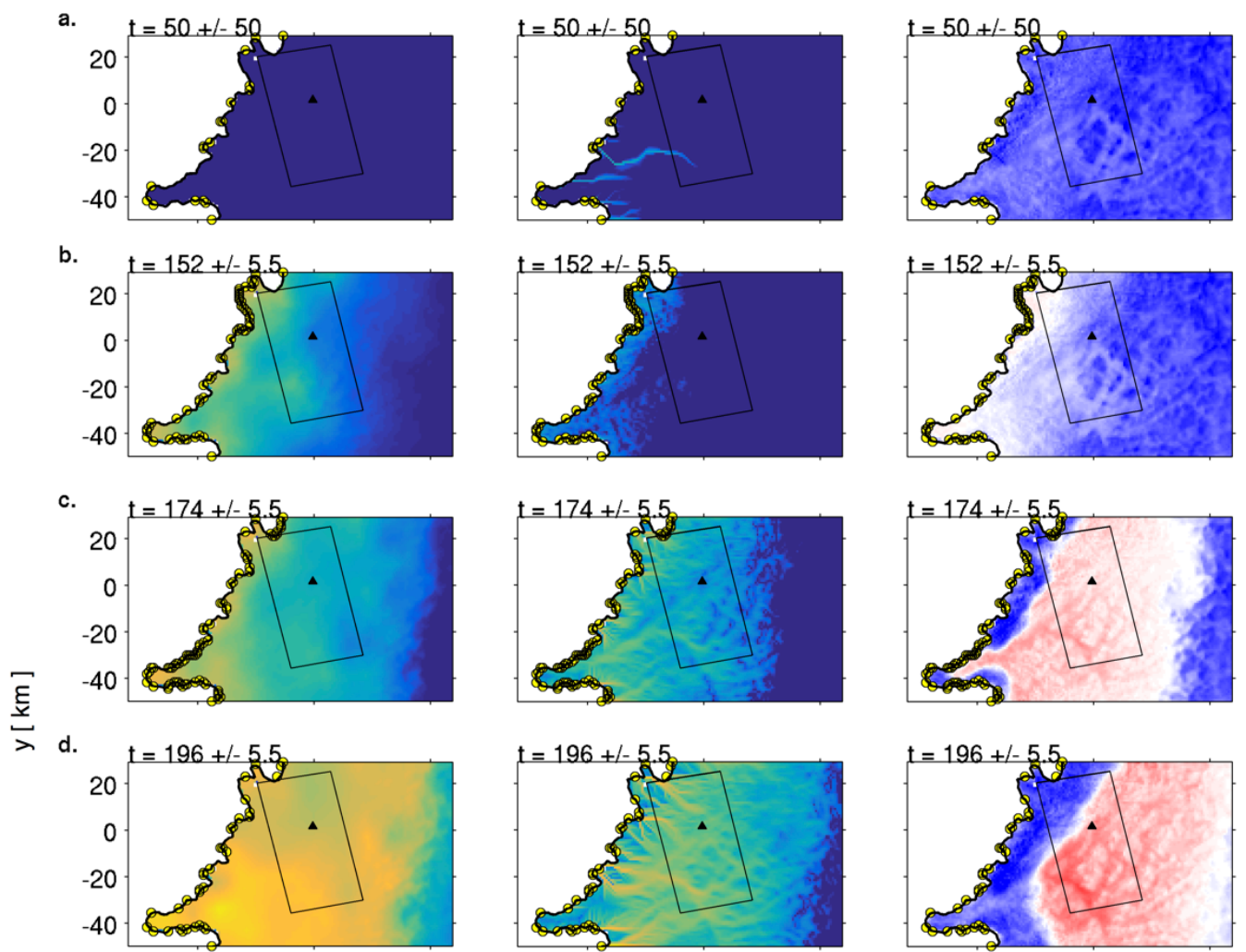

e.
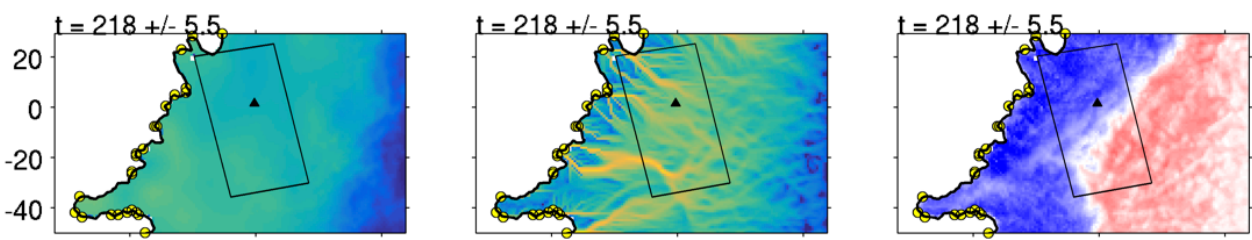

f.
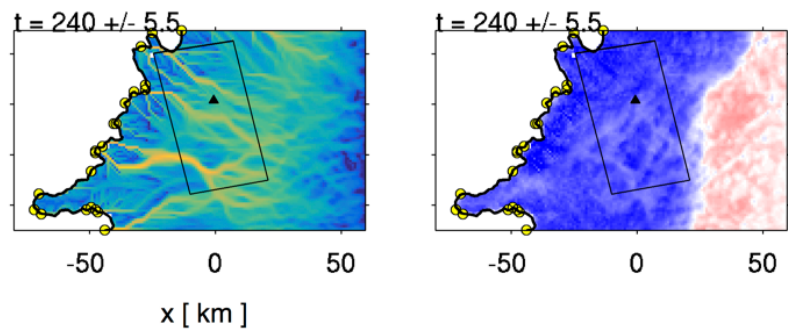

Figure 4-25. Averages of surface melt forcing, $\mathrm{E}\left(\mathrm{mm} \mathrm{day}^{-1}\right)$ (left column), subglacial water discharge, $\mathrm{q}\left(\mathrm{m}^{2} \mathrm{~s}^{-1}\right)$ (middle column), and effective pressure, $\mathrm{N}(\mathrm{MPa})$ (right column), over the 2009 melt season for a distributed surface input scenario with a pressure-dependent melting point. The date at the top of the panel corresponds to the central date for the interval over which the model outputs were determined. The top panels (a) are averages over the first 100 days of the year. The middle four rows of panels (b-e) are 11-day averages corresponding to the dates of summer flow speeds in Figs. 1d and 1e. For this model run, $\mathrm{K}_{\mathrm{s}}=0.001 \mathrm{~Pa}^{-1} \mathrm{~s}^{-1}, \sigma=0.001$, and $\lambda_{c}=1000 \mathrm{~m}$. Black rectangle is the area outline of the ice flow maps in Figure 4-1 c-e. Black triangle marks the location of North Lake. Yellow circles mark discharge outlet locations along the ice sheet margin. 


\section{Chapter 5}

\section{Linking glacially modified waters to catchment-scale subglacial discharge using autonomous underwater vehicle observations}

This chapter was originally published as: Stevens, L. A., F. Straneo, S. B. Das, A. J. Plueddemann, and A. L. Kukulya (2016), Linking glacially modified waters to catchment-scale subglacial discharge using autonomous underwater vehicle observations, The Cryosphere, 10, 417-432. Used with permission as granted in the original copyright agreement.

\subsection{Abstract:}

Measurements of near-ice ( $<200$ meters) hydrography and near-terminus subglacial hydrology are lacking due in large part to the difficulty in working at the margin of calving glaciers. Here we pair detailed hydrographic and bathymetric measurements collected with an Autonomous Underwater Vehicle as close as 150 meters from the ice/ocean interface of the Saqqarliup sermia/Sarqardleq Fjord system, West Greenland, with modeled and observed subglacial discharge locations and magnitudes. We find evidence of two main types of subsurface glacially modified water (GMW) with distinct properties and locations. The two GMW locations also align with modeled runoff discharged at separate locations along the grounded margin corresponding with two prominent subcatchments beneath Saqqarliup sermia. Thus, near-ice observations and subglacial discharge routing indicate that runoff from this glacier occurs primarily at two discrete locations and gives rise to two distinct glacially modified waters. Furthermore, we show that the location with the largest subglacial discharge is associated with the lighter, fresher glacially modified watermass. This is qualitatively consistent with results from an idealized plume model. 


\subsection{Introduction}

Greenland Ice Sheet mass loss quadrupled over the last two decades, contributing roughly $7.4 \mathrm{~mm}$ to global sea level rise from 1992-2011 [Shepherd et al., 2012], and increasing freshwater inputs into the North Atlantic [Bamber et al., 2012]. Ice sheet mass loss occurs through runoff of surface melt, ice discharge through iceberg calving, and submarine melt at marine-terminating outlet glacier margins [van den Broeke et al., 2009; Enderlin et al., 2014]. The synchronous retreat and speedup of marineterminating glaciers in southeast Greenland in the early 2000s was likely initiated by a dynamic change at marine termini [van den Broeke et al., 2009; Rignot and Kanagaratnam, 2006; Thomas et al., 2009] , and points towards common external forcings from the warming atmosphere [Box et al., 2009] and/or ocean around Greenland [Straneo and Heimbach, 2013], though the exact forcing mechanisms and relative magnitudes remain unclear [Joughin et al., 2012; Straneo et al., 2013].

Increased submarine melt rates at outlet glacier marine termini may be a leading cause of Greenland Ice Sheet outlet glacier speed up and retreat [Holland et al., 2008; Joughin et al., 2012; Motyka et al., 2013; Post et al., 2011]. The heat to drive submarine melting is supplied by waters from the subpolar North Atlantic and Arctic seas, whose circulation inside the fjords is a result of processes across a range of spatiotemporal scales [Jackson et al., 2014; Straneo et al., 2010]. Ultimately, melt rates are affected by ocean properties (temperature and stratification) and circulation in near-ice waters $(<200 \mathrm{~m})$ [Jenkins et al., 2010]. Submarine melting is thought to be enhanced in summer as a result of meltwater runoff along the ice sheet bed entering the fjord across the grounding line as subglacial discharge, which provides an additional buoyancy source alongside submarine melt for initiating buoyant plumes along the terminus face [Jenkins, 1999, 2011; Sciascia et al., 2013; Xu et al., 2013]. Relatively fresh waters rising in the core of these plumes become denser as they entrain salty ambient fjord waters, and this entrainment driven by plumes serves as a mechanism for transporting ambient fjord waters to the glacier face [Jenkins, 1999, 2011; Sciascia et al., 2013; Xu et al., 2013).

Plume theory and models combined with melt rate parameterizations suggest that higher subglacial discharge rates are associated with faster flows and entrainment of a greater volume of ambient fjord waters leading to higher submarine melt rates [Jenkins, 1999, 2011; Sciascia et al., 2013; Xu et al., 2013; Carroll et al., 2015], however ocean property and plume measurements needed to inform and validate model simulations and theory are lacking due to difficulty in working at the margin of calving glaciers [Straneo and Cenedese, 2015]. As a result, current modeling-sourced estimates of 
submarine melt rates at tidewater glaciers and their sensitivity to external forcings of the near-ice environment are highly uncertain, and based on unconstrained models of plume dynamics using ice/ocean boundary parameterizations forced by far field $(>1 \mathrm{~km})$ ocean property measurements and largely unknown subglacial discharge magnitude and distribution [Jenkins, 2011; Kimura et al., 2014; Sciascia et al., 2013; Slater et al., 2015; Xu et al., 2012, 2013]. For example, in a recent numerical study the spatial distribution of subglacial discharge along the grounding line was found to have a large effect on both the total submarine melt rate and its distribution along marine termini [Slater et al., 2015]. With a lack of observations of both the near-ice environment and subglacial discharge configurations, we are unable to define likely subglacial discharge scenarios and their associated influence on ice/ocean interactions, resulting in an inadequate and untested understanding of how tidewater glaciers respond to oceanic forcing now and in the future [Straneo and Cenedese, 2015]. Specifically, ocean measurements collected at distances $>1 \mathrm{~km}$ from the glacier terminus provide limited information on the near-ice processes because the signals of glacial modification have, by that time, largely been smeared by lateral mixing processes. Indeed, the picture that emerges from such far-field measurements is of a horizontally invariant overturning cell(s) [Chauché et al., 2014; Inall et al., 2014; Johnson et al., 2011; Mortensen et al., 2011; Straneo et al., 2011; Sutherland et al., 2014].

In this study, we present fjord hydrography and bathymetry measurements from the near-ice environment of a tidewater glacier in west Greenland (Figure 5-1) that allow us to reconstruct the distribution of subglacial discharge and provide key details on the ice-ocean exchanges. We do this by identifying the distribution of Glacially Modified Waters (GMW) — a product of ambient fjord waters mixing with subglacial discharge and glacial melt, including cooling due the melting of ice [Jenkins, 2011; Straneo et al., 2011] — within a few $100 \mathrm{~m}$ of the glacier face, and by delineating the subglacial catchments that route subglacial meltwater to discharge locations along the grounded terminus. These hydrographic measurements were obtained primarily in July 2012, using a REMUS-100 (Remote Environmental Measuring UnitS) Autonomous Underwater Vehicle (AUV) (Figure 5-2 a) to observe the temperature, salinity, and turbidity of waters in Sarqardleq Fjord (SF) from $\sim 2 \mathrm{~km}$ away to within a couple hundred meters of Saqqarliup sermia (SS) (Sarqardliup sermia in Old Greenlandic), a medium-sized tidewater glacier in West Greenland $\left(68.90^{\circ} \mathrm{N} 50.32^{\circ} \mathrm{W}\right.$ ) (Figure 4-1). This novel, highrisk field campaign was successful in obtaining multiple vertical sections of fjord water properties as close as $150 \pm 25 \mathrm{~m}$ from the terminus as well as detailed bathymetry of the previously unmapped fjord. 


\subsection{Field Campaign}

\subsubsection{REMUS-100 AUV}

The REMUS-100 AUV is a small (1.8-m long) and light (45 kilograms) vehicle, rated to 100-m-depth that has been modified for under-ice exploration [Plueddemann et al., 2012] (Figure 5-2 a). REMUS environmental sensors included a Neil Brown Ocean Systems conductivity-depth-temperature (CTD) sensor, a WetLabs Environmental Characterization Optics (ECO) Triplet sensor, and a Teledyne/RDI dual (upward and downward looking) $1200 \mathrm{kHz}$ Acoustic Doppler Current Profiler (ADCP). The ECO Triplet provides measurements of turbidity from backscatter at $660 \mathrm{~nm}$. At the surface, REMUS communications include Iridium satellite telemetry, FreeWave $900 \mathrm{MHz}$ radio acoustic data telemetry, WiFi for local area network for wireless testing and configuration, and a Global Positioning System (GPS) receiver for location fixes at the start and end of missions. At depth, REMUS navigates by acoustically ranging to a network of three moored Low Frequency (LF $10 \mathrm{kHz}$ ) Long BaseLine (LBL) transponders (Figure 5-3). The vehicle continuously updates its position while underway through a combination of dead reckoning algorithms (which incorporate compass data, as well as propeller turns, water velocity and bottom track data from the ADCP), LBL fixes, and surface GPS fixes when available (see Plueddemann et al. 2012).

Field operations from the shore and in small boats took place from 17-27 July 2012 (DOY 199-209). SF is largely free of icebergs after spring sea ice break up, though frequent calving along the SS terminus prevents boat travel within $\sim 200 \mathrm{~m}$ of the terminus. REMUS experienced navigational challenges in fjord environment due to a confluence of factors including a strong surface pycnocline, loud and variable noise from calving and overturning of icebergs, and heavy ice conditions preventing some GPS fixes. Transects presented here include occasional deviations on the order of 5 to $50 \mathrm{~m}$ perpendicular to mission tracks. Data collected during mission track deviations are accepted and collapsed back onto the transect line.

Deployed over the side of a small fishing boat, and eventually from the shore, 11 REMUS missions were completed over 9 days for both engineering and science objectives. Although a minor issue for the localization of water properties, the navigation challenges and track-line deviations caused significant uncertainties in the conversion from vehicle-relative to earth-referenced velocities. As a 
result, only measurements from the CTD and ECO Triplet are presented here. Combinations of yoyo, fixed-depth, and fixed-altitude above bottom sampling paths along transects parallel to the glacier face were used to acquire vertical sections of SF water properties. In total, 5 transects of temperature, salinity, and turbidity along 5 terminus-parallel sections (R1-R5 (Figure 5-3)) at distances 150 to 1500 $\pm 25 \mathrm{~m}$ from the terminus selected based on REMUS navigation quality and best across- and alongfjord coverage are presented in this paper (Table 5-1).

\subsubsection{Hydrographic and turbidity data}

Profiles and sections presented here are made from along-track edited and smoothed REMUS CTD and ECO data. REMUS temperature and salinity data were edited with the removal of occasional erroneous points identified by an along-track first difference filter of density calculated from the temperature and salinity measurements. First differences of $>0.1$ sigma were removed, affecting $0.2 \%$ of the data. Turbidity values were capped at 10 Nephelometric Turbidity Units (NTU). Raw temperature and salinity data were obtained at $0.22 \mathrm{~s}$ intervals, while turbidity measurements were taken at $1.15 \mathrm{~s}$ intervals. Temperature, salinity, and turbidity measurements were interpolated to $0.5 \mathrm{~s}$ and then averaged over $2 \mathrm{~s}$ to obtain smoothed, along-track data for all sensors on a common timebase with along-track resolution of 3.2-3.6 m (based on typical vehicle speeds that ranged between 1.6-1.8 $\mathrm{m} \mathrm{s}^{-1)}$. Contour maps of observed variables versus depth and distance were created from the REMUS mission tracks by optimal interpolation (kriging) of measurements collapsed along glacier face-parallel transect lines (Figure 5-4). Simple, linear fits to computed autocorrelation were used for temperature, salinity, and turbidity. Kriging was completed over a depth and along-track distance range slightly larger than the data range, with a vertical resolution of $2 \mathrm{~m}$ and a horizontal resolution of $100 \mathrm{~m}$, based on the along-track resolution of $3 \mathrm{~m}$ and the horizontal distance between REMUS mid-depth sample lines of $100 \mathrm{~m}$, respectively. Sensitivity tests of different kriging models and linear slopes yielded little impact on resulting sections, demonstrating a robust kriging methodology.

Several shipboard CTD casts, collected using an RBR XR 620 CTD during the field campaign, are presented to supplement the REMUS observations (Figure 5-6). Eight shipboard CTD casts were taken along the R1 transect (Figure 5-3), 8 casts were taken along cross-fjord sections in the outer SF ( $>10 \mathrm{~km}$ from the SS terminus) (triangles in Figure 5-7 a), and 3 casts were taken roughly at the R5 midpoint, northeastern end, and southwestern end (Figure 5-3). REMUS and CTD measurements were cross-calibrated by comparing REMUS R1 measurements with the 8 CTD casts taken along the 
R1 transect immediately following the completion of the REMUS R1 mission. $\theta, \mathrm{S}$, and depth offsets were found to be $0.0015{ }^{\circ} \mathrm{C},-0.05 \mathrm{PSU}$, and $-2.5 \mathrm{~m}$ respectively, between the CTD and REMUS measurements. The RBR XR 620 CTD was calibrated before and after the fieldwork, but the REMUS CTD was not. REMUS measurements were therefore adjusted by $2.5 \mathrm{~m}$ to match the CTD observations, and this offset is assumed to have remained constant throughout the campaign.

\subsubsection{Bathymetric Data}

Detailed bathymetry of the previously unmapped SF was obtained through depth measurements from a shipboard single-beam depth sounder, a shipboard ADCP, and the REMUS downward looking ADCP in bottom-track mode (Figure 5-3). After removing occasional spikes in the REMUS ADCP depth soundings (outliers on order $15 \mathrm{~m}$ deeper than background), depth measurements across the sampling platforms at crossover points were consistent within $<4 \mathrm{~m}$. Coastline positions were assigned a depth of $0 \mathrm{~m}$, and were obtained from digitizing a June 19, 2012 Landsat image (30-m horizontal resolution). Depth measurements were combined across platforms by calculating a binned average depth measurement over a 25 x 25-m grid across the fjord. The Barnes Objective Analysis (Barnes, 1994) was used to interpolate the binned depth measurements with a 175 x 175 -m search radius to create the bathymetry shown in Figure 5-3. The bathymetry product aligns well with the binned depth measurements (less than $1 \mathrm{~m}$ offsets) except in the location of the northern side of the seamount $\left(68.92^{\circ} \mathrm{N} 50.34^{\circ} \mathrm{W}\right)$, which contains the maximum offset from the gridded depth measurements at $\pm 5 \mathrm{~m}$. Due to low data coverage, the Barnes Objective Analysis was not extended to the outer regions of SF. However, with depth measurements from the shipboard echosounder we have mapped the fjord centerline depth to the confluence of SF and Tasiussaq Fjord, 15-km from the SS terminus (Figures 5-1, 5-7 a). 


\subsection{Physical Setting: The Sarqardleq Fjord/Saqqarliup sermia outlet glacier system}

\subsubsection{Fjord bathymetry, subglacial topography, and historical terminus positions}

The Saqqarliup sermia/Sarqardleq Fjord (SS/SF) outlet glacier/fjord system is located in West Greenland roughly $30 \mathrm{~km}$ south of Jakobshavn Isbræ (Figure 5-1). SS is a marine terminating outlet glacier with a 6-km wide terminus and an upstream subglacial catchment area of $400 \pm 50 \mathrm{~km}^{2}$ (Figure 5-7a, Table 5-3; methods described in section 5.4.2). We estimate total annual runoff out of this catchment to be on the order of $1 \mathrm{~km}^{3} \mathrm{yr}^{-1}$ using Regional Atmospheric Climate Model version 2.3 (RACMO2.3) runoff values [van den Broeke et al., 2009] (methods described in section 5.4.2). A bedrock trough 100-150 m below sea level extends $15 \mathrm{~km}$ inland from the terminus, and continues further inland as a bedrock trough above sea level [Morlighem et al., 2014] (Figure 5-7 a). The SS centerline ice thickness is $\sim 200 \mathrm{~m}$ at the terminus and increases inland (Morlighem et al., 2014) (Figure 5-7 a). The Saqqarliup sermia terminus position has been relatively stable in comparison to the large terminus retreats observed at other Greenland tidewater glaciers (Moon and Joughin, 2008) based on our analyses of LANDSAT imagery from 1979 to present (Figure 5-2 b). Modest advance and retreat phases on the order of $\pm 500 \mathrm{~m}$ are observed over recent decades, with a net retreat of $\sim 1 \mathrm{~km}$ within the center third of the glacier terminus observed from 1992 to present (Figure 5-2 b). Average flow velocities within the SS outlet glacier during the 2007-2009 winters were on order 125-175 m yr ${ }^{-1}$, with the center third of the SS terminus reaching speeds of $200 \mathrm{~m} \mathrm{yr}^{-1}$ [Joughin et al., 2013].

The Sarqardleq-Tasiussaq fjord system is the southern side fjord off the larger, deeper Jakobshavn Isbræ (JI) fjord, which connects the largest and fastest Greenland ice stream (JI) to Disko Bugt (Figure 5-1a). From the SS terminus, the shallower Sarqardleq-Tasiussaq Fjord system extends roughly $30 \mathrm{~km}$ to the northwest before reaching JI fjord. SF meets Tasiussaq Fjord over a previously unknown 70-m-deep sill, $15 \mathrm{~km}$ from the SS terminus (Figures 5-1, 5-7 a). Tasiussaq Fjord meets JI fjord over an at most 125-m-deep sill [Gladish et al., 2015a] $30 \mathrm{~km}$ from the SS terminus (Figure 5-1). Waters along the SS terminus range from 20-150-m-depth, and are deepest in two troughs near the center of the glacier (Figure 5-2, Table 5-3). Both SS lateral terminus regions are grounded in relatively shallow lagoons $(<20 \mathrm{~m}$ ) (Figure 5-3). A 40-m-deep seamount is located $2.5 \mathrm{~km}$ from the vertical SS calving face (Figure 5-3). 


\subsubsection{Subglacial catchment and runoff}

To first order, subglacial catchments are defined by ice sheet surface and bed topography, which governs subglacial hydraulic potential at the bed [Cuffey and Patterson, 2010]. Gradients in subglacial hydraulic potential at the ice-sheet bed do not completely dictate subglacial meltwater pathways due to the constantly evolving subglacial hydraulic system over the summer melt season [Andrews et al., 2014; Chandler et al., 2013; Hewitt et al., 2012; Schoof, 2010], but subglacial hydraulic potential gradients are likely the dominant regional factor. This is supported by recent modeling studies, which find a strong topographic control of channelized subglacial meltwater routing over Greenland Ice Sheet outlet glaciers [Banwell et al., 2013; Palmer et al., 2011].

The SS catchment area was determined based on streamline analysis through subglacial hydraulic potential gradient fields to estimate which path water parcels located at the bed under inland ice will follow out to the coast. The downslope subglacial hydraulic potential gradient, $-\nabla \Phi_{\mathrm{h}}$, was calculated following:

$$
-\nabla \Phi_{\mathrm{h}}=-\varrho_{i} g\left[f_{w} \nabla \mathrm{S}+\left[\varrho_{w} / \varrho_{i}-f_{w}\right] \nabla \mathrm{B}\right]
$$

where $\varrho_{i}$ is the density of ice, $\varrho_{w}$ is the density of freshwater, $g$ is the gravitational acceleration, $f_{w}$ is the flotation fraction, and $\nabla \mathrm{S}$ and $\nabla \mathrm{B}$ are the surface and bed gradients, respectively [Cuffey and Patterson, 2010; Shreve, 1972]. We assume water at the bed flows along the steepest subglacial hydraulic potential gradient [Shreve, 1972]. We used two widely available bedrock elevation maps, Bamber et al. (2013) and Morlighem et al. (2014) (hereafter BBM2013 and MBM2014) to calculate $-\nabla \Phi_{\mathrm{h}}$ across a $1-\mathrm{km}$ by $1-\mathrm{km}$ grid [Bamber et al. 2013] and 150-m by 150-m grid [Morlighem et al. 2014] equivalent to the resolution of each bedrock elevation map. MBM2014 beneath SS was updated from the previously published map by adding our SF bathymetry measurements as a boundary constraint along the SS terminus in this otherwise data-sparse region. The MBM2014 used in this study is available online as IceBridge BedMachine Greenland, Version 2 from the National Snow and Ice Data Center (http://nsidc.org/data/docs/daac/icebridge/idbmg4/index.html). Surface ice gradients ( $\nabla \mathrm{S}$ ) are

calculated from the Greenland Ice Mapping Project (GIMP) Digital Elevation Model [Howat et al., 2014]. The flotation fraction was set to $f_{w}=1$ (basal water pressures are equal to ice overburden 
pressure), which resulted in the maximum catchment area possible based on basal hydraulic gradients in this region.

Surface runoff in the SS catchment for 2012 was determined from bilinear interpolation of the 11-km grid resolution RACMO2.3 runoff values (3 grid cells within SS catchment) [van den Broeke et al., 2009] to the 1-km grid from BMB2013 and the 150-m grid from MBM2014 (Figure 5-7 a). Portions of the catchment lower than 400 m.a.s.l. were prescribed the same runoff values as the RACMO2.3 grid point within the catchment at $432 \mathrm{~m}$ a.s.l. $\left(68.82^{\circ} \mathrm{N} 50.19^{\circ} \mathrm{W}\right.$ ) (Figure 5-7 a), as there are no RACMO2.3 grid points at lower elevations within the catchment. We assume that the ice-sheet bed is impermeable (does not store water) over the timescales considered here, and that all surface runoff is transferred immediately to the bed directly beneath the location of runoff formation at the ice sheet surface.

\subsection{Results}

\subsubsection{Glacially Modified Water (GMW) temperature, salinity, and turbidity properties in Sarqardleq Fjord}

The summer Sarqardleq fjord waters are characterized by a $\sim 10-20-\mathrm{m}$ fresh and relatively warm surface layer overlying a thick layer of weakly stratified, relatively salty $(\mathrm{S}=30.5-32.5)$ and cold $(\theta \approx 1$ ${ }^{\circ} \mathrm{C}$ ) waters (Table 5-2, Figure 5-5 a, b). The summer fjord waters are the same as the Surface Waters (SW) and Ilulissat Icefjord Waters (IIW) observed by recent hydrographic surveys throughout Ilulissat Icefjord [Gladish et al., 2015a, 2015b]. SW are a mixture of IIW and fresher, warmer waters originating from local freshwater sources and warmed by summer atmospheric forcing. IIW originates from Arctic Waters observed in Disko and Baffin Bays [Gladish et al., 2015b] that enter SF after crossing sills at the mouth of JI fjord (Schumann et al., 2012), the confluence of JI fjord and Tasiussaq fjord (Gladish et al., 2015a), and the mouth of SF (Figure 5-1). These summer fjord waters are observed in the outer SF by a set of far-field CTD profiles taken near the fjord mouth more than $10 \mathrm{~km}$ from the SS terminus (triangles in Figure 5-7 a). We define ambient fjord waters as the average of these far-field CTD profiles (red profile in Figures 5-5 \& 5-6). 
Near the glacier we observe a range of water masses not found in the outer fjord. These waters are generally colder, fresher, and more turbid than waters near the mouth of the fjord (Figure 5-5 a, b). The REMUS sections reveal two distinct Glacially Modified Waters (GMW), which we refer to as GMW1 and GMW2 (Figure 5-4, Table 5-2). GMW1 and GMW2 are cold anomalies with a high turbidity signal that are most evident at two distinct locations (Figure 5-4). GMW1 is observed in the southwestern ends of R1-R5 at 40-m depth, while GMW2 is observed in the northeastern ends of R1-R5 at 60 m depth (Figure 5-4). Both GMW1's and GMW2's temperature and turbidity anomalies are most pronounced close to the glacier (Figure 5-4 a-c), and decrease as these waters spread away from the glacier (Figure 5-4 g-i). For example, the high turbidity associated with GMW1 spreads laterally beneath the pycnocline at R1 (Figure 5-4 i). Turbidity does not consistently map onto regions of local temperature minima; there are regions in the REMUS sections with high turbidity but with temperatures above $0.9^{\circ} \mathrm{C}$ (northeastern R1 below $80 \mathrm{~m}$ depth (Figure 5-4 i)). High turbidity in these regions may be due to other sources including suspended sediment sourced from proglacial streams that enter SF as surface runoff near the northeastern end of R1 (Figure 5-3) or iceberg discharge.

CTD casts 1-3 were taken closer to the SS face than the R5 transect during the same July 2012 field campaign (Figure 5-3), and provide additional $\theta / \mathrm{S}$ characteristics below the 100-m REMUS depth limit (Figure 5-6 a-c). These casts record deeper cold anomalies at the bottom of SF, as well as cold excursions from $\sim 40$ to $80 \mathrm{~m}$ depth, similar to REMUS measurements (Figure 5-6 a-c). Overall the CTD profiles align well with REMUS measurements where coincident (above 100-m).

Further insight into the origins of GMW1 and GMW2 is found in $\theta / \mathrm{S}$ space, where GMW1 and GMW2 stand out as cold anomalies as compared to waters near the mouth of the fjord (Figures 5-5 d, 5-6 a, b). GMW1 and GMW2 are clustered at two distinct densities (Figure 5-6 a, b). At a density of $\sigma_{\theta} \approx 24.8 \mathrm{~kg} \mathrm{~m}^{-3}$, where $\sigma_{\theta}$ is potential density less $1000 \mathrm{~kg} \mathrm{~m}^{-3}$, GMW1 is lighter than GMW2 $\left(\sigma_{\theta} \approx\right.$ $25.5 \mathrm{~kg} \mathrm{~m}^{-3}$ ) (Table 5-2, Figure 5-6 a, b). In general, GMW is fresher and more turbid compared to ambient waters, consistent with fjord waters mixing with submarine melt and subglacial discharge. If we assume that both GMW1 and GMW2 are driven by subglacial discharge plumes that emerged at the grounding line, then we can assume that the bulk of the entrainment was of deeper waters at densities of $\sigma_{\theta}=25.5-26.5 \mathrm{~kg} \mathrm{~m}^{-3}$ (Figure 5-6 a, b). In $\theta / \mathrm{S}$ space, GMW is further identified with the use of meltwater and runoff mixing lines (Figures 5-5 c, d \& 5-6 a-c), which represent conservative mixing between ambient water and submarine melt or subglacial discharge, respectively [Jenkins, 1999]. 
Endpoints for the melt and runoff mixing lines are set to properties observed by CTD cast 2 at grounding line depth (Figures 5-3, 5-6 b). GMW1 and GMW2 are consistent with the transformation of ambient waters by mixing with submarine melt and subglacial discharge, as they fall between the meltwater and runoff mixing lines in $\theta / \mathrm{S}$ space (Figures 5-5 c, d \& 5-6 a-c).

Thus, near the glacier we observe water masses not found in the outer fjord that we attribute to glacier/ocean interactions [Jenkins et al., 2010; Straneo et al., 2011]. We observe two distinct GMW that are both colder, fresher, and more turbid compared to ambient waters at similar depths (Figures 5-5 a-c, 5-6 a, b) but are located in different regions of the fjord (Figure 5-3). GMW1, observed in the southwestern ends of R1-R5, is considerably fresher and lighter than the colder GMW2 observed in the northeastern ends of R1-R5 (Figures 5-3, 5-6 a, b, Table 5-2). The lighter GMW1 $\left(\sigma_{\theta} \approx 24.8\right)$ is observed at an equilibrium depth of $35-60 \mathrm{~m}$, while the denser GMW2 $\left(\sigma_{\theta} \approx 25.5\right)$ has a deeper equilibrium depth of 50-70 m (Table 5-2), suggesting that GMW1 contains a higher fraction of subglacial runoff than GMW2 (See Section 5.5.3). We further elucidate GMW1 and GMW2 origins in the following section on the SS catchment and subglacial discharge across the SS terminus.

\subsubsection{SS catchment and subglacial discharge across SS terminus}

The $400 \pm 50 \mathrm{~km}^{2}$ area SS catchment extends $15-\mathrm{km}$ up the basal valley beneath the 6-km wide SS outlet glacier snout and widens under inland ice, reaching a maximum inland extent of 35-km just above the $900 \mathrm{~m}$ a.s.l. ice-sheet surface elevation contour (Figure 5-7 a, Table 5-3). Bedrock basins that steer subglacial water to the southwest delineate the southern boundary of the catchment (Figure 5-7 a). The northern extent of the catchment is bounded by the Alanngorliup sermia outlet glacier catchment parallel to SS (Figure 5-7 a). Three sub-catchments-C1, C2, and C3 - are delineated within the SS catchment from binning $-\nabla \Phi_{\mathrm{h}}$ streamline endpoints along the SS face in both the MBM2014 and BBM2013 analyses (Figure 5-7 a). The main difference between the MBM2014 and BBM2013 analyses is the size of the C1 subcatchment (BBM2013 33\% larger), with the BBM2013 analysis delineating the northern inland extent of C1 into a region the MBM2014 analysis places in the Alanngorliup sermia catchment (Figures 5-1 \& 5-7 a, Table 5-3).

The three sub-catchments delineate three sections along the terminus (Figure 5-7 a), with each section mapping onto a directly observed or inferred subglacial meltwater discharge channel (D1, D2, and D3 in Figure 5-3). Subcatchment C1, the largest sub-catchment at $269 \mathrm{~km}^{2}$ area (MBM2014) 
discharges along the middle of the terminus at discharge location D1, while subcatchment C2 and C3 discharge along the northeastern and southwestern extents of the terminus at D2 and D3, respectively (Figure 5-3). D1 and D2 align with two distinct bathymetric troughs of 150 and 132-m depth, respectively (Table 3), bounded by bathymetry highs of 60 to 40 meters depth in SF (Figure 5-3). D1 and D2 also coincide with depressed glacier margin heights along the terminus, enhanced ice sheet velocities [Joughin et al., 2013], and high calving flux relative to the rest of the terminus. D1 is a particularly frequent calving region in comparison to the rest of the terminus, as observed during our two field campaigns. At times, a turbulent, sediment-rich plume reaches the fjord surface at D1, as observed in satellite images and during subsequent fieldwork in July 2013 [Mankoff et al., 2016]. While exhibiting similarly frequent calving, terminus height, and velocity characteristics as D1, surface plumes have not been observed at D2. Subcatchment C3 discharges beneath the slow-moving, southwestern margin of the terminus at D3 (Fig. 3), through a visible, broad channel mouth at the fjord surface, entering into a shallow region of SF (Table 5-3, Figure 5-3).

Variability in calculated subglacial discharge for each subcatchment is controlled primarily by temperature variability, with daily runoff rates a summation of melt and precipitation across the catchment [van den Broeke et al., 2009] (Figure 5-7 b, Table 5-3). During our 2012 field expedition, catchment runoff rates were slightly below the monthly July average, with no above average temperature days falling within the sampling period (Figure 5-7 b). Disregarding the possibility for periods of subglacial water storage during the en- and subglacial transport of runoff to the SS terminus, daily discharge rates across the terminus during the field expedition are $146 \mathrm{~m}^{3} \mathrm{~s}^{-1}$ (MBM2014 estimate) (Table 5-3). An additional though likely minor amount of surface meltwater runoff enters the fjord through proglacial streams, which discharge at land-terminating margins abutting SS (Figure 5-2). Daily runoff discharges for C1 and C2 scale primarily with area differences and are 115.78 and 20.62 $\mathrm{m}^{3} \mathrm{~s}^{-1}$, respectively (MBM2014) (Table 5-3). As error estimates for the RACMO2.3 runoff rates are not available, we take the standard deviation of July 2012 daily discharge rates as a measure of the potential variation observed during the field expedition (Table 5-3).

\subsubsection{Buoyant plume model for the SS/SF system}

As described above, we have found evidence for three main subglacial catchments discharging runoff into SF at three locations along the terminus. The two prominent discharge locations, D1 and D2, coincide with GMW1 and GMW2 observations. The picture that emerges is that different properties 
of GMW1 and GMW2 are attributable to differences in subglacial discharge magnitude at that location. Here, we use a buoyant plume model to investigate the extent to which the two plumes' predicted characteristics compare with the GMW1 and GMW2 observations. Buoyant plume theory states that the growth of a plume is dictated by the plume's buoyancy forcing, which can be due to subglacial discharge at the grounding line and/or submarine melting along the terminus [Morton et al., 1956; Turner, 1979]. The buoyancy forcing of the plume determines the plume's vertical velocity and entrainment of ambient fjord waters [Morton et al., 1956; Turner, 1979]. A class of simple, onedimensional buoyant plume models has been used to investigate plume dynamics and terminus melt rates near glaciers [Hellmer and Olbers, 1989; Jenkins, 1991, 2011]. Solutions to these models estimate plume temperature, salinity, vertical velocity, width, and intrusion depth, the depth at which the plume becomes neutrally buoyant and changes from flowing vertically up the terminus to flowing horizontally away from the terminus. Here we investigate D1 and D2 plume scenarios using the Jenkins [2011] buoyant plume model adapted to a half-conical plume driven by a point-source.

The plume model uses conservation of the fluxes of mass, momentum, heat, and salt, to calculate plume characteristics that are uniform in time and across-flow direction [Jenkins, 2011]. Key initial conditions that we prescribe include an ice temperature of $-10^{\circ} \mathrm{C}$ [Lüthi et al., 2002]; fjord ambient temperature and stratification (Table 5-4); a vertical glacier face; and a modeled subglacial discharge across the terminus, $Q_{s g}$ (Table 5-4). Entrainment of ambient fjord waters into the buoyant plume is modeled as a product of plume velocity, the sine of the ice terminus slope (vertical for SS), and a theoretically defined entrainment coefficient $\left(\mathrm{E}_{0}\right)$ of 0.08 following Sciascia et al. [2013].

The buoyant plume model is calculated for D1 and D2 scenarios and evaluated based on end plume temperature, salinity, and intrusion depth (Table 5-4). Ambient water properties are defined by two CTD measurements of full water column temperature and salinity from nearby D1 and D2 (CTD1 and CTD2, respectively, Figure 5-3). Temperature, salinity, and intrusion depth at the end of the plume are found to be largely insensitive to varying ambient fjord water properties if the ambient waters show strong summer stratification. We use the RACMO2.3-derived estimates of subglacial discharge across the terminus at D1 and D2 $\left(\mathrm{m}^{3} \mathrm{~s}^{-1}\right)$ (using MBM2014 of average daily runoff during the field expedition $\left.\left(\mathrm{m}^{3} \mathrm{~s}^{-1}\right)\right)($ Table $5-3)$. 
Given the observed ocean stratification and the modeled subglacial discharge, the plume model confirms that GMW1 should be notably fresher and lighter than GMW2 (Figure 5-5 c, Table 5-4). This supports the conclusion that GMW1 and GMW2 are the result of two distinct discharge locations with different subglacial discharge magnitudes. For the D2 scenario, the plume model predicts end plume properties and neutrally buoyant depths $(\sim 31 \mathrm{~m})$ that are aligned with the GMW2 observations at similar depths (Figure 5-5c, d). For the D1 scenario, the plume model predicts end plume properties that are lighter and fresher than the observed GMW1 (Figure 5-5 c, Tables 5-2 \& 54). The predicted D1 plume would reach above the 20-m-deep pycnocline at neutral buoyancy depth of $\sim 14 \mathrm{~m}$, (Table 5-4). With a minimum amount of overshoot, we might expect the D1 plume to reach the surface or depths close enough to the surface to be visible during field observations. In reality, the plume at D1 was not observed to reach the surface, and GMW1 was only observed beneath the pycnocline (Figure 5-4). There are several possible reasons for this discrepancy. First, the plume model may have an incorrect entrainment parameterization. Second, the estimated subglacial discharge could be incorrect. In addition, after detaching from the terminus at the plume's intrusion depth, GMW spreads an additional $150 \mathrm{~m}$ away from the SS face before being observed at R5. Over this time, we would expect lateral mixing to further dilute the GMW properties. The plume model does not describe lateral mixing, as the model ends when the plume reaches intrusion depth.

\subsection{Discussion}

\subsubsection{Subglacial catchments, discharge, and GMW observations}

Our analysis of the ocean data and subglacial catchments both suggest that there are two primary subglacial discharge locations along the ice/ocean interface. On the outlet glacier catchment side of the interface, the primary subcatchments, C1 and C2 (Fig. 7a), route substantial $(>90 \%)$ of the total SS meltwater runoff (Table 5-3) into the fjord across the grounding line at discharge locations D1 and D2, respectively (Figure 5-3). On the ocean side of the interface, GMW1 and GMW2 are located near D1 and D2, respectively, and show fresher, colder waters with high turbidity as compared to ambient fjord waters (Figure 5-5 a, b). The properties of these waters, in particular, are consistent with glacial modification due to significant injection of runoff at depth as is expected from a localized discharge of meltwater at D1 and D2. Finally, between D1 and D2, there is a 2-km stretch of the terminus where GMW show cold excursions with low to high turbidity along R4 and R5 (Figure 5-6 c). The formation of this GMW is less clear, though in this region between subglacial discharge locations, GMW 
properties are more indicative of submarine melt and limited subglacial discharge and/or lateral mixing of GMW1 and GMW2.

Although we lack observations within the plumes themselves in 2012, the ocean observations of GMW suggest that these waters are produced by ambient fjord waters interacting with a limited number of discrete plumes along the terminus. Our observations of GMW beneath the pycnocline at a distance of $\sim 150 \mathrm{~m}$ from the terminus suggest that the two plumes reach neutral buoyancy beneath the fjord surface. Visual observations during the 2012 field campaign confirm that the plumes did not reach the fjord surface during this time. In contrast, during the July 2013 field campaign at SF, a vigorous, turbulent plume was observed to break through at the fjord surface at D1 [Mankoff et al., 2016].

Differences in subglacial discharge magnitude entering the fjord at D1 and D2 is both observed and predicted to result in water mass differences between GMW1 and GMW2. Fed by subglacial discharge from the largest subglacial subcatchment, GMW1 is fresher and lighter than GMW2 (Table 5-3, Figures 5-5 a-d, 5-6 a, b). D2 receives roughly 20\% of the subglacial discharge magnitude at D1 (Table 5-3). This smaller subglacial discharge results in a relatively saltier and heavier GMW2 in comparison to GMW1 (Figures 5-5 a-d, 5-6 a, b). While a greater volume of subglacial discharge leads to a fresher water mass, the strength of the resultant buoyant plume also plays a role in near-ice water mass transformation. Plume theory predicts that a plume fed by a greater amount of subglacial discharge will have a stronger buoyancy forcing, leading to both faster entrainment of ambient waters and an increase in the fraction of subglacial discharge in the plume [Jenkins, 2011; Straneo and Cenedese, 2015]. In this fjord, the entrainment of ambient waters into a plume results in GMW with temperatures and salinities that are warmer and saltier than the subglacial discharge entering the fjord $\left(\theta=0{ }^{\circ} \mathrm{C}, \mathrm{S}=0 \mathrm{PSU}\right)$. The volume fraction of entrained water for both D1 and D2 plumes is above 0.9 (Table 5-4), indicating that for this fjord the plume temperature and salinity at neutral buoyancy depth are largely a function of the entrained ambient water mass. Thus, overall, the greater subglacial discharge at D1 drives a more vigorous plume that mixes with both IIW and SW, which results in GMW that is closer in $\theta$ and S to SW than IIW (Table 5-2, Figure 5-6 a). In contrast, smaller subglacial discharge at D2 drives a less vigorous plume that mixes at deeper depths with only IIW, resulting in GMW that retains the cold signature of subglacial discharge and submarine melting (Table 5-2, Figure 5-6b). 
Consistent with the ocean data, the plume model predicts end plume conditions at D1 are fresher and lighter than those at D2 as they contain a greater amount of subglacial discharge (Figure 5-5 d, Table 5-4). However, the end plume conditions from the Jenkins (2011) model for D1 scenarios are lighter than the GMW1 we observe (Figure 5-5 c, Table 5-4). In addition to errors in the plume model and subglacial discharge estimates, lateral mixing within $\sim 150 \mathrm{~m}$ of the terminus is a consideration for comparing the plume model results and observed GMW. Large amounts of mixing with ambient waters likely occur once the plume detaches from the terminus and GMW is exported away from the ice/ocean interface. This lateral mixing has been observed in other marine terminating outlet glacier systems in Greenland, where GMW from an inferred localized subglacial discharge location was found uniformly across the fjord in profiles taken $\sim 200 \mathrm{~m}$ from the terminus [Chauché et al., 2014].

\subsubsection{Observing the heterogeneous near-ice environment}

The coupling of near-ice observations and subglacial discharge routing is necessary for understanding ice-ocean interactions at marine terminating outlet glaciers. While multiple recent studies have observed GMW in fjords [Chauché et al., 2014; Inall et al., 2014; Johnson et al., 2011; Mortensen et al., 2011; Straneo et al., 2011; Sutherland et al., 2014] and others have measured and modeled runoff based on surface catchment area [Mernild et al., 2015], no studies have directly linked the two sides of this interface or considered the role of basal routing on catchment area. For this study, we pair near-ice observations and subglacial discharge routing to show for the first time that the observed GMW characteristics align with the subglacial discharge magnitudes from outlet glacier subcatchments.

Our results highlight the necessity of subsurface observations within the near-ice zone for accurately characterizing the heterogeneous processes at the ice/ocean interface. We observe heterogeneous, subsurface GMW as high turbidity, cold excursions in across-fjord sections as far as $1.5 \mathrm{~km}$ from the SS terminus (Figure 5-4). Further away from the terminus, only the cold excursion at the density of GMW1 remains in the far-field profiles (Figure 5-5 d). Thus, while in the near-ice zone

there are multiple subglacial discharge locations across the SS grounding line and different types of GMW observed, only a modified GMW1 is identifiable in far-field profiles. Noble gas observations of GMW in neighboring Greenland fjords observe a dilution of GMW as you move away from the terminus, suggesting that GMW is highly diluted outside of the near-ice zone [Beaird et al., 2015]. Thus, 
the fact that only a modified GMW1 is detectable in the far-field profiles is likely due to the larger volume flux of discharge from D1 entering the fjord as compared to discharge from D2 (Table 5-4). Sill depth may be an additional factor impeding the export of GMW2; GMW2 is observed at or barely above the 70-m sill depth, while GMW1 is observed at shallower depths (Figures 5-1 \& 5-3, Table 52). The implication is that far-field measurements only provide a partial representation of processes along the ice/ocean interface.

Similar to the single cold excursion observed in the ambient SF waters, many studies have observed evidence of subsurface GMW uniformly distributed across fjord width outside of the nearice zone [Johnson et al., 2011; Mortensen et al., 2011; Straneo et al., 2011; Chauché et al., 2014; Inall et al., 2014; Sutherland et al., 2014]. Observations at Store and Rink glaciers as close as $200 \mathrm{~m}$ to termini identify one to a couple of surface and subsurface plumes along each glacier termini [Chauché et al., 2014]. However, the GMW observed $200 \mathrm{~m}$ from the termini is uniform across the fjord [Chauche et al., 2014]. While our observations of subglacial discharge locations in SF are consistent with the low number of subglacial discharge locations found at Store and Rink glaciers [Chauché et al., 2014], we are able to further differentiate and map types of GMW to outlet glacier subcatchments.

The subsurface nature of the plumes and resultant GMW we observed is consistent with multiple studies that have also observed subsurface GMW [Chauché et al., 2014; Inall et al., 2014; Johnson et al., 2011; Mortensen et al., 2011; Straneo et al., 2011; Sutherland et al., 2014]. Together these findings drive home the point that plumes and other processes at the ice/ocean interface actively driving submarine melt can and often do operate without creating an expression on the fjord surface. Surface expressions of plumes have been detected at many Greenland tidewater glaciers and invoked as evidence for runoff release from the ice sheet into fjords and proglacial streams [Chu et al., 2009; Tedstone and Arnold, 2012], and have even been proposed as a potentially useful remote measure of runoff variability [Chu et al., 2012]. However, our observations of plumes and GMW that reach neutral buoyancy beneath the pycnocline suggest in many cases this relationship does not hold true. The magnitude of subglacial discharge entering a fjord, fjord stratification, and fjord depth have all been shown to affect whether a plume reaches the surface [Sciascia et al., 2013]. The absence of plume surface expression does not negate the presence of subglacial discharge plumes that may be driving significant submarine melt and circulation along a tidewater terminus. Thus, across-fjord subsurface observations 
within the near-ice zone provide the most comprehensive characterization of ice/ocean interactions in Greenland fjords.

\subsubsection{Observational constraints for modeling the heterogeneous near-ice environment}

While spatial distribution of subglacial discharge is a critical component for estimating submarine melt rates at marine terminating outlet glaciers in numerical models [Slater et al., 2015], we have few observations to constrain subglacial discharge scenarios. Model configurations of subglacial discharge for major Greenland outlet glaciers range from a distributed subglacial system where equal amounts of subglacial discharge emerge across the entire grounding line width [Jenkins, 2011; Sciascia et al., 2013], to partitioning subglacial discharge between a number of equally-spaced plumes along the terminus [Kimura et al., 2014; Slater et al., 2015], to routing all subglacial discharge through a single subglacial channel emerging in one, central plume [Slater et al., 2015; Xu et al., 2013]. While all these models, which share the same melt parameterization, agree that submarine melt rates increase with increasing subglacial discharge [Jenkins, 2011; Kimura et al., 2014; Sciascia et al., 2013; Slater et al., 2015; Xu et al., 2012, 2013], the amount and distribution of the increased melting depends on the largely unknown pattern of subglacial discharge [Straneo and Cenedese, 2015]. Most recently, Slater et al. [2015] concluded that a distributed system yields as much as 5 times more submarine melting than a channelized system consisting of a few plumes along the terminus. Thus, spatial distribution of subglacial melt is critically important for accurately estimating submarine melt rates in a numerical model [Slater et al., 2015; Straneo and Cenedese, 2015].

For this system, we observe at least two, localized areas of subglacial discharge separated by wide areas of the terminus with little to no subglacial discharge. Our survey interval was limited to peak summer conditions, when one would expect channelized subglacial discharge. Observations during other times of the year, in particular prior to and during the onset of meltwater runoff early in the melt season, as well as towards the end of the melt season when runoff is reduced again, would be useful to more fully characterize the seasonally evolving magnitude and type of subglacial discharge in this environment. A simple subglacial meltwater routing model using MBM2014, the GIMP ice sheet surface digital elevation model, and RACMO2.3 runoff estimates was able to predict the number, approximate location, and relative magnitude and type of subglacial discharge locations. And while this subglacial catchment delineation method should be supplemented with ocean measurements and field observations where possible, in many cases it may prove a useful first order approximation of 
the spatial distribution of subglacial discharge at other marine terminating outlet glaciers where fjord observations are lacking or difficult to obtain.

\subsection{Conclusions}

Hydrographic surveys completed by an AUV in Sarqardleq Fjord provide several new observational insights to the characteristics and distribution of near-ice GMW in a shallow-silled, moderate-sized west Greenland fjord. Overcoming navigation difficulties in the acoustically noisy, iceberg-filled fjord, the AUV covered a large portion of the near-ice waters along the terminus. AUV observations provide the most comprehensive and spatiotemporally detailed snapshots of across-fjord hydrography in the near-ice zone to date. From these measurements we identified two types of GMW that map onto two plumes based on $\theta / S /$ turbidity near-ice properties and subcatchment runoff estimates. The two plumes are, notably, not observed to reach the surface in the fjords, but attain neutral buoyancy beneath the pycnocline of the strongly stratified summer fjord conditions.

Our observations detail how mixing processes at the ice/ocean interface driven by either submarine melting and/or plumes fed by subglacial discharge can produce GMW that is colder, fresher, and at times more turbid than ambient fjord waters. An idealized plume model for plumes fed by a range of RACMO2.3-derived subglacial discharges appropriate for the two plumes observed in this fjord is qualitatively consistent with the largest subglacial discharge being associated with the lighter, fresher glacially modified watermass. The characterization of GMW and subglacial catchments for this outlet glacier system provides critical observational constraints on the widely varying subglacial discharge scenarios employed by the current set of submarine melt modeling studies. Results supply near-ice observations abutting one Greenland Ice Sheet outlet glacier, though the continued investigation of other Greenland outlet glaciers is much needed to ultimately move towards an accurate representation of oceanic forcing at outlet glacier termini and an improved understanding of the ice sheet's outlet glacier dynamics. 
Table 5-1: REMUS Missions in Sarqardleq Fjord

\begin{tabular}{|c|c|c|c|c|c|}
\hline Mission & Date & $\begin{array}{l}\text { Local Time } \\
\text { at Mission } \\
\text { Start }\end{array}$ & $\begin{array}{l}\text { Duration } \\
\text { (h:mm) }\end{array}$ & Transect Sampling Path (m-depth) & $\begin{array}{l}\text { Distance } \\
\text { Traveled } \\
(\mathrm{km})\end{array}$ \\
\hline R1 & $7 / 18$ & $21: 10$ & $1: 28$ & $\mathrm{Yo}_{\mathrm{O}} \mathrm{Y}_{\mathrm{O}}=5-90$ & 9.00 \\
\hline $\mathrm{R} 2$ & $7 / 21$ & $15: 37$ & $3: 41$ & $\begin{array}{l}\text { Yo-Yo }=5-50 ; \\
\text { Fixed Depth=50, 70; } \\
\text { Altitude }=10 \mathrm{~m} \text { off bottom }\end{array}$ & 23.11 \\
\hline R3 & $7 / 22$ & $14: 58$ & $6: 25$ & $\begin{array}{l}\text { Yo-Yo }=5-55 \\
\text { Fixed Depth }=60,70 ; \\
\text { Altitude }=10 \mathrm{~m} \text { above bottom }\end{array}$ & 41.36 \\
\hline $\mathrm{R} 4$ & $7 / 23$ & $14: 37$ & $5: 05$ & $\begin{array}{l}\text { Yo-Yo }=5-50 \\
\text { Fixed Depth }=60,70 \\
\text { Altitude }=10 \mathrm{~m} \text { above bottom }\end{array}$ & 30.93 \\
\hline R5 & $7 / 24$ & $18: 12$ & $5: 26$ & $\begin{array}{l}\text { Yo-Yo 5-60; } \\
\text { Fixed Depth=40, 55, 70; } \\
\text { Altitude = } 10 \mathrm{~m} \text { above bottom }\end{array}$ & 34.91 \\
\hline
\end{tabular}


Table 5-2: Water mass properties in Sarqardleq Fjord

\begin{tabular}{|c|c|c|c|c|}
\hline Water mass & $\begin{array}{l}\text { Surface } \\
\text { Water (SW) }\end{array}$ & $\begin{array}{l}\text { Ilulissat Icefjord } \\
\text { Waters (IIW) }\end{array}$ & $\begin{array}{l}\text { Glacially Modified } \\
\text { Water } 1 \text { (GMW1) }\end{array}$ & $\begin{array}{l}\text { Glacially Modified } \\
\text { Water } 2 \text { (GMW2) }\end{array}$ \\
\hline Depth range $(\mathrm{m})$ & $0-20$ & 20-SF bottom & $35-60$ & $50-70$ \\
\hline $\mathrm{S}(\mathrm{PSU})$ & $21-30.5$ & $32.5-33.5$ & $30.8-31.5$ & $31.1-32.3$ \\
\hline$\theta\left({ }^{\circ} \mathrm{C}\right)$ & $1.5-10$ & $0.8-1.5$ & $0.75-0.85$ & $0.59-0.75$ \\
\hline$\sigma_{\theta}\left(\varrho_{\theta}-1000 \mathrm{~kg} \mathrm{~m}^{-3}\right)$ & $16.0-24.3$ & $25.9-26.7$ & $24.6-25.1$ & $24.8-25.8$ \\
\hline Turbidity (NTU) & Low $(<4$ & Low $(<4$ NTU $)$ & High $(>9$ NTU) & High $(>9$ NTU) \\
\hline & NTU) & & & \\
\hline Origin/Formation & $\begin{array}{l}\text { Local } \\
\text { formation }\end{array}$ & $\begin{array}{l}\text { Disko and } \\
\text { Baffin Bay }\end{array}$ & Local formation & Local formation \\
\hline
\end{tabular}


Table 5-3: Saqqarliup sermia subcatchments and runoff estimates

\begin{tabular}{llllc}
\hline Subcatchment & C1 & C2 & C3 & SS ( 2 C1-3) \\
\hline Discharge location & D1 & D2 & D3 & --
\end{tabular}

\begin{tabular}{lllll}
\hline Bathymetry along catchment terminus & & & \\
& & & \\
Average depth (m) & 116.4 & 101.5 & 39.9 & -- \\
Maximum depth (m) & 150.4 & 131.8 & 49.9 & -- \\
& & & & \\
\end{tabular}

\begin{tabular}{|c|c|c|c|c|}
\hline \multicolumn{5}{|l|}{ Morlighem et al. (2014) (MBM2014) } \\
\hline Catchment area $\left(\mathrm{km}^{2}\right)$ & 268.74 & 47.97 & 23.31 & 340.02 \\
\hline Catchment area compared to SS $(\%)$ & $79 \%$ & $14 \%$ & $7 \%$ & -- \\
\hline Catchment average daily runoff July 2012 & $115.78 \pm$ & $20.62 \pm$ & $9.97 \pm$ & $146.37 \pm$ \\
\hline$\pm \sigma_{J U L Y}\left(\mathrm{Q}_{\mathrm{sg}}\right)\left(\mathrm{m}^{3} \mathrm{~s}^{-1}\right)$ & 42.59 & 7.33 & 3.47 & 53.26 \\
\hline Average daily July runoff compared to SS & $79 \%$ & $14 \%$ & $7 \%$ & -- \\
\hline \multicolumn{5}{|l|}{$(\%)$} \\
\hline Catchment average daily runoff during the & $88.70 \pm$ & $16.10 \pm$ & $7.89 \pm$ & $112.69 \pm$ \\
\hline field expedition (DOY 200, 203-206) \pm & 42.59 & 7.33 & 3.47 & 53.26 \\
\hline \multicolumn{5}{|l|}{$\sigma_{J U L Y}\left(\mathrm{Q}_{\mathrm{sg}}\right)\left(\mathrm{m}^{3} \mathrm{~s}^{-1}\right)$} \\
\hline \multicolumn{5}{|l|}{ Bamber et al. (2013) (BBM2013) } \\
\hline Catchment area $\left(\mathrm{km}^{2}\right)$ & 402 & 42 & 9 & 453 \\
\hline Catchment area compared to SS (\%) & $89 \%$ & $9 \%$ & $2 \%$ & -- \\
\hline Catchment average daily runoff July 2012 & $171.01 \pm$ & $17.47 \pm$ & $3.72 \pm$ & $192.20 \pm$ \\
\hline$\pm \sigma_{J U L Y}\left(\mathrm{Q}_{\mathrm{sg}}\right)\left(\mathrm{m}^{3} \mathrm{~s}^{-1}\right)$ & 64.27 & 6.40 & 1.36 & 71.75 \\
\hline Average daily July runoff compared to SS & $89 \%$ & $9 \%$ & $2 \%$ & -- \\
\hline \multicolumn{5}{|l|}{$(\%)$} \\
\hline Catchment average daily runoff during the & $122.83 \pm$ & $14.08 \pm$ & $3.05 \pm$ & $139.96 \pm$ \\
\hline field expedition (DOY 200, 203-206) \pm & 64.27 & 6.40 & 1.36 & 71.75 \\
\hline$\sigma_{J U L Y}\left(\mathrm{Q}_{\mathrm{sg}}\right)\left(\mathrm{m}^{3} \mathrm{~s}^{-1}\right)$ & & & & \\
\hline
\end{tabular}


Table 5-4. Buoyant plume model simulations for D1 and D2 scenarios at MBM2014 subglacial discharge values. Plume $\theta$ and $S$ ranges are plotted in Fig. 5 c, d.

\begin{tabular}{lll}
\hline & D1 & D2 \\
\hline Ambient $\theta / \mathrm{S}$ profile & CTD 1 & CTD 2 \\
Calving face depth $(\mathrm{m})$ & 153 & 140 \\
Subglacial Discharge $\left(Q_{s g}\right)\left(\mathrm{m}^{3} \mathrm{~s}^{-1}\right)$ & {$[46.11,88.70,131.29]$} & {$[8.77,16.10,23.43]$} \\
Plume $\theta\left({ }^{\circ} \mathrm{C}\right)$ at neutral buoyancy depth & {$[0.82,0.85,0.84]$} & {$[0.83,0.82,0.82]$} \\
Plume S $(\mathrm{PSU})$ at neutral buoyancy & {$[30.50,29.72,29.17]$} & {$[31.32,30.88,30.56]$} \\
depth & & \\
Plume $\sigma_{\theta}\left(\varrho_{\theta}-1000 \mathrm{~kg} \mathrm{~m}{ }^{-3}\right)$ at neutral & {$[24.34,23.74,23.30]$} & {$[24.90,24.59,24.35]$} \\
buoyancy depth & {$[21.79,14.03,13.79]$} & {$[41.41,31.23,27.68]$} \\
Neutral buoyancy depth $(\mathrm{m})$ & {$[0.94,0.94,0.94]$} & {$[0.96,0.96,0.96]$} \\
Volume fraction of entrained water & & \\
\hline
\end{tabular}




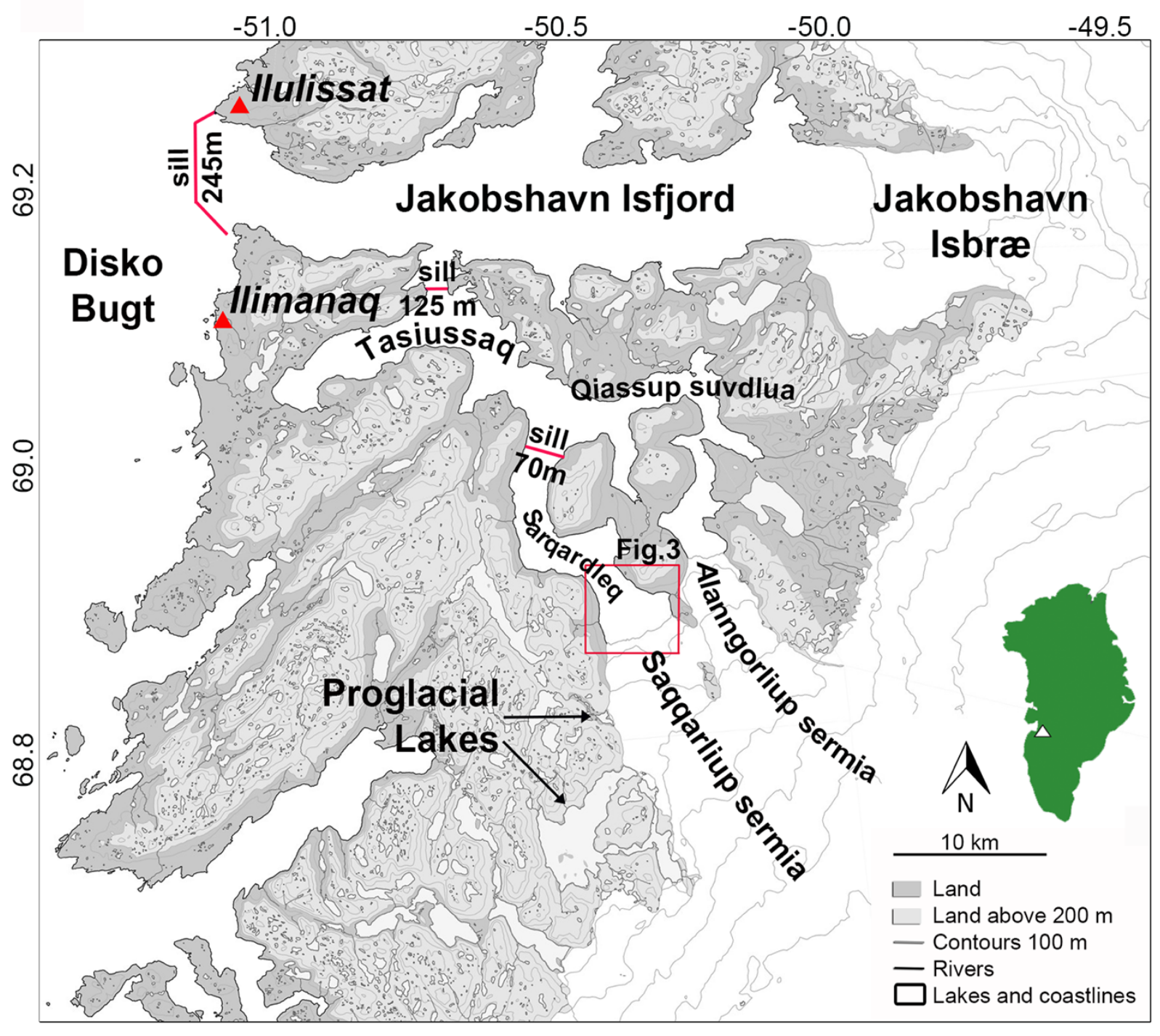

Figure 5-1. The Sarqardleq Fjord/Saqqarliup sermia outlet glacier system in West Greenland. Modified from NunaGIS 1:100,000 map (Asiaq, Greenland Survey). Sill locations shown in red. Fig. 5-3 location shown in red box. 
a

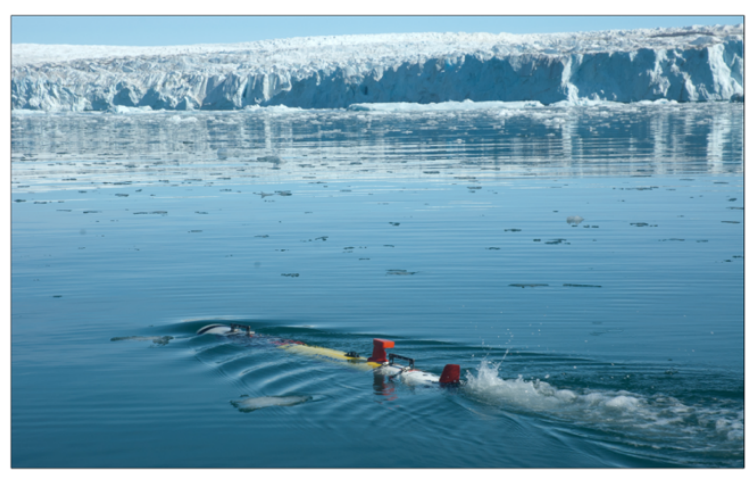

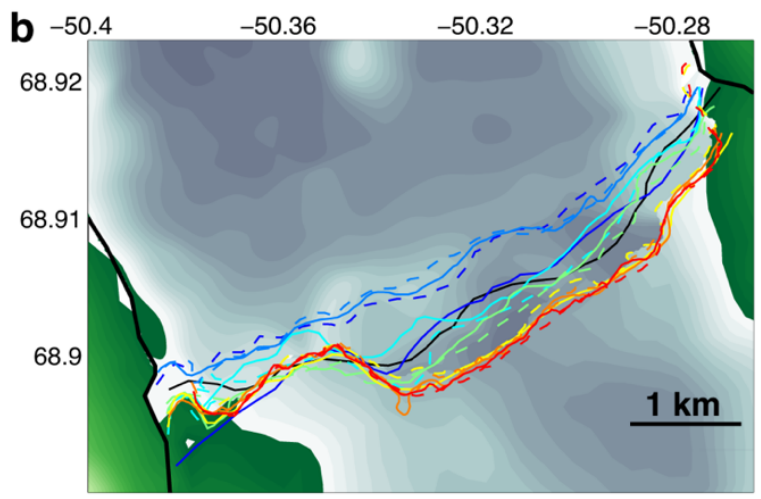

$-1975148-2004127-2012171$

$-1981129--2006177-2012226$

$--1985248-2008176--2013190$

$-1988169-2010172-2013212$

$--1992212-2012155--2013234$

Figure 5-2. REMUS-100 AUV and past Saqqarliup sermia terminus positions in Sarqardleq Fjord. (a) REMUS-100 AUV before deployment in Sarqardleq Fjord. Note dense ice cover along Saqqarliup sermia terminus. (b) Saqqarliup sermia terminus 1975-2013 summertime positions digitized from the Landsat archive (http://earthexplorer.usgs.gov/) over fjord bathymetry and subglacial topography (see Fig. 5-3). Front position dates are listed in the legend as year and day of year. 


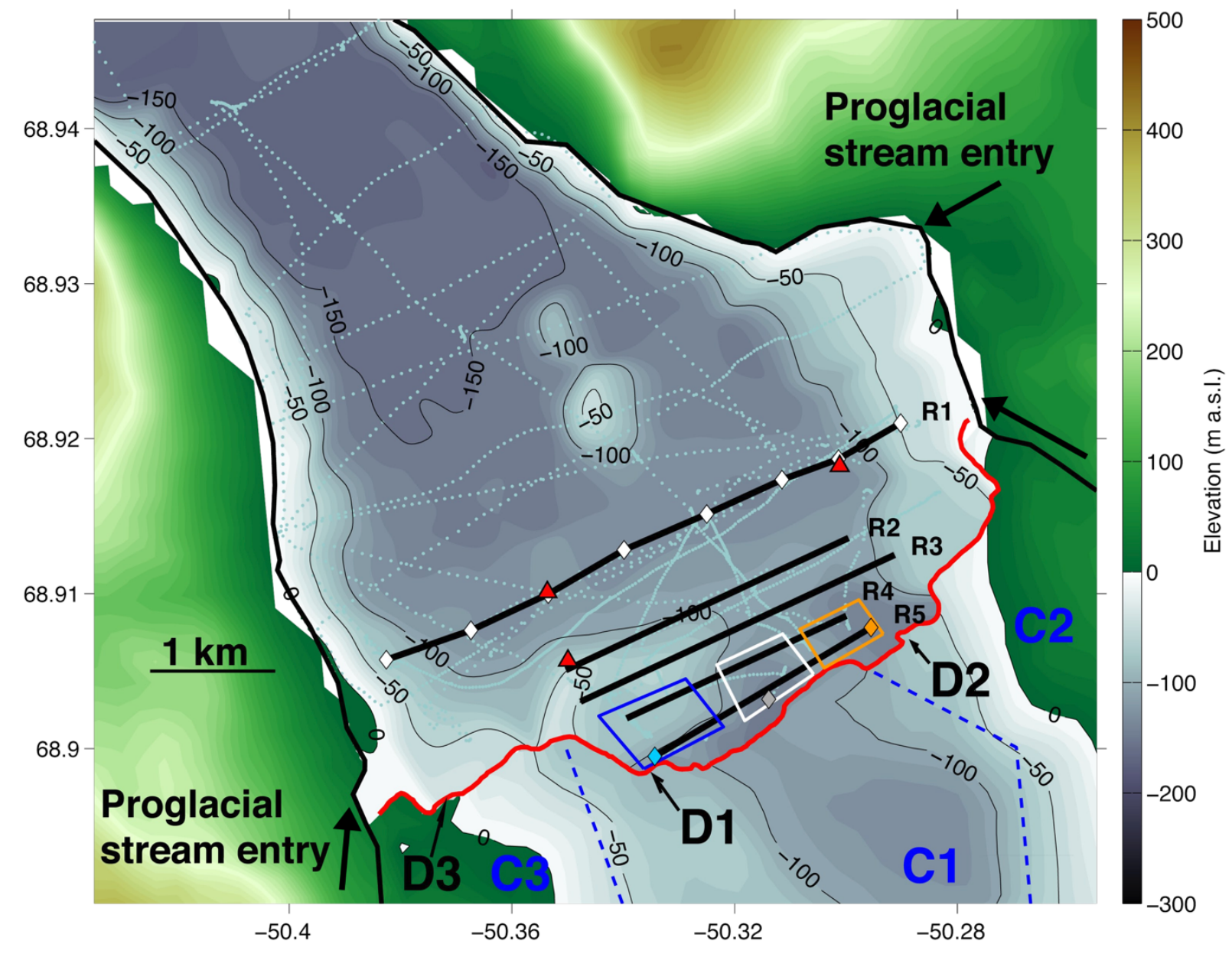

Figure 5-3. July 2012 Survey of Sarqardleq Fjord. Sarqardleq Fjord bathymetry (10-meter colored contours below sea level within fjord) and Morlighem et al. [2014] bedrock elevation map (10-meter colored contours above and below sea level outside of fjord) are shown. The Saqqarliup sermia front position and coastline from a June 19, 2012 Landsat image are mapped in red and black lines, respectively. Depth measurements collected during July 2012 field operations used to create the Sarqardleq Fjord bathymetry are plotted as grey dots over the contoured bathymetry. REMUS transects R1-R5 are shown in black, with LBL transponders mapped with red triangles. Subglacial subcatchments C1, C2, and C3 dividing lines from MBM2014 analysis are mapped in dashed blue line, with the location of D1, D2, and D3 subglacial discharge channels along the submerged terminus shown with thin black arrows. CTD casts are shown with diamonds: white diamonds are CTD casts along R1 used in REMUS cross-calibration, and the blue, gold, and grey diamonds are CTD casts 1, 2, and 3 that were taken along R5 within GMW1, GMW2, and the region between GMW1 and GMW2 (outlined in blue, gold, and white, respectively). Three proglacial stream entries to Sarqardleq Fjord are shown along the northeast and southwest fjord coastlines with thick black arrows. 


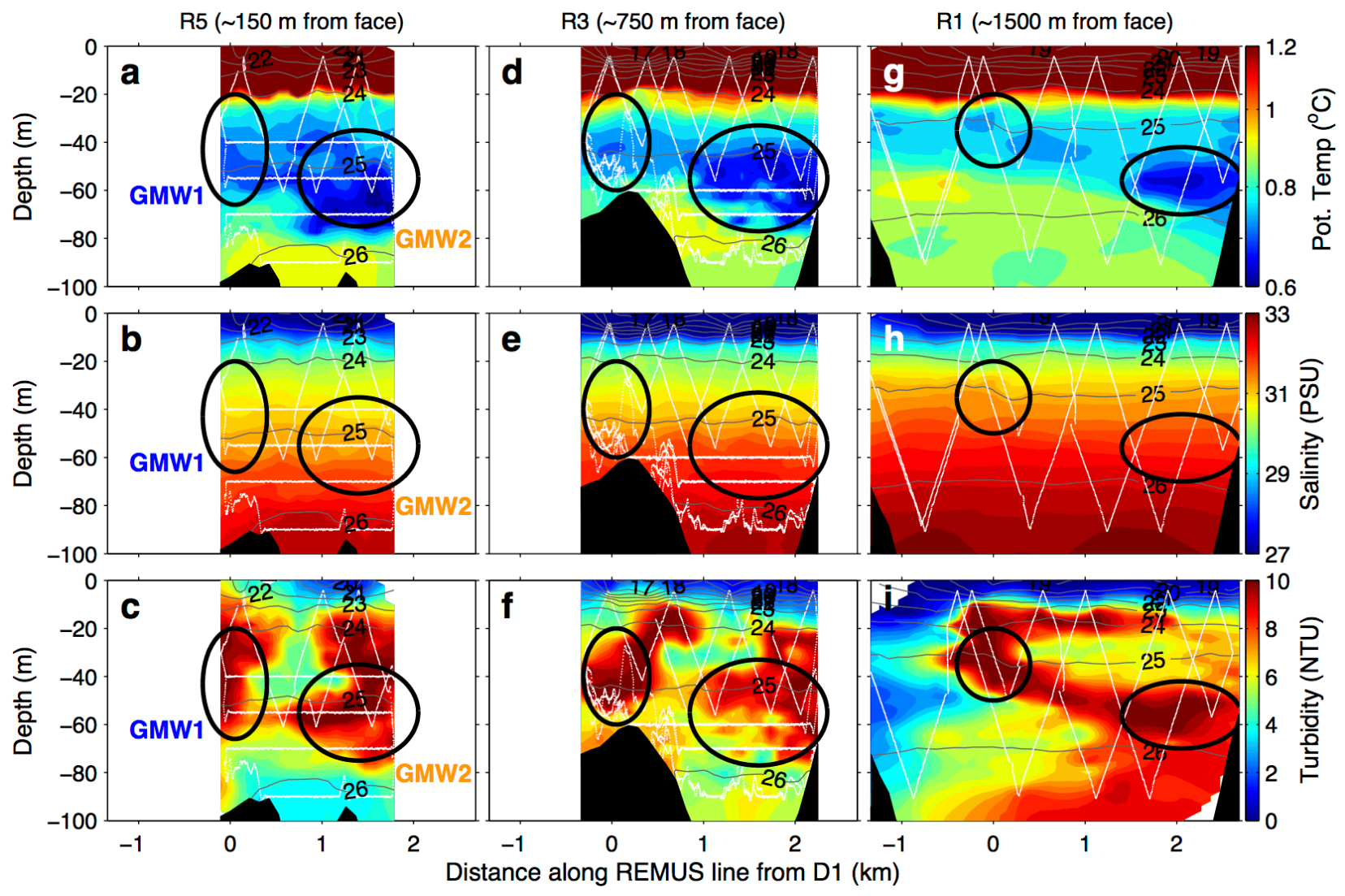

Figure 5-4. Select REMUS Across-Fjord Sections. $\theta\left({ }^{\circ} \mathrm{C}\right)$, S (PSU), and turbidity (NTU) sections along REMUS lines $(\mathbf{a}-\mathbf{c})$ R5, (d-f) R3, and $(\mathbf{g}-\mathbf{i})$ R1 from 0 to $100 \mathrm{~m}$ depth. Sections are oriented looking away from the terminus, with the southwestern end of the section on the left. Across-fjord transect distance is plotted as horizontal distance along section, with $0 \mathrm{~km}$ located at the intersection of the REMUS section with an along-fjord line running from D1 to the southwestern LBL transponder along R1 (Fig. 3). GMW1 and GMW2 regions identified by black ellipses, and labeled in blue and gold, respectively in a-c. Isopycnals plotted in grey, REMUS mission tracks shown in white (Table 5-1), and bathymetry shown in black (Fig. 5-3). 

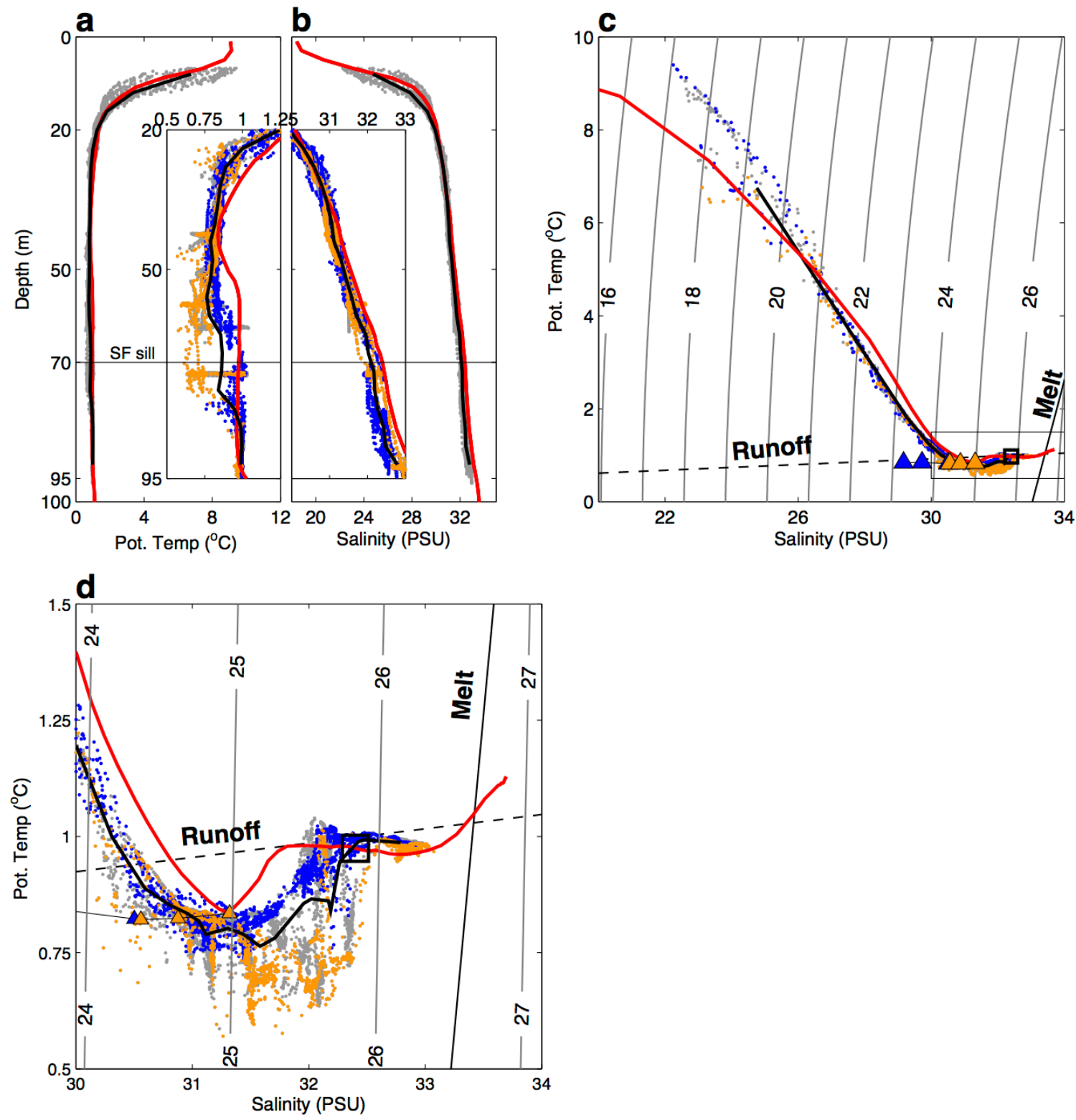

Figure 5-5. Glacially Modified Water in Sarqardleq Fjord. $\theta\left({ }^{\circ} \mathrm{C}\right)(\mathbf{a})$ and $\mathrm{S}(\mathbf{b})$ profiles for R4 and R5 measurements over the full water-column depth (grey), with the average of R4 and R5 measurements and the ambient fjord waters in black and red, respectively. Panel $\mathbf{a}$ and $\mathbf{b}$ insets show same data from 20-95-m depth over a finer $\theta$ or $S$ range, with measurements taken within the GMW1 and GMW2 regions along R4 and R5 (Fig. 5-3) shown in blue and gold, respectively. $\theta / \mathrm{S}$ plots of R4 and R5 measurements (c) (colors same as in $\mathbf{a}$ and $\mathbf{b}$ ), with melt and runoff mixing lines. Intersection for melt and runoff mixing lines set to CTD2 properties at grounding line depth (Fig. 5-6 b). Black square along ambient fjord water profile shows $\theta / \mathrm{S}$ properties at sill depth $(70 \mathrm{~m}) . \theta / \mathrm{S}$ results for the Jenkins [2011] plume modeling (Table 5-4) of D1 (blue triangles) and D2 (gold triangles) shown. (d) Same data as in $\mathbf{c}$ over finer $\theta / \mathrm{S}$ range indicated by thin black box in $\mathbf{c}$. 

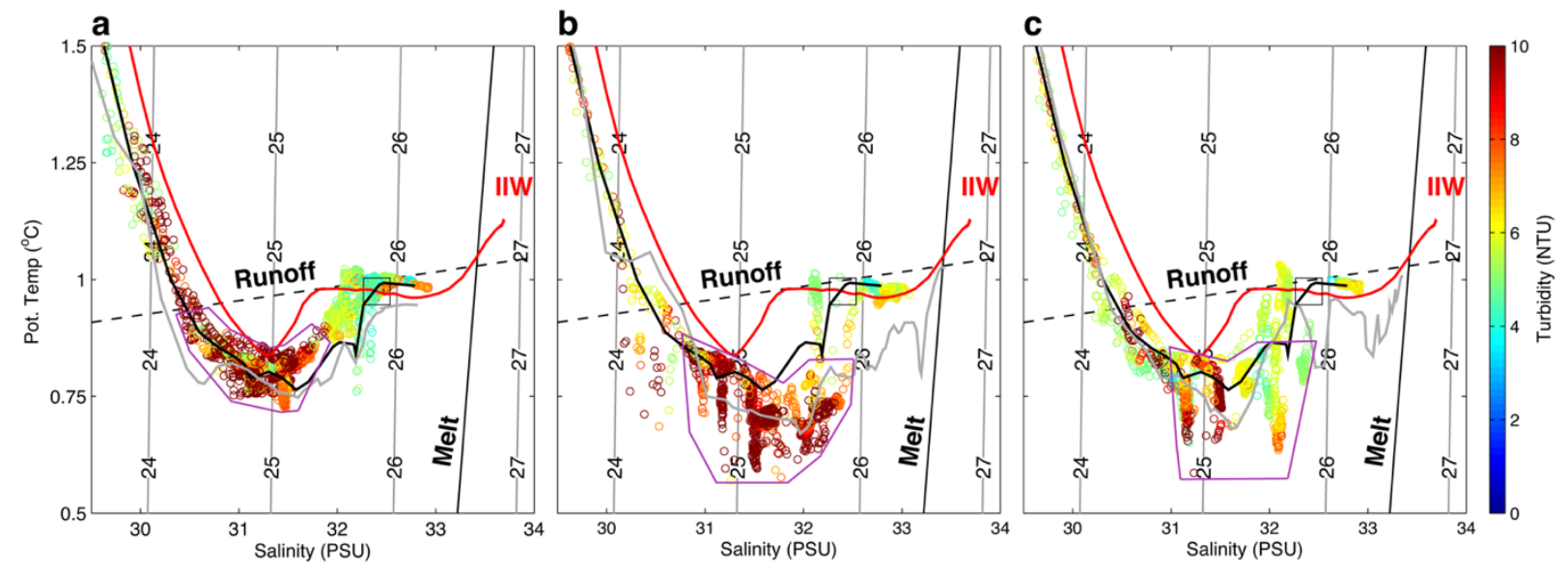

Figure 5-6. Turbidity of Glacially Modified Waters. $\theta\left({ }^{\circ} \mathrm{C}\right)$ and S (PSU) profiles from the regions along R4 and R5 outlined in blue (GMW1 region) (a), gold (GMW2 region) (b), and white (the region between GMW1 and GMW2) (c) in Figure 3, with turbidity plotted as the color of the point. CTD1 (a), CTD2 (b), and CTD3 (c) are plotted in grey. The GMW region in $\theta / \mathrm{S}$ space is outlined in purple. The average of all R4 and R5 measurements and the ambient fjord waters are plotted in black and red, respectively. Black square along ambient fjord water profile shows $\theta / \mathrm{S}$ properties at sill depth (70-m). 

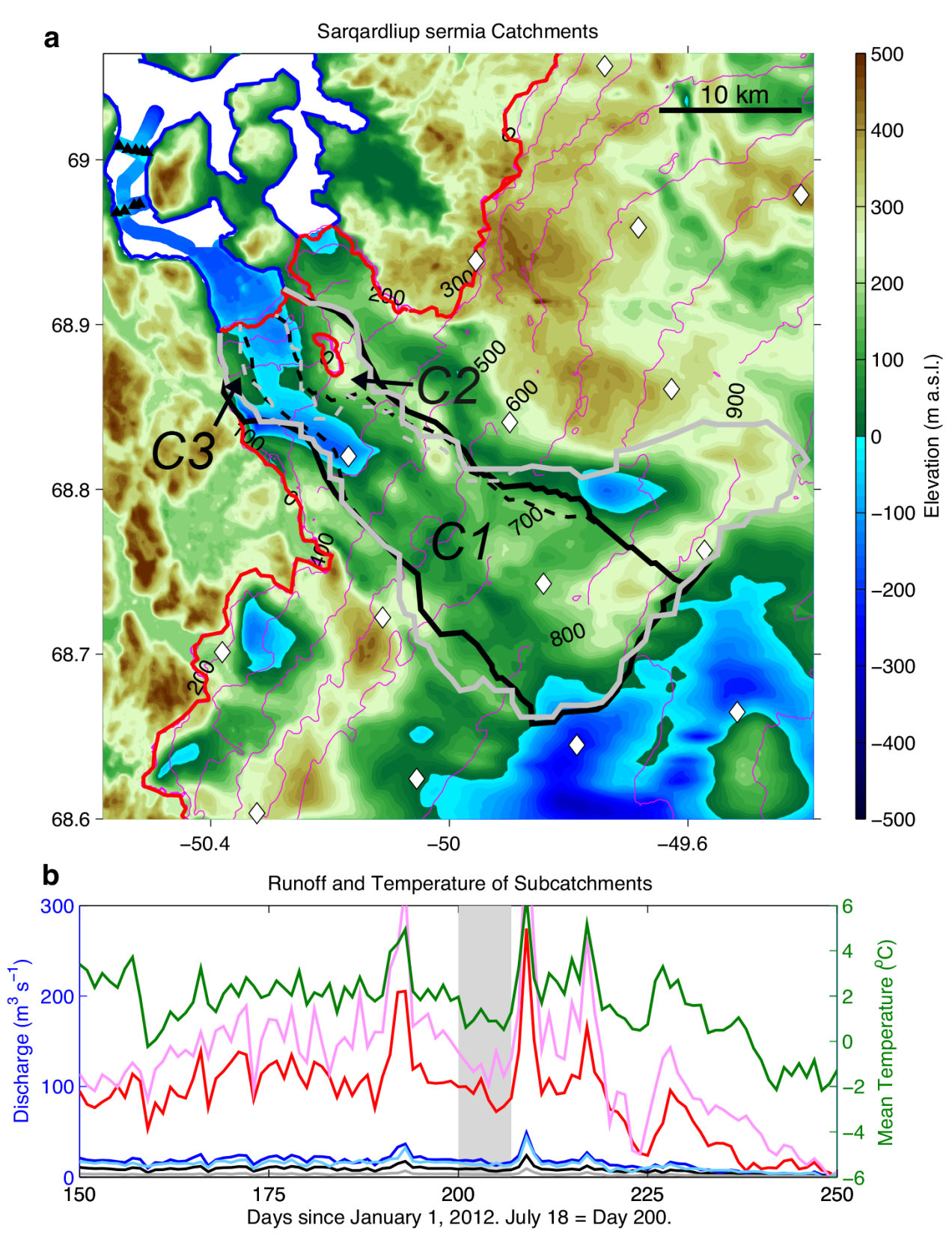

Figure 5-7. Saqqarliup sermia catchments and discharge. a) Estimated Saqqarliup sermia catchment (thick black line) and sub-catchments C1, C2, and C3 (dashed black line) from the MBM2014 analysis over Morlighem et al. [2014] bedrock elevation map (filled contours) and ice sheet surface (magenta contours). BBM2013 catchment and subcatchments outlines in thick solid and dashed grey lines, respectively. Ice sheet margin and coastlines shown in red and blue, respectively. RACMO2.3 11-km resolution grid points shown with white diamonds. Sarqardleq fjord bathymetry and outer Sarqardleq fjord CTD positions (black triangles) and depth measurements also shown. b) Daily C1, C2, and C3 subcatchment MBM2014 RACMO2.3 discharge estimates (red, blue, and black lines, respectively) and daily average RACMO2.3 temperature (green line) across the Saqqarliup sermia subcatchment C1 for DOY 150-250, 2012. Daily C1, C2, and C3 subcatchment BBM2013 RACMO2.3 discharge estimates in pink, cyan, and grey lines, respectively. Dates of REMUS and CTD sampling from DOY 200-207 marked by grey bar. 


\section{Chapter 6}

\section{Conclusions}

\subsection{Thesis Summary}

The rate of mass loss from the Greenland Ice Sheet is accelerating [Shepherd et al., 2012] due to increases in surface melt [Hanna et al., 2013] and changes in ice sheet dynamics [Pritchard et al., 2009]. The dynamical component of mass loss includes iceberg calving at outlet glacier termini [Moon et al., 2008; Nick et al., 2013; Enderlin et al., 2014] and acceleration of the ice sheet interior due to changes in basal sliding [Rignot and Kanagaratnam, 2006; Joughin et al., 2008]. Mass changes across the entire ice sheet derived from satellite observations are increasingly precise [Shepherd et al., 2012; van den Broeke et al., 2016]; however, we are still at the beginning of the work of collecting in situ observations of the processes driving dynamical mass loss. Only through greater understanding of the mechanisms and variability of these processes will we be able to improve predictions of future ice sheet changes driven by atmospheric and oceanic warming.

This thesis integrated observations and numerical modeling across and between the disciplines of glaciology, geophysics, and physical oceanography to investigate mechanisms of dynamical mass loss in a region of the western margin of the Greenland Ice Sheet. We began firmly on the glaciology side of this divide in Chapter 2, with an investigation of a seven-year record of ice-sheet surface motion. Observations from a Global Positioning System (GPS) network operating from 2006-2014 revealed that annual velocities around the North Lake region decrease at an average rate of $-0.9 \pm 1.1$ $\mathrm{m} \mathrm{yr}^{-2}$, consistent with the negative trend in annual velocities observed in neighboring regions of the western margin over recent decades despite increasing surface melt over the same multi-decadal timeframe. Though there is substantial inter-annual variability in surface melting over the GPS record, we found no statistically significant relationship between runoff season characteristics and ice flow velocities within a given year or season. 
While subglacial hydrology and ice-flow models now capture the evolution of the seasonal velocity structure of the ablation zone at a qualitative level [Schoof, 2010; Hewitt, 2013; Werder et al., 2013], the decadal slowdown trend we observe across the western margin is not predicted by current ice sheet models, underscoring that these models do not yet capture all the relevant feedbacks between runoff and ice dynamics needed to predict long term trends in ice sheet flow. Observational studies targeted at long-term records of ice-sheet shape, subglacial hydrology, and basal motion are needed to better understand mechanisms controlling ice-sheet flow on annual to decadal timescales. Moreover, as subglacial hydrology models are further calibrated against regional surface ice flow measurements (Chapter 4), future ice-flow modeling studies should be evaluated alongside the available measurements of ice-flow collected at North Lake, Swiss Camp, and the K-transect.

In Chapter 3, we investigated the upper limits of meltwater's influence on the ice sheet's summer ice flow acceleration by focusing on the same GPS record of ice-sheet surface motion during three rapid supraglacial lake drainages of North Lake in 2011-2013. Lake drainage events rapidly transport large volumes of surface meltwater to the base of the Greenland Ice Sheet, drive transient ice-sheet acceleration, and establish conduits for additional surface-to-bed meltwater transport for the remainder of the melt season [Das et al., 2008]. While it was well established that cracks must remain water-filled to propagate to the bed [Weertman, 1973; Van Der Veen, 2007; Krawcaynski et al., 2009], we determined the precise mechanisms that initiate hydro-fracture events beneath lakes forming in regions of ice sheet surface compression. We observed that each drainage event was preceded by a 612 hour period of ice-sheet uplift and/or enhanced basal slip. Using a Network Inversion Filter to take advantage of the dense GPS network surrounding the lake, we determine the distribution of meltwater at the ice-sheet bed before, during, and after the three rapid drainages, each of which generated tensile stresses that promoted hydro-fracture beneath the lake. For North Lake, these precursors are likely associated with the introduction of melt-water to the bed through neighboring moulin systems.

Based on the three rapid drainages we observed, we hypothesize that if stress transients associated with enhanced melt-water transport to the bed beneath lakes are required to initiate surfaceto-bed hydro-fractures in compressional lake basins, then lakes are less likely to create large-scale hydro-fractures in interior regions of the Greenland Ice Sheet where melt-water access to the bed is limited by lack of pre-existing crevasses [Bartholomew et al., 2011; Joughin et al., 2013; Leeson et al., 2015; Poinar et al., 2015]. Our results imply that as lakes form in less crevassed, higher-elevation interior 
regions of the ice sheet, the creation of new surface-to-bed conduits caused by lake-draining hydrofractures may be obstructed by limited meltwater access to the bed and greater distances between compressive lake basins and extensional crevasse-forming regions. Thus, the supply of melt-water to the bed may not be well correlated with the location, abundance, and size of high elevation supraglacial lakes. This finding complicates the commonly used volume-threshold for supraglacial lake drainage used in supraglacial hydrologic routing studies to predict lake drainages in current and future decades [Clason et al., 2012; Leeson et al., 2015].

In Chapter 4, we widened our spatial focus to the entire ablation zone and investigated annual subglacial drainage system morphology with a numerical subglacial hydrology model. The model incorporates both distributed and channelized flow, and has realistic ice sheet geometry and surface runoff input. We ran the model across two years where regional observations of complex spatiotemporal pattern of melt-season surface speed are available for model calibration. We tested whether model-derived effective pressures exhibit the theorized inverse relationship with surface speeds while also performing much needed model calibration to regional observations of surface speed.

We found that overall drainage system morphology is equivalent in both years, with robust subglacial pathways forming over bedrock ridges and minimal englacial or basal water storage outside of the melt season. Across both years, our results depict the expected inverse relationship between effective pressure and speed when surface speeds are at least $150 \%$ above winter speeds in the midmelt season. Outside of these periods in the early- and late-melt season, effective pressures and speed have a positive relationship inconsistent with the basal sliding model, suggesting the basal sliding model may be incorrect or effective pressure may be less important for speed in comparison to the driving stress. Either subglacial hydrology models still need to improve to better predict effective pressures, or the models are lacking other processes affecting ice flow than effective pressure and driving stress such as variable and/or seasonally evolving bed strength. Future work should continue to calibrate models regional observations and investigate what further model advances are necessary for improving effective pressure estimates.

Finally, Chapter 5 worked to bridge the ice-ocean boundary by pairing detailed hydrographic and bathymetric measurements with modeled and observed subglacial discharge locations and 
magnitudes for the Saqqarliup sermia/Sarqardleq Fjord system, West Greenland. Hydrographic surveys were completed by an Autonomous Underwater Vehicle as close as 150 meters from the ice/ocean interface, providing several new observational insights to the characteristics and distribution of near-ice glacially modified water in a shallow-silled, moderate-sized west Greenland fjord. Overcoming navigation difficulties in the acoustically noisy, iceberg-filled fjord, the Autonomous Underwater Vehicle covered a large portion of the near-ice waters along the terminus. These Autonomous Underwater Vehicle observations provide the most comprehensive and spatiotemporally detailed snapshots of across-fjord hydrography in the near-ice zone to date.

The near-ice observations and subglacial discharge routing indicate that runoff from this glacier occurs primarily at two discrete locations and gives rise to two distinct glacially modified waters. The two glacially modified water locations align with modeled runoff discharged at separate locations along the grounded margin corresponding with two prominent subcatchments beneath Saqqarliup sermia. The two plumes are, notably, not observed to reach the surface in the fjords, but attain neutral buoyancy beneath the pycnocline of the strongly stratified summer fjord conditions. Mixing processes at the ice-ocean interface driven by either submarine melting and/or plumes fed by subglacial discharge produced glacially modified water that is colder, fresher, and at times more turbid than ambient fjord waters. We show that the location with the largest subglacial discharge is associated with the lighter, fresher glacially modified watermass. This is qualitatively consistent with results from an idealized plume model.

The characterization of glacially modified water and subglacial catchments for this outlet glacier system provides critical observational constraints on the widely varying subglacial discharge scenarios employed by the current set of submarine melt modeling studies. Results supply near-ice observations abutting one Greenland Ice Sheet outlet glacier, though the continued investigation of other Greenland outlet glaciers is much needed to ultimately move towards an accurate representation of oceanic forcing at outlet glacier termini and an improved understanding of the ice sheet's outlet glacier dynamics. 


\subsection{Future directions towards synthesis}

Understanding and predicting the Greenland Ice Sheet's dynamic response to atmospheric and oceanic forcing requires interdisciplinary efforts. Though highly specific in their questions and methods, the chapters of this thesis combine to fill in knowledge gaps on the processes driving present day Greenland Ice Sheet hydrodynamics in the ablation zone and at the ice-ocean boundary. From these chapters and other recent work, a better picture can be drawn of the mechanisms of ice sheet flow and outlet glacier retreat. Yet, additional field campaigns and theoretical work reaching beyond traditional discipline boundaries are required to narrow our gap in understanding of the forcing mechanisms and magnitudes of Greenland Ice Sheet dynamic mass loss.

There are enough in situ observational campaigns of inland ice flow with sufficiently long $(>5$ years) data sets to begin comparing different regions of inland ice flow response to melt. Observations from the K-transect [van de Wal et al., 2008, 2015], North Lake [Joughin et al., 2008; Stevens et al., 2016a], Leverett Glacier [Sole et al., 2013; Doyle et al., 2014], and Swiss Camp [Zwally et al., 2002; Colgan et al., 2011] should be evaluated with finer temporal resolution than the comparison of annual records we performed in Chapter 2 (Figure 2-3). For example, daily and seasonal ice motion could be compared against modeled surface runoff across sites to determine if ice flow response has a dependence on multiple parameters including runoff, ice sheet thickness, bed topography, surface hydrology, or surface ice slope. While stations along a transect along the Leverett Glacier depict an elevationdependent annual velocity structure [Sole et al., 2013; Doyle et al., 2014], this relationship should be tested for all inland ice sites across the parameters listed above.

As remotely-sensed ice sheet surface speed measurements at increasingly high temporal resolution (weeks- monthly) from the Sentinel-1 and Landsat-8 satellites become available [Fabnestock et al., 2015; Monginot et al., 2017], contemporaneous GPS observations of ice flow should be used to quality check satellite observations of surface speed. Additionally, contemporaneous satellite observations of surface speed could be used to determine over what area of the ice sheet surface a point-source GPS record of surface speed is applicable. The "practical footprint" of a GPS station may depend on the station's proximity to surface-to-bed meltwater pathways (lakes, moulins, crevasse fields) and the local bed topography. The practical footprint size of a single GPS station would inform what length scales meltwater input and/or bed properties are important for surface ice flow. 
Additionally, knowledge of the practical footprint over a region would improve future GPS network design.

Hydrology and ice-flow models at present [Chapter 4; Schoof, 2010; Hewitt, 2013; Werder et al., 2013] do not capture the trends in decline of ice sheet velocities over recent decades [Tedstone et al., 2015; van de W al et al., 2015; Stevens et al., 2016a]. These coupled models may not accurately predict iceflow variability on longer than seasonal to annual timescales. Observational studies targeted at longterm records of ice-sheet shape, subglacial hydrology, and basal motion are needed to better understand mechanisms controlling ice-sheet flow on annual to decadal timescales. These observations should be used to inform future modeling studies alongside continued model calibration with regional observations of surface ice speeds.

Many open questions remain for the current and future impact of supraglacial lake drainages on ice flow. While lakes in close proximity have been observed to drain in clusters [Selmes et al., 2011; Joughin et al., 2013; Fitspatrick et al., 2014], whether this phenomena is due to lake drainages dynamically triggering the drainage of neighboring lakes or merely an artifact of elevation-dependent melt and supraglacial lake formation is untested. Mechanisms responsible for clustered lake drainages should be investigates with in situ measurements of surface ice movement and stress change over a group of lakes that drain simultaneously. If clustered lake drainage are the result of tensile stress transients at the ice sheet surface instigated by a neighboring lake drainage, we may also be able to constrain a critical radius over which a supraglacial lake drainage can trigger its neighbor. This critical radius could then be used to make a prediction of the drainage characteristics of future lakes forming at higher elevations [Parizek and Alley, 2004; Howat et al., 2013; Leeson et al., 2015] over longer-wavelength surface topography [Lampkin and VanderBerg, 2011; Joughin et al., 2013; Sergienko, 2013; Poinar et al., 2015].

As lakes are projected to migrate inland as climate warms [Leeson et al., 2015], further knowledge on the drainage mechanisms and subglacial consequences of lake drainages in the upper ablation zone is critical for determining when and how the upper ablation zone basal thermal state will change from frozen to thawed [Parizele and Alley, 2004; Alley et al., 2005, 2010]. At this point, the conclusions drawn from modelling surface ice sheet hydrology changes of the upper ablation zone into the future [Leeson et al., 2015; Ignéczi et al., 2016] greatly outpaces our understanding of how lake drainage; moulin and crevasse formation; and subglacial hydrology and bed properties work in the 
upper ablation zone. For these reasons, observations of ice sheet motion and stress changes should also be measured for high elevation lakes. Additionally, greater focus should be placed on determining how processes evolve at the bed and how surface-to-bed pathways open up in the upper ablation zone in order to better constrain predictions of the response of ice flow to the growing area of the ablation zone [Poinar et al., 2015].

The field of ice-ocean interactions remains severely observation-limited. While recent advances have been made in measuring near-ice $(<200 \mathrm{~m})$ hydrographic properties in medium-sized Greenland fjords with low calving rates [Chauché et al., 2014; Mankoff, 2016; Stevens et al., 2016b], these measurements are missing for many studies attempting to estimate subglacial melt rate of mediumsided outlet glaciers [Beaird et al., 2015; Fried et al., 2015; Carroll et al., 2016], the few remaining Greenland ice shelves [Johnson et al., 2011; Wilson and Straneo, 2015], and outlet glaciers with the largest ice discharge and deepest fjords (e.g., Jakobshavn Isbræ, Kangerdlugssuaq Glacier, and Helheim Glacier) [Straneo et al., 2012; Jackson et al., 2014; Jackson and Straneo, 2016; Sutherland et al., 2014; Gladish et al., 2015]. The five largest outlet glaciers have significant persistent ice mélange, which further complicates field operations in their abutting fjords [Straneo et al., 2013].

Future observational campaigns should focus on observing near-ice hydrography and the distribution, size, and geometry of subglacial conduits delivering subglacial discharge to the fjord at the grounding line. At present we have limited hydrographic observations within plumes fed by subglacial discharge [Bendtsen et al., 2015; Mankoff, 2016], resulting in most studies of coupled plumeoutlet glacier dynamics relying on time series of plumes reaching the fjord surface from time-lapse cameras [Fried et al., 2015; Schild et al., 2016; Slater et al., 2017a]. Relying on plume surface expression as a measure of subglacial discharge is inadequate for some tidewater glaciers, as plumes do not always reach the surface of a stratified fjord [Stevens et al., 2016b]. Key questions that need to be answered include "What is the size and geometry of subglacial channels at and before the grounding line?" and "Does fresh subglacial discharge first interact with salty fjord waters at or before the subglacial discharge reaches the grounding line?”. Answering these questions would greatly improve boundary conditions for modeling subglacial discharge plumes [Slater et al., 2015] and aid in determining appropriate scalings for estimating submarine melting from plumes [Slater et al., 2016]. 
Future observational campaigns should also focus on observing the shape of the calving face [Fried et al., 2015] to better understand how melting of the submerged terminus driven by subglacial discharge may affect calving [O'Leary and Christoffersen, 2013; Slater et al., 2017b]. Though there are many calving laws [reviewed by Benn et al., 2007], a calving law that incorporates fjord hydrographic conditions has yet to be proposed despite recent observations of several Svalbard tidewater glacier calving rates tightly varying with sub-surface fjord temperature [Luckman et al., 2015]. Additional work should consider variability in subglacial discharge location and timing and is possible affect on spatial heterogeneity in calving and termini geometry with promontories and incisions [Fried et al., 2015; Schild et al., 2016; Stevens et al., 2016b; Slater et al., 2017a]. Finally, the observational targets suggested above should be attempted across the range of size and velocity of outlet glaciers and temperature, stratification, and depth of fjords to determine if mechanisms acting at medium-sized outlet glaciers translate to larger outlet glaciers with higher velocities and calving rates.

\subsection{An appreciation for complexity}

In summary, the work of this thesis and other recent work cited in section 6.2 draws a better picture of the mechanisms of ice sheet flow and outlet glacier retreat. Over the five years I have worked on this thesis, we have developed a new appreciation for the complexity of the Greenland Ice Sheet's behavior. We have shown that while ice sheet annual velocities are decreasing across the Western margin on decadal timescales, the increase in annual surface melt over the same time period is not sufficient to determine a causal link between runoff forcing and ice sheet velocities over decadal timescales. We have discovered that the triggering of lake drainage events depends not on a volumethreshold large enough to drive a crack to the bed, but rather on local, transient stress perturbations that promote crevasse initiation. By comparing regional surface velocity observations with modelderived effective pressures, we have challenged the seasonal-invariance of the theoretical model for basal sliding. And finally, we have observed spatially complex glacially modified waters in the near-ice environment that suggest heterogeneous subglacial discharge along the grounded terminus of an outlet glacier. In each chapter, the findings of this thesis both clarify the mechanisms at play, while also highlighting their previously unknown intricacies. 
An appreciation for the complexity of the ice sheet's behavior points towards future research directions that work to define and measure the mechanisms governing ice flow and hydraulic processes in small geographic areas. Through a greater understanding of these mechanisms, the findings from site-specific studies may provide suitable analogs for regions of the ice sheet that are projected to experience increased surface melt in the coming decades. For example, while a cluster of supraglacial lake drainages in the mid-ablation zone may be observed in daily satellite images, determining whether or not one lake drainage leads to the triggering of subsequent lake drainages requires in situ observations of ice sheet surface motion and strain. The knowledge gained from in situ observations of clustered lake drainages could then be extended to predict the potential for clustered lake drainages in regions of greater ice thicknesses and lower density spacing of supraglacial lakes. Additionally, site-specific studies may provide suitable analogs for regions of the ice sheet that are more difficult to observationally access but contribute significantly to dynamic ice loss through ice discharge. While investigating the dynamics of subglacial discharge at a small tidewater glacier with minimal calving and negligible ice mélange is a necessary starting point, we need to consider how translatable these processes are to the largest outlet glaciers with high calving flux and heavy ice mélange that rest on below sea level bed troughs that extend far inland. Do characteristics of the subglacial drainage system and subglacial discharge at the glacier terminus we have observed in slowerflowing outlet glaciers translate to the fast-flowing outlet glaciers with the highest ice discharge rates? Or, is there some critical velocity reached in an outlet glacier trunk where the subglacial hydrology of slower-moving regions is no longer a suitable analog? In order for future research strategies to take into account the complexity of the ice sheet's behavior, we must continue to focus on testing and refining classically-held assumptions of ice flow with investigations that are both process-based and potentially translatable to other regions and future states of the ice sheet. 


\section{References}

Alley, R. B., P. U. Clark, P. Huybrechts, and I. Joughin (2005), Ice-sheet and sea-level changes., Science, 310(5747), 456-60, doi:10.1126/science.1114613.

Alley, R. B., T. K. Dupont, B. R. Parizek, and S. Anandakrishnan (2005), Access of surface meltwater to beds of sub-freezing glaciers: preliminary insights, Ann. Glaciol., 40(1), 8-14, doi:10.3189/172756405781813483.

Alley, R. B. et al. (2010), History of the Greenland Ice Sheet: paleoclimatic insights, Quat. Sci. Rev., 29(15-16), 1728-1756.

Andrews, L. C. et al. (2014), Direct observations of evolving subglacial drainage beneath the Greenland Ice Sheet. Nature 514, 80-83.

Andrews, L. C. (2015), Spatial and Temporal Evolution of the Glacial Hydrologic System of the Western Greenland Ice Sheet: Observational and Remote Sensing, The University of Texas at Austin.

Van Angelen, J. H., van den Broeke, M. R., Wouters, B. \& Lenaerts, J. T. M. (2013), Contemporary (1960-2012) evolution of the climate and surface mass balance of the Greenland ice sheet. Surv. Geophys. 35, 1155-1174.

Arnold, N. S., Banwell, A. F. \& Willis, I. C. (2014), High-resolution modelling of the seasonal evolution of surface water storage on the Greenland Ice Sheet. Cryosph. 8, 1149-1160.

Bartholomaus, T. C., R. S. Anderson, and S. P. Anderson (2011), Growth and collapse of the distributed subglacial hydrologic system of Kennicott Glacier, Alaska, USA, and its effects on basal motion, J. Glaciol., 57(206), 985-1002.

Bartholomew, I., P. Nienow, D. Mair, A. Hubbard, M. A. King, and A. Sole (2010), Seasonal evolution of subglacial drainage and acceleration in a Greenland outlet glacier, Nat. Geosci., 3(6), 408-411, doi:10.1038/ngeo863.

Bartholomew, I. D. et al. (2011), Seasonal variations in Greenland Ice Sheet motion: Inland extent and behaviour at higher elevations. Earth Planet. Sci. Lett. 307, 271-278.

Bartholomew, I. et al. (2012), Short-term variability in Greenland Ice Sheet motion forced by timevarying meltwater drainage: Implications for the relationship between subglacial drainage system behavior and ice velocity. J. Geophys. Res. 117, F03002.

Bamber, J., van den Broeke, M., Ettema, J., Lenaerts, J. and Rignot, E. (2012): Recent large increases in freshwater fluxes from Greenland into the North Atlantic, Geophys. Res. Lett., 39(19), 14, doi:10.1029/2012GL052552. 
Bamber, J. L., Griggs, J. a., Hurkmans, R. T. W. L., Dowdeswell, J. a., Gogineni, S. P., Howat, I., Mouginot, J., Paden, J., Palmer, S., Rignot, E. and Steinhage, D. (2013): A new bed elevation dataset for Greenland, Cryosph., 7(2), 499-510, doi:10.5194/tc-7-499-2013.

Banwell, A. F., N. S. Arnold, I. C. Willis, M. Tedesco, and A. P. Ahlstrøm (2012), Modeling supraglacial water routing and lake filling on the Greenland Ice Sheet, J. Geophys. Res., 117, doi:10.1029/2012JF002393.

Banwell, A. F., Willis, I. C. and Arnold, N. S. (2013): Modeling subglacial water routing at Paakitsoq, W Greenland, J. Geophys. Res. Earth Surf., 118(3), 1282-1295, doi:10.1002/jgrf.20093.

Banwell, A., I. Hewitt, I. Willis, and N. Arnold (2016), Moulin density controls drainage development beneath the Greenland Ice Sheet, J. Geophys. Res. Earth Surf., 121, 2248-2269, doi:10.1002/2015JF003801.

Barnes, S. L. (1994): Applications of the Barnes Objective Analysis Scheme. Part I: Effects of Undersampling, Wave Position, and Station Randomness, J. Atmos. Ocean. Technol., 11, 1433-1448.

Beaird, N., Straneo, F. and Jenkins, W. (2015): Spreading of Greenland meltwaters in the ocean revealed by noble gases, Geophys. Res. Lett., 42, doi:10.1002/2015GL065003.

Bendat, J. S., and A. G. Piersol (1993), Engineering Applications of Correlation and Spectral Analysis, 2nd ed., John Wiley, New York.

Bendtsen, J., J. Mortensen, K. Lennert, and S. Rysgaard (2015), Heat sources for glacial ice melt in a West Greenland tidewater outlet glacier fjord: The role of subglacial freshwater discharge, Geophys. Res. Lett., n/a-n/a, doi:10.1002/2015GL063846.

Benn, D. I., C. R. Warren, and R. H. Mottram (2007), Calving processes and the dynamics of calving glaciers, Earth-Science Rev., 82(3-4), 143-179, doi:10.1016/j.earscirev.2007.02.002.

Bevis, M. et al. (2012), Bedrock displacements in Greenland manifest ice mass variations, climate cycles and climate change., Proc. Natl. Acad. Sci. U. S. A., 109(30), 11944-8, doi:10.1073/pnas.1204664109.

Bougamont, M., P. Christoffersen, A. L. Hubbard, A. A. Fitzpatrick, S. H. Doyle, and S. P. Carter (2014), Sensitive response of the Greenland Ice Sheet to surface melt drainage over a soft bed, Nat. Commun., 5(5052), doi:10.1038/ncomms6052.

Box, J. E., and K. Ski (2007), Remote sounding of Greenland supraglacial melt lakes: Implications for subglacial hydraulics, J. Glaciol., 53(181), 257-265, doi:10.3189/172756507782202883.

Box, J. E., L. Yang, D. H. Bromwich, and L.-S. Bai (2009), Greenland Ice Sheet Surface Air Temperature Variability: 1840-2007*, J. Clim., 22(14), 4029-4049, doi:10.1175/2009JCLI2816.1. 
van den Broeke, M., J. Bamber, J. Ettema, E. Rignot, E. Schrama, W. J. van de Berg, E. van Meijgaard, I. Velicogna, and B. Wouters (2009), Partitioning recent Greenland mass loss., Science, 326(5955), 984-986, doi:10.1126/science.1178176.

van den Broeke, M., E. Enderlin, I. Howat, P. Kuipers Munneke, B. Noël, W. J. van de Berg, E. van Meijgaard, and B. Wouters (2016), On the recent contribution of the Greenland ice sheet to sea level change, Cryosph., 10, 1933-1946, doi:10.5194/tc-2016-123.

Budd, W. F. \& Jacka, T. H. (1989), A review of ice rheology for ice sheet modeling. Cold Reg. Sci. Technol. 16, 107-144.

Carroll, D., D. A. Sutherland, E. L. Shroyer, J. D. Nash, G. a. Catania, and L. a. Stearns (2015), Modeling Turbulent Subglacial Meltwater Plumes: Implications for Fjord-Scale BuoyancyDriven Circulation, J. Phys. Oceanogr., (Woods 2010), 150612105344002, doi:10.1175/JPO-D15-0033.1.

Carroll, D. et al. (2016), The impact of glacier geometry on meltwater plume structure and submarine melt in Greenland fjords, Geophys. Res. Lett., 43, 1-10, doi:10.1002/2016GL070170.

Catania, G. A., Neumann, T. A. \& Price, S. F. (2008), Characterizing englacial drainage in the ablation zone of the Greenland ice sheet. J. Glaciol. 54, 567-578.

Chandler, D. M., Wadham, J. L., Lis, G. P., Cowton, T., Sole, A., Bartholomew, I., Telling, J., Nienow, P., Bagshaw, E. B., Mair, D., Vinen, S. and Hubbard, A. (2013): Evolution of the subglacial drainage system beneath the Greenland Ice Sheet revealed by tracers, Nat. Geosci., 6(4), 1-4.

Chauché, N., Hubbard, A., Gascard, J. C., Box, J. E., Bates, R., Koppes, M., Sole, A., Christoffersen, P. and Patton, H. (2014): Ice-ocean interaction and calving front morphology at two west Greenland tidewater outlet glaciers, Cryosph., 8(4), 1457-1468, doi:10.5194/tc-8-1457-2014.

Chen, G. (1998), GPS kinematics positioning for the Airborne Laser Altimetry at Long Valley, California, Massachusetts Institute of Technology, Cambridge, Massachusetts.

Chu, V. W., Smith, L. C., Rennermalm, A. K., Forster, R. R., Box, J. E. and Reehy, N. (2009): Sediment plume response to surface melting and supraglacial lake drainages on the Greenland ice sheet, J. Glaciol., 55, 1072-1082, doi:10.3189/002214309790794904.

Chu, V. W., Smith, L. C., Rennermalm, A. K., Forster, R. R. and Box, J. E. (2012): Hydrologic controls on coastal suspended sediment plumes around the Greenland ice sheet, Cryosph. Discuss., 5, 2365-2407, doi:10.5194/tcd-5-2365-2011.

Chu, W., D. M. Schroeder, H. Seroussi, T. T. Creyts, S. J. Palmer, and R. E. Bell (2016a), Extensive winter subglacial water storage beneath the Greenland Ice Sheet, Geophys. Res. Lett., 1-9, doi:10.1002/2016GL071538. 
Chu, W., T. T. Creyts, and R. E. Bell (2016b), Rerouting of subglacial water flow between neighboring glaciers in West Greenland, J. Geophys. Res. Earth Surf., 121, 1-14, doi:10.1002/2015JF003705.

Clason, C., Mair, D. W. F., Burgess, D. O. \& Nienow, P. W. (2012), Modelling the delivery of supraglacial meltwater to the ice/bed interface: application to southwest Devon Ice Cap, Nunavut, Canada. J. Glaciol. 58, 361-374.

Creyts, T. T., and G. K. C. Clarke (2010), Hydraulics of subglacial supercooling: Theory and simulations for clear water flows, J. Geophys. Res. Earth Surf., 115(3), 1-21, doi:10.1029/2009JF001417.

Colgan, W., H. Rajaram, R. Anderson, K. Steffen, T. Phillips, I. Joughin, H. J. Zwally, and W. Abdalati (2011), The annual glaciohydrology cycle in the ablation zone of the Greenland ice sheet: Part 1. Hydrology model, J. Glaciol., 57(204), 697-709, doi:10.3189/002214311797409668.

Cowton, T., P. Nienow, A. Sole, J. Wadham, G. Lis, I. Bartholomew, D. Mair, and D. Chandler (2013), Evolution of drainage system morphology at a land-terminating Greenlandic outlet glacier, J. Geophys. Res. Earth Surf., 118(1), 29-41, doi:10.1029/2012JF002540.

Cuffey, K. M. and Patterson, W. S. B.: The Physics of Glaciers, 4th ed., Elsevier., 2010.

Das, S. B., I. Joughin, M. D. Behn, I. M. Howat, M. A. King, D. Lizarralde, and M. P. Bhatia (2008), Fracture Propagation to the Base of the Greenland Ice Sheet During Supraglacial Lake Drainage, Science, 320(5877), 778-781.

Dow, C. F. et al. (2015), Modeling of subglacial hydrological development following rapid supraglacial lake drainage, J. Geophys. Res. Earth Surf., 120(6), 1127-1147, doi:10.1002/2014JF003333.

Doyle, S. H. et al. (2013) Ice tectonic deformation during the rapid in situ drainage of a supraglacial lake on the Greenland Ice Sheet. Cryosph. 7, 129-140.

Doyle, S. H. et al. (2014) Persistent flow acceleration within the interior of the Greenland ice sheet. Geophys. Res. Lett. 41, 899-905.

Dutton, A. (2015), Sea-level rise due to polar ice-sheet mass loss during past warm periods, Science, 349(6244), doi:10.1126/science.aaa4019.

Enderlin, E., I. M. Howat, and S. Jeong (2014), An improved mass budget for the Greenland ice sheet, Geophys. Res. Lett., 41, 866-872, doi:10.1002/2013GL059010.

Fahnestock, M., T. Scambos, T. Moon, A. Gardner, T. Haran, and M. Klinger (2015), Rapid large-area mapping of ice flow using Landsat 8, Remote Sens. Environ., 185(2016), 84-94, doi:10.1016/j.rse.2015.11.023. 
Felikson, D. et al. (2017), Inland thinning on the Greenland ice sheet controlled by outlet glacier geometry, Nat. Geosci., (April), doi:10.1038/ngeo2934.

de Fleurian, B., M. Morlighem, H. Seroussi, E. Rignot, M. R. van den Broeke, P. Kuipers Munneke, J. Mouginot, P. C. J. P. Smeets, and A. J. Tedstone (2016), A modeling study of the effect of runoff variability on the effective pressure beneath Russell Glacier, West Greenland, J. Geophys. Res. F Earth Surf., 121(10), 1834-1848, doi:10.1002/2016JF003842.

Flowers, G. E. (2011), Glacier hydromechanics: Early insights and the lasting legacy of three works by Iken and colleagues, J. Glaciol., 56(200), 1069-1078, doi:10.3189/002214311796406103.

Flowers, G. E. (2015), Modelling water flow under glaciers and ice sheets, Proc. R. Soc. A Math. Phys. Eng. Sci., 471.

Fitzpatrick, A. A. W. et al. (2014), A decade (2002-2012) of supraglacial lake volume estimates across Russell Glacier, West Greenland. Cryosph. 8, 107-121.

Forsyth, D. W. (1985), Subsurface loading and estimates of the flexural rigidity of continental lithosphere, J. Geophys. Res. Planets, 90(B14), 12623-12632, doi:10.1029/JB090iB14p12623.

Fountain, A. G., and W. V Tangborn (1985), The Effect of Glaciers on Streamflow Variations The Effect of Glaciers on Streamflow Variations, Water Resour. Res., 4(1985), 579-586, doi:10.1029/WR021i004p00579.

Fountain, A. G. and J. S. Walder (1998), Water flow through temperate glaciers, Rev. Geophys., 36(3), 299-328, doi:10.1029/97RG03579.

Fowler, A. C. (1987), Sliding with cavity formation, J. Glaciol., 33(115), 255-267.

Fried, M. J., G. A. Catania, T. C. Bartholomaus, D. Duncan, M. Davis, L. A. Stearns, J. Nash, E. Shroyer, and D. Sutherland (2015), Distributed subglacial discharge drives significant submarine melt at a Greenland tidewater glacier, Geophys. Res. Lett., 42(21), 9328-9336, doi:10.1002/2015GL065806.

Gladish, C., Holland, D. M., Rosing-Asvid, A., Behrens, J. W. and Boje, J. (2015a): Oceanic Boundary Conditions for Jakobshavn Glacier. Part I: Variability and Renewal of Ilulissat Icefjord Waters, 2001-14, J. Phys. Oceanogr., doi:10.1175/JPO-D-14-0044.1.

Gladish, C. V., Holland, D. M. and Lee, C. M. (2015b): Oceanic Boundary Conditions for Jakobshavn Glacier. Part II: Provenance and Sources of Variability of Disko Bay and Ilulissat Icefjord Waters, 1990- 2011, J. Phys. Oceanogr., 45(2003), 33-63, doi:10.1175/JPO-D-14-0045.1.

Glen, J. W. (1995), The creep of polycrystalline ice. Proc. R. Soc. A Math. Phys. Eng. Sci. 228, 519-53.

Hanna, E. et al. (2013), Ice-sheet mass balance and climate change, Nature, 498(7452), 51-59, doi:10.1038/nature12238. 
Harper, J. T., J. H. Bradford, N. F. Humphrey, and T. W. Meierbachtol (2010), Vertical extension of the subglacial drainage system into basal crevasses., Nature, 467(7315), 579-582, doi:10.1038/nature09398.

Hellmer, H. H. and Olbers, D. J. (1989): A two-dimensional model for the thermohaline circulation under an ice shelf, Antarct. Sci., 1(4), 325-336.

Hewitt, I. J. (2011), Modelling distributed and channelized subglacial drainage: The spacing of channels, J. Glaciol., 57(202), 302-314, doi:10.3189/002214311796405951.

Hewitt, I. J. (2013), Seasonal changes in ice sheet motion due to melt water lubrication, Earth Planet. Sci. Lett., 371-372, 16-25, doi:10.1016/j.epsl.2013.04.022.

Hewitt, I. J., C. Schoof, and M. A. Werder (2012), Flotation and free surface flow in a model for subglacial drainage. Part 2. Channel flow, J. Fluid Mech., 702, 157-187, doi:10.1017/jfm.2012.166.

Hobbs, P. V. (1974), Ice physics. Clarendon Press.

Holland, D. M., R. H. Thomas, B. de Young, M. H. Ribergaard, and B. Lyberth (2008), Acceleration of Jakobshavn Isbræ triggered by warm subsurface ocean waters, Nat. Geosci., 1(10), 659_ 664, doi:10.1038/ngeo316.

Hoffman, M. J., G. A. Catania, T. A. Neumann, L. C. Andrews, and J. A. Rumrill (2011), Links between acceleration, melting, and supraglacial lake drainage of the western Greenland Ice Sheet, J. Geophys. Res., 116(F4), F04035, doi:10.1029/2010JF001934.

Hoffman, M. J., L. C. Andrews, S. A. Price, G. A. Catania, T. A. Neumann, M. P. Luethi, J. Gulley, C. Ryser, R. L. Hawley, and B. F. Morriss (2016), Greenland subglacial drainage evolution regulated by weakly-connected regions of the bed, Nat. Commun., 7, 13903, doi:10.1038/ncomms13903.

Howat, I. M., I. Joughin, and T. A. Scambos (2007), Rapid changes in ice discharge from Greenland outlet glaciers., Science, 315(5818), 1559-1561, doi:10.1126/science.1138478.

Howat, I. M., S. de la Peña, J. H. van Angelen, J. T. M. Lenaerts, and M. R. van den Broeke (2013), Brief Communication "Expansion of meltwater lakes on the Greenland Ice Sheet," Cryosph., 7(1), 201-204, doi:10.5194/tc-7-201-2013.

Howat, I. M., A. Negrete, and B. E. Smith (2014), The Greenland Ice Mapping Project (GIMP) land classification and surface elevation data sets, Cryosph., 8, 1509-1518, doi:10.5194/tc-8-15092014.

Iken, A. (1981), The effect of the subglacial water pressure on the sliding velocity of a glacier in an idealized numerical model., J. Glaciol., 27(97), 407-421. 
Iken, A., and R. A. Bindschadler (1986), Combined measurements of subglacial water pressure and surface velocity of Findelengletscher, Switzerland , J. Glaciol., 32(110), 101-119.

Iken, A., and M. Truffer (1997), The relationship between subglacial water pressure and velocity of Findelengletscher, Switzerland, during its advance and retreat, J. Glaciol., 43(144), 328-338, doi:10.1017/CBO9781107415324.004.

Ignéczi, Á., A. J. Sole, S. J. Livingstone, A. Leeson, N. Selmes, N. Gourmelen, and K. Briggs (2016), North-east sector of the Greenland Ice Sheet to undergo the greatest inland expansion of supraglacial lakes during the 21st century, Geophys. Res. Lett., doi:10.1002/2016GL070338.

Inall, M. E., T. Murray, F. R. Cottier, K. Scharrer, and T. J. Boyd (2014), Oceanic heat delivery via Kangerdlugssuaq Fjord to the south-east Greenland ice sheet, J. Geophys. Res. Ocean., 119, 631-645, doi:10.1002/2013JC009295.

Jackson, R. H., and F. Straneo (2016), Heat, salt, and freshwater budgets for a glacial fjord in Greenland, J. Phys. Oceanogr., 2735-2768, doi:10.1175/JPO-D-15-0134.1.

Jackson, R. H., F. Straneo, and D. A. Sutherland (2014), Externally forced fluctuations in ocean temperature at Greenland glaciers in non-summer months, Nat. Geosci., 1-6, doi:10.1038/ngeo2186.

Jenkins, A. (1991), A one-dimensional model of ice shelf-ocean interaction, J. Geophys. Res., 96(Cll), 671-677.

Jenkins, A. (1999), The Impact of Melting Ice on Ocean Waters, J. Phys. Oceanogr., 29, 2370-2381.

Jenkins, A. (2011), Convection-Driven Melting near the Grounding Lines of Ice Shelves and Tidewater Glaciers, J. Phys. Oceanogr., 41(12), 2279-2294.

Jenkins, A., K. W. Nicholls, and H. F. J. Corr (2010), Observation and parameterization of ablation at the base of Ronne Ice Shelf, Antarctica, , 2298-2312, doi:10.1175/2010JPO4317.1.

Johnson, H. L., A. Münchow, K. K. Falkner, and H. Melling (2011), Ocean circulation and properties in Petermann Fjord, Greenland, J. Geophys. Res. Ocean., 116, 1-18, doi:10.1029/2010JC006519.

Joughin, I., R. B. Alley, and D. M. Holland (2012), Ice-Sheet Response to Oceanic Forcing, Science, $338,1172-1176$.

Joughin, I., S. B. Das, G. E. Flowers, M. D. Behn, R. B. Alley, M. A. King, B. E. Smith, J. L. Bamber, M. R. van den Broeke, and J. H. van Angelen (2013), Influence of ice-sheet geometry and supraglacial lakes on seasonal ice-flow variability, Cryosph., 7(4), 1185-1192, doi:10.5194/tc-7-1185-2013.

Joughin, I., S. B. Das, M. A. King, B. E. Smith, I. M. Howat, and T. Moon (2008), Seasonal Speedup Along the Western Flank of the Greenland Ice Sheet, Science, 320(5877), 781-783. 
Joughin, I., B. Smith, I. Howat, and T. Scambos (2016), MEaSUREs Multi-year Greenland Ice Sheet Velocity Mosaic, Version 1. Boulder, Colorado USA. NASA National Snow and Ice Data Center Distributed Active Archive Center. doi: http://dx.doi.org/10.5067/QUA5Q9SVMSJG. [Accessed 8 July 2017].

Joughin, I., B. Smith, I. Howat, T. Scambos, and T. Moon (2010), Greenland Flow Variability from Ice-Sheet-Wide Velocity Mapping, Journal of Glaciology. $56.415-430$. http://dx.doi.org/10.3189/002214310792447734.

Joughin, I., S. Tulaczyk, M. Fahnestock, \& R. Kwok (1996), A mini-surge on the Ryder Glacier, Greenland, observed by satellite radar interferometry. Science 274(5285), 228-230.

Kamb, B. \& Echelmeyer, K. A. (1986), Stress-gradient coupling in glacier flow: I. Longitudinal averaging of the influence of ice thickness and surface slope. J. Glaciol. 32, 267-284.

Kanamori, H. (1983), Magnitude scale and quantification of earthquakes. Tectonophysics 93, 185-199.

Kimura, S., P. R. Holland, A. Jenkins, and M. Piggott (2014), The Effect of Meltwater Plumes on the Melting of a Vertical Glacier Face, J. Phys. Oceanogr., 44(2003), 3099-3117, doi:10.1175/JPOD-13-0219.1.

Kirby, J. F. (2014), Estimation of the effective elastic thickness of the lithosphere using inverse spectral methods: The state of the art, Tectonophysics, 631(C), 87-116, doi:10.1016/j.tecto.2014.04.021.

Krawczynski, M. J., Behn, M. D., Das, S. B. \& Joughin, I. (2009), Constraints on the lake volume required for hydro-fracture through ice sheets. Geophys. Res. Lett. 36, L10501.

Lampkin, D. J. \& VanderBerg, J. (2011), A preliminary investigation of the influence of basal and surface topography on supraglacial lake distribution near Jakobshavn Isbrae, western Greenland. Hydrol. Process. 25, 3347-3355.

Lemke, P. et al. (2007), Observations: Changes in snow, ice and frozen ground, in Climate Change 2007: The Physical Science Basis. Contribution of Working Group I to the Fourth Assessment Report of the Intergovernmental Panel on Climate Change, edited by S. Solomon, D. Qin, M. Manning, Z. Chen, M. Marquis, K. B. Averyt, M. Tignor, and H. L. Miller, pp. 337-383, Cambridge University Press.

Leeson, A. A. et al. (2015), Supraglacial lakes on the Greenland ice sheet advance inland under warming climate. Nat. Clim. Chang. 5, 51-55.

Lewis, S. M., and L. C. Smith (2009), Hydrologic drainage of the Greenland Ice Sheet, Hydrol. Process., 23, 2004-2011, doi:10.1002/hyp.

Lindbäck, K., R. Pettersson, A. L. Hubbard, S. H. Doyle, D. As, A. B. Mikkelsen, and A. A. Fitzpatrick (2015), Subglacial water drainage, storage, and piracy beneath the Greenland ice sheet, Geophys. Res. Lett., 42, 7606-7614, doi:10.1002/2015GL065393. 
Luckman, A., D. I. Benn, F. Cottier, S. Bevan, F. Nilsen, and M. Inall (2015), Calving rates at tidewater glaciers vary strongly with ocean temperature, Nat. Commun., 6, 8566, doi:10.1038/ncomms9566.

Lüthi, M., Funk, M., Gogineni, S. and Truffer, M. (2002), Mechanisms of fast flow in Jakobshavns Isbræ, Greenland, Part III. Measurements of ice deformation, temperature and cross-borehole conductivity in boreholes to the bedrock, J. Glaciol., 48(162), 369-385.

Mankoff, K. D. (2016), Structure and dynamics of a subglacial discharge plume in a Greenlandic fjord, J. Geophys. Res. Ocean., 121, 3372-3380, doi:10.1002/2015JC011421.

Mernild, S. H., Holland, D. M., Holland, D., Rosing-Asvid, A., Yde, J. C., Liston, G. E. and Steffen, K. (2015), Freshwater Flux and Spatiotemporal Simulated Runoff Variability into Ilulissat Icefjord, West Greenland, Linked to Salinity and Temperature Observations near Tidewater Glacier Margins Obtained Using Instrumented Ringed Seals, J. Phys. Oceanogr., 45, 1426-1445, doi:10.1175/JPO-D-14-0217.1.

Mohr, J. J., Niels, R., \& S. N. Madsen (1998), Three-dimensional glacial flow and surface elevation measured with radar interferometry, Nature, 391, 273-276, doi:10.1038/34635.

Moon, T. and Joughin, I. (2008): Changes in ice front position on Greenland's outlet glaciers from 1992 to 2007, J. Geophys. Res., 113(F2), F02022, doi:10.1029/2007JF000927.

Moon, T., I. Joughin, B. Smith, and I. Howat (2012), 21st-Century Evolution of Greenland Outlet Glacier Velocities, Science, 336(6081), 576-578.

Moratto, Z. M., Broxton, M. J., Beyer, R. A., Lundy, M. \& Husmann, K. (2010), Ames Stereo Pipeline, NASA’s Open Source Automated Stereogrammetry Software. 41st Lunar Planet. Sci. Conf.

Morlighem, M., E. Rignot, J. Mouginot, H. Seroussi, and E. Larour (2014), Deeply incised submarine glacial valleys beneath the Greenland ice sheet, Nat. Geosci., 7, 18-22, doi:10.1038/ngeo2167.

Mortensen, J., K. Lennert, J. Bendtsen, and S. Rysgaard (2011), Heat sources for glacial melt in a sub-Arctic fjord (Godthåbsfjord) in contact with the Greenland Ice Sheet, J. Geophys. Res., 116, doi:10.1029/2010JC006528.

Morton, B. R., Taylor, G. and Turner, J. S (1956), Turbulent Gravitational Convection from Maintained and Instantaneous Sources, Proc. R. Soc. A Math. Phys. Eng. Sci., 234(1196), 1-23, doi:10.1098/rspa.1956.0011.

Motyka, R. J., W. P. Dryer, J. Amundson, M. Truffer, and M. Fahnestock (2013), Rapid submarine melting driven by subglacial discharge, LeConte Glacier, Alaska, Geophys. Res. Lett., 40(19), 5153-5158, doi:10.1002/grl.51011. 
Mouginot, J., E. Rignot, B. Scheuchl, and R. Millan (2017), Comprehensive Annual Ice Sheet Velocity Mapping Using Landsat-8, Sentinel-1, and RADARSAT-2 Data, Remote Sens., 9(364), 1-20, doi:10.3390/rs9040364.

Miyazaki, S. (2003), A transient subduction zone slip episode in southwest Japan observed by the nationwide GPS array. J. Geophys. Res. 108, 2087.

Miyazaki, S., Mcguire, J. J. \& Segall, P. (2011), Seismic and aseismic fault slip before and during the 2011 off the Pacific coast of Tohoku Earthquake. Earth, Planets Sp. 63, 637-642.

Nick, F. M., A. Vieli, I. M. Howat, and I. Joughin (2009), Large-scale changes in Greenland outlet glacier dynamics triggered at the terminus, Nat. Geosci., 2(2), 110-114, doi:10.1038/ngeo394.

Noël, B., W. J. van de Berg, E. van Meijgaard, P. Kuipers Munneke, R. S. W. van de Wal, and M. R. van den Broeke (2015), Evaluation of the updated regional climate model RACMO2.3: summer snowfall impact on the Greenland Ice Sheet, Cryosph., 9(5), 1831-1844, doi:10.5194/tc-9-1831-2015.

Noël, B., W. J. van de Berg, H. Machguth, S. Lhermitte, I. Howat, X. Fettweis, and M. R. van den Broeke (2016): A daily, 1-km resolution dataset of downscaled Greenland ice sheet surface mass balance (1958-2015), The Cryosphere Discuss., doi:10.5194/tc-2016-145.

Nye, J. F. (1960), The Response of Glaciers and Ice-Sheets to Seasonal and Climatic Changes, Proc. R. Soc. Lond. A. Math. Phys. Sci., 256(1287), 559-584.

Nye, J. F. (1976), Water flow in glaciers: jökulhlaups, tunnels and veins, J. Glaciol., 17(76), 181-207.

Okada, Y. (1985), Surface deformation due to shear and tensile faults in a half-space. Bull. Seismol. Soc. Am. 75, 1135-1154.

O'Leary, M., and P. Christoffersen (2013), Calving on tidewater glaciers amplified by submarine frontal melting, Cryosphere, 7, 119-128, doi:10.5194/tc-7-119-2013.

Palmer, S., A. Shepherd, P. Nienow, and I. Joughin (2011), Seasonal speedup of the Greenland Ice Sheet linked to routing of surface water, Earth Planet. Sci. Lett., 302(3-4), 423-428, doi:10.1016/j.epsl.2010.12.037.

Parizek, B. R. \& Alley, R. B. (2004), Implications of increased Greenland surface melt under globalwarming scenarios: ice-sheet simulations. Quat. Sci. Rev. 23, 1013-1027.

Pimentel, S. \& Flowers, G. E. (2010), A numerical study of hydrologically driven glacier dynamics and subglacial flooding. Proc. R. Soc. A Math. Phys. Eng. Sci. 467, 537-558.

Plueddemann, A. J., Kukulya, A. L., Stokey, R. and Freitag, L (2012), Autonomous Underwater Vehicle Operations Beneath Coastal Sea Ice, IEEE/ASME Trans. Mechatronics, 17(1), 5464. 
Poinar, K. et al. (2015), Limits to future expansion of surface-melt-enhanced ice flow into the interior of western Greenland. Geophys. Res. Lett. doi:10.1002/2015GL063192

Post, A., S. O’Neel, R. Motyka, and G. Streveler (2011), A Complex Relationship Between Calving Glaciers and Climate, EOS Trans., 92(37), 305-312.

Price, S. F., Payne, A. J., Catania, G. A. \& Neumann, T. A. (2008), Seasonal acceleration of inland ice via longitudinal coupling to marginal ice. J. Glaciol. 54, 213-219.

Pritchard, H. D., R. J. Arthern, D. G. Vaughan, and L. A. Edwards (2009), Extensive dynamic thinning on the margins of the Greenland and Antarctic ice sheets., Nature, 461(7266), 971975.

Rennermalm, A. K., L. C. Smith, V. W. Chu, R. R. Forster, J. E. Box, and B. Hagedorn (2012), Proglacial river stage, discharge, and temperature datasets from the Akuliarusiarsuup Kuua River northern tributary, Southwest Greenland, 2008-2011, Earth Syst. Sci. Data, 4, 1-12, doi:10.5194/essd-4-1-2012.

Rignot, E., and P. Kanagaratnam (2006), Changes in the velocity structure of the Greenland Ice Sheet., Science, 311(5763), 986-90, doi:10.1126/science.1121381.

Röthlisberger, H. (1972), Water pressure in intra- and subglacial channels, J. Glaciol., 11(62), 177-203.

Ryser, C., M. P. Lüthi, L. C. Andrews, M. J. Hoffman, G. A. Catania, R. L. Hawley, T. A. Neumann, and S. S. Kristensen (2014), Sustained high basal motion of the Greenland ice sheet revealed by borehole deformation, J. Glaciol., 60(222), 647-660, doi:10.3189/2014JoG13J196.

Schild, K. M., R. L. Hawley, and B. F. Morriss (2016), Subglacial hydrology at Rink Isbræ, West Greenland inferred from sediment plume appearance, Ann. Glaciol., 1-10, doi:10.1017/aog.2016.1.

Schoof, C. (2010), Ice-sheet acceleration driven by melt supply variability, Nature, 468(7325), 803806.

Schoof, C., I. J. Hewitt, and M. A. Werder (2012), Flotation and free surface flow in a model for subglacial drainage. Part 1. Distributed drainage, J. Fluid Mech., 702, 126-156, doi:10.1017/jfm.2012.165.

Schoof, C., C. A. Rada, N. J. Wilson, G. E. Flowers, and M. Haseloff (2014), Oscillatory subglacial drainage in the absence of surface melt, Cryosphere, 8(3), 959-976, doi:10.5194/tc-8-959-2014.

Schumann, K., Völker, D. and Weinrebe, W. R (2012): Acoustic mapping of the Ilulissat Ice Fjord mouth, West Greenland, Quat. Sci. Rev., 40, 78-88, doi:10.1016/j.quascirev.2012.02.016.

Sciascia, R., F. Straneo, C. Cenedese, and P. Heimbach (2013), Seasonal variability of submarine melt rate and circulation in an East Greenland fjord, J. Geophys. Res. Ocean., 118, 2492-2506, doi:10.1002/jgrc.20142. 
Segall, P. \& Matthews, M. (1997) Time dependent inversion of geodetic data. J. Geophys. Res. 102, 22391-22409.

Selmes, N., Murray, T. \& James, T. D. (2011), Fast draining lakes on the Greenland Ice Sheet. Geophys. Res. Lett. 38, 1-5.

Sergienko, O. V. (2013) Glaciological twins: basally controlled subglacial and supraglacial lakes. J. Glaciol. 59, 3-8.

Seymour, M. S., and I. G. Cumming (1994), Maximum likelihood estimation for SAR interferometry, Proc. Int. Geosci. Remote Sens. Symp., 4, 2272-2275.

Shepherd, A. et al. (2012), A Reconciled Estimate of Ice-Sheet Mass Balance, Science., 338(6111), 1183-1189.

Shreve, R. L. (1972), Movement of water in glaciers, J. Glaciol., 11(62), 205-214.

Simons, F. J., R. D. van der Hilst, and M. T. Zuber (2003), Spatiospectral localization of isostatic coherence anisotropy in Australia and its relation to seismic anisotropy: Implications for lithospheric deformation, J. Geophys. Res. Earth, 108(B5), 2250, doi:10.1029/2001JB000704.

Simons, J., M. T. Zuber, and J. Korenaga (2000), Isostatic response of the Australian lithosphere: Estimation of effective elastic thickness and anisotropy using multitaper spectral analysis, $J$. Geophys. Res., 105(B8), 19163-19184.

Slater, D., P. Nienow, A. Sole, T. O. M. Cowton, R. Mottram, P. Langen, and D. Mair (2017a), Spatially distributed runoff at the grounding line of a large Greenlandic tidewater glacier inferred from plume modelling, J. Glaciol., 1-15, doi:10.1017/jog.2016.139.

Slater, D. A., P. W. Nienow, T. R. Cowton, D. N. Goldberg, and A. J. Sole (2015), Effect of nearterminus subglacial hydrology on tidewater glacier submarine melt rates, Geophys. Res. Lett., 42, 1-8, doi:10.1002/2014GL062494.1.

Slater, D. A., D. N. Goldberg, P. W. Nienow, and T. R. Cowton (2016), Scalings for Submarine Melting at Tidewater Glaciers from Buoyant Plume Theory, J. Phys. Oceanogr., 46, 1839-1855, doi:10.1175/JPO-D-15-0132.1.

Slater, D. A., P. W. Nienow, D. N. Goldberg, T. R. Cowton, and A. J. Sole (2017b), A model for tidewater glacier undercutting by submarine melting, Geophys. Res. Lett., 1-9, doi:10.1002/2016GL072374.

Slepian, D. (1978), Prolate spheroidal wave functions, Fourier analysis, and uncertainty. V-The discrete case, ATT Tech. J., 57(5), 1371-1430, doi:10.1002/j.1538-7305.1978.tb02104.x.

Smith, L. C. et al. (2015), Efficient meltwater drainage through supraglacial streams and rivers on the southwest Greenland ice sheet. Proc. Natl. Acad. Sci. 112, 1001-1006. 
Sneed, W. A., and G. S. Hamilton (2007), Evolution of melt pond volume on the surface of the Greenland Ice Sheet, Geophisical Res. Lett., 34, L03501, doi:10.1029/2006GL028697.

Sole, A., P. Nienow, I. Bartholomew, D. Mair, T. Cowton, A. Tedstone, and M. A. King (2013), Winter motion mediates dynamic response of the Greenland Ice Sheet to warmer summers, Geophys. Res. Lett., 40(15), 3940-3944, doi:10.1002/grl.50764.

Solomon, S. (2007), Climate change 2007-the physical science basis: Working group I contribution to the fourth assessment report of the IPCC., 4th ed., Cambridge University Press.

Stevens, L. A., M. D. Behn, J. J. McGuire, S. B. Das, I. Joughin, T. Herring, D. E. Shean, and M. A. King (2015), Greenland supraglacial lake drainages triggered by hydrologically induced basal slip, Nature, 522, 73-76, doi:10.1038/nature14480.

Stevens, L. A., M. D. Behn, S. B. Das, I. Joughin, B. P. Y. Noël, M. R. van den Broeke, and T. Herring (2016a), Greenland Ice Sheet flow response to runoff variability, Geophisical Res. Lett., 43, 1-9, doi:10.1002/2016GL070414.

Stevens, L. A., F. Straneo, S. B. Das, A. J. Plueddemann, and A. L. Kukulya (2016b), Linking glacially modified waters to catchment-scale subglacial discharge using autonomous underwater vehicle observations, Cryosph., 10, 417-432, doi:10.5194/tc-10-417-2016.

Straneo, F., and C. Cenedese (2015), The Dynamics of Greenland's Glacial Fjords and Their Role in Climate, Ann. Rev. Mar. Sci., 7, 89-112, doi:10.1146/annurev-marine-010213-135133.

Straneo, F., and P. Heimbach (2013), North Atlantic warming and the retreat of Greenland's outlet glaciers., Nature, 504(7478), 36-43, doi:10.1038/nature12854.

Straneo, F., G. S. Hamilton, D. A. Sutherland, L. A. Stearns, F. Davidson, M. O. Hammill, G. B. Stenson, and A. Rosing-Asvid (2010), Rapid circulation of warm subtropical waters in a major glacial fjord in East Greenland, Nat. Geosci., 3, 182-186, doi:10.1038/ngeo764.

Straneo, F., R. G. Curry, D. A. Sutherland, G. S. Hamilton, C. Cenedese, K. Våge, and L. A. Stearns (2011), Impact of fjord dynamics and glacial runoff on the circulation near Helheim Glacier, Nat. Geosci., 4(5), 322-327.

Straneo, F., D. A. Sutherland, D. Holland, C. Gladish, G. S. Hamilton, H. L. Johnson, E. Rignot, Y. $\mathrm{Xu}$, and M. Koppes (2012), Characteristics of ocean waters reaching Greenland's glaciers, Ann. Glaciol., 53(60), 202-210.

Straneo, F. et al. (2013), Challenges to Understanding the Dynamic Response of Greenland's Marine Terminating Glaciers to Oceanic and Atmospheric Forcing, Bull. Am. Meteorol. Soc., 94(8), 1131-1144, doi:10.1175/BAMS-D-12-00100.1.

Stocker, T. F. (2014), Climate change 2013: the physical science basis: Working Group I contribution to the Fifth assessment report of the Intergovernmental Panel on Climate Change. 
Sundal, A. V. et al. (2009), Evolution of supra-glacial lakes across the Greenland Ice Sheet. Remote Sens. Environ. 113, 2164-2171.

Sundal, A. V., A. Shepherd, P. Nienow, E. Hanna, S. Palmer, and P. Huybrechts (2011), Meltinduced speed-up of Greenland ice sheet offset by efficient subglacial drainage., Nature, 469 , 521-524, doi:10.1038/nature09740.

Sutherland, D. A., F. Straneo, and R. S. Pickart (2014), Characteristics and dynamics of two major Greenland glacial fjords, J. Geophys. Res. Ocean., 119, 3767-3791, doi:10.1002/jgrc.20224.

Tedesco, M. et al. (2013), Ice dynamic response to two modes of surface lake drainage on the Greenland ice sheet. Environ. Res. Lett. 8, 34007.

Tedstone, A. J. and Arnold, N. S. (2012): Automated remote sensing of sediment plumes for identification of runoff from the Greenland ice sheet, J. Glaciol., 58(210), 699-712, doi:10.3189/2012JoG11J204.

Tedstone, A. J., P. W. Nienow, A. J. Sole, D. W. F. Mair, T. R. Cowton, I. D. Bartholomew, and M. A. King (2013), Greenland ice sheet motion insensitive to exceptional meltwater forcing., Proc. Natl. Acad. Sci. U. S. A., 110(49), 19719-24, doi:10.1073/pnas.1315843110.

Tedstone, A. J., P. W. Nienow, N. Gourmelen, A. Dehecq, D. Goldberg, and E. Hanna (2015), Decadal slowdown of a land-terminating sector of the Greenland Ice Sheet despite warming, Nature, 526(7575), 692-695, doi:10.1038/nature15722.

Thomas, R., Frederick, E., Krabill, W., Manizade, S. and Martin, C. (2009): Recent changes on greenland outlet glaciers, J. Glaciol., 55(189), 147-162, doi:10.3189/002214309788608958.

Thomson, D. J. (1982), Spectrum estimation and harmonic analysis, Proceeding Ieee, 70, 1055-1096.

Tsai, V. C. \& Rice, J. R. (2010), A model for turbulent hydraulic fracture and application to crack propagation at glacier beds. J. Geophys. Res. 115, F03007.

Turner, J. S.: Buoyancy effects in fluids, Cambridge University Press., 1979.

van de Wal, R. S. W., W. Boot, M. R. van den Broeke, C. J. P. P. Smeets, C. H. Reijmer, J. J. A. Donker, and J. Oerlemans (2008), Large and Rapid Melt-Induced Velocity Changes in the Ablation Zone of the Greenland Ice Sheet, Science, 321, 111-114.

van de Wal, R. S. W. et al. (2015), Self-regulation of ice flow varies across the ablation area in southwest Greenland, Cryosph., 9, 603-611, doi:10.5194/tc-9-603-2015.

van den Broeke, M., J. et al. (2009), Partitioning recent Greenland mass loss., Science, 326(5955), 984 986, doi:10.1126/science.1178176.

Van der Veen, C. J. (1998), Fracture mechanics approach to penetration of surface crevasses on glaciers. Cold Reg. Sci. Technol. 27, 31-47. 
Van Der Veen, C. J. (2007), Fracture propagation as means of rapidly transferring surface meltwater to the base of glaciers. Geophys. Res. Lett. 34, L01501.

Vaughan, D. G. et al. (2013), Observations: Cryosphere. Climate Change 2013: The Physical Sci- ence Basis. Contribution of Working Group I to the Fifth Assessment Report of the Intergovernmental Panel on Climate Change, , 317-382, doi:10.1017/CBO9781107415324.012.

Vieli, A., and F. M. Nick (2011), Understanding and Modelling Rapid Dynamic Changes of Tidewater Outlet Glaciers: Issues and Implications, Surv. Geophys., 32(4-5), 437-458, doi:10.1007/s10712-011-9132-4.

Werder, M. A., I. J. Hewitt, C. G. Schoof, and G. E. Flowers (2013), Modeling channelized and distributed subglacial drainage in two dimensions, J. Geophys. Res. Earth Surf., 118(4), 2140 2158, doi:10.1002/jgrf.20146.

Weertman, J. (1973), Can a water filled crevasse reach the bottom surface of a glacier? LASH Publ. 95, 139-145.

Wilson, N. J., and F. Straneo (2015), Water exchange between the continental shelf and the cavity beneath Nioghalvfjerdsbræ (79 North Glacier), Geophys. Res. Lett., 42(18), 7648-7654, doi:10.1002/2015GL064944.

Xu, Y., E. Rignot, D. Menemenlis, and M. Koppes (2012), Numerical experiments on subaqueous melting of Greenland tidewater glaciers in response to ocean warming and enhanced subglacial discharge, Ann. Glaciol., 53(60), 229-234, doi:10.3189/2012AoG60A139.

Xu, Y., E. Rignot, I. Fenty, D. Menemenlis, and M. M. Flexas (2013), Subaqueous melting of Store Glacier, west Greenland from three-dimensional, high-resolution numerical modeling and ocean observations, Geophys. Res. Lett., 40(17), 4648-4653, doi:10.1002/grl.50825.

Yang, K., L. C. Smith, V. W. Chu, C. J. Gleason, and M. Li (2015), A Caution on the Use of Surface Digital Elevation Models to Simulate Supraglacial Hydrology of the Greenland Ice Sheet, IEEE J. Sel. Top. Appl. Earth Obs. Remote Sens., 8(11), 5212-5224, doi:10.1109/JSTARS.2015.2483483.

Zachos, J. C., G. R. Dickens, and R. E. Zeebe (2008), An early Cenozoic perspective on greenhouse warming and carbon-cycle dynamics., Nature, 451(7176), 279-83, doi:10.1038/nature06588.

Zwally, H. J., W. Abdalati, T. Herring, K. Larson, J. Saba, and K. Steffen (2002), Surface meltinduced acceleration of Greenland ice-sheet flow., Science, 297, 218-222, doi:10.1126/science.1072708. 
